\title{
WRITING INTELLECTUAL DISABILITY: GLIMPSES INTO PRECARIOUS PROCESSES OF RE/MAKING A CULTURAL PHENOMENON
}

\section{By}

\author{
Chelsea Temple Jones
}

Master of Arts in Critical Disability Studies, York University, Toronto, Ontario, 2010

Bachelor of Arts in Journalism, University of Regina, Regina, Saskatchewan, 2008

A dissertation submitted in partial fulfillment of the requirements for the degree of Doctor of Philosophy in Ryerson University and York University's Joint Program in Communication and Culture

Toronto, Ontario, Canada, 2016

CChelsea Temple Jones, 2016 


\section{AUTHOR'S DECLARATION FOR ELECTRONIC SUBMISSION OF A DISSERTATION}

I hereby declare that I am the sole author of this dissertation. This is a true copy of the dissertation, including any required final revisions, as accepted by my examiners.

I authorize Ryerson University to lend this dissertation to other institutions or individuals for the purpose of scholarly research.

I further authorize Ryerson University to reproduce this dissertation by photocopying or by other means, in total or in part, at the request of other institutions or individuals for the purpose of scholarly research.

I understand that my dissertation may be made electronically available. 


\title{
WRITING INTELLECTUAL DISABILITY: GLIMPSES INTO PRECARIOUS PROCESSES OF RE/MAKING A CULTURAL PHENOMENON
}

\author{
Chelsea Temple Jones \\ Doctor of Philosophy \\ Communication and Culture \\ Ryerson University and York University \\ 2016
}

\begin{abstract}
We make each other mean through precarious processes of engagement. This dissertation posits intellectual disability as a modernist subject category characterized by un-belonging and a presumed lack of normative expression. The author takes a hesitant, interpretive, and phenomenological approach to confronting the question of what it means to re/make intellectual disability as presence and process rather than as problem. The researcher engages with intellectual disability by introducing expressive writing as method under a feminist poststructuralist framework of exploratory, relational ethics. In doing so, this project introduces the concepts of wonderment and triple-labelling to the fields of cultural studies and critical disability studies. This work advocates for a reorientation toward meaning-making and researchbased engagement with intellectual disability as cultural, contextual, and relational phenomenon that remains unsettled as it situates researchers at a perceived limit of knowledge.
\end{abstract}


This dissertation privileges process over resolution. The writing launches from an affectladen epistemology of wonderment, and thus struggles to resolve its own ethical and methodological uncertainty as it attempts to center intellectual disability without (completely) privileging normative ways of un/knowing. This approach allows that the body is implicated in uncertain discursive processes that re-construct and circulate meanings about the body, the self, and the Other. Then, relying on Foucault's conceptions of power and knowledge and Snyder and Mitchell's cultural location of disability framework, the study describes Western cultural memory: processes of mind/body splitting and subject-category building traceable through esoteric pre-modernity, eugenic modernity, and the post-identity politics of Davis's dismodernity. A discussion of research ethics follows, which challenges rational methodological conceptions of intellectual disability that rely on preconceived notions of vulnerability. Before describing expressive writing as a primary research method, the author also makes a case for engaging with triple-labeled people (those labeled disabled, vulnerable, and incompetent) by writing in-relation-to, privileging silence and absence over "giving voice," engaging in unfamiliarity and untranslatability, and attending to "the space between" the self and the Other. This writing uses reflexive vignettes and critical analysis to lead readers toward the researcher's final phenomenological reflections on experiences with triple-labeled people writing in a Toronto day program. 


\section{Acknowledgements and Dedication}

Without whom ...

Anne MacLennan
David Jones
Emily Jones
Esther Ignagni
Fady Shanouda
Flora
Grandmaster B
Jan Temple-Jones
Julie McGonegal
Kathryn Church
Kevin Jones
Mary
Mr Clark Kent
Nancy La Monica
nancy viva davis halifax
Owen
Paul Moore
Missy \& Pepe
Prince Diana
Raymond
Ross
Sharon
Tanya Titchkosky

And, to name she who deserves the most heartfelt ...

Carolina Véliz 


\section{Table of Contents}

Abstract

Acknowledgements and Dedication $\quad$ v

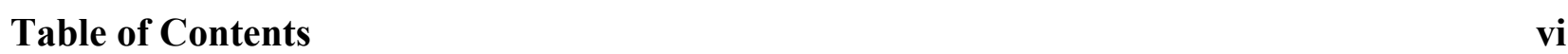

Prelude: A vulnerable researcher 1

Chapter 1: Attending to theoretical perspectives, research questions, and wonderment 13

Thinking in feminist poststructuralist frameworks $\quad 14$

Linking the poststructuralist and the phenomenological through praxis 18

Overview of influential theoretical perspectives: Disability and cultural theories 20

Cultural studies and disability perspectives 23

Cultural disability studies: Blending theoretical and ethical perspectives 27

Moving into affect: A theoretical springboard for wonder 29

Research Questions $\quad 32$

Chapter 2: Necessary interruptions: Discourses, language, and wonderment 35

Vignette: An interruption $\quad 37$

Relationalities: Discovering discourses of the self and the other 46

"Mapping" the body through language: People first? 49

Beginning with wonderment

$\begin{array}{ll}\text { Chapter 3: Reaching back and re/making intellectual disability } & 58\end{array}$

Vignette: Beginning research

Mapping intellectual disability as familiar and unfamiliar $\quad 61$

PART I: The body's pre-modern dys/appearance $\quad 65$

$\begin{array}{ll}\text { Pre-modern understandings of the body } & 67\end{array}$

$\begin{array}{ll}\text { Encountering pre-modern Otherness } & 70\end{array}$

$\begin{array}{ll}\text { A turn toward God as a turn toward charity } & 73\end{array}$ 
PART 2: Disability as it emerges in modernity $\quad 78$

$\begin{array}{lr}\text { The "normal" body in modernity } & 81\end{array}$

Building intellectual disability by labeling the body $\quad 82$

Silencing as a modernist signifier of intellectual disability $\quad 88$

Iatrogenesis: Medicine, the body, and intellectual disability 90

Moving into "the outskirts of intelligibility" 92

Medicine and the threat of biopower $\quad 97$

Biopower and the docile body 98

Individualization, health, and the "normal" subject 101

The myth of normality and the naturalization of abnormality 103

$\begin{array}{ll}\text { Normalization technologies } & 107\end{array}$

Eugenics: Disappearing the intellectually disabled "other" 108

Institutionalization: Managing the divided body 113

$\begin{array}{ll}\text { Institutionalization as a contemporary threat } & 116\end{array}$

Maintaining intellectual disability as "natural" through ableism 119

Chapter 4: Intellectual disability as a contemporary cultural project: Disability studies, neoliberalism, and moving beyond the problem of "giving voice"

$\begin{array}{ll}\text { Disability as disciplinary anchor } & 123\end{array}$

$\begin{array}{ll}\text { Disability as cultural project: Crip epistemologies and cultural locations } & 127\end{array}$

$\begin{array}{ll}\text { Vignette: The next few moments } & 130\end{array}$

$\begin{array}{ll}\text { Disability and contemporary neoliberal interventions } & 131\end{array}$

Disability and ("entrepreneurial") citizenship 131

Community living as neoliberal response to disability 133

$\begin{array}{ll}\text { Investing in intellectual disability } & 135\end{array}$

"Giving voice" and being on the "winning" side of neoliberalism 138

The potential value of "presence" over "voice" 141 
Vignette: Naming the participants; naming the research

Triple-labeling in disability-based research 145

Navigating research relationships 150

Reaching for informed consent in cultural locations of supposed incompetence

Chapter 6: Re-making the body in dis/postmodernity

Dismodernity and a new ethics of the body

Calling for a new "ethics of the body" 166

Locating disability discourses in dis/postmodernity 169

The body and intellectual disability

Ontological differences

Chapter 7: Expressive writing and phenomenology as methods of un/knowing the body

Vignette: (Still) beginning research

Disability research history: A select overview

Vignette: Attending to details

Reconciling research

Research roles: Vulnerable subjects, vulnerable observers 202

Ethical decision-making $\quad 205$

Taking up "the ethics of ethics" 209

$\begin{array}{ll}\text { Vignette: Collecting informed consent forms } & 210\end{array}$ 
Chapter 9: "Why writing?": Reflections on method, motion, and writing as intellectual disability

A note on functional writing

Arriving at writing

Writing as motion

Narrowing writing toward method and motion

223

The political edge to writing

Returning to the research

Expressive writing as method

Vignette: Notes from December 12, 2014

235

Notes on expressive writing as gesture

Chapter 10: Necessary interruptions: On not being participatory, emancipatory, or transformative

Edging toward (and away from) arts-based inquiry

Un-categorizing the research

Chapter 11: Moving into a phenomenological approach: Gathering and explicating moments

Turning toward a phenomenological approach: Bracketing and orientation

252

Phenomenological starting points

Thinking phenomenology, thinking methods 255

Intellectual disability and phenomenology 258

Instructions for doing phenomenological research: Max van Manen's hermeneutic (and pedagogical) approach

Describing (vs. demonstrating) characters (participants) 263

Lived experience description: Prince Diana 264

Digging into essences 269 
Reading Writing: Mary 274

Reading Writing: Owen 285

Reading writing: Flora $\quad 294$

Chapter 13: Keeping intellectual disability open: Interruptions, insights, and afterthoughts

$\begin{array}{ll}\text { Summary of research goals } & 307\end{array}$

Insights: Remarks on the research process $\quad 311$

First research question: Where does disability come from? 313

Second research question: How do we orient toward intellectual disability? 316

Third research question: What foresights follow? 321

Fourth research question: What would it mean for untranslatable writing to be re-read? 323

Afterthoughts: Moving into memory 326

$\begin{array}{ll}\text { Vignette: Let them eat cake } & 330\end{array}$

$\begin{array}{ll}\text { Appendices } & 333\end{array}$

Appendix A: Ryerson University Research Ethics Board Approval Letter 333

Appendix B: Community Living Toronto Ethics Approval Letter 334

Appendix C: Informed Consent Form 335

$\begin{array}{ll}\text { Reference List } & 341\end{array}$ 


\section{Prelude: A vulnerable researcher}

There is worry and hesitation throughout this writing.

This project begins reflexively by watching my brother, Kevin, write. The body — his body, his self, and my self — are bound in language and also in writing. Even typing Kevin's name makes me cringe a little: Where will this story go? It won't be written up as inspirational and sappy, will it? What am I willing and unwilling to tell?

So, I begin by positioning myself as a researcher. There is a running joke in my family that all my academic writing will begin with the words, "My brother, Kevin ..." because these three words opened a winning speech I wrote in sixth grade — and then recycled in seventh and eighth grade, unaware, as I was, of the concept of self-plagiarism. The speech focused on the dire, moral dangers of using the word "retarded" because it refers to people like Kevin — language constructs us and constricts us, and I only inferred then, as I do now, that to write back might somehow deconstruct the label. I essentially used my brother to publicly "out" my peers as abusive labelers. That'll show 'em. The results were anticlimactic. The masses never stopped saying "retarded." My public rebuke also positioned me as the brunt of a gentle (but ongoing) family taunt.

The joked expectation that I would launch every piece of writing at Kevin's expense, however, edges toward concerns about anxiety and voyeurism that can spiral researchers into unnecessarily detailed self-analysis Patti Lather (2007) calls "an implosion into the self” (p. 44). It is perhaps for this reason that some academics distance themselves from the scholarly affects of the personal in attempt to stake a place of their own. I have encountered writers, filmmakers, students, and others working on disability-related projects who have not openly "outed" 
themselves as related-to or in-relation-to. For instance, in her meditations on the philosophy of intellectual disability Licia Carlson (2010) writes about intellectual disability from both personal and scholarly positions:

One of the first questions I am often asked by other philosophers when I tell them about my interest in intellectual disability is, 'Oh, do you have a disabled family member?' The question might not have struck me as odd had it not been asked so consistently. I became increasingly irritated by the assumption that seemed embedded in the question ... : the only reason I would have an interest in this topic is because someone in my family has an intellectual disability (p. 2).

Carlson goes on to explain the assumptions embedded in this question: that people carrying the label of intellectual disability are owed respect and justice not only by virtue of non-disabled family members, but because they are their own selves, their own bodies, their own lives. She also points to a dilemma inherent in this question that sometimes prompts her to deny any type of positioning: that those related to labeled people are the only ones close enough to understand them, but are too close to ever be objective enough to produce serious work on the topic of disability (p. 2). Even without fully understanding her proximity to disability, I relate to Carlson on this matter. It's not that I can't handle a bit of jostle about where my motivations come from: "my brother, Kevin ..." of course. However, the particular closeness to disability to which Carlson alludes to both includes and excludes researchers like me from the conversation, situating them as both insiders and outsiders all, usually, without much consultation with the labeled people to whom we exist in-relation-to.

Other writers take something of a fess-up approach. James Berger (2014), whose work on the dys-/articulate also informs my understandings of non-normative communication, tells readers that he has two sisters, Susan and Claudia, carrying intellectual disability labels. In a poem, Berger describes these women by characterizing them as people who cannot speak (p. 16). He confesses feeling sad and ashamed that he only visits his sisters in their respective group 
homes twice each year. He later admits that his poetry is intertwined with his scholarly work, even though "one does not expect to see family dramas play out in a scholarly monograph" (p. 7). Berger eventually decides, and explains, that his work always, and perhaps always-already, is an expression of his sisters (p. 7). Others, still, manage a more complicated pride. Consider the opening pages of Jay Dolmage's 2014 book, Disability Rhetoric, where a poem written in memory of his brother, Matthew, immediately confronts readers:

I can write the words ...

But I forever miss you in

And I'm so glad to see you in

And look at the friends we invited in

The space between (Disability Rhetoric, opening passage).

This poem seems to say, make no mistake: Matthew is in this writing. The poem is an invitation for the reader, too, to move into "the space between" and to find the writer, and Matthew, there. This dissertation is an iterative process continually aiming for "the space between" — that invisible essence that makes up much of what we know, and don't know, about intellectual disability. The first thing to note is that intellectual disability is more than a label. It is an entire cultural phenomenon that produces and routinely disavows its own subjects in the face of modernist notions of normality and production, and carries its own misunderstandings through the ontological turn toward the "posts" — poststructuralism and postmodernity included — by excluding those embodying this label/phenomenon from entry into conversations about themselves. Intellectual disability, and its synonyms, becomes a part of our lives in ways that are both familiar and unfamiliar, and positions us precariously and sometimes uncomfortably inrelation-to each other and the world.

When I think about my positioning I am thinking of subject positions offered up amid a flurry of available meta-narratives, cultural discourses, and institutional norms (Benwell and 
Stokoe, 2006 in Kostouli, 2009, p. 102). Indeed, in disability studies-based research all positions are "part of a complex web of discourses and politics" and therefore must be uncovered for scrutiny and thought (Price, 2012, p. 172). The presence of the researcher is necessary. Her positions are often multiple and overlapping. In accounting for my positioning I am learning how to acknowledge the experiences and affects tied to a combination of concern, shame, and pride. I worry about being taken seriously when I describe my position in-relation-to - but what else can I be? I am embedded in both familial and scholarly relation to the phenomenon of intellectual disability and persons whose bodies are chosen, largely by modernist discursive formations of medicine, to personify this phenomenon and give it cultural location. I turn to Susan Wendell for some support here:

There is a cultural gulf between the disabled and the non-disabled; to become disabled is to enter a different world. Yet experiences of living with a disability are not by their nature private, separable from the rest of life and the rest of society. They can and should be shared throughout the culture as much as we share experiences of life, work, and family life (1996, p. 66).

Yet, I suspect Wendell to be too generous. Sharing experiences should be an exercise in critical thinking, an arena snagged with unresolved meaning. Margrit Shildrick (2009) takes a harder line. She points out that non-disabled people - those constituting a dominant group that share a modernist, rational, meta-narrative of disablement — have a responsibility "not to speak on behalf of others like themselves, but to interrogate their own cultural and psycho-social locations as non-disabled" (p. 9). I trust Shildrick on this point. Still, dominant groups like to talk to each other only. And I intend to pressure Shildrick's point by not dwelling on the interrogation of my own location. Instead, I am interested in the cultural location of intellectual disability, and how the socio-cultural phenomenon of intellectual disability is inscribed on particular bodies. 
This dilemma of positioning is apparent in other works as well, where disability inevitably intersects with race, sexuality, and other interwoven identity markers that serve to abstract the concept of normality by highlighting whatever and whoever can be read as off-center (Fumia, Feb. 4, 2015). In a 2001 interview Lather, a feminist scholar, spoke about being mistaken for a black woman by writing about blackness. She later described herself as a "double outsider" in reference to herself as a white woman researching non-white women's experiences with HIV (2007, p. 23). She asked, "How do you earn your stripes?" and, for that matter, how do you earn access to experiences that are not your own? (2007, p. 23). Lather insists that there are no easy answers, and that her work is criticized if she does bring up intersectional identity collisions and if she doesn't — damned-if-you-do-damned-if-you-don't (p. 31). Her suggestion to researchers is to begin with the notions of learning and building trust. If I could respond to her writing, though, I would ask: how is my positioning in-relation-to intellectual disability enough for this research? What if I'm located in the wrong spots and my viewpoint is too obscured? The answer, I hope, would be a suggestion that imperfection is the stuff of interpretivist research, especially in a postmodernist climate characterized by doubt towards the promise of methods and suspicion toward truth claims (Richardson, 2000, p. 928). Perhaps this partial knowledge is still a way of knowing. And perhaps partial knowledge is more constructive (or deconstructive, as the point may be) in a project like this one where imperfection and the unknown are tools of thought and wonder. Perhaps this process is (un)learning? Perhaps the necessary condition for this (un)learning is trust?

As a so-far non-disabled white woman of working age in-relation-to intellectual disability, I hope that by being upfront about myself from the get-go I am on my way to building trust between the reader and this writing. Also, this work is meant to be about more than 
dominant groups talking to each other about "researching down" toward a specific group on the periphery. Rather, this research aims to throw light on a group of writers whose expressive writing transcends normative notions of literacy and creates something more in tune with the socio-cultural phenomenon of intellectual disability. Though this dissertation can't always be more than that. My writing, and the core research questions and ideas that drive it, ignore a whole continuum of people, including some of the participants in question, because this writing engages in normative language and therefore in dominant forms of meaning making.

Nevertheless, when I ask myself if my positioning qualifies me to be part of philosophical conversations about intellectual disability, my answer is affirmative based on my conviction that all people, including those carrying the label, should be included in these conversations. Undoubtedly we need more intellectually disabled scholars, which means we also need more accessible scholarship - a type of scholarship that chooses presence over absence, no matter how difficult. Barriers to intellectually disabled people's participation are profound and deeply embedded in Western culture; their absence is notable across all disciplinary fields. Perhaps my work can bring us closer, perhaps not. But in the spirit of trying to breach the unknown, I am writing in a style that is not quite plain language (officially speaking) but is meant to be straightforward; draft after draft I am attempting to uncomplicate the complicated. This writing style is best labelled creative analytic practice (CAP) ethnography, which is a style of prose first described by Laurel Richardson (2000) that uses writing as a research practice and as a method of discovery. CAP writing is circular and unpredictable. It uses narrative and poetic representation, among other devices, to analyze the social world when normative, linear language is not enough. It relies on the struggle and crystallization of mixed methods. CAP includes writing that aims to deconstruct traditional writing practices in order to make writers 
conscious of conventions and therefore more capable of transcending them. Perhaps most importantly, CAP demands a text that takes up "a fleshed out, embodied sense of lived experience" (p. 937). Therefore, for me, this dissertation is an attempt to locate myself in a language that can be claimed somewhere between the passionate and the normative - it is less mapped out and, at times, more emotive than usual. This stab at unconventional writing reflects a brief, public discussion between Nirmala Erevelles and Kathryn Church in March 2015 when both scholars articulated the disjunction between understandability, utility, and academic prose in disability-based discussions. The writing here is another element of research imperfection and research process. Another element of learning. Another element of trust.

Before launching into the theoretical, I'll quickly note that in some ways, too, I am embarrassed that this entire dissertation is not Kevin-centric. I am not close enough to Kevin geographically (and perhaps emotionally) to have suggested an auto/ethnographic approach that would spark narrative and life-meaning inquiry, even if such an approach would fit snugly into CAP procedures and therefore be easily explainable. Yet my work is grounded in feminist poststructural goals that allow for more personal narrative than is offered here. Perhaps a better sister could take on such a task - there's that shame that draws me to Berger's (2014) work. And perhaps also toward Hélène Cixous (1993) who, more sharply, writes: "In my life, as soon as I say $m y$, as soon as I say $m y$ daughter, $m y$ brother, I am verging on a form of murder, as soon as I forget to unceasingly recognize the other's difference" (p. 13). There is danger in the inaccuracy that an auto/ethnographic approach might take in this case, given my distance from Kevin. Yet, drawing back a little, in her discussions about anthropology as a field for "vulnerable observers,” Ruth Behar (1996) suggests, “vulnerability doesn't mean that anything personal goes" (p. 14). Rather, for vulnerability — the worry, the hesitation — to work it must be 
essential to the argument at hand. So, establishing positioning also requires truth telling and an effort not to "forget" the other's difference still works even if Kevin is not directly implicated (Cixous, 1993, p. 13). In this spirit I will suggest that a sister's drive to be an advocate is not dissimilar to the researcher's drive to actively discover and dis-order. Sistering and researching cannot be disconnected - even if the distance is written into the dissertation, my positioning is inconceivable without Kevin as a personal starting point. However, I don't believe using a personal voice throughout this writing will necessarily bring us closer to the questions this work intends to confront, which will be named shortly. What's more, writing without personal story doesn't mean giving up intellectual and emotional engagement. At least, I don't think so. Right? And then we're back: the worry, the hesitation.

I have rounded my topic and I don't wish to go on. Not at the moment. However, I have breached something here through freewriting, a method of writing I explain later that relies on the "unknowing consciousness" to guide an outpouring of words (van Manen, 2014, p. 47). Through freewriting I have found some words; they flow out faster than I can stop them.

Kevin sits at his desk. Long, deep breaths. He wobbles through each letter at geological speeds. The lines of his writing shake precariously as though each letter is quivering in fear that it might fall off the page. He takes several minutes to fill a line with letters. He takes days to fill a page. Sometimes he copies passages from dog-themed magazines or paragraphs from his wide canon of dog breed encyclopedic reference books. Lately he writes the words "best buddies" at the top of the page and brings the paper out to show my parents, prompting a conversation about his friends, an upcoming dance, a Halloween party.

While Kevin writes upstairs at his desk, I am downstairs filling pages with an epidemic of words that keep spreading. I write essays, magazine articles, a sniff of poetry, and an anthill of 
fiction. I am rewarded with grades, publications, editors, and the odd award. Kevin's shivering letters are never rewarded, other than, perhaps, with the time and space to write them. Yet Kevin's dedication is more disciplined than mine. He is patient with himself and he cares about each stroke of his pencil. He doesn't say, "screw it," when he doesn't like what he's written. Kevin shifts into writing as though he is moving into meditation; his breathing slows, his eyes are fixed, his words a Mandela I don't understand. Kevin is a better writer than I am.

Through freewriting it may be possible to access "the space between" (Dolmage, 2014). Freewriting is a method that uses memory work and the subconscious to tap into thoughts and realizations that otherwise remain hidden or invisible. Freewriting is a practice of writing the immediate, and jotting down whatever arises from the unconscious. The unconscious, Cixous (1993) explains, is the source of all writing material — the "instincts that will be the motors of writing" (p. 88). This type of writing appears throughout this dissertation under the label "vignettes," because although freewriting takes different forms for different people I often find my form in short, slice-of-life stories. These stories are built out of using writing as method and relying on field notes, transcription sound bytes, reflection, and memory.

The "space between" Kevin's position and my own is created by moments of mis- and un-understanding that are too often glazed over as gaps in the research; these are moments there simply isn't time to address, sometimes. There are other specifics that become difficult to address: how many participants are in the room at any given time, who said what, how often, and what did we do, exactly. I learned quickly that I have little control over these things, and my research ethics board application now looks like a list of broken promises: that there would be a certain number of consistent participants; that informed consent could or would be constant; that participants would not be penalized for leaving the research. So, by freewriting and relaying 
some experiences that led to these promises over which I realized I had little control, I (finally) found my reason: the goal of this dissertation isn't to become closer to the poignant point of intellectual disability that touches my life in particular. The goal of this dissertation is to broadly confront intellectual disability in its messy, uncontrollable manifestations - one of which is writing. The discrepancy between normative understandings of what writing is, what it should $b e$, and what lived-out gestures of writing are is often unacknowledged, tucked away in a desk, thrown out, made invisible. Yet, writing plays a role in how people are positioned and repositioned as subjects by different and competing discourses (Kostouli, 2009, p. 98). The space I have available to explore these understandings is a dissertation space; an institutionalized, colonial space that continues to circulate discourses of dis/ableism even as it advocates for inclusive types of research (the types of research mine could masquerade as if needed in this particular dissertation space where passing is permitted).

And, here is my writing on the page for you, because, again, dominant groups like to talk to each other. Whether I like my words and their a/effects or not, I will likely earn something for simply placing them here in front of you. Sustaining the normative is the affect of repetition of bodily actions over time, including writing, especially when these actions "retrace" the "straight lines" already set out for them (Ahmed, 2006, p. 66). Thus, my position as normative-privileged is established and sustained.

And so it is by sorting through and unpacking some of the "emotional and intellectual baggage the [researcher] takes on the voyage" that I come to think about writing, and that I follow Behar's (1996) lead and come to be a vulnerable researcher (p. 8). In particular, I think about writing by labeled people that resists and transcends the rigid, rational, masculinist forms of writing Cixous (1976) and Julia Kristeva (1984) write against, for example. Yet, the writing 
you will find in this work — near the end, when my narration quiets down and prose belonging to participants begin to take shape — isn't what we in cultural studies might call "poetic language." It's something else. Something equally expressive, but with its own form and its own un/translatabilities.

The purpose of this dissertation, then, is to get over functional language and to re-orient myself and readers toward expressiveness as valid in all its rumbling, creaking, squawking, silent, cracking moments of untranslatability. This purpose lodges me into moments of wonderment - of feeling curious about the phenomenon at hand, but helpless to do much about it; the moments of hesitation that otherwise allow me to think in taken-for-granted terms of “well, that's just how things are." These moments are the forgotten spaces between the familiar and the unfamiliar that are internalized and also external, that are somehow overlooked as “natural” (van Manen, 2014, p. 61). Maurice Merleau-Ponty (1964) suggests that the natural-ness of this divide is a result of modern thought that allows us to "rediscover the world in which we live, yet which we are always prone to forget” (p. 39). I have therefore pegged this space between discovering and forgetting a space of wonderment as one location of my study, if wonderment can be considered the affect of turning toward (instead of away from) the taken-forgranted and reflecting on it as phenomenon.

For all of the reasons above - the worry, the hesitation, the shame, the pride, the embarrassment - my study involves people. I turn my attention toward people I identify as inrelation-to. This re-orientation positions me as researcher as worrier (Gray, 2000), researcher as normative-privileged, and researcher as knower, among other roles that I slide into and out of as the process unwinds. These people are sometimes writing, sometimes not. Sometimes they write in ways I understand, sometimes my understanding is not enough. Together we engage in 
moments that produce intellectual disability; in experiences and reflections that highlight the discursive production of this phenomenon and aim to deconstruct it so it may be reconstructed again, anew, for better or for worse. This process is part of expressive writing that aims to enter the invisible, disavowed, "in between" space, which, as it turns out, is in many ways a space of learning and trust. 


\section{Chapter 1: Attending to theoretical perspectives, research questions, and wonderment}

In positioning intellectual disability as a cultural phenomenon, I am suggesting that disability is an experience with particular cultural locations: as a pre-modern conception dealt with through both esoteric reasoning and charity; as a discursive construct dealt with in modernity through eugenic technologies, silencing, incarceration and individualization; and as a location of deconstruction of the ethics and limits of humanness. Situating disability as a cultural location makes the corporeal a central factor in orienting to the world, acknowledges normality without centering it, and provokes us to attend (or not) to ontology.

The experience of intellectual disability emerges through being in-relation-to participants whose selves are where intellectual disability is said to be happening. This dissertation names no particular "type" of intellectual disability because each person comes to this category in a different way, and intellectual disability is a construct not a personhood. To specify people's disabilities — to ask for and reveal such labels — is to repeat the violent naming of bodies that aims to distort humanness, as I will further explain when I write about disability and modernity. The point is that intellectual disability raises questions of bodily context, relational ethics, and humanness. These experiences are horizontal and historical, and they are embedded in the cultural imaginary where we find ourselves and others contextually located; intellectual disability ought not be dealt with only through case studies — the phenomenon opens the possibility of exploring variants of humanness through wide-reaching theoretical paradigms (Carlson, 2010, p. 11).

In a modernist socio-cultural milieu privileging rationality and normality, persistent disavowal of people carrying such labels in Western contexts leads to interpretations of certain 
people's realities and knowledge as bodily (mind/body) disorganization. Disavowal, as we will understand it here, refers to a fascination with the exceptional "otherness" of disabled people in the face of adversity, "alongside a simmering hostility" (Goodley, 2012, p. 189). The theoretical approaches informing my core assertion are therefore drawn from the disciplines of critical disability studies and cultural studies, each of which umbrellas intersecting approaches including a cultural model of disability, feminist poststructuralism, affect theory, and phenomenology — that hum through this writing at different places and in different circumstances. Many of these theoretical perspectives are overlapping and interrelated, and the theory is sometimes spread broadly and is other times contained and directed toward a specific point. All of these approaches will be outlined as the writing unfolds. For now, this chapter offers an overview of these theoretical perspectives and outlines the research questions that follow.

\section{Thinking in feminist poststructuralist frameworks}

Because my slightly phenomenological approach allows reflexivity, I am also called to attend to the discourses that shape subjectivities in a general (rather than individualized) sense.

Poststructuralists commonly use the term discursive practice to mean the ways in which people actively produce, engage in, and experience social realities (Davies, 2000, p. 88). Discourses are more generally understood as institutionalized languages or communication systems - the ways we are written and spoken into existence (Derrida, 1976). As Bronwyn Davies (2000) explains, one can only ever be what certain discourses allow, or make possible, and one's being in the world "shifts" as the conditions that make intellectual disability a possible phenomenon change over time (p. 13). Discursive practices and discourses are historically contextualized processes 
still present in cultural memory, and they can be deconstructed through narrower theories of modernity, neo-liberalism, and relational ethics, among others. Again, though, I begin broadly by asserting that although the day-to-day experiences in human lives are the effects of discourse, humans have ways of making each other mean that are more than the effects of discourse.

Many meanings are caught up in structures — some more readily identifiable than others, such as eugenics and its technologies which are topics this dissertation will include, albeit briefly. Here, I rely on Michel Foucault (1978) to demonstrate the constituting power of discourse; the self and the other are always discursively constructed. I begin with Foucault, rather than with method, in hopes that his ideas will lead me into motions of methods and rooms of methodologies that are compatible with the inseparable processes of thinking and doing. This beginning point follows Elizabeth Adams St. Pierre's (2014) directive that methodology should not be separated from epistemology and ontology because this separation risks reducing the project to formula rather than exploratory process (pp. 3, 4).

And with this understanding of meanings and structures I build my feminist poststructuralist positioning that aims to observe the work of multiple discourses people confront at any point in time, and then work to deconstruct and, in some cases, reconstruct such discourses (Davies, 2000). Part of the purpose of this research is to create an entry point into another discourse of the body that includes intellectual disability as a terrain for meaningmaking, which means understanding "the person as process" (constituting, being constituted, and being the subject of constitution) and moving beyond normalized conditions of subjection (Davies, 2000, p. 38, 54). Following John O'Neill (1979), this discourse of the body refers to the "lived body," with "communicative bodily presence to which we cannot be indifferent" and, turning to Sara Ahmed (2006) and Margaret Somerville (2006), with moral imperatives we orient 
ourselves toward or away from as we engage with imagination as the core of our ethical being. Poststructuralist thought is abstract and interactive, and not always logical because it is not necessarily based on a "predetermined chain of reflections" that ends in tidy conclusions (Sondergaard, 1999 in Davies, 2000, p. 9). Exploration of thought in these conditions sometimes takes place with others, and sometimes takes place alone; thought relies on both presences and absences, and thus poststructuralism is present here as a way of thinking that is "particularly powerful in its capacity to render the invisible visible — and therefore revisable" (Davies, 2000, p. 16). I will also venture to suggest that under this theoretical framework the invisible, which may manifest as absence, should also, at times, be left invisible.

Poststructuralism works against views that "words refer only to other words" and that discourses and discursive practices are truthful and unshakable (Vernon, 1979, p. 93). Thus, feminist poststructuralism in particular is a helpful tool to break up dualisms and give permission for multiple narratives and meanings to work through the body at one time (Davies, 2000, p. 49). Jacques Derrida's (1976) argument that the stability of oppositional binaries (mind/body, normal/abnormal, intellectual/physical, among others) are achieved by the suppression of the other leads toward the premise that the mind/body binary typifies all bodies, and particularly singles out those whose minds appear faulty, irrational: those whole bodies (read: minds) are read as a problem and lack and subsequently give rise to the socially-driven call for solution to such problems (Bauman, 1990; Carlson, 2010; Titchkosky, 2014). Binaries lead to a comparison of types, and it is the so-called "types" of bodies and lived realities where the phenomenon of intellectual disability is located that are involved in this investigation (Titchkosky, 2011). In this study, the word "embodiment" will refer to the mind and the body not as separate bits of a person, but as an encompassing mixture of characteristics of personhood, including the mind and 
body combination that operates in the same breath. Further, the notion of "body" will refer to "anything that affects or is affected" - meaning a body can also be a body of sounds, a gesture of writing, a mind, an idea, an animal, a machine (Deleuze, 1992 in Davies, 2000, p. 17).

Some overarching methodological questions that stem from feminist poststructuralism inform this research. These questions help me attend to patterns of thinking and being that always in process - become increasingly reflexive as I acknowledge my multiple positionings (in-relation-to, researcher as worrier, and so on) and as I catch myself in the often-unavoidable act of constituting the world in particular ways (Davies, 2000, p. 13). The questions I consider throughout this writing are paraphrased from a set of research questions Davies offers her readers in a body of writing 1990-1999 (2000, p. 60): Who defines this phenomenon as it is? Through which discourses is this phenomenon made/constituted? Who is granted an authoritative position within these discourses? Can this discourse be resisted? Can it be undone? Through these questions, and others like them that emerge as the inquiry moves along, poststructuralism allows this research to stretch into real and imagined spaces where the discursive practices that shape the phenomenon of intellectual disability as we currently and commonly understand it become unstable. These practices stem from always-already constructed, re-constructed, and evercirculating moments of cultural discontinuity. These movements that keep certain discourses alive also link the underlying lines of inquiry here to focus on modernity and the "spread of rationality" and normality as one way of rooting intellectual disability in cultural memory, which is the rationale for the upcoming literature review (Singer, 2001, p. 24; Davis, 2013).

The launching point for this work is a poststructuralist realization that also shares some theoretical ties with cultural disability studies: people with intellectual disabilities are positioned in unique cultural locations, and their bodies are taken up as structural oppositions to modernist 
reasoning, and as primordial and unworthy of cultural participation (Carlson, 2010; Stiker, 1999). Poststructuralism and disability studies — particularly the feminist veins of these approaches - emphasize the possibilities of non-normative corporeal realities (Haraway, 1990; Garland-Thomson, 2013; Shildrick, 2009; Wendell, 1996). Feminist poststructuralism is particularly useful in that it focuses on the limits of Enlightenment rationality and common sense-making that build rational frameworks of explanations (and meta-narratives) (Lather, 2007, p. 5).

Feminist poststructuralism also understands the structures available in our cultural memory as definitive of disciplinary knowledges and as ultimately unsettled (Pardo, 1995, in Lather, 2007, p. 8). These imaginings, however, come without many concrete suggestions of how to re-imagine issues of the mind (such as rationality and intelligibility) to include the untranslatable expressions and presences of people with intellectual disabilities (Erevelles, 2001). The intellectually disabled experience as both a lived-out reality in-relation-to and a cultural phenomenon continues to fester in realms of the invisible, often due to biomedical cultural structures that assume incapability (to write, to consent, to be in the world as human). The discourses and discursive practices that produce these structures lead to state-driven policies that may restrict access to (and research of) self-expression and human connection, such as that which can take place through writing. And from here, methods and methodology begin to materialize.

\section{Linking the poststructuralist and the phenomenological through praxis}

With an opportunity to write in non-traditional ways - meaning untranslatable, non-normative modes of writing - people may or may not transcend traditional functional literacy expectations 
of expression. The "may not" possibility is, indeed, what makes this research both valuable and vulnerable because, as nancy viva davis halifax mentioned in personal conversation, paying attention to usually-forgotten remnants of moments helps us begin to think about particular phenomena through reflexive questions and wonderings (Jan. 27, 2015). Thus, a phenomenological approach informed by feminist poststructuralist practice is a fair pairing for this type of work. A phenomenological approach to the methods - meaning the interpretation of the phenomenon at hand - aids with this vulnerability by forcing research and writing to be aspects of one process rather than placing heightened value on what we might call "results" or "findings" (van Manen, 2014). This continuous leaning toward ongoing, circular, never-quitecaught-in-the-moment phenomenology also diverts attention away from the predominance of social opinions (and "facts") about intellectual disability toward the thoughtful explication of meanings (pathic meaning structures) as we live them in our everyday experiences (lifeworlds) and the unsolvable quandaries that emerge in these instances (van Manen, 1990).

Methodological approaches linked to feminist poststructuralism and phenomenology also search for binary oppositions in texts and intend to "worry at them" and "put pressure on them" (Burman \& MacLure, 2011, p. 288). These include the material/textual binary that separates "face-to-face" fieldwork from already-written theory as if they are not one in the same gesture, as explained by Elizabeth Adams St. Pierre (2014, p. 12). These motions shift the research toward interpretive, reflexive methodologies. For instance, there are moments in this study that roll over the "pot-holes of discourses" where, for the researcher, "there is a similar eye on what subjects are saying, writing, doing. But the other eye, a cock-eye, is on what is not said, what discourses make it possible to say, what practical or theoretical logics hide away ... " (Miller, Whalley, \& Stronach, 2011, p. 307). These "pot-holes," as Stronach et al. (2011) call them, are 
the result of a method of deconstruction that focuses on the constitution of subjectivity through discursive powers (including power-discourses, a concept outlined by Foucault in one of his 1976 lectures). “Here,” writes Lather (2007),

... the complexity of subject formation includes how various axes of power are mutually constitutive, productive of different local regimes of power and knowledge that locate subjects and require complex negotiations of relations, including the interruption of coherence ... (p. 103).

Poststructuralism is much about the "interruption of coherence," the loss of signifiers, or the loss of "truth" that comes with structuralism, and about situating references amid various meaningmaking systems and possibilities (pp. 102-103).

This study uses writing as its method and employs poststructuralist/deconstructive invitations to challenge fundamental Enlightenment rationalism (the "interruption of coherence"), which is so influential in creating and locating the body and corporeal realities, by recognizing that "all meaning is represented by signs which are arbitrary" — that is, all that has been built can come apart (Somekh \& Lewin, 2011, p. 285). The interpretive, exploratory approach here dispels notions that knowledge about human experience is cultivated only through hard scientific methods that quantitatively constitute, or try to solve, the body and its apparent problems. Thus this research brings questions of the body, rationalism, and the ethics of encounters involving these to the forefront through a feminist poststructuralist perspective that navigates through the research via reflective phenomenological approaches.

Overview of influential theoretical perspectives: Disability and cultural theories

Though feminist poststructuralism and phenomenology weigh heavily in this work, this research is also informed by a handful of other overlapping theoretical perspectives. In an effort to consider meanings of intellectual disability — a concept that will soon bring us to the more 
pointed research questions — and to apply and understand the notion that people make each other mean, additional theoretical perspectives that ripple through this writing include: critical disability studies, affect theory, theories of liberal citizenship, cultural studies, and relational ethics. Many of these standpoints — or sitpoints - consider the effects of discourse and discursive practices, the politicization of bodies, categories of oppression, cultural locations of disability, meaning-making in relation to everyday experiences of the body, and "re-imaginings" of meanings (Garland-Thomson, 2013). Each of these perspectives "reassigns meaning" to the body and offers new approaches to bringing the body out from under modernist-laden cultural imaginings of the body as problem (Linton, 1998; Shildrick, 2009; Titchkosky, 2008).

In particular, this work calls into question how little attention is paid to intellectually disabled people as knowing subjects (Carlson, 2010, p. 15). Presently, intellectual disability is commonly understood as indicative of faulty or abnormal rationalities and "lacking" mental processes (Carlson, 2010; Prendergast, 2001): this description is the starting point of this dissertation, which eventually runs through the moral, intellectual, and biological considerations of intellectual disability in pre-modern, modern, and post-modern thought respectively. People carrying labels of intellectual disability have not yet been "explicitly linked with knowledge production" in disability studies and other disciplines/theoretical perspectives (Ignagni \& Church, 2008, p. 627). From here, the research confronts intellectual disability as a cultural phenomenon with particular socio-cultural locations by blending theoretical discussions of embodiment with ambitions of (re)discovering and (re)understanding meaning.

This portion of the wider discussion begins with critical disability studies, the transdisciplinary lens that frames this research. A critical disability studies approach highlights intersectionalities and extends to a variety of fields (including feminism, critical race theory, 
queer theory, and others) that speak to notions of embodiment, normality, and forms of oppression (Goodley, 2011; Davis, 1995; 2010). Critical disability studies watches vigilantly over the political and ontological complexities of disability in relation to impairment and lived, corporeal experiences. The field works from the rights-based perspective that suggests people be defined by more than their marginality, and that concepts of impairment and exclusion be taken up as experience, cultural location, and conditions of possibility rather than as definite features of humanness (Goodley, 2011, p. 157; Rajan \& Odette, Feb. 5, 2015).

A disability studies perspective traditionally uses the social model and its limitations to distinguish between impairment as a bodily limitation and disability as a determining factor of social participation in social structures. However, because the field of critical disability studies also takes a holistic approach to intersectionalities, it serves as a pillar for this work in its willingness to acknowledge that disability, and intellectual disability in particular, is undeniably imbricated in several forms of difference: race, class, gender, age, and others. Intellectual disability often appears to emerge as an unexpected form of human embodiment with unstable, and therefore troubling, characteristics. Intellectual disability is temporary and permanent, visible and invisible, familiar and unfamiliar. In these ways, as Carlson points out, intellectual disability is simultaneously static and dynamic: changeable and unchangeable at the same time (2010, pp. 36-37).

Yet, the predictability of intellectual disability is bound in discursive practices that make it a possible, and possible-to-be-unexpected, phenomenon (Titchkosky, 2008). Here, critical disability studies follows Shildrick's notion of intercorporeality: the idea that the competencies of each person are established based on how s/he realizes her or his corporeal awareness (or, taken-for-grantedness) insofar as bodies do not (or will not, or have not) coincide(d) with the 
normativities established in the cultural imaginary (2009, p. 32). According to Shildrick (2009), the cultural imaginary unifies all corporeal demarcations that distinguish the normal from the abnormal, and it is where our individual self-understanding is determined and implicated ( $\mathrm{p}$. 180). In other words, every person, regardless of personal forms of embodiment, is implicated in the "shared responsibility" of the socio-cultural imaginary whose discourses shape our contemporary situations, and therefore also our lives and subjectivities (pp. 7-8). Further, our individual self-understandings are implicated in the cultural imaginary (p. 82). The goal then, from a critical disability studies perspective that carries Shildrick's philosophy through its exploration, is to find ways to (re)understand the nature of the cultural imaginary of intellectual disability as phenomena rather than problem instead of simply extending the traditional frameworks in which intellectual disability is understood.

\section{Cultural studies and disability perspectives}

This motion of (re)understanding weighs heavy with affect — that is, the in-between-ness, and the body's capacity to affect and be affected by epistemological foundations of rationality. First, though, (re)understanding forces a turn toward interpretive methodologies that are informed by many of the theoretical perspectives above - feminist poststructuralism, phenomenology, critical disability studies — and also by cultural studies. Terry Eagleton (2000) explains that culture represents a social history that is "exceptionally tangled and ambivalent" (p. 2). Importantly, culture is a very complex and abstract concept sometimes set against notions of nature, as if the activities of life go on in opposition to nature (Eagleton, 2000). Culture requires certain social and political conditions that influence subjectivities and identities, meaning that the division between culture and nature — or society and the body, as the debate translates into 
discussions of corporeal realities (Shildrick, 2009) - makes culture "a matter of selfovercoming as much as self-realization" in that culture identifies, celebrates, and disciplines the self (Eagleton, 2000, pp. 5-6, 10).

Cultural studies' understandings of embodiment suspend and "take apart" binary-driven notions of culture/nature, society/body, and physical/intellectual and instead illustrate the body as a whole, a blend of mind and body as one being (O’Neill, 1985). In understanding the body as a tool of inter-subjectivity, ethics, and culture potentially unrestricted by binaries, this research can begin reaching into cultural locations of disability to understand how intellectual disability is discursively formed and where it is situated (Erevelles, 2001; Siebers, 2010; Snyder \& Mitchell, 2006). Cultural locations of the body can be described, as they are by Ahmed (2006) when she is writing about Judith Butler's use of phenomenology in feminism, as what bodies "tend to do" and "can do" (and cannot do) given the effects of culturalized histories (p. 56).

A study of this nature includes theoretical and practical interventions that consider a historical material analysis of the body to render visible and invisible the political and social interests that construct intellectual disability (Erevelles, 2005). By looking to Foucault (1986, 1979), in particular, it is possible to identify centralized power-discourse effects, such as biopower and governmentality, that route everyday discourses toward normalizing effects of the body. All play a role in dividing the normal from the abnormal, and the physical from the intellectual. This aspect of theory tends to illuminate discussions of liberal citizenship, neoliberalism, and biomedicine. To this end, cultural theory digs into the age of reason and uncovers "the heroic subject of modernity" — the normal, patriarchal, citizen of the Global North who emerges as a "cultural abstraction" and as the axis of all bodily classifications; he, and our cultural imaginings of him, represents the condition of possibility through which a 
phenomenon such as intellectual disability emerges (Harvey, 1990). He is the normal to the abnormal, the subject to the object, the civilized to the natural; he is the provocateur of dividing practices (Bauman, 1990; Davis, 2010; Eagleton, 2000; Foucault, 1979; Goodley, 2011, p. 38). A cultural studies lens throws a glaring light on these binaries and promotes a re-understanding of the body as both unified and never stagnant, with a postmodern emphasis on the unstable subject and fragmented presences (Baudrillard, 2006; O’Neill, 1985).

Further, a cultural studies perspective influences the methods of this project because cultural studies is interested in mapping modern and postmodern locations of disability (Titchkosky, 2002). The emergence of the modern capitalist economy relies on state-endorsed medicalized categorization of the body (as Tanya Titchkosky demonstrates in her analysis of person-first language, which refers to the standard Canadian catch-phrase "people with intellectual disabilities") (2001) that makes subjectivities and constructs disability as problem (Titchkosky, 2008). The intellectually disabled subject that stems from these fixed constructions is one whose agency is either advanced or stifled by mental ability (Shildrick, 2009, p. 39). As such, intellectual disability bodily categorizations also carve out and normalize disability’s taken-for-granted social meanings that this dissertation (sometimes) brackets and (at other times) navigates (Oliver, 1990; Vagle, 2014). Further, under neoliberalism, which characterizes the instability or "liquidity" of our current cultural context (Harvey, 2005; Bauman, 2000), locations of intellectual disability tend to fall outside of the labour market/movements and into the in/formal, segregated realms of rehabilitation, the moral discourses of individual responsibility/choice, and a politics of "care" (Soldatic \& Meekosha, 2012). These neoliberal locations are sometimes at odds with disability-centric activism, which forms the foundations of disability studies (Prince, 2012). 
From these locations, the disabled body is transformed into social policies that reflect the way people understand and produce disability, namely as quantifiable condition(s) that make people objects of medicine and ensure that intellectual disability is a quality that groups of individuals possess (Titchkosky, 2008, p. 61). By locating disability in this way, the positionality of this project is located anew: an institutionalized day program in an urban Canadian city under observation by a researcher with her own institutionalized agenda and restrictions. As Behar (1996) aptly writes, the methodology of participant observation "is split at the root: act as a participant, but don't forget to keep your eyes open" (p. 6). The contemporary location of this research echoes past locations of intellectual disability, where the body is rendered both static and dynamic (Carlson, 2010), and both subject and object (Snyder \& Mitchell, 2006). This type of research is also vexed with notions of vulnerability that relate to participants, the researcher, and the methods.

Overall, this study is concerned with the experiences of people who live their day-to-day lives largely outside of the labour force, and are often expected to convey (un)intelligibility and lack as per a cultural imaginary acquainted with intellectual disability as concept and as persons (Shildrick, 2009). Because the cultural imaginary relies on leftover discourses from the early Christian era and from the age of Enlightenment reason that are deeply embedded in late capitalist systems whose values of productivity commodify the body (Soldatic \& Meekosha, 2012), which this dissertation will explore more thoroughly in an upcoming chapter, the purpose of this research is to organize a space and a discourse of intellectual disability that imagines a realm outside of ideas of rationality and intelligibility that constitute this research as a contemporary cultural location of intellectual disability. 


\section{Cultural disability studies: Blending theoretical and ethical perspectives}

The theoretical perspective of cultural disability studies also plays a strong role in this writing. Cultural locations of disability are spaces produced mainly through the classification of disabled bodies as research objects, again re-stating Ahmed's (2006) mention of what bodies “can do" and what they "tend to do" in particular contexts (p. 56). Sharon Snyder and David Mitchell (2006) refer to the development of techniques such as labeling, segregating, researching, and individualizing bodies as disabled as a quintessential expression of modernity (p. 134, 179). These techniques, which operate under the complex guise of language, work to conceal the "sometimes untidy reality of human experience" and encourage us "to see order where in fact there is disorder" (Walton \& Madjar, 1999b, pp. 6-7). This work of ordering is part of culture: culture as social history, culture as personhood and as citizenship, culture as internalization, and culture a "self undoing" (Eagleton, 2000, p. 17). Or, in other words, culture as "a form of universal subjectivity at work within each of us" (p. 8). Also significantly, some scholars suggest modernist locations of disability result in the present and ongoing exclusion of labeled people from meaningful participation in the evolving invention of culture (Snyder \& Mitchell, 2006, p. 3; Wendell, 1996). The cultural approach to disability critiques notions about where disability "belongs" and what techniques are at work putting it in its place (segregated, problematized, under investigation).

Berger (2014), for example, launches his investigation into discursive practice by presenting a particular cultural location of disability: $d y s$-/disarticulate. The dys-/disarticulate is "that place" which exists "beyond all discourse that would provide a final affirmation or negation to the social-symbolic world" (p. 13). Here, Berger refers to the subjects of this study: those outside of normative language whose communication is often understood as untranslatable and 
unfamiliar. Indeed, these spaces highlight the invisibility of disability in contemporary neoliberal contexts (for example, the separation of day programs from the daily workforce). The activities that take place in these spaces point to isolated discourses of disability that are overshadowed by dominant biomedical interpretations of disability as problem to be solved and segregated rather than as a presence representative of ongoing life experiences. Contemporary locations of disability, and the discourses leading up to these locations that peg disability as problem, are the very processes that make intellectual disability the investigable phenomenon that is (the) subject to (and of) this dissertation.

Berger (2014) also writes about ethics among the dys-/disarticulate. He explains, “ ... the ethics of composite beings suffused with otherness must recognize the incomprehensibility and the vulnerability of the other," bringing us to a wider conversation about the ethics involved in this study (pp. 20-21). And in this study, ethics and affect are intertwined with the politics and practice/praxis of not knowing. In this research, reading without understanding is part of the ethical imperative. As Lather (2007) writes, "reading without understanding is required if we are to go beyond the imaginary 'real' of history" that has shaped our cultural imaginary of any phenomena, including intellectual disability (p. 85). Lather's point is important because it illuminates a core cultural studies' notion that culture is inherently unstable and always evolving. As Eagleton asserts, "culture is not some vague fantasy of fulfillment, but a set of potentials bred by history and subversively at work within it" (2000, p. 23). Therefore, this study is tangled in historical and contemporary ethical quandaries that lend themselves to all of the theoretical lenses described so far. The ethical knots, both theoretical and material, are so recurring throughout that a large portion of this dissertation is devoted to picking at their snags and finding out if I get anywhere. 
And, further, to the extent that labeled people live through historically-based discursive practices that construct and assign their bodies as problem outside of realms of intelligibility (namely, through the systematic promotion of normative literacies that set them up for failure), it seems as though such people are already (re)constructed through text-based analysis. These kinds of theoretical and practical ethical tensions build up in this writing, and are performed on the page against a backdrop of ethical dilemmas highly charged with vulnerabilities. Therefore, even as I engage in it, I wonder how much more text-based analysis is entirely useful. And then I wonder what it means for research to be useful: To whom? For what? Under what conditions? One helpful way of meeting these questions is by adopting Carolyn Ellis's relational ethics approach (2007) and learning from post-colonial methods (Smith, 1999). A relational ethics approach urges researchers to move beyond institutional and personal standards of ethics, and to embrace indirect paths toward meaning-making and knowledge creation in relation to positionality, relationship-building, experience, reflection, invisibility, and not knowing (Ellis, 2007; Somerville, 2006) — bringing this research around again to its grounding phenomenological and poststructural frameworks.

Moving into affect: A theoretical springboard for wonder

... We can prepare for wonder, but we cannot control it. - van Manen, 2002, p. 5

Wonder is repeatedly hailed as the beginnings of philosophy (Rubenstein, 2008). Typically, wonder is used to describe a state of shock and awe. Wonderment is rooted in wonder - the feeling of being struck by the extraordinary in the ordinary, or the oddity of the familiar (Ahmed, 2006, p. 83). And this feeling of struck-ness relates to what Ahmed (2006) calls a "politics of disorientation" whose purpose is to "sustain wonder from the very forms of social gathering" ( $p$. 
24). A preoccupation with wonder, and wonderment, is the crux of this writing's affective motivations.

However, I use wonderment here to re-term an evocation, an affect, whose beginning is elusive and fleeting as it springs from wonder. On the pretense that wonder can be cultivated as a phenomenological practice because it is a feeling that provokes questions and can lead us to adopt a reflective attitude, I posit that wonderment is the ever-present, gut-clenching affect of wonder that emerges specifically in relation to wonderings about the phenomenon of intellectual disability but is absent in literature about this topic (van Manen, 2014, p. 32). Wonderment is a word that stands in for all the instances of, "that's just the way it is"; it is the recognition of familiar normativity as it is bound by common sense, and the feeling that something could be different about all that. Wonderment is a worried affect. It is all the moments of guilt and curiosity, and guilt about curiosity, common to non-disabled bystanders who watch, and gaze at and gaze into, intellectual disability as the phenomenon weaves through cultural locations and intersects with bodies, as we are being-in-the-world-with others (Price \& Shildrick, 2002). Wonderment is the state in which this writing emerges: sometimes without beginnings and certainly without endings that wrap up smoothly; this is not the type of study that leads to explanation, though it is rich with exploration, reflection, narration, wonder, and wonderment.

Wonderment is an ever-present affect of wonder that emerges when the mind has stirred up a reflexive mood that tends to react, however subtly, to the extraordinariness of the ordinary world. This is the state of mind van Manen (2014) calls a possible "antecedent to inquiry" for its reliance on interest over method (p. 37). Wonderment is the effect of already being in tune with a phenomenon's vibrations in the world, and encountering the already suspected significances that may never be known or pinned down satisfactorily. This affective vibration is experiential and 
reflective in that it is a way of relating to common sense while simultaneously being unsure how to relate to common sense. Even though the language of the above theoretical perspectives and disciplines aids in articulating the motions of this work, it is in a state of wonderment that I find my ambivalence in moving forward with research I'm not sure can, or should, be done or ever properly described.

To close this conversation on theoretical positionings, I'll mention that each of the approaches outlined here — phenomenological, poststructural, cultural/disability studiesoriented, ethical, and affective — challenge taken-for-granted assumptions about the ordinary, everyday experience of intellectual disability in order to "open up" or "tangle up" textual spaces that seem closed or inaccessible (Burman \& MacLure, 2011, p. 288). These approaches rely on a cyclical analysis of data as part of their methods (Leavy, 2009) and the use of theory during data analysis in order to open up new/alternative interpretations (Tenni et al., 2003 in Leavy, 2009); in this way the theoretical approaches that are described in depth later are bound to the project's methods (Adams St. Pierre, 2014). This cyclical approach calls for me to be aware of the process and outcomes of the research as well as the affective patterns in which it unfolds under the umbrella of intersecting theoretical approaches. Therefore the nature of the work also calls on readers, and the writer, to confront fears of intellectual disability as problem and as lack.

For Ahmed (2006), fear is an emotion that takes shape not because of someone or something, but because of our orientation ("how we turn") toward the phenomenon (p. 2). Coming to terms with my own discursive practices that include the label "intellectual disability" and how it comes to be a valid utterance is one way of turning toward the phenomenon, and I eventually crack open my thoughts on the term in the next chapter of this dissertation with a narrative. For now, though, I close this section with Carlson's (2010) strange and foreboding 
words of caution and of wonderment. And in pulling out this quotation I'm reminded of Thomas King's (2015) joke in The Inconvenient Indian about his own writing that relies on Ezra Pound's words: "There's nothing like a good quotation to help a body escape an onerous task" (p. xi). And this research task is onerous because, as Carlson straightforwardly reminds us, all research is a classifying practice that locates disability as research-able, including what is written here:

As long as there are experts in different disciplines to define them, institutions to house them, schools to teach them, scientists to study them, psychologists to test them, educators to classify them, people to judge them, and theorists to debate the validity of the label itself, persons with intellectual disabilities will continue to be objects of knowledge (2010, p.101).

\section{Research Questions}

The research questions for this study are the result of phenomenological lines of questioning aimed toward the phenomenon of intellectual disability. Confronting these questions involves processes of making sense of intellectual disability (meaning-making), and embracing the stuff of which sense is never made. This process also involves highlighting meaning in the taken-forgranted, un-extraordinary and unresolved spaces where labels imposed on people (often thought of as Others in an us-and-them dichotomy) provoke ongoing curiosities. These particular curiosities seem to have inadequate outwardly found explanation(s) and resound inwardly, familiarly, and unsettlingly: "that's the way it is." Thus the politics of this research has much to do with vulnerabilities, practices of not knowing, political disorientation, and wonderment in the face of contemporary cultural locations of disability. This research strives to open four particular questions designed to thoughtfully re-orient considerations of intellectual disability not as problem but as presence. 
Each question begins with wonder and/or wonderment, and attempts to pick up some taken-for-granted aspects of the phenomenon of intellectual disability. Following van Manen's (2014) directives on forming phenomenological questions, these questions intend to ask "what a possible human experience is like" and how it is "given to us" (p. 298). These questions also inquire into the conditions of possibility that allow phenomena to emerge (Fumia, Feb. 4, 2015). The first two questions below lead to empirical generalizations and theory development in order to structure the upcoming literature review. The third and fourth research questions are meant to evoke lived experience descriptions rather than direct answers that unfold through the processes of data gathering and analysis later in the dissertation. The questions are meant to address the state of wonderment from which they stem, and to hold up presence as a possible reorientation toward intellectual disability as a cultural phenomenon.

1. Where does intellectual disability come from? In other words, how is intellectual disability culturally constructed in Western contexts, and where is it located? Is the problem of intellectual disability socially constructed? Or are intellectually disabled individuals socially constructed? And how are labeled people made both subjects and objects through research that asks such questions of their corporeal realities?

2. As disability can be temporal, how can those not (yet/anymore/ever) marked as disabled orient themselves toward intellectual disability, and what are the ethical implications bound up in efforts to (re)connect with the "always already" situated and interconnected (Gallagher, 2012) “others” carrying this life-long label? 
3. What foresights follow persistent understandings of intellectual disability as socially invisible (i.e. through societal segregation, genetic technologies, and so on)? This question considers the problem of intellectual disability to be a bio-medical, neoliberal interpretation of the body wherein biomedical understandings of the faulty minds/bodies binary inform the policies under which all people must live their lives in relation to intellectual disability (Scully, 2002; Wendell, 1996).

4. What would it mean for "untranslatable," expressive writing — as a communicative tool — to be read, in some cases, as reflecting the pre-verbal sensations present in the lifeworld (Cixous, 1993; van Manen, 1990)? Could such a phenomenological reading, accompanied by poetic response-writing, assist in widening expectations of cultural participation and unbinding intellectual disability from contemporary invisibleness? Could such experiences expose the untranslatable utterances of the body as "bodily presences" meant to be felt and present rather than as foibles to be corrected, hidden, and disavowed (Abram, 1996, p. 89)? And, further, could the inclusion of such writing in academic discussions about intellectual disability nudge researchers toward spaces of unintelligibility that constitute a valid arena for the interpretation of experience? 


\section{Chapter 2: Necessary interruptions: Discourses, language, and wonderment}

Although it is tempting to launch into literature or elicit ethics at this point, it is important to first clarify the weight of discourse and language on any discussion about disability in the context in which I work. And, because my slight phenomenological approach allows reflexivity, I am called to attend to the language and discourses that shape subjectivities in a general (rather than individualized) sense. As Davies (2000) explains, one can only ever be what certain discourses ${ }^{1}$ allow, or make possible, and one's being in the world "shifts" as the conditions that make intellectual disability a possible phenomenon change over time (p. 13). Discourses and discursive practices are historically contextualized processes still present in cultural memory, and they can be deconstructed through narrower theories of modernity, neoliberalism, and relational ethics, among others. I begin broadly by asserting that although the day-to-day experiences in human lives are the effects of discourse, humans have ways of making each other mean through language that are as troubling as the effects of discourse.

I begin with Foucault (1978) to demonstrate the constituting power of discourse in hopes that his ideas will lead me into motions of methods and rooms of methodologies that are

\footnotetext{
${ }^{1}$ Poststructuralists commonly use the term discursive practice to mean the ways in which people actively produce, engage in, and experience social realities (Davies, 2000, p. 88). Discourses are more generally understood as institutionalized languages or communication systems - the ways we are written and spoken into existence (Derrida, 1976). Kostouli (2009) explains that some theorists, such as James Gee (1991), propose and use a distinction between Discourses (with a capital "D") and discourses (with a lower-case "d"). The former refers to "certain, systemic ways of talking, listening, acting, interacting, and using tools and objects..." through which people realize particular social identities while "discourses" simply, and more technically, refers to the languages in use (i.e. words, sentence structures) (p. 102). I do not make the distinction between Discourses and discourses, but I do wish to acknowledge it here. I also wish to acknowledge Wendell's (1996) warning that we must be careful not to write about discourses as though that's all there is: discourses come with affect, and have real impact on people's lives (p. 44).
} 
compatible with the inseparable processes of thinking and doing. Foucault's concern with ethics, medicine, and psychiatry can be, and is, applied widely by disability scholars who identify hubs of knowledge that could push the evolution of disability as a concept toward postmodernity (Carlson, 2005, p. 134; Corker \& Shakespeare, 2002, p. 7). Foucault's work is used to show how impairment ${ }^{2}$, and the concept of disability that follows, is socially constructed (Hughes, 2005, p. 79) ${ }^{3}$. Beginning with Foucault follows Adams St. Pierre's (2014) directive that methodology should not be separated from epistemology and ontology because this separation risks reducing the project to formula rather than exploratory process (pp. 3, 4). And with this understanding of meanings and structures I work with a feminist poststructuralist positioning that aims to observe the work of multiple discourses people confront at any point in time, and then work to deconstruct and, in some cases, reconstruct

${ }^{2}$ It is important to unpack the term "impairment". The Union of the Physically Impaired Against Segregation (UPIAS), which played a large role in solidifying the social model of disability during the first and second waves of disability studies, insists that the social model differentiate between impairment and disability. The way this organization, in particular, observes the differences in these concepts is as follows: Impairment involves parts of the body that are missing or work differently throughout the course of everyday living. Disability, however, is something that happens when someone is prevented from carrying out particular activities based on barriers such as "inaccessible information, housing and transport, segregated and/or poor quality schooling, hostile environments and attitudes and ways of working which exclude disabled people - these are what underpin...exclusion." The idea, simply, reflects a social modelist perspective which is foundational in conversations of disability studies: if society removed disability from its cultural landscape, the needs of people with impairments would be met (Greater Manchester Coalition of Disabled People).

${ }^{3}$ Disability scholars have cushioned their work within Foucault's ideas about the body, inclusion and exclusion, and his writing on discourse, pathology, and health through understandings of bio-politics and the subject (Davis, 2010; Hughes, 2005; Tremain, 2005/2015). For example, Carlson challenges the idea that "mental retardation" is a persistent, culturally constructed classifier of disability which points to "a particular kind of problem to be solved," applying a Foucaultian analysis to long-lasting bureaucratic political processes such as institutionalization (2005, p. 132-135; Rossiter \& Clarkson, 2013). Carlson rejects the apparent self- evidence of this category, and argues that such a category has developed a "new kind of individual" whose very existence triggers definitions and practices that mold our cultural ways of living and thinking through disability. 
these discourses (Davies, 2000).

Part of the purpose of this research is to create an entry point into another discourse of the body that includes intellectual disability as a terrain for meaning-making, which means understanding "the person as process" (constituting, being constituted, and being the subject of constitution) and moving beyond normalized conditions of subjection (Davies, 2000, p. 38, 54). Again, following John O’Neill, (1979), the lived body is key to understanding intellectual disability because the lived body represents humanness, which places people in contemporary Canadian cultural locations (Snyder \& Mitchell, 2006) — as a disciplinary anchor for an institutionalized field of study, as the subject of neoliberal intervention, and as the topic of activist work. Later in the writing I take stock of contemporary disability tropes that inform the cultural imaginary and by grappling with our orientation toward these representations also explore the actions and reactions involved in moving through disability representation and citizenship as we work to understand intellectual disability. For example, the motion of "giving voice" in contemporary research contexts is problematized and the writing returns to silence in order to briefly explore postmodern understandings of ontological difference. Poststructuralist thought is abstract and interactive, and not always logical because it is not necessarily based Ron a "predetermined chain of reflections" that end in tidy conclusions (Sondergaard, 1999 in Davies, 2000, p. 9).

Vignette: An interruption

A student raises her hand. "Can I just ask a question? What do you mean by intellectual disability'?"

Eleven sets of eyes on me. The question I routinely avoid in my own writing is brought on 
by someone I hardly know, someone who (quite reasonably) expects a response. I try to deflect: "Does anyone want to tackle that question?" The classroom is quiet. Someone is staring at his phone. I am suddenly feeling self-conscious about knowing — or, more accurately, not knowing — the answer to a question. What do I mean by "intellectual disability"?

The question comes at the heels of a discussion about "mental age" and its fallacy. In today's class we are thinking and re-thinking disability through language or, as Simi Linton might have it, "reclaiming" disability through language (1998). One student says she works with a kid in a public school who is routinely held back because of his "mental age." Another woman contends with our reading from Rachel Simon's book, Riding the bus with my sister (2002), because in this text "mental age" is regarded as both a factual phenomenon established by those researchers qualified to calculate it, as well as an all-too-common phrase used against the author's sister. I recall cutting “mental age”-based descriptions out of a writer's feature story about abortion last year when I worked as an editorial intern at The United Church Observer magazine. And just last weekend, I received an email from a colleague inviting me to meet an editor. "I think you'll have a lot in common," he wrote. "She has a developmentally delayed sister who is 21 (about 14 if we're talking mental age)." The notion of "mental age" tends to be a sweeping, sour label used in place of other, more sinister labels, perhaps. When we aren't sure about someone, we can reduce her or him to a lower-than-accurate mental age. The phenomenon rarely works oppositely, as a non-clinical compliment. I've never heard anyone say, "I want you to meet my friend, she's your age, but her mental age is 62 or so." In any case, the students in this class and I have been on the topic of labeling for about an hour. "Intellectual disability" is really just another filler label — one I use (too) liberally without much apology because language is annoyingly insufficient sometimes. And, really, labels aren't all bad and constraining. They give us a place to start (Ignagni, personal communication, 
March 7, 2015).

“Well," I swallow my breath, trying to sound explanation-ready. One student shrugs. Another looks at her shoes. Most are staring at me. "We could think of 'intellectual disability' as a lot of things." This might take a while. "I suppose I look to Carlson's understandings of intellectual disability to form my own" - the students have read Carlson (2010) excerpts, so this shouldn't be too distant. I charge on, opening a past Prezi slide that paraphrases Carlson's three points describing how intellectual disability is usually and contemporarily understood (p. 10-11):

1. Intellectual disability is taken to be natural, and people generally assume others know what they mean when referring to someone with an intellectual disability; the assumption is that there is something inherently bad about the person in question.

2. Intellectual disability is associated with normative assumptions that disability is undesirable, tragic.

3. People with intellectual disabilities are discussed in ways that are ahistorical, their situations generally used as case studies rather than wider-reaching theoretical paradigms.

I swallow my breath and sum up these points aloud. "Basically, when I think about 'intellectual disability' I'm thinking about people whose lives are constituted based on other people's assumptions about them. People whose lives are often considered undesirable. People who are discussed in contexts that are ahistorical - taken-for-granted people. People so taken-forgranted that it's nearly impossible to imagine them being in this classroom because that's not part of the reality they, or we, experience." I decide not to enter the us-versus-them discussion even though the language slipped out of my mouth. There is such risk in speaking. Instead I am ready to wipe my hands of this experience. Ready to move on and- 
"But what about people who use iPads?” someone asks.

"Pardon?"

“I mean, people who I don't think about, but when they get on iPads or something they can communicate with the world? Aren't we making room for those types of disabled people? They're not completely excluded like they used to be." The student wants more. I can't blame her, really. But I also don't quite know how iPads factor into this discussion. I recall a conversation with my advisor who once asked me if the participants in my dissertation research use iPads or other technology that might be useful to mention in a grant application. No. The participants I work with - who I call "intellectually disabled" — work nearby a small room of clunky, donated, desktop computers. There are usually seven participants at a time, meaning there are more participants than computers, so we work on paper notebooks. Where does this sudden surge of interest in disability and iPads come from?

I say that there's some truth to what the student is saying. Even in news media, researchers (Blaser et al., 2015) detect that people with assistive communication devices, including iPads, tend to appear more frequently in news stories than ever before. The mix of technology and disability is proving newsworthy. Credit for people's newfound success with communication is often given to the technology, however, rather than to the people using the technology. "But," I go on, "I am sometimes thinking of people who don't have access to that type of technology, and maybe never will."

Another student raises her hand. "So do you mean people on the more severe end of the autism spectrum?”

“Well, I'm trying to stay away from diagnosed labels. I think that when we use labels we narrow our understandings of what disability means in, well ... " I'm not sure I should take the plunge in this direction. "Well, in the context of personhood and humanness." 
Silence. Whose personhood and humanness am I allowed to comment on other than my own? I am not only thinking of people who are diagnosed with labels that can be categorized as intellectual disability. I'm also thinking about the discursive category of "disabled" and the experience of belonging to, or being in-relation-to, that essentialist category similarly to how Cixous (1993), Butler (1999), bell hooks (1997), and Davies (2000) interrogate the category "woman" for political gain - but of course they're so much better at this than I am, and I'd bet real money that nobody asks them whether people categorized as "women" who use iPads count as women.

I slow down. Gently, now. "What I mean is that 'intellectually disabled' is a term that's relatively okay to use now, but it's bound to change. We are constantly recalibrating what disability means, and when I think of people I want to call attention to in some way or another, I am thinking about people who are not allowed to be in on those conversations in many formal ways - such as in a university classroom. So, sure, this might include people whose lives are impacted by different technologies, like iPads. But I'm also thinking about forgotten people. Or people who are so well established as 'intellectually disabled' - and the many things that might mean - that any other possibility of being is discounted for them. People that are very familiar to us, but at the same time are so far way in our cultural imagination of what it means to be human that they are sometimes not even often included in disability studies research. Does that make a bit more sense?"

The student who originally posed the question nods. I'm not convinced, but thank her for her question even though I still feel a little stumped. I ask again, "Does it make some sense, at least? I know it's not a direct answer. But to answer the question directly, in my mind, would be dangerous. It would follow suit with other types of labels imposed on bodies, including on minds. You know, the way mental age pins a number on someone's body ... there's violence in 
that kind of pointed labelling; there's not much room left for nuance and abstraction that might better constitute the many ways of being a person."

I consider that not feeling very ready to explain the labels I use is also dangerous. The room is quiet again. Maybe what I've said makes a pinch of sense. Maybe it doesn't. Maybe it shouldn't. Maybe they're just over it. "So, on to the next thing then?"

The opening research question directing this writing asks: where does disability come from? Part of the answer to this question involves establishing where disability lands, and what power determines its past and present cultural locations. For Foucault (1978), power is relational. It cannot be reduced to the acts of any particular individual. Therefore, how intellectually disabled people are "made subjects" — and how intellectual disability is produced as a part of culture is a nuanced discursive process that includes forming an understanding of the self and the other. Through this relational gesture, we are not only effects of discourse; we also make each other mean (Titchkosky, May 7, 2014).

Although significant shifts occur in dominant discourse, there is never a single discourse at work but rather a "mix of interwoven ideas and beliefs that belies the notion of historicist or progressive periodization" (Shildrick, 2009, p. 44). Because professionalized understandings of labeled people are often essentialized understandings that uphold hegemonic norms, discourse makes the subject by reinforcing the modernist bodily categories under which all subjects operate and are operated upon (Rapley, 2004). Thinking about disability in these theoretical terms both responds to the discourse that makes disability and "takes apart" its binary codes (Shildrick, 2009, p. 3). Later I argue that modernist technologies, such as pathology and diagnosis, use eugenic streams of thought to inform normal and abnormal body types, specifically in the presence of problem (and therefore divided and objectified) minds (Foucault, 
1978, p. 143). Under the ongoing, authoritative hand of biomedicine, the subject is one whose agency is either advanced or hindered by physical or mental ability (Shidrick, 2009, p. 39). Intellectual disability is a product of a series of ongoing discursive practices, rather than of any real, tangible binary between the mind and the body, normal and abnormal, material and textual. Using eugenics as a primary tool, biopower transforms human life and contributes to subject development that establishes — and departs from — the imagined norm by making the emergence of the problem individual a matter of scientific concern, or a matter of professionalized understandings.

In terms of how we make each other mean, Goodley and Rapley (2002) suggest that interaction, impairment, and disability have much to do with creating the disabled subject. They suggest notions of vulnerability and pathology — which are often affiliated with what intellectual disability means — are dangerous for people carrying this label (p. 128). In part, they argue, the creation of the disabled subject is possible because "impairment is up for grabs in the discursive world," meaning that because disability can seem so out of reach, it is all too easily claimed by researchers as research-able and definable (2002, p. 139). For example, Goodley and Rapley write about "acquiescent bias" to demonstrate how characteristics commonly associated with intellectual disability, such as acquiescence and incompetence, have been established as natural truths about intellectual disability through discursive psychology. They argue that such characteristics of people are better understood as aspects of social interaction. Their argument is launched by Sigleman et al.'s 1981 paper titled "When in doubt, say yes: acquiescence in interview with mentally retarded persons." Goodley and Rapley (2002) outline instances of coercion and resistance embedded in this paper to suggest that such biomedical literature is not accurately representative of the interview subjects' competence or the interviewer's. Here, discursive psychology is pathology; discursive psychology is the mode of social constructivism 
that makes intellectual disability a discursive construction based on diagnostic/diagnosed identity.

Further, some discourses that build and re-built intellectual disability include widely circulated stereotypes of people labeled with intellectual disabilities: as both uncomplicated and mysterious; as reprise for moral wrongdoing but always innocent (Eiesland, 1994; Sontag, 1978, p. 61); as ever-suffering and simultaneously incapable of human suffering (Carlson, 2010); as comparable to animals or non-humans (Carlson, 2010; Tremain, 2005). In addition, people labeled with intellectual disabilities are commonly understood as incapable of using their minds, and therefore unable to adapt to ableist meta-narratives of rationality. Thus, they are also understood as unimaginative, ahistorical, unreflective, and (echoing postcolonial thought) unwilling to make the most of their lives even after being "shown the way" by professionals whose disciplines revolve around intellectually disabled "clients" (Smith, 1999). People with intellectual disabilities are considered among the lowest rank of "uncivilized" because they force non-disabled observers to place themselves amid the degrees of separation between nature and culture that also inform subject development (Carlson, 2010, 4; Eagleton, 2000). Here we recall, again, Carlson's (2010) words “the philosopher's worst nightmare” — a phrase she summons after describing Georgia Kleege's description of the blind as the filmmaker's worst nightmare in her 1999 book Sight Unseen (p. 4). Because labeled people occupy these visions in the cultural imaginary, locating intellectual disability in contemporary culture is both a theoretical and tangible process, as disability still "haunts and produces humanity" (Goodley, 2013, July).

Intellectual disability is an active phenomenon etched into the cultural imaginary, which continually contributes to meaning-making about, and bridges, the body, the self, and the Other. Consider Foucault's assertion that ever-relational power does not exist without resistance to it, even though resistance to repression supports its domination (Dreyfus \& Rabinow, 1982, p. 169; 
Foucault, 1978). We hardly need be reminded that deinstitutionalization, for example, does not happen on its own, but is "something for which many were [and are] relentlessly advocating" for and against (Ben-Moshe, 2013, p. 138). Having been segregated by dividing practices and having acquired a label that marks a firm bodily classification that continues to ring through the cultural imaginary, labeled people are object-characters in cultural locations of disability where people "have been taught how to be intellectually disabled and how to be [workers] in services for people with intellectual disabilities" (Nunkoosing and Haydon-Laurelut, 2013, p. 197-198). These locations are built on a combination of discourses that construct experiences of intellectual disability as Other. What follows: modernization technologies divide the Othered body from the normalized body; curiosity about particular people's cultural locations is lost; and disability is brought into being as explanation for cultural norms. Thus, intellectual disability is both familiar and unfamiliar. This discursive process of political orientation toward disability naturalizes Otherness, and thus the de/familiarization process is one of political disorientation and wonderment (Ahmed, 2006). In other words, disability disavowal is a learned form of subjectification applied to both the self and the other as we are brought into being and as we make each other mean. As Shildrick writes, "the issue, then, is not simply to go on extending the formal framework in which people who experience disabilities can maximize their own potentials, but to seek ways of first understanding and then transforming the nature of that imaginary" $(2009$, p. 5). 
Relationalities: Discovering discourses of the self and the other

Our bodies are doors, sometimes closed and sometimes open, and when they are open they are the means by which we go out into the world and encounter other beings.

- Vernon, 1979, p. 12

One way of understanding the cultural imaginary that informs familiar conceptions of intellectual disability is to focus on discourse and how it builds phenomena (Shildrick, 2009, p.

5). Discourses are the conditions of possibility for something to exist, in this case for the problem of intellectual disability to exist (Fumia, 21 Jan 2015). The subjectivity of each person, regardless of personal embodiment, is deeply intertwined with a materialist cultural imaginary that shapes our corporeal realities (Shildrick, 2009). Another way to think through conditions of possibility is to pull language into the conversation, as the signs and signifiers that bring order to discourse (Hall, 1980). Vernon's (1979) thinking about language begins with the realization that one's body is inevitably "woven" into the material world that surrounds it (p. 13). In other words, the cultural imaginary unifies all corporeal demarcations highlighted by the material world that distinguish the normal from the abnormal (Shildrick, 2009), creating the conditions of possibility from which the concept of intellectual disability emerges.

In the West, this cultural imaginary relies heavily on rationalistic discourses: metanarratives or power-discourse formations of normality that continually wrap and re-shape us as our bodies engage in transformations that keep the body open to possibility. The body is never closed — never an autonomous island — because the body needs air, food, thought, and all things caught up in the material world (Vernon, pp. 12-13). Therefore our experiences of self, others, and decentralized institutions of power unfold gradually and inevitably. The discourses that drive these experiences emerge through routine engagement with disciplinary (dividing) technologies that uphold hegemonic meta-narratives of bodily normality, including dualisms that separate the mind and the body in this modernist, materialist context. 
In thinking about subjectivities, then, there is the temptation to divide the discussion into two parts: self and other. So far this work has operated on this dualism in order to explain the process of making each other mean. Here, however, the writing takes a turn and begins to speak of relation rather than separation. Language, already compartmentalized into signs and signifiers, is a tool for the division of such topics, and to continue to write in this way is to adhere to the limitations of language. Indeed, we depend on such divisions to categorize and establish ourselves; as Esther Ignagni points out, the language that breeds labels often gives us a place to start (personal communication, March 7, 2015). Further, we use the gravity of the notion of "self" to establish ourselves - our own self — in opposition to the other; the production of any sense of the external and internal other always points back at the self. Therefore, it is important to realize that though the words "self" and "Other" appear as separate entities, their signifiers are interconnected and co-dependent on each other to the point that they can be made one in the same: the self is the other, and the other is the self, and in this spirit we only ever experience the world in-relation-to others.

This dynamic of interconnectivity, however it is felt, can be a troubled experience. Foucault (1979) understands the "self" and the "Other" as the effects of power. The self can also be discovered as both object and subject, as in being a self is having a self to which "I" can refer. This dynamic ultimately occurs through objectification, by pointing to one's self in the mirror, perhaps, and thinking, "there I am," as Lacanian psychoanalytic theories might describe (Lacan, 1977). What's more, the felt division between "self" and "other" is a discursive motion that churns up desire, following hooks. hooks (1992) describes this type of dangerous division as characteristic of an era newly departed from modernity:

... [people] afflicted by the postmodern malaise of alienation, no sense of grounding, no redemptive identity, can be manipulated by cultural strategies that offer Otherness as appeasement, particularly through commodification (p. 369). 
When, for example, intellectual disability is constructed and read as "Other" it risks becoming a pleasurable site for research and discovery — in hook's words, an "alternative playground" for dominant groups that identify as the "self" and whose power is affirmed as desirable (or normal) for both the "self" and the "Other" (1992, p. 367).

The prospective social relationship, or "cultural strategy," hooks describes names one party as subject and the other as object. Thus, this relationship opens opportunities to research labeled people in ways that are ultimately insufficient in leaving behind ableist experience and entering the world of the other, as any desire to enter the world of the other points to an oftenmuddled distinction between cultural appropriation and cultural appreciation characteristic of modernity (hooks, 1992/2006, p. 380, 368; Talpade Mohanty, 1991/2006). The desire in this type of social relationality is, by hooks's explanation, a desire to assuage feelings of lack by allowing the "self" to be acted upon and changed by the "Other" (1992, p. 368). The chain of contact is an invasion that can be drawn out roughly in this order: the "self" (understood as normal, active subject) connects to the "other" (understood as abnormal, passive object) and takes from the "other" whatever experience will heighten (change, improve) the experience of the "self," leaving the "Other" cast aside, changed or unchanged. This research will find its movement mainly in the first section of this relationship: the moment when the "self" connects to the "other" and then both (mainly the researcher "self") are stumped, knowing that desire makes resistance possible, but neither can be approached uncritically (p. 380).

In addition, the "I" in "there I am" is the now of individual experience. Sartre once suggested that there is no "I" when scrambling to catch a bus. It is only when the story is recalled — "I ran to catch the bus" - that the storyteller reflects on a moment of lived individual and social existence; the "I" who performed the action of running to catch a bus is a different "I" than the one recalling the moment (van Manen, 2014, p. 60). This re-shaping of the 
"I" is, again, the difference between pre-phenomenal experiences and reflection (Husserl, 1970). And, as Abram (1996) points out, the life-world is very different for each person based on her or his experiences. "The world that a people experiences and comes to count on is deeply influenced by the ways they live and engage in the world," he explains (p. 41). In the case of this research, from the "I" perspective that draws a line between the "self" and the "Other" despite the realization of interconnectivity, one way to understand the cultural imaginary that informs familiar concepts of intellectual disability is to pay attention to the unfamiliarities embedded in moments of connection. Unfamiliarity helps deconstruct always-already discursively constructed social relations, and even slightly deconstructing the "self" and "other" relationalities that build normality and thus notions of intellectual disability is a small but not insignificant gesture of resistance that asks: How might we understand this phenomena as other than intellectual disability?

"Mapping” the body through language: People first?

As we move forward in the process of defamiliarizing intellectual disability and re-thinking the nature of the cultural imaginary, we are embedded in the conversation about discursive practices and language that opened this discussion. The question "what do you mean by 'intellectual disability'?" still dangles in this text. The discursive construction of intellectual disability is influenced by ever-changing language that manages disabled people — language that aims to illustrate that part of the population is made up of certain types, "and to show what part of a person is made up by disability by locating it in the body" (Titchkosky, 2002, p. 101).

Titchkosky (2002) calls this discursive practice "mapping." In attempting to map culture (both "map" and "culture" as verbs, so two motions working at once) we use tools such as language to draw up maps that point out the locations and severity of disability. For example, 
she writes, such maps include the terms "mild," "moderate," and "severe" to "predict one's chances of arriving at a place of disability" (p. 101). Further, clear speech and clear writing work as examples of discursive systems that produce subjects as both the effects of discourses and as meaning-makers. And indeed when we are embedded in a conversation that asks, "where does intellectual disability come from? How is intellectual disability constructed in Western contexts, and where is it located?" part of the answer fails in language.

Yet, language is always insufficient in addressing the particular questions, such as the rhetorical question Stockholder (1994) poses: "What do I call a person who is said to be mentally retarded?" (p. 153). The answer to this question, in Ontario, at least, is "developmentally disabled"4 . The advocacy organizations behind this language are attempting to use their knowledge of what bodies "can do" to re-assert what they "tend to do" by acknowledging humanness given the effects of culturalized conceptions of intellectual disability (Ahmed, 2006). I often follow their approach, but choose my home province's preferred "intellectual disability" instead given that it is the label I most often say aloud when I am thinking of my brother and thus when I am thinking of the people involved in this project. However, in light of the critique of person-first language that follows, I more often choose to refer to people carrying intellectual disability labels as "labelled people" in order to draw

\footnotetext{
${ }^{4}$ In a 2015 resource booklet for service providers distributed by the Canadian Association for Community Living and the DisAbled Women's Network, the distinction between "intellectual disability" and "developmental disability" is explained. The latter is known in some provinces, including Ontario and British Columbia, as an update to the language of "mental retardation," which, in turn, refers to a wide group of people (non/verbal people, people with Autism, etc.) (Odette \& Rajan, 2015, p. 31). However, People First movements and Community Living movements have "mapped" disability differently, and their rationale is footnoted in the booklet: "Developmental implies that a person is not fully developed or is 'stuck' at an earlier stage of development and/or that people with intellectual disabilities are 'slow' or delayed in development, rather than acknowledging that they are fully developed human beings with a difference in intellectual capacity" (p. 31).
} 
attention to intellectual disability as a construct rather than as an inherent characteristic of personhood.

Language has long been a tumultuous issue for disability advocates struggling to refer to themselves and to be referred to by others (Linton, 1998; Clare, 1999). Commonly people-first language is used across Canada to avoid hurtful, and apparently politically incorrect, phrasing or labels (such as "the blind" or "the spastic") that reduce people to their particular disability status. Titchkosky (2001) has suggested that "apolitical” people-first language, such as the phrase "people with a disability" deserves sociological consideration because this type of language is a form of social organization that undermines socio-political understandings of disability (pp. 129, 137). She argues that "people-first phraseology conceives of disability as a troublesome condition arbitrarily attached to some people" (p. 126). In other words, it thinks of disability as a condition (unlike gender, race or ethnicity) that is only significant as a remedial, managerial, or medical "issue" that disconnects people from normalcy while at the same time promoting "people-first” ideology that suggests “"people with disabilities' are normal but for their disabilities" (p. 137). Titchkosky further suggests that person-first language supports government-driven accounting procedures in the "enterprise of othering" as governments survey populations by measuring a particular individual's otherness via "lack" as "they" identify with (rather than without) a disability, making disability an "abnormal [limitation] that happens to be 'attached' to over four million Canadians" (p. 130). She explains:

Bodies differ, sense-abilities differ, minds differ. All people possess these differences, but only some of these differences have been defined in terms of lack and limitation disability. ... This version of diversity needs 'people with disabilities' language if it is to be seen as diversity at all. If disability is lack and limitation, then self-identification with 'it' would require understanding one's self as the negation of ability, and this would be at least strange, if not ... disabling (p. 133). 
Titchkosky ends her argument with the suggestion that "a diversity of terms and expression" could stand in for any particular phrasing of/about disability (p. 138).

Throughout this dissertation the people I work with are referred to several different ways, involving terms such as "labeled people," "intellectual disability," "disabled people," “in-relation-to," "people with — ," crip ${ }^{5}$ and, where possible, by their names and pseudonyms. If we are asking where disability comes from, we are asking where people are located and what conditions of possibility placed them there. I will later argue that silence is an absolute signifier of intellectual disability, while at the same time claim that words make the body. Throughout this writing, words sit on the page under the weight of knowing that they will someday be newly problematized and eventually date the work itself. They are not always the "right" words, but they do serve to make disability emerge on the page — and its appearance can and should be attended to in the research. Still, even words that leave the writer with a queasy feeling need to be rolled around and used in order to build a story, or make a case. If readers will kindly think of these words as imperfect constituents that will eventually build a larger work of wonderment, we can proceed with an awareness of both the linguistic violence and the poetic tenderness ahead.

\footnotetext{
${ }^{5}$ Crip writing is a place where "disability emerges as a possible horizon of desire, and as the ground for contemporary performances of criticism and writing" (Kuppers, 2007, p. 89). Another well-known voice foundational to the notion of crip culture is Linton's, who, in Reassigning Meaning (1998), argued that negative ideologies of disabilities may collapse if people with disabilities "claim disability" through her written self-exploration of disability. Caitlin Wood (2014) describes crip writing as "daring," anti-assimilationist, and evolutionary (p. 1). Eli Clare (1999) illustrates the difference between reclaiming particular words and resisting others. His explanation reads like the difference between empowering counterdiscourses and giving in to institutional labels: "Cripple makes me flinch; it too often accompanied the sticks and stones on my grade school playground, but I love crip humor [sic], the audacity of turning cripple into a word of pride. Gimp sings a friendly song, full of irony and understanding. Retard on the other hand draws blood every time, a sharp, sharp knife" (p. 69).
} 
Beginning with wonderment

While both wonder and wonderment are reactionary (emotion and affects of the emotion respectively), wonder is understood to be effortless and provoked by phenomena external to the self, while wonderment is an ongoing, sometimes unsettling thought process — something like an ongoing churning of the stomach, or a dead-end thought constellation. Wonder is closely tied to theoretical discussions of awe and emotion (Naussbaum, 2001, in Vasalou, 2012, p. 22); it makes us do in response to first-time phenomenon that we understand as "remarkable, extraordinary, unexpected" (Vasalou, 2012, p. 20, 27). Meanwhile, wonderment is something that makes us wonder what there is to do. Wonder is also deep, while wonderment tends to be shallow — it floats closer to the surface of our thoughts, and undoubtedly resides in ableist understandings of the body.

Ableism is a reaction to disability triggered by emotions of disgust, fear, and pity. This reaction is thought to spill out violently, loudly, and quietly, mainly from non-disabled people who are, as Bill Hughes (2012) suggests, in denial about their own inevitable vulnerability, decay, and death (p. 18, 21, 23). Ableism often manifests in careless language. Because wonderment emerges quietly, and often disgustingly — for certainly "that's just the way it is" reeks of uncritical avoidance via its false disguise of superficiality — it floats near the surface of the mind where it can be easily scooped up and thrown away as an afterthought. Wonderment is the verge of that scooping motion - the afterthought that is only just about to be let go. Yet, wonderment is significant because of its emergent, reactionary nature. Holding on to wonderment can re-focus the internal and external gaze in a swing of political disorientation (Ahmed, 2006); it is the disgust tied up in wonderment that makes it political, and has it edging toward Titchkosky's (2011) politics of wonder. 
Titchkosky suggests that it is possible to "nurture a desire to wonder about the everyday politics of disability" (p. 6). A politics of wonder considers the political reaction to wonder about disability specifically; it is a way of responding to disability and its cultural locations that does more than "produce more of the same" and instead focuses on future belonging (p. 130). What makes wonder political, she suggests, is the relationship between the self and the world, and how disability arrives at an "intersection between the perceiver and the perceived" (Titchkosky \& Aubrecht, 2009 in Titchkosky, 2011, p. 129). This study, then, gleans from Titchkosky (2011) an awareness that responding to wonder is political because it sometimes means participating in the current discourses that lead us to wonder about the ordinary in the first place (p. 17). This participation can come in the form of slowing down — halting the discourses to mull over them (Cixous, 2008, p. 81 in Titchkosky, 2011, p. 137). Participating in wonder also means entering spaces where poetic knowledge emerges, and where normative language is not always sufficient for making meaning (p. 129). In this sense, the wonderment that follows can be captured in oftenfleeting thoughts tied to the taken-for-granted: the ordinarily extraordinary phenomenon of intellectual disability as it is assigned to the lives of others, and in relation to the self. And here wonder and wonderment meet and overlap, if we heed Ahmed's (2006) instruction that to wonder is "to remember the forgetting" and to observe the familiar as a process of repetition (pp. 82-83 as quoted in Titchkosky, 2011, p. 133).

Wonderment's primary departure from wonder rests in the stagnant estrangement from/of the ordinary, and in the "burdensome awareness" of constraints imposed upon the freedom of ourselves and others (Bauman, 1990, p. 66). Wonderment, as understood here, is sometimes accompanied by feelings of helplessness, by awareness that inward-looking contemplation and outward-reaching political action are not necessarily useful. Wonderment can emerge in the realization that irrationality can be more effective than rationality; as Zygmunt Bauman (1990) 
writes, "rationality means being guided by the head rather than by the heart" (p. 132) and that some are freer than others to exercise irrationality (Prendergast, 2001). Irrationality is, in its way, a method of turning the rational, or the ordinary, inside out. Kathleen Stewart (2007) describes the ordinary as "a mode of attending to the possible and threatening, it amasses the resonance of things" (p. 12). Wonder, then, tends to be outward looking and positioned at the beginning of inquiry about the extraordinary within the ordinary "with the assumption that explanation should purge it," while wonderment is always-already tied up and remains unresolved by explanation the never-to-be-known (p. 12). Wonderment is stuck in the "resonance of things" — in the lingering, unsettling space of thought where we find awareness and unfulfilled curiosity, unresolved problems, the never-to-be-known. When layered with the poststructural and phenomenological influences of this study, wonderment is threaded through the texts — detailed descriptions of ordinary happenings related to intellectual disability — as a troubled awareness that there is no end or resolution to the repetitive stuff of everyday life.

There is also risk in wonderment and its connections to language. Hegel writes that the biblical Adam annihilated the world's creatures when he assigned them names (1979), and that language abstracts or "kills" the moments of experience it attempts to describe with one perfect word, with "no generalizing and no system function, and thus ... no slippage or signifiers, no ambiguity" (Berger, 2014, p. 18). Naming is a type of purposeful "speech act" that "live[s] in complicated aggregates of meaning" - neither coincidence nor accident, it is a way of intentionally organizing the world into concepts, allowing us to evoke and gain access to these concepts at our convenience (Stockholder, 1994, p. 154; Vernon, 1979, p. 61, 63). Naming is a convention with important consequences in constructing social reality (Stockholder, 1994, p. 178). As John Vernon (1979) explains, “[w]hen we name, language lodges in the world like a hook, and brings things forward; yet, it releases them at the same time” (p. 62). In this sense, 
illuminating the invisible is also arguably an ableist act of distorting the invisible by reducing its complexity and narrowing it down to a single name, phrase, or speech act that results in misunderstanding of certain concepts (Stockholder, 1994). There is risk, then, in calling naming — this cringing sensation wonderment, when, by naming it, the feeling might be robbed of its “existential richness," as Van Manen (2014) describes (p. 21).

In this line of thought, however, it is also powerful to realize that to label a person as intellectually disabled — or any other word or acronym that denotes this position — is to destroy, to "kill," her or his singularity and particularity as a distinct human by means of categorizing the body under a stigmatized heading (van Manen, 2014, p. 84). Cixous writes this another way: "In life, as soon as I say $m y$, as soon as I say $m y$ daughter, $m y$ brother, I am verging on a form of murder, as soon as I forget to unceasingly recognize the other's difference" (1993, p. 13). This murder is in the naming, though Cixous places emphasis through italics on the possessive my. To name is to claim, and to name is to insert the self in the Other and thus steal the other's autonomy. This killing, or murder, of the Other describes the weight of violence that naming can bring to a conversation.

Yet, on the other hand, giving this affect, wonderment, a name allows me to evoke it and hold some power over it, so that wonderment does not remain in the pit of the stomach but can instead be flicked onto the page, which is a space where I can take action with it (Vernon, 1979). Perhaps I need to claim the Other in order to claim space, or to claim a starting point that would otherwise go unnoticed. Wonderment is the stuff that leads to moments of inquiry that I best not pass by, as described by Stewart: 
... at once concrete and ephemeral ... accidents and derailments, watching to see what happens when things collide or de-compose. It encounters things, takes to things, piles things up, soothes, and has to get out and go. It dies in itself and grows vigilant. It claims a place for itself only through the constant experimental activity of foolin' with thangs, and so finds itself vulnerable to things frightening and sublime, uncanny and disastrous (Stewart, 1996, pp. 205-206 as quoted in Lather, 2007, p. 72).

These "accidents and derailments" — aren't they the site of killing? Similar to empathy in that its antithesis is the emotive of ableism, wonderment emerges and burns abruptly and without preconditioned thought, but to sustain it requires practice, rigor, and error (Smith, 2006, p. 22). Wonderment is both ableist and non-ableist in that it exists, and when named becomes an object for and through interrogation.

Much like language and wider discourses, wonderment leaves us dwelling in the dark, and does not entertain notions of extraordinariness, acknowledgement, explanation, or resolution. In this research, my aim is to stay in the dark for a little while, and to lead the reader here so we may explore what this invisibleness offers. Therefore I take up wonderment as part of my theoretical positioning. Wonderment is the internal reaction to the phenomenon of intellectual disability, and carries both political and emotional undertones; as I enter into a literature review that aims to describe intellectual disability as a culturally located phenomenon I attempt to pluck wonderment from wherever it emerges so that it is not overlooked, so that it does not slide away as easily as usual. 


\section{Chapter 3: Reaching back and re/making intellectual disability}

I will begin re/making intellectual disability where this writing eventually ends: with phenomenology. The nature of this research demands an understanding of how, or when, an experience becomes a phenomenon. The differences between doing phenomenology and taking a phenomenological approach are many, and they are outlined later in the section on methods. To abbreviate this distinction now, I turn to Edmund Husserl (1991) — often named the "father of phenomenology" — who claims it is necessary to distinguish between "the prephenomenal being of experiences, their being before we have turned toward them in reflection, and their being as phenomena" (p. 132 in van Manen, 2014, p. 56). Max van Manen (2014) restates Husserl's call by explaining that researchers must distinguish between the modes of reflection (which are temporal) and "the prereflective now" (which is not based in time) (p. 56). All this is to say that a phenomenological approach concerned with intellectual disability understands it as an ongoing experience that is lived out as an everyday part of the world and can be reflected upon; in other words, intellectual disability is not a taken-for-granted nothing that can't be researched, nor is it a concept that should be limited to individualized differences. Intellectual disability is a phenomenon we come to individually and collectively, and the ways in which it emerges in moments teach us something about the ways in which it is experienced.

Because intellectual disability is in a unique position in our cultural imaginings as something both familiar and unfamiliar, it is a prephenomenal human experience in that its presence is part of our human and consequently cultural landscape; intellectual disability exists before we have turned toward it in reflection. It is the "space between" the phenomenon's existence and the researcher's turn toward it that this dissertation attempts to capture. The turn toward the phenomenon, then, welcomes a new orientation in-relation-to it and prioritizes, 
through writing and reflecting, experiences — everyday moments of encounter — that demonstrate how intellectual disability is discursively constituted and culturally circulated. These circulations take place specifically through the events of writing, including its enactments, and through reflecting on such enactments and their remnants (halifax, personal conversation, Jan. 27, 2015). This approach, which is an interpretive approach informed by phenomenology (and therefore cannot strictly be called "doing phenomenology"), requires me, as the researcher, to experience moments of encounter and disconnection in-relation-to the phenomenon and in the presence of the people whose bodies are built through its discourses. And following Foucault (1971), bodies are built on discourses because discourses are "practices that systemically form the objects of which they speak," and these discourses must be revealed in order to reflect on when an experience becomes a phenomenon (p. 48 in Adams St. Pierre, 2014, p. 14).

Vignette: Beginning research

"Can everybody just drop their pens for a minute?"

I'm standing at the front of the JS Manson boardroom cradling a dozen informed consent forms. Six faces look up at me. One participant lifts his arm high in the air and drops his pen on the Mahogany-veneer finished table. The pen rolls and clatters to the floor. "Oops, " he says softly, picking it up.

“Thanks everybody." I launch into the words I rehearsed in my mind as I biked to this fieldwork site. The thick, frosty air outside left me panting. Leaves are raining from the trees, though there are no windows in this room for us to see the pulsing autumn orange that's painted the treetops in the nearby Don Valley. It is the Friday morning before Thanksgiving. Sweater weather. 
"Remember last week, when I handed out these flyers?" Nobody responds, though I don't mean to ask rhetorically. Perhaps because I didn't pick up on the pen-dropping joke - I would have laughed if I had; the joke made me smirk when I looked back on my notes. My audience is so-far non-committal. I hold up the recruitment flyer and attempt to re-explain my research in a few, plain language words not meant to sound condescendingly simple, though they probably do. Only one person is a new recruit to the expressive writing group, despite a presentation of the recruitment flyers to about 40 potential candidates a week earlier. The usual attendees, who have been coming here to write - for a "class" or "session" or "meeting" as staff call it before I label it "research" - are sitting in their usual spots around the table. My chatter has interrupted their writing.

"So," I try to wind down my explanation of research quickly. "If you're interested in being part of the research, I need you to fill out this form. "I debut the informed consent form, holding it up so everybody can see what it looks like.

"Okay," one man leaves his seat and reaches for a form.

“Well, maybe I'll go through it with you first?" I hand him a form anyway.

I begin by pointing to the logo on the top right corner. "This is the school where I study." Someone asks how he can get to that school: Will the bus go there? What stop should he ask for? I tell him it's not necessary for him to visit Ryerson University. He slumps down in his seat and looks up at me quizzically, "Are you sure, Chelsea?"

I describe the title of the research, and move downward into the details. I summarize the form first, for those who wish to read it on their own. During my summary, ABBA karaoke blares in the background. We are a week away from JS Manson's annual talent show, "Manson's Got Talent." Some of the semi-regular writers are singing through rehearsal. The processes of 
describing, understanding, and signing the informed consent form will bleed into the coming weeks.

\section{Mapping intellectual disability as familiar and unfamiliar}

Familiar parts of our daily lives tend to be routine and monotonous. Some familiar things are close to us, in terms of our proximity to specific surroundings and our motions as we move through the world. Other familiar things can ring common, or mundane, while being rather far from our experience. Disability, in general, is no different: “ ... disabled people are present everywhere, and disability is one thing that all cultural endeavors bring into being," Titchksoky (2008) writes (p. 4). That intellectual disability, more specifically, is a taken-for-granted part of the social order brought "into being" everywhere makes it a phenomenon both intimately familiar and vaguely unfamiliar, dynamic and static, often depending on a person's relation to it (Carlson, 2010).

Often, of course, our proximity to certain people around us determines our relation-to and orientation toward intellectual disability. This relationality is also determined by disability's space and place within culture, and cultural practices and representations that influence one's relation to disability (Titchkosky, 2002, p. 101) ${ }^{6}$. Repetition of the familiar tends to make things self-explanatory, erasing any arousal of curiosity; as Bauman (1990) writes, "familiarity is the staunchest enemy of inquisitiveness and criticism" (p. 15). And as Stewart (2007) writes (cautionary or not), "The ordinary can happen before the mind can think" (p. 63). That we orient

\footnotetext{
${ }^{6}$ In my case, for example, intellectual disability is familiar in that I encounter it each day, whether through this writing, through my disciplinary school of thought, or through family members. Intellectual disability's cultural location as de-centered, outside of normativity, or as "Other" to my "self" and often located in separate spaces outside of the normative institutional frameworks that govern my day-to-day routine is a familiar and largely unquestioned position of the phenomena.
} 
ourselves toward phenomena also suggests that a phenomenon is oriented toward us; positionality is action and reaction.

Intellectual disability is a phenomenon that risks easily falling into the lull of the ordinary when the self-explanatory - the common sense and scientific knowledge (forces that instruct our opinions on the body) that work to bring disability into being — also tells us what intellectual disability ought to be (Wendell, 1996). As Berger (2014) explains when he characterizes the "dis-/dys" in his term dys-/disarticulate, what we know about intellectual disability "stands as an alternative to the prevailing social order, and yet at the same time has neither clear definition nor power" (p. 8). We get comfortable with the notion of intellectual disability as something positioned in a place both vague and familiar in all its non-specific un/certainties. In particular, from a cultural disability studies perspective, Berger identifies the dys-/articulated as "that place" which exists "beyond all discourse that would provide a final affirmation or negation to the social-symbolic world" that has been discursively constructed to — somehow, some way — house intellectual disability (p. 13).

Therefore, it is imperative to de-familiarize intellectual disability. De-familiarization of the ordinary is a way of making time to think about the ordinary that "may open up new and previously unsuspected possibilities of living one's life with more self-awareness, more comprehension — perhaps more freedom and control" (Bauman, 1990, p. 15). De-familiarizing intellectual disability, then, means firing up questions: where does intellectual disability come from? Where do we find it? How is it made? And, importantly: Is the problem of intellectual disability socially constructed? Or are intellectually disabled individuals socially constructed?

Such questions reject assumptions that the phenomenon is non-emergent and ahistorical, that it lacks roots. To answer these questions we might turn to disability history. However, a 
history of intellectual disability is missing from the literature, though many theorists acknowledge this and work intellectual disability history into their writing (Carlson, 2010; Rapley, 2004; Stiker, 1999). $T^{7}$ herefore, this writing merely glimpses into cultural memory rather than taking up the task of recalling history. The writing begins by describing and framing social constructivism. Then, using pre-modern conceptions of the body that serve to construct the concept of intellectual disability as a launching point, modernist notions of the body that determine cultural locations are brought to the fore. These notions include eugenic accounts of normalcy and intelligibility which are used to naturalize abnormality in modernity. From here "docile bodies" are labeled, categorized, and continually accounted for under the technologies of biopower such as institutionalization (Foucault, 1979). The writing of many of the researchers and theorists cited here relies on cultural memory to dig up traces of disability on display throughout history in order to point us toward how the familiar comes to be in the world today. The silence, or invisibleness of disability history, and intellectual disability history, says much about its position as oppressed in contemporary understandings of disability.

Then, I rely on silence to re/make the intellectually disabled subject through discourse and language. As Foucault (1978) teaches, silence such as this is the other side of discourse that holds its own meaning:

Silence itself - the things one declines to say, or is forbidden to name, the discretion that is required between different speakers - is less the absolute limit of discourse, the other side from which it is separated by a strict boundary, than an element that functions alongside the things said, with them and in relation to them within all-over strategies (p. 27).

\footnotetext{
${ }^{7}$ They also call for disability historians to account for intellectual disability history in their work, and for academic institutions to support the work of disability studies historians (Berger, 2014; Carlson, 2010; Snyder \& Mitchell, 2006). Disability history is a field of inquiry "still in its infancy," to borrow French and Swain's (2006) description (p. 384).
} 
Foucault's work here brings to mind Erevelles's more literal notion of silence and silenced bodies when, as earlier, she reminds us of the precariousness of labelling the "voiceless".

In the case of this research, silence is also an affirmation that intellectual disability is, following Carlson (2010), assumed to be ahistorical. The questions of how disability comes to be also get us thinking specifically about intellectual disability, which is commonly separated from other types of disability (separating words include "physical," "psychiatric," "invisible," "learning," "cognitive," "special," and so on) while simultaneously remaining a critical theoretical category that "can also account for the challenges posed by other constructs of difference" such as gender, race, and spirituality among others (Erevelles, 2001, p. 93).

Therefore, the investigation continues by following lines of questioning about what the concept disability is and how it is used to split bodies into various dualisms in Western socio-cultural contexts: physical/intellectual, normal/abnormal, disabled/non-disabled, etc. As with all processes of classification for all types of bodies, the reductive classification of bodies on the basis of dis/ability is linked to control, and to the action of "slotting someone into that which is already known" (Davies, 2000, p. 38). Further, these dualisms demonstrate how it is possible to divide the body into these categories even when synthesis of the body — "an arrangement of parts and whole" - is also that which is already known (Vernon, 1979, p. 53).

The human condition is key here in understanding intellectual disability as an element of humanness that places people in contemporary Canadian cultural locations (Snyder \& Mitchell,

\footnotetext{
${ }^{8}$ What Erevelles meant is that silence is embodied, imposed and assigned to particular bodies in particular cultural locations. Also, silence, in this sense, is active in that it can manifest as a choice not to listen rather than as a taken-for-granted quality of a person, or the discourse that constructs a person's identity. While it is suggested that "the other side" of discourse is silence, it is also suggested that to dwell in the realm of silence is to ignore what is present. Therefore, locating the intellectually disabled subject in the realm of silence returns us to a project of "mapping" the body through language.
} 
2006): as a disciplinary anchor for an institutionalized field of study, as the subject of neoliberal intervention, and as the topic of activist work. The third and final section of this chapter takes stock of contemporary disability tropes that inform the cultural imaginary by grappling with our orientation toward these representations. This section also explores the actions and reactions involved in moving through disability representation and citizenship as we work to understand intellectual disability. For example, the motion of "giving voice" in contemporary research contexts is problematized and the writing returns to silence in order to briefly explore postmodern understandings of ontological difference.

\section{PART I: The body's pre-modern dys/appearance}

Social constructivism is useful in framing the practices that represent cultural locations of disability in contemporary society, and in pointing, then, toward some answers to questions of how intellectual disability is constructed and where it is located (Stiker, 1999, p. 72) ${ }^{9}$. Common discursive understandings of intellectual disability locate the phenomenon as a

\footnotetext{
${ }^{9}$ The first thing to accept about social constructivism is the rather deflating realization that something we dislike is not the result of one system, or one person, but more likely a consequence of the sometimes-invisible working of a faceless system built of discourses that form and continually inform our understandings of self and others as subjects (Bauman, 1990, p. 14; Foucault, 1978). Here, we must grapple with the institutionalized language systems of discourses and common-place understandings: One way to understand discourse is through a poststructuralist lens, which follows Foucault, who writes of discourse as practices that are comprised of ideas and referents that circulate (or are silenced) to systemically construct both the subjects and objects they surround (Dreyfus \& Rabinow, 1982). Bauman's use of Thrift's words in summing up discourse is also useful: "meta-languages that instruct people how to live as people" (Thrift, in Bauman, 2000, p. 54). However, when reframing "discourse" specifically as communication through language (rather than entirely in Derrida's terms of institutionalized referents) (1976), it should be realized how easily the non-disabled body slides into language. Titchkosky (2002) demonstrates our constant metaphorical references to bodily condition: "People just jump into the shower, run to the store, see what others mean while keeping an eye on the kids or skipping from office to office and, having run through the day while managing to keep their noses clean, hop into bed" (p. 103).
} 
problem (Carlson, 2005) — often an Othered problem set apart from the self — separate from the "normal" body and/or mind. This dualistic construction, or understanding, of intellectual disability dominates modernist thinking of intellectual disability as an impairment of a mind lacking ability (sometimes articulated in language/discursive practices of labeling such as "cognitive impairment" or "mental retardation"). This familiar way of understanding intellectual disability drives our understanding of self, other, and self-and-other: the $d y s-$ /disarticulated self, or side of the body, that dwells in the mental (rather than the physical, as if these were somehow in opposition) is a taken-for-granted problem interwoven in elements of the Other's embodiment.

What's more, on the topic of intellectual disability there seems to be a muddy middleground between "pure constructs" and "real entities" (Carlson, 2010, p. 86). In other words, disability, as a culturally contextual process and socially constructed category, exists alongside "real people who have been labeled "mentally retarded" (p. 86). Social constructivist perspectives tend to make firm distinctions between the biological and the social, although as Wendell (1996) spells out, in discussions about disability these distinctions cannot be made sharply because they are interactive (p. 35). Disability is socially constructed by a failure to create ability among people who do not fit into modernist bodily expectations (pp. 39-41) ${ }^{10}$. Wendell claims that "the social response to and treatment of biological difference constructs disability from biological reality" to determine the nature and degree of disability (p. 42). That is to say that the social construction of disability involves the interpretation of difference that leads to a perceived inevitability of classification

\footnotetext{
${ }^{10}$ Wendell points to social circumstances that create and erase disability: medical intervention, pace of life, social expectations of bodily performance, technological evolution, and cultural exclusion of people from particular activities and representations (pp.42-43).
} 
(Carlson, 2010, p. 87, 90). The "interpretive step" that tangles up constructs and reality, in Carlson's words, is as follows: “a biological condition is given meaning by an ableist society, and the experience of it becomes disabling based on this interpretation" (p. 89).

It is through, and within, the establishment of these types of normative discourses and the processes of construction and interpretation that the phenomenon of intellectual disability emerges as routine, unremarkable, and self-explanatory. Often intellectual disability is a thing telling of the distance between the self and the other: What is our proximity to intellectual disability? How do you make contact with it, and under what circumstances? And, as Bauman (1990) points out, the distance we experience from people often informs our general attitudes toward them (p. 39). It is through these various stages of "discontinuous moments and reform" within the cultural imaginary that intellectual disability is discursively and historically constructed and brought into the present as both familiar and ambiguous (Carlson, 2010, p. 23).

Pre-modern understandings of the body

... a society reveals just as much about itself by the way it speaks of a phenomenon. The imaginings of society just as much as its praxis. The gap between praxis and the collective 'imaginary' may be large, and be due to quite other reasons than ideology in the Marxist sense of the world. The social imagination is also social reality. - Stiker, 1999, p. 46

It is impossible to pinpoint where the phenomenon of intellectual disability comes from and how it grew to be unquestioningly applied to bodies of specific people. I approach this cultural memory not as a chronological story but as a "constant circulation and recirculation of ideas — both articulated and hidden" (Shildrick, 2009, p. 45). This circulation and recirculation of ideas is a movement that, in Fred Stockholder's (1994) words, “does not disappear" (p. 161). Under the pretense that knowledges are often reproductions of "what- 
already-is," this section attempts to locate past knowledges about the body in order to understand present knowledges about the body that bring us into practices of institutionalized knowledge production about particular “types” of people (Titchkosky, 2011, p. 130).

Pre-modern understandings of disability land on disability as a social space that provides the room for later, more clearly defined socio-political locations of disability (Titchkosky, 2002; Snyder \& Mitchell, 2006). Or, as Izabella Pruska-Oldenhof has explained, the blend of mythical thinking and rational, scientific thought in pre-modern eras involved a type of esoteric "intellectual bricolage" that urged people to orient their thinking toward the future shape of the world by recalling the past (May 13, 2013). This section aims to uncover some of this "intellectual bricolage." What is taken away from this exploration of pre-modern understandings of disability is the realization that any direct line between what was and what now is today, in terms of intellectual disability, is discursively produced, entirely imagined, and yet still performed as we act out contemporary cultural imaginings of what intellectual disability means.

Many researchers offer thorough accounts of pre-modern understandings of disability: Berger (2014), Stockholder (1994), Henri-Jacques Stiker (1999), Snyder \& Mitchell (2001, 2006), and Mark Rapley (2004). As Carlson (2010) notes through her own reading of Stiker (1999), philosophers who have written about disability as an integrated part of our cultural imaginary are relatively difficult to find (p. 3). Writing about disability as part of society rather than as something on the outskirts, Stiker notes, is "a method more critical, even more militant, than to address [disability] in terms of exclusion. ... Integration passes more unnoticed" (Stiker, 1999 in Carlson, 2010, p. 3) ${ }^{11}$. These researchers share the commonality of admitting,

\footnotetext{
${ }^{11}$ Indeed there is no available comprehensive history of intellectual disability, and this dissertation does not attempt to undertake such a massive task. Carlson's 2010 book, The
} 
in various ways, that they've fallen into a research rhythm that leads them to write a cultural history of disability rather than a thorough historical account. Alongside cultural histories, social and medical attitudes toward intellectual disability tend to be taken as the two common ways of understanding it. Sometimes these understandings, which reflect both social constructivist and essentialist views of disability, overlap ${ }^{12}$. Foucault (1978), however, suggests that silence can be used as yet another way of understanding a phenomenon - its "other side" - and this third understanding (after the social and medical understandings) is what this dissertation reaches into. To get to this "other side," the conditions of possibility for intellectual disability as a familiar, taken-for-granted, ever-present phenomenon must be taken into account.

Stiker's (1999) analysis leans most closely to a chronological, historical understanding of disability because he offers an era-logical timeline: a medieval period that develops concepts of marginality that further directs attention toward categories of fortunate (sociable) and unfortunate (outside of society); followed by the classical period which names the body healthy (social) or unhealthy (outside of society) and calls for separation with ambitions to categorize bodies; and a modern era that ushers in notions of restoration of the body that vary in degrees of success and manifest in a variety of praxis. These applied practices include

faces of intellectual disability: Philosophical reflections draws on many comprehensive historical studies of intellectual disability in particular and therefore would be a strong starting point.

${ }^{12}$ Carlson (2010), for example, argues that two types of views of disability that intertwine the medical and the social tend to operate simultaneously: dynamic and static. Dynamic views of disability tend to be associated with "an age of optimism" that understands disability as changeable and/or treatable. Static views of intellectual disability tend to be associated with "an age of pessimism" wherein disability is believed to be incurable and unchangeable (Carlson, 2010, pp. 36-37). These "ages" of optimism and pessimism chronicled in The faces of intellectual disability: philosophical reflections (2010) both involve institutionalization, rehabilitation, biomedical interventions, and eugenic thought all operating simultaneously to contain, improve, and eliminate intellectual disability. 
rehabilitation, education, segregation, and bio-technologies that append the body and lead to further, bio-ethical conversations that characterize the later cyborgian/post-human/dis-modern era best described by Lennard Davis $(2010,2013)$ and potentially categorized as the present.

\section{Encountering pre-modern Otherness}

Importantly, it is false to assume that the modernist mind/body dualism has always existed, thus giving way to a classification of intellectual disability (Goodley \& Stainton, 2001, p. 225). Stockholder (1994) suggests the first theories of the mind appear with Aristotle and Plato where material elements of the self (such as the mind) are considered inferior to spiritual elements. This binary, Stockholder suggests, is the original splitting of the body between mentality (thinking and ideas, as tied to virtue) and necessity (the physical body, which encompasses material needs and labour) (p. 164). The pre-modern life is one where "social order is dominated by the most powerful mentalities" and those outside of social order (meaning those with psychiatric and intellectual disabilities as we might label them today) are pushed into the remoteness of otherness (p. 162). Otherness, as it were, is still the product of social processes that produce particular identities, including those of impairment and disability, even prior to modernist notions of a body/mind split (Paterson \& Hughes, 1999, p. $609)^{13}$.

\footnotetext{
${ }^{13}$ These processes are described by Wendell (1996), and can be applied to all of the cultural contexts described throughout this writing: 'When we make people 'Other,' we group them together as the objects of our experience instead of regarding them as subjects of experience with whom we might identify, and we see them primarily as symbolic of something else - usually, but not always, something we reject and fear and project on to them. To the non-disabled, people with disabilities ... symbolize, among other things, imperfection, failure to control the body, and everyone's vulnerability to weakness, pain, and death" (p. 60)
} 
We might, however, re-consider Otherness as we recall the pre-modern - a time where, as Stiker (1999) explains, "normality was a hodgepodge, and no one was concerned with segregation, for it was only natural that there should be malformations" (p. 65). That is to say, people lived an existence where solutions to bodily problems were inaccessible (and sometimes unimaginable), and the body was likely to run its course; the body that survives infancy is born in particular shapes and with particular characteristics that evolve over time as memory lapses, eyesight blurs, and so on (p. 65). The body continually collapses and rises as it comes up against time and the physical barriers of the surrounding world and its pulsing social patterns.

Yet, contrary to Stiker's analysis, Foucault (1973a) paints a picture of the history of Western reason that suggests a more sinister reality of incarceration and confinement governed by those deeply concerned with Otherness and segregation. Foucault reminds us of leprosariums scattered across Europe and "ships of fools," which "haunted the imagination of the entire early Renaissance" (p. 9). He then moves into the end of the medieval period and traces this type of confinement into the 1500s, when lazar houses held "incurables and madmen" — the "vagabonds, criminals, and 'deranged minds' [that] would take the part played by the leper" for the sake of their own salvation and for the salvation of their caregivers as well (pp. 6-7). Foucault's memory of these folks offers the first hint of moral lack affiliated with pre-modern conceptions of disability ${ }^{14}$.

Still, what we might think of as "abnormalities" or "malformations" exist and continue to exist as the discourse surrounding them changes and circulates, moving from discourses of

\footnotetext{
${ }^{14}$ Carlson, as well, points out that people "believed to suffer from idiocy" have been viewed as "possessed, holy innocents, eternal children, and diseased organisms" throughout history - blending conceptions of moral lack that could be pinned down on any historical roadmap between pre-modernity and contemporary biomedicine (2010, p. 24).
} 
natural life course to more dualistic discussions of normality/abnormality and mind/body. Such discourses, for instance, include discourses of monstrosity, whose conditions of possibility are found in a time when explanation of the human condition (which sometimes meant not knowing) fused with myth:

These monsters herald the coming world of retribution. But, beyond this aspect, ... monsters are located in a geographical unknown, on the boundary of the explored world, and they provide relief for the fear in people's hearts. They 'demonstrate' what could happen to the human body. The anguished question to which they give the answer is: how would we be if we were not the way we are? (Stiker, 1999, p. 69)

Also, fear of social ill is linked to fear of the body in pre-modern times. Fear is located alongside the notion of the monstrous - a notion that fills the blank spaces of our cultural imaginary about difference, and about bodily deviations, the spot where our imagining of ourselves in the Other disappears (Carlson, 2010). Further, even with normality as "hodgepodge" Stiker posits that people with disabilities could not have simply blended into the crowd - their histories, however, remain largely silenced short of histories of the poor and of slavery which may have constituted many lives in-relation-to intellectual disability (Ben-Mosche, 2013; Stiker, 1999, p. 66):

Beyond these figures, so important for the middle ages — the beggar, the monster, the criminal - lies the silhouette of the disabled, borrowing features from the other three all at the same time or successively, and yet sharply contoured, taking us down into the depths of as yet unthought social ideas (Stiker, 1999, p. 72)

These figures, who inform social structures, are characters in pre-modern times, though I would venture that social ideas relating to these figures may not be entirely "unthought" and may rather point us back to the dilemma of an invisible disability history.

Where disability history is apparent, however, is in literature that shows a clear alignment of disability with chronologies of life for the poor (Stiker, 1999; Snyder \& Mitchell, 2006). Particularly in Western, charity-based contexts, where poorness and madness are shown 
to intersect, both parties are brought forward for transformation into productive labourers as social discourses become increasingly rational. This period - beginning at the end of the Middle Ages and moving into the Renaissance — becomes intrinsically tied to the body and manifests in the societal segregation of people in such places as almshouses (Stiker, 1999, p. 67). Segregation itself is linked with charity, and labeled people maintain statuses of "the cared-for, integrated marginalized; that is, under supervision the fool was admitted to ordinary life" (p. 69).

We might remind ourselves that these people are those thought of as "incurables," as Foucault (2003) points out — the emphasis on curing the body still present even without the institutional language of classification that would come later in modernity under a widespread medical gaze. This gaze is an important aspect of disciplinary power characterized by the subject under constant watch or observation (p. 47) - though, following Stockholder (1994), the term "fool" was employed later by Christian idealists who "understood the fool as a person with a special order of knowledge; his foolishness marked him as a man touched by divinity" (p. 163). Nevertheless, this general absence of classification — the silence of labels — hardly stopped exclusion. "Interest in cure and in exclusion coincide: madmen were confined in the holy locus of a miracle," Foucault (1965) explains (p. 10). Here, a reminder that disability and spirituality are connected, and this connection is especially pronounced as labeled people are both included in and distinguished (by degrees of divinity) from the poor at the end of the seventeenth and beginning of the eighteenth centuries (Stiker, 1999, p. 72).

\section{A turn toward God as a turn toward charity}

Importantly, some researchers locate traces of Western intellectual disability identity in the medieval institution of Christianity (Eiesland, 1994; Stiker, 1999; Rapley 2004). The European 
cultural turn toward God further reveals familiar, modernist understandings of disability linked to charity and care (Soldatic \& Meekosha, 2012). This location of disability is important because it sets the stage for a modernist turn away from religion and notions of divinity in the Western world, which triggers a re-orientation toward notions of charity and care that tie together both pre-modern and modern assumptions of Otherness.

In her foundational theological critique, Nancy Eiesland (1994) holds that "disability has never been religiously neutral," but is "shot through with theological significance" even though the ongoing relationship between disabled people and the Christian church is complex, ambiguous, and enigmatic (p. 69,100$)^{15}$. In Christian traditions, disability has served to symbolize romanticized notions of individual sin, virtuous suffering, and the "overcomer" (Eiesland, 1994, pp. 101-102). Eiesland (1994) explains,

The persistent thread within the Christian tradition has been that disability denotes an unusual relationship with God and that the person with disabilities is either divinely blessed or damned: the defiled evildoer or the spiritual superhero. As is often the case with such starkly contrasting characterizations, neither adequately represents the ordinary lives and lived realities of most people with disabilities (pp. 70-71).

Though the narratives of sinner/overcomer seem relatively straightforward, early Christianity also represents a movement that disrupted the mental/spiritual body split by bringing demonic forces and images of objectified evil into discourses of embodiment. As Stockholder (1994) explains, "mental anomalies were understood not merely as self-created chaos — the person suffering from them was a victim who was properly the recipient of care" (p. 162).

\footnotetext{
${ }^{15}$ As examples: Stiker (1999) analyses the story of Francis of Assisi; Snyder and Mitchell (2006) re-think historical accounts of feral children through a disability studies lens that involves spiritual input about the holiness of such exiled children; and, Rapley (2004) and Carlson (2005) recount a pre-modern European era where disability is an embedded part of the community fabric rather than a problem to be dealt with through state- and church-sanctioned control mechanisms (such as almshouses).
} 
The effect of cordoning some people off as "recipients of care" and others as potential caregivers opens the biblical theme of giving that continues to shape patterns of interactions between disabled and non-disabled people. This effect represents what Foucault (1965) refers to when he writes about incarceration, particularly the institutionalization of people from the 1500 s onward, as "a rigorous division which is social exclusion but spiritual reintegration," again embodied by the "fool" (p. 7) ${ }^{16}$. Further, Berger (2014) focuses on "sacred fools," who occupy a cultural location in the early Christian era that can be taken as one of intellectual disability. People labeled with intellectual disabilities in some cases also embodied characteristics of divinity. Berger explains that in this era there is a popular desire to "speak with the non- speaking," which is vast territory that includes attempts to speak with animals, to God, to the dead, to eco-systems and other bodies (p. 15). However, this attempt at understanding the Other also includes intentions to speak to certain humans. Berger (2014) narrows his description:

The dialogue has extended also to human beings who lack (or are, or were, presumed to lack) the use of language, or whose linguistic capacity is impaired: those with stutters, developmental cognitive impairments, and a range of conditions now understood by the term 'autism'; those who are deaf; and those growing up apparently without socialization or language - the so-called 'wild children.' (p. 15).

This theme of "lack" — highlighted by my italics — is an important one that re-emerges throughout this writing as disability studies scholars have narrowed in on "lack" as a defining characteristic of discursive formations of intellectual disability (Foucault, 1973a). Intellectual

\footnotetext{
${ }^{16}$ Foucault (1965) describes the "fool": "While the man of reason and wisdom perceives only fragmentary and all the more unnerving images of it, the Fool bears it intact as an unbroken sphere: the crystal ball which for all others is empty is in his eyes filled with the destiny of an invisible knowledge" (p. 22). Specifically in relation to biblical passages such the Apostle Paul's for whom the "overthrow" of the "existing order," Berger (2014) suggests a direct alignment between divine alterity and newfound (Christian) wisdom (pp. 24-25). Berger explains that "only a fool would wish this" overthrow of prevailing norms wherein forms of "cognitive impairment" would fit into the intersectional category of "fool" that embodies deviance and moral lack (p. 24).
} 
disability has historically and philosophically been linked to "lack" (of reason) while other disabilities, such as physical disabilities and madness, are thought of as a fix-able "error" of the mind and/or body (Carlson, 2010, p. 24). Through the early Christian lens, disability became socially located as sacred, deviant, and feared Otherness — as lacking — thus familiar but separate from the masses whose charge it became to care for the Other (Eiesland, 1994; Stockholder, 1994, pp. 162-163).

While almsgiving may have provided a means for survival for social outcasts who lacked intelligibility and morality in the pre-modern era (Eiesland, 1994, p. 73), this charitable orientation toward the body makes certain people seemingly chaotic, victimized, and subject to the care or pity of others - an example of what disabled and non-disabled bodies "can do" and "tend to do" in certain circumstances (Ahmed, 2006). Familiar notions of charity, which will be later explored in neo-liberal capitalist contexts, are linked to religious conviction and civic dis/order; they are "located on a vector of control, containment, and order" (Stiker, 1999, p. 99). Through charity, non-disabled people are offered the opportunity (or obligated) to pursue the "God-like work" of comforting those who have been discursively constructed as mentally inferior without having to necessarily be mentally superior themselves, thus framing familiar, contemporary notions of care that inform many present-day vocations (Stiker, 1994, p. 162). As Stiker (1999) points out, ... that is not to say that the disabled, ... are integrated in the contemporary sense of the term; rather, they no longer symbolize metaphysical and biological difference that questions the species and the society unit. They now constitute a difference to be loved, helped, aided, furthered (p. 77).

Thus, the body needing help is further linked with deviance (read: sin and moral lack) and can be accused of "marring the divine image in humans" and thus shaping social perceptions of certain people through the divine gaze of the Christian church (Eiesland, 1994, p. 71). 
The turn toward God, in the Judo-Christian context, is an important one in terms of establishing Western cultural locations of disability because here the roots of much contemporary action toward disability, specifically notions of care as they are embedded in vocational contexts, are found. Pre-modern discourses that construct meta-narratives of different, ahistorical, charitable, monstrous, holy, pitiful, and feared bodies are well established even in Western modernity. This cultural transition introduced more formal, rational classifications of bodies that became and remains important in sustaining capitalist systems of production. This reorientation toward disability is, in short, a cultural shift that narrowed human possibility from the pre-modern variety ${ }^{17}$ to a dualism between those who are fortunate and those who are "springboards for charity" (Stiker, 1999, p. 88). In other words, as Carlson explains, the belief that intellectual disability is simply a question of "lack" or of "less or more" humanness allows for the infantalization of people carrying this label (2010, p. 29). Growing from this conceptualization are discourses of pity, innocence, and charity that surround some people's lives and subjectivities only to transform into notions of vulnerability in contemporary research contexts.

${ }^{17}$ Though we must be careful not to romanticize variety as ideal, the way notions such as "multiculturalism" have been taken up (Hebdige, 1979/2006). 
PART 2: Disability as it emerges in modernity

What is natural is integral. This may seem banal, because this division of things is so often to be found.

- Stiker, 1999, p. 32

Modernity is a cultural project commonly understood to come into focus around the eighteenth century as a reaction to new conditions of production, circulation, and consumption (Habermas, 1983 in Harvey, 1990, pp. 12-13). Dan Goodley (2011) summarizes:

Modernity describes a unique period of time based on secular principles of science and positivism, intimately correlated with the emancipatory aims of reason and liberty, locked into globalised forms of rational capitalism (p. 38).

The era is characterized by a secular departure from irrationality and a new embrace of skepticism, "with God on a protracted leave of absence" (Bauman, 2000, p. 35) ${ }^{18}$. In short, modernity stands for a social order rooted in idealized normality. The era relies on biomedicine, individualization, rationalism, and capitalist progress in its "experiment of betterment" (Harvey, 1990; Tester, 2004, p. 19):

The development of rational forms of social organization and rational modes of thought promised liberation from the irrationalities of myth, religion, superstition, released from the arbitrary use of power as well as from the dark side of our own human natures (Bauman, 1990, p. 13).

Thus, though some pre-modern conceptions of the body that peg disabled bodies as monstrous, closer to God, and worthy of charity still stick today, these discourses began to shift and construct notions of diagnosable, different, problem bodies eligible for treatment

\footnotetext{
${ }^{18}$ And, by Stiker's (1999) account, modernity is a time when "the priest, monk, or friar is no longer our means of access to the new cultural era" (p. 91). Whereas pre-modern conceptions of the body relied on a turn toward God, modern re-considerations of the body turn away from spiritual and mythical realms. In this milieu, where an intellectual climate urges people to think more scientifically about the theme of elimination of alterity via rationality, "a rationalized world" is a profound idea (Berger, 2014).
} 
and elimination (solution) in modernity. Intellectual disability is given meaning through silence and confinement in modernity.

Intellectual disability is "the quintessential modernist experiment" for its cultural location as a familiar and indisputable category of being under which bodies and corporeal realities are managed as objects of classification eligible for cures and return to normalcy (Snyder \& Mitchell, 2006, p. 4). This is the next narrative of disability in our journey through the pre- modern, modern, and post-modern: problem that calls for solution. Problem that needs fixing. Problem that does not belong. Or, to rephrase: lack of intelligence compounded with lack of morals that can be reformed through education, rehabilitation, and training under the watch of administration and, later, medicine. The phenomenon of intellectual disability in particular can be tracked in modernity more concretely than in pre-modernity because of the signifiers that emerge in its name — notions of "feeblemindedness" (Carlson, 2010), eugenics (Grekul et al., 2004; Malacrida, 2015) — and the volatile nature of biomedical epistemologies that encounter and seek to eliminate intellectual disability (Hubbard, 2013; Saxton, 2010).

Accounts of intellectual disability are integrated into modern reasoning where "they still haunt us" by upholding the familiar narrative of disability as problem even though these accounts have been displaced by materialist reasoning (Stockholder, 1994, p. 161). Locations of intellectual disability in modernity include, and span beyond, institutions and "expert" knowledge from above that divides those in its medical "gaze" into subjects and passive, objectified Others whose bodies illuminate sites of knowledge (Foucault, 1973a). These Others are further divided into mind and body, self and other, normal and abnormal. A timeline for this phenomenon might unfold in this way: non-scientific, administrative "houses of correction" and hospitals "of confinement" from the fifteenth to seventeenth centuries (Foucault, 1965); then the scientific achievement of bodily classification via taxonomic science 
(such as intelligence testing) in the eighteenth and nineteenth centuries (Stockholder, 1994); followed by the simultaneous rise of institutions, which are later divided into asylums (for people labeled "insane") and rehabilitation centers (for those labeled "simple"), to house vagabonds and other social deviants (Carlson, 2010); still followed by a brief interlude where "freakshows" shed a new, imperialist light on the ways in which racism and ableism intersect to display intellectual disability (Clare, 1999); leading then to the slow, steady movement toward disability-based policy and simultaneous "newgenics" of the twentieth and twenty-first centuries (Malacrida, 2015). These contemporary eras also institutionalize particular people and inform current public, neoliberal understandings of what kind of problem disability is and who embodies this problem - and what kind of solutions ought to be sought, including segregatory, welfare-driven, and eugenic/bio-ethical solutions (Titchkosky, 2008, Rapley, 2004).

Beyond relying on chronological accounts of the creation of intellectual disability as a familiar, ideological phenomenon, we must also consider how theoretical acknowledgement of intellectual disability as a living, working concept serves to destabilize ontological questions of humanness. For example, what does it mean to talk about postmodern humanness in a modernist context where intellectual disability is commonly perceived as separate from non-disabled or "normal" subjectivities? Modernist notions of the body, in particular the "normal" body, help to (re)consider myths of bodily control and mind/body divisions. Thus, to re-think, defamiliarize, and later re-write bodily myths, this analysis makes its launching point a brief overview of normality in modernity because this pivotal concept shapes the familiar, lived out, intersectional realities of many - especially if intersectionalities are read, as Titchkosky suggests, "as a call to watch our watching, to read our readings, and to uncover a few of the ways we identify differences, including those 
differences that are today identified as disability" (2008, pp. 3-4).

The "normal" body in modernity

... the normate belief in the organic unity and autonomy of the body: our bodies are essential things; they do not really change. Our culture is obsessed with agentive and often artificial physical change toward ideality and at the same time petrified of 'organic' and inevitable bodily change. Fear of disability is in some shape this fear of change, the fear that we are temporarily able-bodied, a fear that the body is not static, rational, and whole ...

- Dolmage, 2014, p. 111

Dolmage's description of the normalized belief in the organic unity and autonomy of the body describes a highly modernized interpretation of disability that emphasizes individualism and fear, where desired change is welcome but "natural" change is both unwelcome and undesirable. This paradox, characteristic of modernity, is particularly problematic given each person's high susceptibility to disability in his or her lifetime simply by means of being born, living, and ageing (Shakespeare, 2006a). Modernity creates and maintains its own "dark side" by promoting a unidimensional social order (Harvey, 1990; Stiker, 1999).

Modernity's mission to create a new world involves destroying, and losing respect for, what came before — including lived truths (Harvey, 1990) — and replacing past thought with science that retains its own discursive grounding through self-referential grand narratives (Lyotard, 1979). These grand narratives solidify bodily ideas of normality, including Cartesian dualisms loaded with notions that individualize control over the body and objectify it through the "cultural splitting" of the mind (the intellectual) and the body (the physical) (Wendell, 1996, p. 85-86). This "cultural splitting" is particularly important to the creation of intellectual disability: intellectual disability is the process of objectifying the body to the point that the physical may be separated and observed apart from the mind, as if the two were entirely separate entities of the same person. Such narratives are part of the familiar systems that 
establish the notion of impaired minds - a notion that tends to be temporary, and thus is also a mark of modernist thinking (Stockholder, 1994).

\section{Building intellectual disability by labeling the body}

This temporariness of modernist systems of thinking returns us to discourses and language, a touchstone conversation that my writing winds back to time and again. Stockholder (1994) demonstrates this temporariness by chronicling the evolution of modernist language referring to disability and the ongoing distortion of its meanings ${ }^{19}$. For example, Stockholder explains that in Ontario in the 1840s the word "idiot" meant "someone who was close to being incurably insane" (p. 169). The word held different meanings in other parts of the Western world, however, such as the United States where institutional understandings of "idiot" more simply referred to "a human who needed care" (p. 196). Stockholder (1994) describes modernity as a period of re-naming wherein "thinkers developed euphemisms hiding new harsher attitudes" toward scientifically named people: "simple," "half-wit," "insane" and others (p. 164; Carlson, 2010):

The older medieval names contained some charitable respect for their bearers. The 'lunatic' because he is moonstruck, is a significant figure in an enchanted universe. The new terms moved beyond enchantment. Today, charity toward these victims means giving money to help them .... The institutions housing them have grown harsher and more punitive (Stockholder, 1994, p. 164).

\footnotetext{
${ }^{19}$ Of the many examples of labels and language sprinkled through Stockholder's (1994) writing to mark particular people's intellectual (de)merits — "mentally retarded," "moron," "child," "fool," "silly," "simple," "idiot" — perhaps the most familiar is the word "retarded," a contemporary taboo in Canada. The term originated through medical labeling and held biomedical connotations designed to typify/diagnose certain people. The word, today referred to in activist campaigns as "the r-word" ( $r$ - word.org), has roots in early modernity: the name "mentally retarded" was developed in Canada and in the United States in the mid-twentieth century to refer to people with varying conditions, who would "pass through institutions" over a lifetime and could be expected to be released from them in favour of "normal" development, depending on their particular "degrees of retardation" (Stockholder, 1994, p. 169).
} 
Through language, the past is still present in the social order wherein we name and categorize people (p. 170).

Yet, the word itself carries social meaning that sticks, and positions the body in cultural locations. For example, Eli Clare (1999) writes a social history of the word "freak" by centering on mid-1880s freakshows. Clare describes "the history of freakdom" as an elaborate tool of social construction that reaches far back into Western society in its fictionalization of histories of disability and that includes familiar figures: the court jester, the "pet” dwarf, giants, monsters, and other humans-made-spectacles of the entertainment business displayed in circuses, carnivals, museums, and traveling vaudeville companies. These shows existed alongside almshouses and institutions, once again demonstrating the static and dynamic nature of intellectual disability as something to be hidden and made invisible, or something to be made highly visible through spectacle and earning potential ${ }^{20}$. The spectacle was one of the "sciences" of teratology. Clare offers insight into the social imagination of the audiences who came to view "freaks":

They came to gawk .... They came to have their ideas of normal and abnormal, superior and inferior, their sense of self, confirmed and strengthened. And gawk they did. But who were they gawking at? (p. 71).

Throughout his essay, Clare (1999) answers his own question in arguing that ableism and racism intersected to create particular performances. For example:

Hiriam and Barney Davis performed wildly for their audiences, snapping, snarling, talking gibberish from the stage. The handbill sold in conjunction with their display described in lengthy, imagined detail 'What We Know About Aino and Plutano, the Wild Men of Borneo.' In reality Hiriam and Barney were white, developmentally disabled brothers from an immigrant farm family who lived in Ohio (p. 72) ${ }^{21}$.

${ }^{20}$ In a cultural climate where disabled people could choose between being freakshow performers or being institutionalized, freakshows were, Clare argues, an important source of income and relative freedom for some people.

${ }^{21}$ Hiriam and Barney were sold to the freak show by their mother in exchange for a wash pan full of gold and silver, according to Clare (1999, p. 79). 
Clare goes on to lament historicism and moralization in the context of exploitation, explaining that disability historians (and freakshow historians) must also examine wide contexts that include ableism, classism, and racism, and ask what other choices people had in their lives.

Indeed, modernity's success in maintaining essentialist preconceptions can be measured by the realization that our present cultural memory is only, at best, questionably accurate in light of pre-modern thought. Any glimpse backward risks historicism. Therefore, cautiously observing modernity is an exercise in identifying power-discourse formations that bleed into present rationalism (Bhabha, 1994). Following Harvey (1990), engaging in this exercise means considering whether to support or abandon the project of modernity and its "bodily based inferiority rationale" that is so closely tied to language and the discourses that build our subjectivities (Snyder \& Mitchell, 2006, p. 12) — depending, as it were, on how modernity's "dark side" can be attributed to "defects of Enlightenment reason [or] lack of its proper application" (Harvey, 1990, p. 14).

Importantly, however, modernity is also an era governed by what Harvey calls "concrete abstractions" (such as money, time, and space) that rely on deeply entrenched symbolic modes of thought — such as language — that present reality as natural knowledge even in instances where it is constructed (Harvey, 1985). "Concrete abstractions" of embodied reality (such as dis/ability) align closely with metanarratives of normality that precondition modern life (Wendell, 1996). For example, labour value commodifies the body as a tool of production in modernity, thus giving weight to the notion that personal, bodily value can be measured by one's ability to participate (and earn money) through capitalist systems of production (Carlson, 2010; Erevelles, 2005) ${ }^{22}$.

\footnotetext{
${ }^{22}$ Even the freakshow is knotted up in this conundrum of labour production: the end of the
} 
During one round of revisions of this dissertation, Anne MacLennan pointed out that in Canada such language as that Clare (1999) and Stockholder (1994) describe is also entrenched in the national census. A brief and interesting overview of past census records shows how such language was used to categorize the national population. For example, the 1871 Census marked the first "regularly scheduled collection of national statistics" and tracked people as "infirmities" under the categories "deaf and dumb," "blind," and "unsound mind" (Library and Archives Canada, 2015). Since 1921 Censuses have been distributed and collected by Statistics Canada. The Census questionnaires are publicly available, though as Titchkosky (2008) points out they ask little about disability and instead separate these questions into The Canadian Survey on Disability (Statistics Canada; Titchkosky, 2008). The 2011 Survey focuses on individual limitations of disability and asks questions such as, "Does your condition completely prevent you from working at a job or business?” (p. 59). Titchkosky (2008) also targets Statistics Canada's The Participation and Activity Limitation Survey for its focus on individual limitations, and its development and use of "filter questions" as a way of ascertaining "who will and will not count as "limited"" as a means of social organization (p. 67) - in other words, as a way of culturally locating the modern-era "infirmities" whose being-in-the-world is not that of modernist contribution ${ }^{23}$.

We are caught in a web of power relations that upholds "concrete abstractions" such as names and labels that perform the work of "cultural splitting," and represent the uniquely modernist discursive realms in which we operate and are produced (Davies, 2000; Leavy, 2007). Foucault is useful here because his subjects are allowed to be multi-dimensional, freakshow in the twentieth century meant the end of employment for some people with disabilities who worked as freaks, likely leading many toward institutions or into poverty (Clare, 1999, p. 86).

${ }^{23}$ That people are named and categorized continually, and with varying degrees of nuance and obviousness, are topics broadly discussed, read and taken up in Titchkosky's (2008) Reading \& Writing Disability Differently and Prince's (2010) Absent Citizens. 
unclearly defined, and sometimes messy against a modernist backdrop. They are permitted to be read as incoherent and/or incompetent, from a social and scientific perspective. An example of these characteristics is found in Foucault's 1975 text, I, Pierre Rivière, Having Slaughtered My Mother, My Sister, and My Brother. The inclusion of characters who deviate from the norm draws in researchers such as Erevelles, whose writing on the crisis of the subject in relation to autism queries whether or not people labeled developmentally disabled can represent themselves through thinking and behaviour that would, without the presence of disability, be considered "normal" (2005, p. 46-47). Erevelles (2015) chooses Douglas Biklen's (1990) seminal experiments with facilitated communication as a starting point, arguing that the salience of this process points to how and why certain kinds of knowledge are formed. Facilitated communication is a controversial method of communication wherein a person with a disability conveys a message with the physical and emotional support of an outside source. Often, as the communicator points to letters and symbols on a communication board, someone holds her hand, wrist, or shoulder as she composes messages (Erevelles, 2005, p. 52). Biklen's early experimentations with facilitated communication in the $1980 \mathrm{~s}$ are groundbreaking because people who were previously perceived as having lower competence levels than others were able to convey sophisticated thoughts (Erevelles, 2005; Biklen \& Cardinal, 1997). However, as Erevelles notes, Biklen's work quickly came under scrutiny as ethically unfounded because it did not rely on scientific evidence, and failed to meet the criteria of scientific validity, reliability, and generalizability based on institutionalized ideas of legal competence (2005, p. 46). Critics have argued that people with disabilities relying on facilitated communication did not author the text in their messages;rather, their facilitators unconsciously scribed messages (p. 55). "In making this sort of argument," Erevelles writes, "the critics of facilitated communication also invoke the ideal of the humanist subject - 
rational, coherent, and above all autonomous — as the impossibility that haunts persons who are labeled autistic" (p.55).

And, through his genealogies, Foucault uncovers and contests the particular, the "centralizing power effects that are bound up with the institutionalization and works of any discourse" (in Shildrick, 2009, p. 41). Foucault (1978) posits that power, and its relationship with knowledge, generates discourses bound within a web of power relations. Foucault examines "the ways power operates within everyday relations between people and institutions" in ways that are not necessarily negative, but produce discourses and cultural situatedness (Mills, 2003, p. 33). To stick to the example at hand, I'll also point out that Clare (1999) echoes some of Foucault's notions of power in his examination of the freak show. Clare suggests that for people with intellectual disabilities in particular, who perhaps did not have control over their displays or the legal power to agree to their own exhibition, power is/was multi-directional. Nevertheless, questions about exploitation are complicated; "simple answers collapse easily" (p. 75), he writes. Clare explains that for many people working in "freak shows" as "freaks" the power relations were more nuanced than they may appear - several performers capitalized on their production value:

The complexities of exploitation pile up, layer upon layer. ... Boss and worker together consciously manipulated their audience. That same audience willingly used lies to strengthen its own self-image. Given this maze of relationships, I have trouble accepting the assessment that exploitation in the freak show, if it existed at all, wasn't truly serious. Rather, I believe it existed in many directions (pp. 76-77).

Power is inherent in Foucault's concerns about the relations between social structures and individuals; power is performed and "individuals are the vehicles of power, not its points of application" (Foucault, 1978, p. 98). Power is a relational "form of action or relation between people, which is negotiated in interaction and, as such, ... is never fixed or stable" because we always affect one another's actions (Kostouli, 2009, p. 104; Carlson, 2010, p. 15). In other 
words, individuals can be read as a "place" where power manifests; the body is a site of power enactment and resistance (Mills, 2000, p. 35).

\section{Silencing as a modernist signifier of intellectual disability}

Language is the modernist, naturalistic evidence for humankind (Abram, 1996, p. 78).

Language is a tool used "to demonstrate the excellence of humankind relative to all other species," leaving non-human animals in culture's outskirts of civility (p. 78). A uniquely modernist question, then, is one taken up by contemporary philosophers such as Peter Singer: Are people outside of language human? (Titchkosky, 2013; McBryde Johnson, 2013) And, the question that follows: What does it mean to be human? Here, we are bracing for a postmodern turn because arguably modernist, essentialist frameworks are not equipped to answer such a question that might move the conversation into one of multiplicities of identity and destabilization of the subject.

Erevelles (2005) has studied how disabled people interact with institutions, and the language that maps them within and outside of these spaces, such as the term "incompetence" (p. 46, 47). She writes about the social backlash against methods that might reveal language in cultural locations wherein it is assumed absent, such as in situations involving facilitated communication. This backlash turns processes of language discovery into a passing fad and instead of integrating participants into society and re-centering the subjects of the study returns people to segregated institutions. Here, normative language is privileged: “... to speak as though to be understood is to speak through the production of some transparent signifier, that which maps easily onto taken-for-granted regimes of meaning” (Lather, 2007, p. 85). Through understanding how human beings are constituted as both subjects and objects - 
simultaneously, interchangeably, and sometimes unpredictably — Erevelles (2005) develops intersectional, poststructuralist understandings of disability in suggesting that the subject is an effect of language produced by multiple signifiers and meaning systems (Yates, 2005, p. 68). She ultimately argues that those who are considered deviant from the norm — such as people using facilitated communication, whose identities intersect with the communication barriers faced by the people present in this study - threaten to expose the violence of normality.

To wrap up this discussion of modernist language we return to silence as a signifier of intellectual disability. Cultural "maps" of disability place disability outside of language (Berger, 2014), and cultural influences aim to ensure disability remains outside of normality. In this way, functionality in language has a way of working against people, of placing people in situations where their utility as objects of research to be worked upon is most advantageous in maintaining the neoliberal norm. Even language in the name of inclusion — such as "fitting in" or "giving voice" - can fail (Erevelles, 2005) ${ }^{24}$. Often, including in this dissertation, those labeled with intellectual disability and/or communication differences are "reduced to silence," hidden, and made invisible (Yates, 2005, p. 61). And silence, as we recall from Foucault (1978), is "the other side" of discourse — silence is active, albeit unfamiliar to the "normate" reader (Garland- Thomson, 1997).

\footnotetext{
${ }^{24}$ The inability of even an assimilative method of communication such as facilitated communication to prove its validity and therefore its functionality in normative spheres was (and still is) its downfall. As recently as October 2015 this complication is outlined in a The New York Times feature article that follows the U.S. criminal trial of Anna Stubblefield.
} 
Iatrogenesis: Medicine, the body, and intellectual disability

The doctor started out by noting, 'I'm choosing my words very carefully ...'

- Devaney, 2013, p. 103

No doctor can diagnose a person and get it right for their whole life. They get it wrong. They did that with two of us. Both of us got told that we would be a 'cabbage.' How pathetic is that?! How wrong is that?!

- Docherty et al., 2010, p. 433

Scientific classification is an essential step in understanding the phenomenon of intellectual disability because it offers a way to read the social history of labeled people as both visible and invisible (Carlson, 2010, p. 46). Intellectual disability is a concept based on perceived quantitative difference between people (p. 30). It is a label that reaches forward and becomes a phenomenon, a thing that relates to a hierarchy of humans as people graded on their intelligence and categorized accordingly into social sites — cultural locations - of disability (Snyder \& Mitchell, 2006). Using biopower to explain discursive productions of biomedical pathologies, Carlson analyses the bodily category of intellectual disability, in particular, on a barometer of normality that articulates acerbic labels such as "idiot," "feebleminded," "handicapped," and others (Carlson, 2005/2010). These labels are the discursive practices that build notions of deviance and abnormality embedded in an unwillingness or inability to participate in normative labour (Carlson, 2010; Clare, 1999; Stiker, 1999). Thus these labels work as discourses that rely on perceived inferior rationality in order to establish particular subject positions (Carlson, 2010, p. 22; Kostouli, 2009).

Intellectual disability is also given meaning through confinement. In her discussion of institutions and their histories, Carlson (2005/2010) pinpoints the late seventeenth century as a time when "experts" of intellectual disability emerge alongside a realm of deviance that aggressively Othered people, particularly those in cultural locations of $d y$ s/disarticulation 
(Berger, 2014). These "experts" took the form of institution superintendents, mainly meaning white men who were often medical doctors and whose work was supplemented by women who worked as attendants, teachers, and matrons (Burch \& Joyner, 2007). They were the original "students of intellectual disability" who could use the bodies inside the institutions as research objects, making them subject to the expert gaze (Carlson, 2010, pp. 26, 62-63). Eventually their task was to manage bodies outside of asylums, poorhouses, and institutions for those "suffering from madness" (p. 26). The emergence of a new category of intellectually disabled people to be governed separate from other classifiable types of disability led to a new breed of expertise on how to govern such labeled bodies. What followed was a new focus on development — or perhaps underdevelopment — of the mind as this population was considered to have vacuous intellectual functions. In Madness and civilization (1973b) Foucault describes John Howard, who, at the end of the eighteenth century, investigated and made publicly visible "centers of confinement" (meaning hospitals, prisons, and jails) across Europe:

... [Howard's] philanthropy was outraged by the fact that the same walls could contain those condemned by common law, young men who disturbed their families' peace or who squandered their goods, people without profession, and the insane. Proof that even at this period, certain meaning had been lost: that which had so hastily, so spontaneously summoned into being all over Europe the category of classical order we call confinement (pp.44-45)

A more journalistic type of investigation took place in Orillia, Ont. in 1960 when Pierre Burton visited the Ontario Hospital School (today known as the Huronia Regional Centre). The Toronto Star reporter wrote about the 2,807 people living in the institution, and he described their living conditions: leaky floors and split floorboards covered in 70 years of grime, among other deplorable conditions. He called the intellectually disabled people living there "prisoners" and suggested that "the 'village idiot' of our forefather's day is likely to be a patient at Orillia now" (1960/2014, Toronto Star). 
In modernity, the people who care about intellectual disability are not religiouslydriven charity providers, but are instead invested in being part of the medicalized, philanthropic thrust of social history and the continuation of silencing bodies. As Carlson (2010) points out,

The incarceration of idiots in institutions far from public view was, in part, an attempt to render feeblemindedness invisible to the rest of the population, though paradoxically it was the humanitarian campaign that exposed the horrific conditions in which they were living that brought them under the public's gaze (p. 47).

In sum: intellectual disability is a label that emerges from the observational research of "experts" - researchers of all kinds, not only of the scientific variety — and remains in circulation by institutional discourses as articulated by "experts" whose work involves uncovering and describing the workings of intellectual disability to an unfamiliar public. Yet, the cultural locations of intellectual disability tend to be those of silence and incarceration. This positioning repeats understandings of intellectual disability as moral and intellectual lack. The moral onus is re-assigned to non-disabled people to notice misfortune. This troubling dynamic too often assumes intellectual disability is invisible until it is made visible by outsiders.

\section{Moving into "the outskirts of intelligibility"}

Indeed, by the eighteenth century, the social and cognitive authority of medicine was instilled through the practices of institutions such as hospitals and physicians (Stiker, 1999, p. 104; Wendell, 1996). The family physician became "a new kind of priest" (Stiker, 1999, p. 104) and institution administrators developed new types of knowledges and expertise in search of elaborate possibilities for medical interventions on the body (Carlson, 2010). In a modern era where the concept of intellectual disability is possible because of iatrogensis, biomedical measurements rank certain humans "on the outskirts of intelligibility" and rationality 
(Erevelles, 2001, p. 97). Snyder and Mitchell (2006) posit:

This [phenomenon of classified bodies] is not the product of objectivity or sound scientific practice; rather it is the outgrowth of a history in which disability has functioned as the 'obviously' undesirable location in a geography of beliefs that must repeatedly perform their neutrality by reasserting, again and again, this defining undesirability (p. 21).

Specifically, the phenomenon was made measurable through intelligence testing in the early twentieth century, ${ }^{25}$ which established intellectual disability as a deviant bodily category (Carlson, 2010, p. 47). Intellectual disability remains a particularly heterogeneous classification meant to bring order to disability hierarchies - labeled people continue to be described by "severity," "mental age," "degrees of intelligence" and trainability/educability/literacy (Carlson, 2010, p. 91). Each of these terms is taken up in Simon's 2002 memoir, Riding The Bus With My Sister - the very book that triggered one of my students to ask about the term "intellectual disability" in the earlier vignette. In one poignant moment of her story, Simon begins an online search to find out what "mental retardation" really means in relation to her sister, and amid this search she observes the fallacies tied up in her own vocabulary in relation to each of these terms. For example, Simon realizes her "old nemesis," the term "mental age," has merit because it refers to a correlation between one person's responses on a standardized IQ test as compared to the average person in a certain age bracket (p. 147). On the same beat, Simon simultaneously understands the disparity between the sign ("mental age") and its signifier (disability), highlighting the realization that modernist speech acts often have more

\footnotetext{
${ }^{25}$ Part of the purpose of intelligence testing, or IQ tests, was to make invisible disabilities visible, reflecting intellectual disability's swing from invisibility to visibility over time: "the IQ test was able to definitively fix the level of this elusive, invisible, yet indispensable feature of humanness: intelligence" (Carlson, 2010, p. 49). For example, the label "moron" worked as a speech act to bring the invisible into the visible and to carry a "new load of meaning" beyond its original scientific intentions (Stockholder, 1994, p. 155). A person ranked below normal intelligence scores but whose physical embodiment would not imply as much because her or his physical characteristics appeared suitable for modernist utility could be positioned in the realms of deviance by being assigned the "moron" label.
} 
influence, or more staying power, than the act of naming (Stockholder, 1994):

Saying that an older person with mental retardation is like a younger person of a younger age or has the 'mind' or 'understanding' of a younger person is incorrect usage of the term. ... . In other words, 'mental age' does not mean, as some erroneously believe, that the clock stopped ticking in some people's minds when the hands reached two or seven or fifteen. Mental retardation is not a childhood that has simply gotten stuck" (Simon, 2002, p. 147).

And similarly, the notion that there is a type of disability relegated to the mind - somehow separate from the rest of the body and classifiable as other — also has staying power.

Intellectual disability, as signified through its many names that are all rooted in modernist, medicalized classifications of the body, is a discursively constructed social construct that remains widely used and strongly divisive of people despite its bluff that the dys/articulate body is a deviant, problem-riddled body.

Importantly, deviance intersects with many ways of being in the world, including through gender and race (Snyder \& Mitchell, 2006; Titchkosky, 2008; Puar, 2013). Intellectual disability is a deeply gendered phenomenon, mainly positioning male "experts" against a profoundly female population of intellectually disabled subjects. Carlson (2010) points specifically to intersections between the concepts of "feeblemindedness" and femininity: for women, moral disobedience (inability) included bearing illegitimate children, which was historically punished through ostracism. This stigmatization is compounded by the perceived deviance attached to their minds that historically heightened their rate of "feeblemindedness" and shoved them in, or near, the category of intellectual disability (p. 57-58). Women's ability to procreate, and stereotypes against women's sexual immorality generally, made "female feeblemindedness" a dangerous prospect, especially in a eugenic era where the heredity of intellectual disability remained in question. Carlson's argument suggests that the "feebleminded woman," with her disregard for moral codes and her threat to productivity, was classified in an effort to make sense of the threats against modernity. Notions of an inadequate 
mind also rely on perceptions of inferiority as attributed to race. For example, medical doctor John Langdon Down coined the label "Mongolian idiots" in an 1866 paper titled "Observations on the Ethnic Classification of Idiots" to refer to those people who are today assigned the medicalized label of Down's Syndrome (Down, 1866, n.p.). "Mongolian idiots" was both insulting to Mongolians and to Victorians perceived not to have caught up with modernization (Borthwick, 1990) ${ }^{26}$.

With an understanding that intellectual lack is not individual but is a category linked to larger politics of gender and race, we return to one of professional medicine's most insidious tools in seeing itself as a "unidimensional order" to be maintained: the "medical gaze" that produces information and knowledge about bodies and populations (Foucault, 1973a; Hughes, 2005 , p. 81$)^{27}$. This turn toward medicine signals the solidification of the medical model, which privileges neo-liberal notions of individual pathology — of disability as a failing of the self, or as problem, through/in the body — that still retain dominance in contemporary culture where the abnormal is often positioned as the opposite of normal (Shildrick, 2009, p. 42). For Foucault, abnormality (like subjectivity) is reinforced through institutional control, such as that experienced by the human monster - a figure produced when the normative lens ends up "seeing more than [it] is supposed to see," perhaps (Sontag, 2001a, p. 12). The human

${ }^{26}$ Consider Stockholder's assessment of the origins of the Down syndrome label: "Dr. Down divided people with intellectual disabilities into types which he named after racial groups, succeeding in one intellectual move in demeaning both the races of the world and people with intellectual disabilities. Sir Peter Medawar, the late anglo-Indian biologist, joined with other Asians in a successful request to the London Times that its style sheet disallow the term "Mongolian idiot" and replace it with Down syndrome. That Down believed his taxonomy to be science - unprejudiced, pure knowledge - gives a clear measure of how unaware intelligent thinkers can be in the naming process" (Stockholder, 1994, p. 167).

${ }^{27}$ This gaze is later taken up by Garland-Thomson as an act that defines the norm by picturing the deviant (2001, p. 336) - through an imagined opposition to the norm an abnormal emerges. And, it might be helpful to mind Susan Sontag's (2001) warning that "gazing can become snooping, or at least seeing more than one is supposed to see" (p. 12). 
monster, by Foucault's (2000) count, is the dangerous, deviant individual who "combines the impossible with the forbidden" (p. 51), reminding us of the vague, familiar-but-out-of-reach understandings of intellectual disability that trigger wonderment: these incorrigible individuals are to be corrected through interventionist, disciplinary techniques set on producing docile bodies (p. 51- 52).

Foucault's (1979) “docile body" — a body to be subjected, used, transformed, and improved through external mechanisms (p. 136) — becomes part of a particular subjectivitymaking process under the authoritative and productive capacity of biopower. Docile bodies are objectified bodies that lack history — bodies whose familial and community connections are severed through the hegemonic power of medicine (O’Neill, 1985; Pruska-Oldenhof, May 13, 2013). This process, as Titchkosky (2002) explains, following Martin Heidegger, is "alwaysalready constituted" (p. 8). In other words, our familiar understanding of intellectual disability — as an unfamiliar problem to be identified even in fetal stages, and as a deviation so far from the norm that it must be contained and segregated until what is left of the physical body has died (McCabe \& Holmes, 2011) — is tied to the risk of iatrogenesis and a modernist fear of disability that suggests intellectual disability is the mark of the regressive, pre-modern, monstrous figure. Wendell (1996) explains: “ ... the non-disabled must live with the fear that illness, accident, or old age will render their own lives or those of their non-disabled loved ones worthless to themselves and society" (p. 52).

In modernity, fear is often our "orientation toward" disability (Ahmed, 2006). Thus, intellectual disability is a "human cost" of modernity — an era whose "dark side" is revealed through "concrete abstractions," such as medical labeling, that reinforce normality and disability as fear-worthy problem amid its obsession with progress (Berman, 1982, p. 25; Harvey, 1990). 


\section{Medicine and the threat of biopower}

The dominant cultural imaginary of the body in the West — what is commonly considered familiar - relies on ever-growing and evolving meta-narratives of biomedicine and normality that emerged in modernity. Foucault's insights relate bodily situations to systems of knowledge that codify techniques of social control in modernity such as biopower - and normalization is a central component of biopower (Foucault, 1979; Harvey, 1990, p. 45). Biopower maintains categories of humanness including normality and its negation, disability, by using technologies and binaries to position disability as (often unproductive, cure-worthy) departure from the norm. Disability, therefore, is a "concrete abstraction" linked to the larger web of power and knowledge that renders bodies useful (functional) or not under the authority of modernist biopower.

Using biopower to explain discursive productions of biomedical pathologies, Carlson analyses the bodily category of intellectual disability, in particular, on a barometer of normality that articulates acerbic labels such as "idiot," "feebleminded," "handicapped," and others (Carlson, 2005/2010). These labels are the discursive productions of notions of deviance and abnormality embedded in an unwillingness or inability to participate in normative labour, and in a perceived inferior rationality (Carlson, 2010, p. 22). Under these conditions, people marked with intellectual disabilities are object-characters in cultural locations of disability where people "have been taught how to be intellectually disabled and how to be [workers] in services for people with intellectual disabilities" — disability disavowal is learned (Nunkoosing and Haydon-Laurelut, 2013, pp. 197-198). Where disavowal is learned, biomedical measurements rank certain humans "on the outskirts of intelligibility" and rationality (Erevelles, 2001, p. 97). 
I choose to consider intellectual disability so heavily in this dissertation for this very reason - for its unique ability to pull the researcher and the reader into "the space between" nature and culture (Dolmage, 2014). Shildrick (2009) describes reluctance to move beyond visible corporeal differences (p. 88) because while risk of acquired physical disability strikes fear into the ableist population, "the putative threat to our [inner] stability is perhaps even greater" $(\mathrm{p} .88)^{28}$. As it rolls forward, this investigation aims to confront intellectual disability — or, in Carlson's (2010) words, “the philosopher's worst nightmare” (p. 4) — head on.

Biopower and the docile body

In Discipline and Punish: The Birth of the Prison Foucault (1979) discusses the ways in which establishments - educational, medical, psychiatric and others - institutionalize the body. Under these discursively constructed systems of power and knowledge, human beings are made into subjects through three "modes of objectification": scrutiny via professionalized inquiry and "dividing practices" (from self and from others), scientific classification, and subjectification whereby individuals turn themselves into subjects. Any defiance of these systems of governance through "departures of corrective behaviour" — or non-normativity — are punishable (Foucault, 1979, p. 178; Sullivan, 2005, p. 28). The goal of bio-power,

\footnotetext{
${ }^{28}$ To paraphrase Shildrick (2009) is to enter into a conversation about disability hierarchies: Physical disability tends to disrupt the observer's sensory field (p. 50). Physical disability is important because it is the foundation for the material ideology that roots disability studies, known as the social model, and it is the foundations for a mass, disciplinary re-think of disability. Indeed physical disability is arguably even more easily encountered than much other embodiment that may not visibly manifest itself on the surface of another's, or the self's, body. Physical disability is a constant, visible reminder of disability for those with vision enough to see it and sensory abilities enough to sense it. Intellectual disability, however, manifests as both visible (it has been measured in eye shape, gait, skin colour and other supposed determinants of feeblemindedness) and invisible — as in the body rather than only on the body.
} 
then, is to make the body so docile it may be transformed.

This goal of docility and transformation is unanimously aligned with, and rearticulated by, medical model notions of locating disability as a flaw in the individual body and attempting to fix or cure the body as a means of solving the problem of disability (Sullivan, 2005, p. 29, 35; Corker \& Shakespeare, 2002, p. 8). For example, Yates describes the subjectification of people with "learning difficulties" living in a group home under community care. Yates' subjects describe themselves as separate from "normal" and in doing so, create institutionalized divisions of power between themselves and the staff who oversee their homes and limit their actions by enforcing punishment for deviant or "bad" behaviour (Yates, 2005, pp. 71-73, 74). The acts of bio-power that govern people with disabilities result in tensions between the way people with disabilities understand themselves and their relationship with their environments (p. 74).

These methods of turning humans into objectified subjects will be explored further with examples other than those named in the upcoming discussion on institutionalization, which speaks primarily to "dividing practices." Exclusion from social spaces through processes of stigmatization can be framed as another "dividing practice" that results in subjectification (Goffman, 1963). For example, the phenomenon of IQ testing that quantified the separation between physical and intellectual disability is a clear example of the transformation of scientific classification and subjectification; whereas once disability appeared on someone as a mark of difference, such as through colour of skin (race), queerness, or movement (a certain gait), with intelligence testing even seemingly invisible disability could be detected, measured, and diagnosed as something separate from physical disability (Rapley, 2004; Carlson, 2005). As such, these modes of technology extend to non/disabled subject development through external control that informs internalized cultural understandings of the 
body. Bio-power is also reflected in halifax's (2009) description of her experiences in hospital when she writes, "medicine was studied upon this body — this body became the academy" (p. 56). In other words, a person experiencing disability unavoidably becomes the subject of inevitable medical management (Hughes, 2005, p. 82). And, following Mark Vagle (2014), the phenomenon of the subject shifting toward an ontological position of the object is of phenomenological importance as well in that the inherent inseparability of the subject (in the Foucaultian sense, and in the phenomenological sense of human beings as experiences) and the object (the inanimate experienced) is broken through medicalized objectification of the subject. When a rehabilitative goal is present people become separated from the larger social group and individualized as objects, and are further objectified when disability becomes the topic of either the physical body or the mind-body.

It is valuable to note that a precursor to Foucault's (1978) description of biopower and its effect in shaping the subject is "the repressive hypothesis" that conditions a cultural atmosphere of power as submission, specifically obedience to law that governs populations through surveillance. Foucault's writing on "the repressive hypothesis" presents modernist biopower as a cultural condition with roots, and serves as a reminder of its construction. From a disability theory lens, it is notable that Foucault (1978) demonstrates one site of biopower in a case referring to a "village halfwit" in 1876 whose sexual "games" are revealed to authorities (pp. 31- 32). Experts report on "the simple minded" man and punish him through institutionalization at a hospital in Maréville:

The pettiness of it all; the fact that this everyday occurrence ... could become, from a certain time, the object not only of a collective intolerance but of a judicial action, a medical intervention, a careful clinical examination, and an entire theoretical elaboration (p. 31). 
This "theoretical elaboration" speaks to disciplinary techniques of establishing and reacting to difference through disciplines of study, such as human and social sciences. Foucault (2003) describes disciplinary power as contact between political power and the individual body ( $\mathrm{p}$. 41). Disciplinary power is a continuous and exhaustive "capture of the individual's body, actions, time, and behavior" (p. 46). The overarching force of discipline operates primarily by objectifying and manipulating "the smallest twitches of the body and the most minute stirrings of the soul" (Dreyfus \& Rabinow, 1982, p. 169). Biopower, then, is concerned with the classification of human species through medical diagnoses, which Harvey (1990) calls the "master codes" for the categorization of people (p. 47)

Individualization, health, and the "normal" subject

What we had thought of as human nature is, rather, a regulatory fiction through which people can be ordered and located in hierarchies.

- Butler, 1999, p. 24

Foucault's (2000) notions of subjectivity formation name "the docile body" as modernity's target. Docility denies a person's ability to be a self _ _ "an agent of self- and social transformation" (Hughes, 2005, p. 80) - by ensuring the body can be subjectified, used, transformed, and improved through external mechanisms that influence self-perception (Foucault, 1979, p. 136). One strategy of bodily subjectification is individualization, a process tied to fear of bodily change (Dolmage, 2014, p. 111). Through individualization the body becomes the "object and target" of power by being reduced to form and function in a modernist context where lack of either corresponds to social disavowal and individual fault, or

\footnotetext{
${ }^{29}$ Classification also serves to measure population, and is therefore part of Foucault's (1991) governmentality, which relies on populations as a principle form of knowledge (p. 102). Knowledge, of course, refers to powerful sets of assumptions, expectations, and explanations that structure the ways we think about "natural," "normal," and "civilized" culture/behavior (Foucault, 1972; Kostouli, 2009, p. 102). In effect, governmentality drives institutional responses to the body (p. 180), ensuring that policy initiatives are never as straightforward as they may seem (Shildrick, 2009, p. 11).
} 
problem (Foucault, 1979, p. 136). In other words, the formation of "the docile body" and the subjectification via individualization tied to this formation is a cultural endeavor that brings intellectual disability into being (Titchkosky, 2008, p. 4).

Further, Bauman (2000) describes individualization as essential to our current state of "liquid" modernity, wherein human identity is transformed from a "given" to a personal "task" (p. 34), meaning that the way people live reflects the task of self-constitution through mind-, will-, and body-control (Bauman, 1999b, p. xii). Thus, in modernity, dependency and vulnerability are understood as a disservice to progress and a consequence of failing to establish the modernist phenomenon of identity ${ }^{30}$ (Snyder \& Mitchell, 2006, p. 37). Likewise, modernity carries a cultural desire to outwardly express attitudes about one's self, meaning that conditions of the body represent a person's individual character (Sontag, 1978). In return, one's character is understood to be responsible for one's bodily condition — the notion that illness and disability are individual problems caused by negative attitudes or personal defects

\footnotetext{
${ }^{30}$ Identity is a broad, epistemological social construction with varying degrees of fluidity often intertwined with the politics of the cultural imaginary that recognizes the familiar and the unfamiliar (Humphrey, 1999, p. 174-188). Siebers (2010) describes disability as a "baseline by which humanness is determined," indicating that disability comes with value judgments related to individual identities within a broader cultural context (pp. 325, 333). Often, as we try to avoid defining disability in medical terms, disability identity is pushed into the arena of social oppression through the lens of the social model (Gilson and DePoy, 2000, p. 211; Goodley, 2011). Through this common sense of identity, some people with disabilities may define themselves as a culture, including "crip culture" (Wood, 2014) and speak of "disability identity" (Goodley, 2011, p. 211). A common example of the redefinition of culture is found in d/Deaf culture, wherein d/Deaf people cite a history of social oppression and wish to be considered a cultural group based on several differences, including language variations and a unique history of segregation that leads to conceptions of "D/deaf identity." However, because identity and difference can segregate people, some people with disabilities do not agree that defining themselves as a separate culture is useful (Marks, 1999, p. 78), whereas others, such as Wood in her comments precluding a collection of crip literature called Criptiques (2014), might disagree: "Criptiques was inspired by the inherent rebellion found in crip culture. We as disabled people are well acquainted with ableism (and all other-isms...), and many in our community draw on these shared experiences of oppression as fuel for visionary works of creativity" (p. 2).
} 
rather than social or environmental circumstance ${ }^{31}$ (Sontag, 1978; Shakespeare, 2006a).

Therefore, following Bauman, discourses of health (or "repetitious self-care," wherein bodily anxieties are buried in an obsessive preoccupation with bodily maintenance) dominate in modernity. As such, the notions of progress under capitalism that characterize modernity offer degrees of alienation and opportunity depending on one's classification as ab/normal (Harvey, 1985, p. 34). Further, individualization through normalization characterizes our current state, wherein modernist understandings of bodies as types — disabled/non-disabled and the sub- categories of intellectual/physical disability — praise the rational-mind-andproductive-body combination as an ideal. Failure to meet this ideal leaves one on the other side of normal: unbalanced, unstable, uncivilized, and irrational are among some of the descriptors that create the "concrete abstraction" of intellectual disability by negating notions of normality (Harvey, 1985).

The myth of normality and the naturalization of abnormality

Lennard Davis (2013a) positions the hegemony of normality at the heart of cultural production in the modernist project. He describes eighteenth-century Western industrialization as an era

\footnotetext{
31 This sentence alludes to the tensions between the materialist social model of disability and the longstanding individual/medical model. In short, the social model of disability defines disability as social relational as opposed to biologically determined by distinguishing between disability (as social/public exclusion) and impairment (as physical/private bodily issue), while the medical model continues to understand disability as undesirable bodily dysfunction in need of cure/elimination (Oliver, 2009; Shakespeare, 2006a; Thomas \& Corker, 2002). One point of tension for the social model, then, is that in its understanding of disability as the fault of society, it tasks people with disabilities with their own liberation. Thus the model falls into modernist, individualist assumptions about where disability exists; that is, it implies that disability is embodied only by those labeled as disabled rather than part of a wide variety of corporeal identities (Corker \& Shakespeare, 2002, p. 3).
} 
that ushered in the concept of normative experience as a natural state of being in order to advance the self under the capitalist agenda of progress. Within this ideological framework, the "normal" man was constructed: white, healthy, hetero-normative, non-disabled, rational — a God-like "hub around which the imaginary of the world rotated" (Bauman, 1999b, p. xi) ${ }^{32}$. With normality firmly in place, a person's ability to labour and keep up with technology emerged as a cornerstone of humanness that, if inscribed on all people, translated into a cultural destiny of success (Snyder \& Mitchell, 2006).

To understand the weight of normality in social and psychoanalytic terms, Davis looks to the lexicon of the word "norm," specifically its sister terms "normality" and "normalcy" (rooted in English-speaking culture between 1840 and 1850) (Davis, 1995, p. 24-25). Then, Davis follows Freudian analysis, wherein people begin as "normal" and shift in various degrees toward "abnormal" through processes of development (Freud, 1977, p. 386 in Davis, 1995, p. 39). These words, products of the symbolic, brought us into consciousness and assigned language to a concept of the ideal body that would then call for an opposite and, consequently, thrust people with disabilities into the symbolic as "other" (1995, p. 24-25). "The 'problem' is not with people with disabilities; the problem is the way that normalcy is constructed to create the 'problem' of the disabled person," Davis explains (p. 24). The naturalization of this problem is the "basic premise of the social processes of able-ism, patriarchy, and colonialism" (Titchkosky, 2008, p. 6). A failure to defamiliarize the familiar, or try to understand what is presented as natural, is to give in to the weight of normality.

Presupposing difference under the increasing bureaucratic oversight of human lives in modernity (Bauman, 1999a, p. 31) is a more drawn-out process than rationalizing abnormality

\footnotetext{
${ }^{32}$ Stiker (1999) names this power-discourse formation "the principle of the empirical norm," which involves the repetitious effect of comparing people to establish disability over time ( $\mathrm{p}$. 134).
} 
as a biological standard of difference opposite to that of normality ${ }^{33}$. Foucault (1979) locates the modernist realization of difference as bodily problem being "offered up to new forms of knowledge" through subjectification:

It is the body of exercise, rather than of speculative physics; a body manipulated by authority, rather than imbued with animal spirits; a body of useful training and not of rational mechanics, but one in which, by virtue of the very fact, a number of natural requirements and functional constrains are beginning to emerge (p. 155).

Individualistic technologies of modernity that produce "the docile body" go on to manage and further narrow the healthy-normal and unhealthy-abnormal divide (Bauman, 2000). This narrowing ensures both populations are accounted for by developing a healthy-normal way of being whose realms of possibility could extend into professionalized ambitions to disassociate from and solve the problem of the unhealthy-abnormal, thus naming the latter group the objects and subjects of the former group. The wide-ranging discipline of biomedicine and its branches produces a "crowd of researchers" (nurses, psychologists, teachers, researchers, government representatives) in "caring" positions (whose vocational mantra of care has stuck since the establishment of this early modern, spiritually-driven discourse) that work out strategies to "repair" the body for normative use (Stiker, 1999, p. 165). After all, as Jackie Scully (2002) points out, (ab)normality in medical science involves agreeing upon the magnitude of deviation from a quantitative norm and assigning language to it through scientific classification (p. 49). Thus biomedicine operates on a wide-reaching system of diagnosis that labels the problem of disability in order to codify and manage it, and, in doing so, also re-circulates meta- narratives of normality through research industries that "reveal" disability as inadequacy time and time again (Snyder \& Mitchell, 2006, p. 21; Rapley, 2004). Biomedicine seeks to "naturalize" abnormality — making it integral to upholding systems of medicine (Stiker, 1999) 
— in order to justify its cultural exclusions (Erevelles, 2001, p. 101). The rationale of "naturally different" also works to digest notions of humanism: race, sexuality, criminality, madness, and other modes of being Mel Starkman (2013) describes as unexplainable by biomedicine. Therefore, one's degree of normality, although imperative to the subject development of oneself, is wider than that: normality relies on deeply rooted early religious, modernist, biomedical discourses that organize life experiences in proximity to the analytical spaces of disability.

The myth of normality is a cultural meta-narrative - a "concrete abstraction" (Harvey, 1990) - that influences the formation of subjectivities as they are ordered through the violence of normalization. Subjects, in the Foucaultian sense, who may understand themselves as non- disabled, are the dominant group who share a meta-narrative of disablement and sustain it through tools of biopower. What follows is that the problem body in modernity is a problem identity — an embodiment of deficit or lack (Tremain, 2005, p. 11) wherein one's subjectivity is formed through abjection (Kristeva, 1984) ${ }^{34}$. To internalize the identity of abnormal is to cure disability by acknowledging it as an embodied problem; the cure, so to speak, is conformity by understanding the body - whether your body or another's — as transgressing the accepted categories of humanness and thus deviant enough to be reformed (punished), often through the use of modernist technologies (Dreyfus and Rabinow, 1982, p. 8).

${ }^{34}$ Consider Shildrick's (2009) fitting reading of Kristeva's (1984) notion of the abject: as something neither wholly part of the subject nor outside of the subject - "disavowed, yet disturbingly familiar" (Shildrick, 2009, p. 91). 


\section{Normalization technologies}

In the societies where Western science and medicine are powerful culturally, and where their promise to control nature is still widely believed, people with disabilities are constant reminders of the failures of that promise, and of the inability of science and medicine to protect everyone from illness, disability, and death. They are the 'Others' that science would like to forget.

- Wendell, 1996, p. 61

Although modernist technologies ${ }^{35}$ take many forms, often these tools take the form of controlling populations. Following George Grant (1990), "technology” represents what we think of as "good" and also reflects our conceptions of justice and rationality as these exist somewhere in the rationalism of the West, which has produced both science and philosophy and therefore demands the tools to manage them (p. 26, 32). The modernist fantasy that someday disability will be cured remains a significant obstacle for disabled people (Wendell, 1996, p. 55). This section of the writing describes how institutionalization in particular upholds eugenic standards of humanness by affirming oppressive stigmas and working to ensure the docility of bodies (Foucault, 1986). Such eugenic practices are brought to us as if they exist separately from the paradigms of knowledge that uphold them (Grant, 1990, p. 21). Eugenics was (some might say "is," so I will use "was" and "is" interchangeably here to crip tense just a little) another response — or solution — to disability.

In the case of intellectual disability, in particular, institutionalization makes real the notion of mind-based impairment and serves to discursively construct people as quasi-human and abnormal by upholding narratives that promote the possibility of normalization: new

\footnotetext{
${ }^{35}$ happening encompasses the act of simultaneously knowing and making, the co-operation of what it is to know and what it is to make, and, finally, the persuasive mode of being in our political and social lives (p. 11, 12, 13, 17, 34). Teratology, for instance, showed us various freak shows and, throughout modernity, transformed into embryology and later into a path of genetics that will lead us to the current "newgenics" (such as sterilization) and rehabilitation, which, as Stiker 99) so eloquently devastates in A History of Disability, supposedly rescues people from disability in due time for assimilation into normality (Hughes, 2012, p. 25).
} 
technologies serve as interventions to fix, regulate, and manage deviant bodies for the greater good (Garland-Thomson, 2013, p. 342). Modernist, eugenic technology served — and ultimately failed — to introduce and maintain normalized orders or rationality and human betterment by attempting to make certain Othered populations, including people marked with intellectual disabilities, disappear.

Eugenics: Disappearing the intellectually disabled "other"

Solutions come before problems; solutions seek the problems they might be able to solve. To put it in a different way: more often than not an aspect of life is not perceived as a problem, as something that cries for a solution, until expert advice or technological objects appear claiming to be the solution.

- Bauman, 1990, p. 200

Bauman (1990) writes about culture as human activity — "a labour of artificial order" — performed on other humans (p. 145). "Culture is about making things different from what they would otherwise be," he explains, emphasizing that despite the sometimes-fuzzy distinction between culture and nature (p. 143, Eagleton, 2000), culture often reigns. Culture is about introducing and maintaining order and rationality, and diminishing the unorderly and the irrational (Bauman, 1990, p. 144).

In his writing on normality, Davis (1995/2010/2013b) describes this type of cultural order as a reliance on norms wherein humans become both objects and subjects of modern classification systems. For example, the concept of the norm, unlike the concept of the ideal, implies that the majority of the population must be socially positioned as normal and begs for a definition of normalcy (2013a, p. 3) $)^{36}$. The social positioning of people is a eugenic act aimed

\footnotetext{
${ }^{36}$ Davis (2013 a) looks to Darwin and Galton's work as foundational for establishing norms and defining modern conditions of bodily normalcy: Darwin for his central biological theory
} 
to raise consciousness of what the human body should be; the bodily politic finding its language. Eugenic thinking, which I will write about here in very broad strokes, promotes a cultural location of disability on the margins. This type of thinking then calls on the people who experience the world in these bodies to accept and understand the pronouncement of their own deviance as a way of maintaining social order (Bauman, 1990; Collins, 1990; Dossa, 2005).

Undoubtedly modernity is characterized as an era of new knowledge(s) - the copenetration of knowing and making aimed at personal and cultural transformation — that could not exist without new technologies (Grant, 1990, p. 11, 12, 34). We can feel these motions of knowing and making intermingling when Carlson points out, following Nichole Hahn Rafter (p. 36), that the institution superintendent's expertise on intellectual disability gained professional legitimacy through the rhetoric of eugenics (in Carlson, 2010, p. 35). Eugenic rhetoric involves curbing, eliminating, and resisting intellectual disability mainly through biomedical interventions. Eugenics is the process of elimination paired with correction that seeps into our social consciousness as we consider where particular people ought to be located in our world - eugenics broadly refers to a process of selection and placement (Hughes, 2012, p. 17).

I write about eugenics here as a way of thinking because examples of eugenic policies being violently applied to bodies are abundant in the literature, and repetition of these horrors

of evolution, which placed "disabled people on the wayside as evolutionary defectives to be surpassed by natural selection" (p. 3); Galton for following-up his cousin's work with the idea that the physical qualities of a person can be measured on a "normal distribution" curve (p. 4). This curve accounts for height, intelligence, strength, fertility, and so on, with the norm as the most common characteristics (and the "ideal" as tied to only particular traits, such as higherthan-common intelligence ranking) (p. 4). Those on the tail ends of this curve are categorized as deviant, unorderly, irrational, and abnormal — on the fringes of modern cultural codes of normalization. 
risks a perfunctory presentation in this context where I am attempting to establish the conditions for a social imaginary that defamiliarizes and disavows intellectual disability. Also, the social history of eugenics (especially one enriched by examples) is a book-length project that I dare not attempt to squeeze into a few paragraphs. However, it is important to note that eugenic histories play an important role in informing disability history and present-day abelism as it intersects with other forms of oppression. Some researchers have taken into account the direct racism, classism, and abelism that are the result of eugenic-based laws and policies (primarily in Western contexts) (Ignagni, personal communication, July 8, 2015). For example, in his book The Black Atlantic: Modernity and double-consciousness Paul Gilroy (1993) targets eugenics as an imperialist event beginning with slave trades. Gilroy suggests that eugenics gained strength through imperialist justification that used science to argue for the clarification and classification of human (slave) in/capabilities. Bauman (1990), too, points out that historical violence has been authorized and routinized, leading to the dehumanization of groups. Theoretically, it may be possible to draw a parallel between Bauman's examination of Nazi death camps, which separated and exterminated less in the name of values than in the name of instrumentality (Tester, 2004, p. 114). Snyder and Mitchell (2006) make it clear that disability was no parallel demonstration of dehumanization — rather, people with disabilities were the first subjects of Nazi eugenics, and extermination opens the curtain to another dark, quintessential narrative of disability that has yet to be fully uncovered. We can also look at examples closer in time and proximity, such as cases of sterilization of "feebleminded" women in Albertan state-run institutions, as instances of eugenic policies and actions meant to eliminate the possibility of future disability (Grekul et al, 2004). In modernity, disability emerged as a threatening signal of social and cultural regression, and eugenics came to symbolize the completion of the modernity project — the 
ultimate achievement of the normal, "modern man" who would ensure a promising future (Snyder \& Mitchell, 2006, p. 31).

Eugenics emerged at a time when pre-modern coping techniques of integrating bodies outside of normality into society were no longer sufficient in the task of upholding culture and civility (Rapley, 2004). Therefore, the task of eugenics is to inscribe civility on the body in order to civilize society, the reasoning somewhat summarized in Davis's (2013a) bodily metaphor that illustrates this societal understanding: "a hunchbacked citizenry would make a hunchbacked nation" (p. 20). The rationale for killing, disposing, and hiding disabled bodies through eugenics grew from the fear of the abnormal and the drive to eliminate and correct disability in a project that "sought to 'improve' society's 'genetic stock" by limiting the reproductive capabilities of those considered deviant, socially undesirable, unorderly, and irrational (Hughes, 2012, p. 17-18; Rossiter \& Clarkson, 2013, p. 13). Labeled people, already subjects and objects of classification, were targeted in an attempt to eliminate "feeblemindedness" in particular. The disabled body, then, became a concept, or tool, used for "cultural diagnosis" in that it served "to discount entire populations as biologically inferior" (Snyder \& Mitchell, 2006, p. 12).

Eugenic understandings of bodily inferiority are intertwined in notions of biological determinism and a "dominating, hegemonic vision of what the human body should be" (Davis, 2013, p. 5). This vision plays an important role in authorizing today's diagnostic regimes and rehabilitation initiatives (Stiker, 1999; Snyder \& Mitchell, 2006, p. 70). Eugenic thinking epitomizes a modern promise: the eradication of disability is possible, which means unwanted characteristics (such as "feeblemindedness") can be removed from humans and/or from humankind. Thus, the fear of individual bodily change is somewhat assuaged. Eugenic praxis secured the divide between abnormality and deviance in a hegemonic formulation of 
exclusionary practices based on research-based formulas of deviancy (Snyder \& Mitchell, 2006, pp. 26, 73). With "experts" and categorization techniques well in place by the late eighteenth and early nineteenth centuries, intellectual disability emerged as a biomedical object of knowledge. The eugenics movement can help us understand this emergence, and how labeled people become subjects and objects of ableist meta-narratives that conform to the myth of normalcy — in particular, the myth of a normal mind.

Returning briefly to a Foucaultian approach to the ontological problem of disability, I underscore the contingent nature of the emergence of eugenics through power-knowledge relations that orchestrate subject development via the professionalization of normalization (Foucault, 1979, p. 143). Using diagnosis as a primary tool, biopower transforms human life and contributes to subject development that establishes — and departs from — the imagined norm. This positioning via diagnosis spurs the emergence of the problem individual — or the individual with a problem - as a matter of scientific concern. Thus, discipline is "making" and attempting to eliminate the subject through the modernist technology of pathology that is supported by discourses of normalized health (Foucault, 1978, 143).

As Marshall Berman (1982) explains, part of the modern cultural code means living a life rife with contradiction: to be overpowered by institutions, and yet to still attempt to "make the world our own" by becoming both subjects and objects of modernization - to be made both subject and object at once (p. 13). Eugenics was not the supposed problem of the disabled body, but was a performance of cultural values, both aesthetic and moral, that found people with intellectual disabilities (and other "types" of people) to be an intolerable threat against the modernist ambition of progress (Shildrick, 2009, p. 53). In an effort to contain this threat, technologies and strategies of control were put in place to preserve the constitution of a normalized body politic (Ignagni, July 8, 2015). 


\section{Institutionalization: Managing the divided body}

Institutionalization is a persuasive type of carceral intervention with standard, widely uncontested sites of power- discourse formation through/over past and present bodies. In the eighteenth century, institutions - almshouses, schools, and jails - emerged in European cities to absorb outcasts (whose labour, in most cases, was not up to normative snuff). By the early twentieth century, cultural locations for intellectually disabled people were well established. As Carlson (2010) outlines in her comprehensive history of U.S. institutions, these technologies also served as a "vehicle" for biomedical professionals to propel and strengthen their respective disciplines (p. 27). This strengthening of disciplines was done through the justification that institutions could be research centers where the cause of intellectual disability could be uncovered and extinguished, and where intellectually disabled people could be trained to become useful to society (p. 137): "Within this complex institutionalized world, intellectual disability was both found and made, knowledge was remade and reported, patterns were recognized, invented, imposed" (p. 22). In this sense, institutionalization engages the copenetration of knowing and making, a technological process Grant (1990) suggests produces subjects on which technology can operate - a process at the forefront of research ethics concerns which will be discussed later in this dissertation.

By producing authoritative knowledge to render the abnormal body docile, institutions served as "omni-disciplinary" entities that contributed to the professionalization of normalization (Foucault, 1977). In other words, institutions worked similarly to prisons (and other forms of incarceration) that "assumed responsibility for all aspects of the individual, his physical training, his aptitude to work, his everyday conduct, his moral attitude, his state of mind" (Foucault, 1977 in Carlson, 2010, p. 27). These procedures enable subjects in order to constrain them (Foucault, 1986, p. 136). For instance, Carlson (2005) describes how, in some 
instances, mid-nineteenth century superintendents considered "feebleminded" people "helplessly static" (therefore eligible to be cordoned off from normative experience) but "improvable" enough to be labourers within asylum walls, which, in turn, created an efficient system of labour to maintain the buildings and surrounding grounds through manual labour (a task generally relegated to men) and to care for "lower-grade" people (a task reserved for women) (p. 144; 2010, p. 64). As Carlson (2010) observes, the gendered nature of this labour points again to the gendered nature of incarceration:

What is remarkable about feeble-minded women caring for other inmates, $\ldots$ is that the very women who embodied ... quintessential female traits were the same women who had given birth to illegitimate children, ... and were thought to have perverted the sexual behavioural norms expected of women. Though the feebleminded woman needed to be segregated and protected by virtue of her deficient intellect and moral faculty, her caregiving nature remained intact (pp. 64-65).

Here, again, women in particular are examples of both static and dynamic modes of disability: useful inside an institution but dangerous outside. Patient labour has historically maintained the economic demands of institutions (Ben-Mosche, 2013). Further, those whose ability as labourers might be useful outside of asylums might be "planted" in communities not as members of society, but as cogs in a larger economic machine (McKittrick, 2013, p. 8). This strategic positioning of people speaks to particular cultural locations of disability as economically valuable in systems of medicalization. This positioning also gives way to principles of rehabilitation that suggest that with enough effort, bodies can be pushed into normality and even those experiencing intellectual lack may participate in culturally specific labour roles informed by Western values of progress and gender norms (Stiker, 1999, p. 145; Snyder \& Mitchell, 2006). 
By Foucault's (2000) count, abnormal people are "individuals to be corrected" — the "faded monster[s]" who "escape normativity" and are therefore subject to "training" in institutions out of concern for human betterment through disciplinary processes of individualization (docility) and usefulness (utility) of bodies (pp. 52-53). Thus, pre-modern notions of monstrousness and uselessness follow us into modernity via discourses of not belonging performed through dividing practices. Through divisiveness, "power is productive, rather than oppressive" because it creates new structures that bring disability into being rather than diminishing it, once again re-affirming Titchkosky's (2008) point that disability is something brought into being by cultural endeavors (p. 4; Sullivan, 2005, p. 29).

Both of these pre-modern notions continue to inform our cultural imaginary of intellectual disability in a current context where the awards of inclusion in social arenas (such as employment) remain bogged down with the cultural demands that people meet normative mind/body standards to fit into the labour market and demonstrate utility (Wendell, 1996, p. 47). Further, with growing expertise around intellectual disability in the late nineteenth century, improvability of disability could eventually be predicted; if someone could get over their individualized problem of the mind, the person could perhaps become productive and even employable ${ }^{37}$

Nevertheless, institutionalization is a persuasive technology with standard, widely uncontested sites of power-discourse formation through/over past and present bodies. In some cases institutions are places — cultural locations of disability — designed specifically for people labeled as intellectually disabled. Institutions are "omni-disciplinary" spaces because

\footnotetext{
${ }^{37}$ Carlson describes how the goal of productivity eventually brought some people with intellectual disability out of institutions and into another disciplinary realm of education, also reflective of modernizing culture (Carlson, 2010, p. 44).
} 
they aim to cut off people from society while simultaneously targeting individuals for work/vocational training, moral attitude adjustments, normative literacy training, and general state-of-mind "improvement" (Carlson, 2010, p. 27). Somewhat paradoxically, institutions attempt to remove people from society and impose social customs upon them despite their separate status, almost as if in attempt to create a separate sub-culture of intellectual disability (Foucault, 1979 in Carlson, 2010, p. 27). This movement between segregation and integration again speaks to the precarious state of unbelonging, static and dynamic, characteristic of intellectual disability. The movement in the cultural imagination that institutionalization represents is a movement that shifts from the invisible to the visible, and it is dividing practices that allow this shift to take place; the creation of "the space between" that Dolmage (2014) references and where this research is situated is the space that takes wonderment and political disorientation to bridge (Ahmed, 2006).

\section{Institutionalization as a contemporary threat}

To close this discussion on institutionalization we can cast our gaze to a more contemporary timeline. Through institutionalization biopower is at work qualifying bodies for separation from several spheres — judicial, educational, employment — through the long reach of medicine (Wendell, 1996). Therefore modernist subjects trust biopower's authority even though it poses a real threat of incarceration for many: anyone aging, anyone undergoing life activities that could result in accident, anyone who has not met the goals of community living and is returned to an institution, and so on (Ben-Moshe, 2013; Wendell, 2013). Following Grant (1990), part of what makes this institutionalization so successfully persuasive is that it is brought before us as a historic anomaly — as though it is separate from the present paradigms of knowledge that originally pushed it into the realm of possibility (p. 21). The contemporary 
institution's work buries the complicated politics of humanness - a myth that, in

Titchkosky's words, sells disability as a type of "degraded social difference" that seems ordered by nature rather than culture (2013, July). Using institutionalization as a persuasive technology of modernity, the meta-narrative of normality is still hard at work continually recasting the "concrete abstraction" of disability as problem to be solved (Harvey, 1985).

In a cultural context where humanness manifests in societal and medical labels of deviance, stigmatized people are needed for non-stigmatized people to establish standards of undesirability and then to work toward the goal of "normal" (Coleman Brown, 2013, p. 148149). It is through the construction of a binary between normality and deviance that bodies are

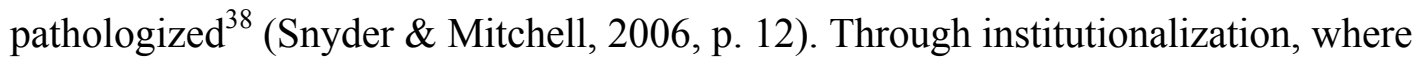
stigmatized bodies are counted, controlled, taxonomized and gazed upon, entire fields of study are devoted to the assessment, cataloging, pathologizing, objectification, and rehabilitation of disabled people. These specializations impose normality on the disabled body, punishing it for failing to subscribe to the Enlightenment's ongoing project of "human betterment" and striving to lift the body into standards of normality by reducing corporeal difference (Simpson, 2007 in Rossiter \& Clarkson, 2013, p. 4; Hughes, 2012, p. 17-22; Grant, 1990$, p. 16$)^{39}$.

\footnotetext{
${ }^{38}$ Other examples of modernizing tools working to establish concepts of normality include the charity economy (Snyder and Mitchell, 2006, pp. 56-65); the movement of psychiatry, which plays a role in the evaluation and incarceration of bodies, and the establishment of social parameters of sanity (Foucault, 2003; 1977); intelligence testing, the delicate and precise establishment of which created numerical baselines to legitimize the principles of medicine and professionalize the practice (Snyder and Mitchell, 2006, p. 72-72; Stiker, 1999; Carlson, 2005); and genetic practices that have stemmed from eugenic histories such as prenatal screening and genetic engineering (Davis, 2013b, p. 269) among others.

${ }^{39}$ As Carlson (2010) points out, it is important not to reduce histories of intellectual disability to institutionalization. Certainly many lives were lived outside of institutional walls, especially when racialization is included in histories; Carlson explains that in the U.S. many early institutions were built for white patients only, and most non-white "feebleminded" people were housed in asylums (2010, p. 32). However, I focus on institutionalization here because it is a part
} 
Importantly, contemporary issues of institutionalization still vibrate in our cultural consciousness. Consider, for example, the people involved in the recent class action lawsuits and settlements involving the government of Ontario and provincially-run institutions for people with disabilities (Rossiter \& Clarkson, 2013) ${ }^{40}$. Additionally, the Saskatchewan government has ordered the closure of a Moose Jaw institution in 2016, adding to the turbulent reality of de- institutionalization and community living movements elsewhere (Canadian Broadcasting Corporation, 2014). Yet, as some disability theorists suggest, these and other institutional settings might be might be more accurately understood today as incarceration or through the replacement label of "group home" (Ben-Moshe, 2013; Nunkoosing \& Haydon-Laurelut, 2012; Rapley, 2004). These sites of segregation rely on the (cognitive and social) authority of biomedicine with a eugenic edge to observe and mark the body as unsuitable for normal social participation, and to remove the problem of disability from direct lines of normative encounter ${ }^{41}$ (Wendell, 1996).

of intellectual disability history that drags into the present, and also because as a normalizing technology institutionalization plays a significant role in carving our cultural conceptions of intellectual disability as unfamiliar and separated from the norm. And, as Carlson argues, these institutions in the mid-nineteenth century "were arguably the most significant means by which knowledge about intellectual disability was produced and organized" (p. 45).

${ }^{40}$ In 2010 residents of three provincially-run institutions, including one specifically for people with intellectual disabilities, launched class action lawsuits against the government of Ontario alleging maltreatment (Alamenciak, 2013; Rossiter \& Clarkson, 2013). In 2014 the lawsuit was settled.

${ }^{41}$ Wendell writes at length about the cognitive and social authority of medicine. She employs Addelson's (1983) notion of cognitive authority (in Wendell, 1996, p. 117) to describe the experience of having one's "descriptions of the world taken seriously" while social authority refers to biomedicine's influence outside of its professions, as manifested in insurance companies, government bureaucracies, charities, and so on. Wendell (1996) suggests the consequences of these authorities of medicine are compounded for those who have little cognitive or social authority of their own (p. 119). 
Maintaining intellectual disability as "natural" through ableism

Intellectual disability is one manifestation of modernity's "human cost" — an era whose "dark side" is revealed through the "concrete abstractions" of normality and disability as problem created amid obsession with progress (Berman, 1982, p. 25; Harvey, 1990).

Ableism occurs when space narrows between the unachievable ideal body and the apparently normal body, and when those left out of these modernist categories are cast aside as Others lacking normality. People with intellectual disabilities, in particular, exist under a diagnosed category of humanness that naturalizes the problem of intellectual disability as a problem of abnormality. As Dolmage (2014, pp. 21-22) explains, following Fiona Kumari Campbell (2008), normativity is built out of the interconnected discourses of ableism and disablism ${ }^{42}$. Ableism lives by "the corporeal standard" - a particular type of self and body — that excludes disability as "a diminished state of being human" (Campbell, 2001, p. 44). In Dolmage's words,

${ }^{42}$ Campbell (2008) warns against using the terms "ableism" and "disablism" interchangeably. She explains that ableism "is described as denoting an attitude that devalues or differentiates disability through the valuation of able-bodiness equated with normalcy" and, following Vera Chouinard (1997), ableism refers to social relations that "presume ablebodiedness, and by doing so, construct persons with disabilities as marginalized ... largely invisible "others"" (Chouinard, 1997, p. 380 in Campbell, 2008, unpaginated). Broadly speaking, ableism encourages people with disabilities to hate themselves and it encourages non-disabled people to hate them, similar to the effects of patriarchy on women as described by Cixous (1976, p. 878) and the processes of subjectification via internalization described by Foucault (1978). Meanwhile, disablism can be understood as "a set of assumptions (conscious or unconscious) and practices that promote the differential or unequal treatment of people because of actual or presumed disabilities" (Campbell, 2009, p. 4 in Dolmage, 2014, p. 22). As sure as race is a scientific/social category out of which racism grows, impairment and disability encompass a cluster of scientific categories out of which ableism and disablism emerge (Stockholder, 1994, p. 161). 
Ableism renders disability as abject, invisible, disposable, less than human, while ablebodiedness is represented as at once ideal, normal, and the mean or default. Disablism constructs disability as negative quite directly and literally. Ableism constructs a mythical able-bodied norm, thus differentially constituting disability (Dolmage, 2014, p. 22)

An ableist culture enforces already-established methods of language based on rules, structure, and presumed logical thinking (including eugenic thinking that, as mentioned earlier, characterizes modernity) represented in a symbolic order. In ableist societies such as contemporary Western societies, any cultural location of disability is a location of Otherness. By using disability as an object against which all subjectivities and bodies are discursively developed (Titchkosky, 2013, July), modernity opens up ontological questions that morph into none other than what Bauman claims all modernist projects to be: an assault on what it means to be human (in Tester, 2004, p.118).

Yet, as Berger (2014) points out, Otherness is not a general, permanent mode of being that is "out there" and will remain static and unshakable against the familiar (p. 25). Otherness takes different forms in various cultural circumstances, and otherness is a condition of possibility: "whatever cannot be thought or said" in particular cultural locations and particular times (Attridge, 2004, p. 30 in Berger, 2014, p. 25). Part of locating intellectual disability, then, involves the process of finding the "Other" by recognizing the difference between presence and absence, or visibility and invisibility. Presence and visibility are forms of normative dependency (Bauman, 1990, p. 29) ${ }^{43}$. Such hidden discourses are then positioned as

\footnotetext{
${ }^{43}$ For example, to be a doctoral candidate I depend on my ability to conform to the normative institutional standards of academia and, specifically, Ryerson University. My degree(s) of freedom within these normative boundaries is locatable, or I might say translatable, in writing that I present to the authorities of this structure: my committee, fellow students with scholarly opinions, the University's Research Ethics Board (REB), and so on. Meanwhile, absence and invisibility are often the remains of writing belonging to those who do not, or choose not, to conform to such forms of normative dependency.
} 
discourses of the other from my own "normate" vantage positioning which churns up its opposites frequently and easily. Moving forward, it remains clear that participation in dis/ableist constructions of humanness is not enough — or, as Shildrick (2009) writes, "buying into the existing system — as though the problem were simply one of exclusion" is inadequate (p. 7).

Arguably, a release from modernist, dis/ableist myths of normality that govern all corporeal realities could lead to a more nuanced understanding of disability as other than problem. Certainly a turn toward postmodern bodily theory could add a "critical bite" to this conversation by, perhaps, calling-out disability for what it more accurately may be: an inevitable, socially dehumanizing "concrete abstraction" applied in some degree to all human bodies through power-discourses (Berman, 1982, p. 33). However, attitudes long survive the conditions that give rise to them, and current perceptions of the body shaped by modernist notions of normality continue to impact the development of each person's subjectivity (Stiker, 1999, p. 126). As Wendell (1996) warns, disabled people's experiences tend to be made invisible in the discourse of postmodernity because in attempting to transcend the "real" and “constructed" social constructivist divide lived experience is sometimes overshadowed by theoretical imagining (p. 45; Carlson, 2010, p. 86).

Before launching into postmodern analysis, it is worth pausing to consider material visions of the body through cultural memory, cultural imagination, and current circumstance. Cultural memory, in particular, involves eugenic bodily meta-narratives of discipline that have already been discussed. The cultural imagination puts into motion ableist technologies and discourses that determine subject development. Current cultural circumstance, which has yet to be discussed in depth, determines our relation-to one another and the ways in which we make each other mean in the world. To paraphrase Dolmage (2014), this three-fold 
theoretical reflection is useful because "futuristic" disability rhetoric will not settle for segregating or eradicating disability, but will rely on cultural analysis to understand how disability is made possible when no one's corporeal reality is apart from others (p. 2, Ahmed, 2006, p. 43). 


\section{Chapter 4: Intellectual disability as a contemporary cultural project: Disability studies, neoliberalism, and moving beyond the problem of "giving voice"}

Contemporarily, disability is conceptualized as an identity marker, and sometimes even a cultural category (as in crip culture) spanning across a broad range of (often inevitable and sometimes invisible) human experience ${ }^{44}$. In Western contexts disability is often thought of through interventions: charity, "care” systems, governments and tax dollars and agencies, social work, medicine. The discourses that build disability as natural also frame it as multifaceted and never static. These discourses hold down disability near its modernist roots, liking it to impairment and to bodily splits of the intellectual and the physical. Eventually our cultural imagining of disability reaches a rupture point where we must stop and look around to figure out where intellectual disability is located today.

\section{Disability as disciplinary anchor}

Until the early 1970s disability was viewed by the public (and social scientists who bothered to think about it) as a personal tragedy and bodily impairment diagnosed by medicine (Barnes, Mercer and Shakespeare, 1999, p. 10; Linton, 1998, p. 10; Davis, 2010, p. 301). Impairments and disabilities have been classified as natural pathological blips in the human population — a result of normalizing judgment arguably based on modernist ontologies that constitute disability (Lyotard, 1999; Jameson, 2006, p. 504; Talpade Mohanty, 2006, p. 400, 407; Hughes, 2005, p. 83). Davis (2010) suggests that disability studies moved away from models of tragedy and

\footnotetext{
${ }^{44}$ In earlier portions of our cultural memory, disability was dealt with differently because it was situated in different cultural locations, and thus took on different trajectories of being. As Stiker summarizes, illness in infancy, accidents in pregnancies and births, and the fatality of various sicknesses meant "society was not obligated to deal with elevated numbers of disabled, as today" (Stiker, 1999, p. 78).
} 
impairment gradually, and emerged through a series of cultural waves, similar to the evolutionary waves of feminism (2010). The first and second waves of disability studies were set in the 1970 s and 1980 s respectively ${ }^{45}$. These waves carved disability as a personal identity marker for many through the conceptualization and adoption of certain ideologies that would later be defined as models to ground the discipline. The social model, sometimes known as disability studies' "big idea," was, at this time, formalized through the articulation of principles set out by a group of U.K. socialist, counter-culture activists during the second wave (Hasler, 1993 in Shakespeare, 2006a, p. 29) ${ }^{46}$. In 1981 the United Nations declared the International Year of Disabled Persons, and the years 1983 through 1992 were marked as the Decade of Disabled Persons (Barnes, Mercer and Shakespeare, 1999, p. 11). This period is associated with dislocation and multiculturalism, which have come to be understood as signifiers of postmodernity (Davis, 2010, p. 301-304).

In this era, disability became less hidden, and social scientists were taking notice; if you didn't (yet) experience disability, you probably knew somebody who did (Barnes, Mercer and Shakespeare, 1999, p. 32). For those with a vested interested in disability, the social model emerged as an ideology professing disability as a loaded word used to describe a way of life not natural, but socially constructed (Marks, 1999, p. 78; Tremain, 2005, p. 9; Bérubé in Linton,

${ }^{45}$ The ebb of the first wave of disability studies drew up an identity shift as labeled people engaged in activism to move away from modernist ideologies that pegged them as sufferers of Godinflicted misfortune and towards the role of minority citizens deserving of equality. The second wave flowed soon afterward as labeled people began to fight against constructed barriers that contributed to their cultural segregation, such as institutions and intelligence testing, and began seeking societal inclusion through protest (Davis, 2010, p. 301-304; Carlson, 2005, p. 134). ${ }^{46}$ This model is first articulated in a 1972 letter to The Guardian newspaper written by Paul Hunt, who wrote on the behalf of the UPIAS to oppose individual and medical accounts of disability ("“Growing Pains"”, n.d.). The UPIAS later compiled its recommendations in summary notes of a discussion held in November 1975 called the Fundamental Principles of Disability. One main focus of the organization's concern is society's role in disabling physically impaired people. For example, in asserting that physically disabled people are an oppressed group in society the Union suggests that particular aspects of people's oppressions, such as low incomes, are a result of isolation and segregation rather than individual will (1976, n.p.). 
1998a, p. vii). Unsurprisingly, an opposite of this model materialized; the medical model pegs a person with disabilities as an object of clinical diagnosis and as a candidate for a cure who may be categorized in the interests of policies such as welfare or segregated living (Oliver, 1990, pp. 24, 30). Though the medical model/social model binary is widely viewed as an understandable, teach-able re-thinking of disability in theoretical terms, more recently scholars have pointed out that this dualism only represents another manifestation of material analysis open to feminist, post-modern, and cultural critique (Corker \& Shakespeare, 2002; Davis, 2010; 2013b; Goodley, 2002; 2011; Hughes, 2005; Titchkosky, 2008). Feminists were the first to lead this critique, pointing out the absence of women's voices and the dominance of whiteness in the social model (Morris, 1991; Wendell, 1996).

The third wave of disability studies began in the 1990s. It represents the discipline's wide reach into other disciplines by locating the body as central to all ontologies: philosophers taking up queer theory — crip narratives/art, notions of passing and "coming out" — and disability (Clare, 2013; Kafer, 2013; Kuppers, 2007; McRuer, 2013; Shildrick, 2009); scholars refusing to leave race relations as a gap in the literature, including conversations about contemporary forms of incarceration (Erevelles, 2014; Ben-Mosche, 2013; Puar, 2013); scholars insisting that understandings of disability are integral to understandings of popular culture and media representations of people (Garland-Thomson, 1997; Haller, 2010; Barounis, 2013); philosophers blending thoughts on disability, illness, madness, and pain (Lewis, 2013; Price, 2012; Wendell, 1996; 2013; Wipond, 2013); and critics attending to the new emergence of cyborgian narratives in relation to the transhumanist politics of disability and biomedical technologies (Bérubé, 2013; Corker \& Shakespeare, 2002; Hubbard, 2013; Kuppers, 2002). 
Many of the authors cited here write so broadly across disciplines, or genres of disability, that they are difficult to categorize ${ }^{47}$. However, it is clear that feminism is deeply embedded in contemporary disability studies, though not without tension. Rosmarie Garland-Thomson (2013) criticizes disability studies for taking itself as a starting point as it so widely spreads across "this larger undertaking called identity studies" (history, literature, philosophy, and so on) (p. 333). She writes,

Indeed, I must wearily conclude that much of current disability studies does a lot of wheel reinventing. This is largely due to the fact that many disability studies scholars simply don't know either feminist theory or the institutional history of women's studies. All too often the pronouncements in disability studies of what we need to start addressing are precisely issues that feminist theory has been grappling with for years ... feminist theory can offer profound insights, methods, and perspectives that would deepen disability studies (p. 333).

Further, despite the trans/cross-disciplinary leanings of disability studies, few researchers have tried to dismantle the binary between labeled and non-labeled people by asking what labeled people want and where they (usually meaning "they" as objects in relation to the researchers as subjects) fit into Western culture (Barnes, Mercer and Shakespeare, 1999, p. 10; Davis, 2010, p. 3; Goodley, 2011, p. 7).

As it continues to evolve, disability scholarship remains decidedly unsettled. This type of scholarship is characterized by its attempt at cultural resistance via activism as disabled people seek to define themselves in both individual and group contexts through rights-based cultural critiques and through a pointed move toward crip epistemologies (Dolmage, 2014; Longmore, 2003, pp. 3-14; Straus, 2010, pp. 535-560). Disability studies epistemologies are rooted in

\footnotetext{
${ }^{47}$ Jasbir Puar (2013), for example, argues for a deconstruction (feminism) of dis/ability in relation to the popular "It gets better" media campaign (media studies) against queer youth suicide (queer studies) by linking suicide (mad studies) to forms of slow death (philosophies of pain) and neoliberalism (cultural studies). This blending of disability across multiple theoretical planes is characteristic of today's disability studies.
} 
sociology, and are not always easily transferred to cultural studies except, perhaps, in areas where researchers have blended these disciplines (Snyder \& Mitchell, 2006; Haller, 2010; Goodley, 2011). To paraphrase Snyder and Mitchell (2006), this type of politicization re- imagines disability as more than dysfunction and problem (p. 4). Or, as halifax (2009) explains, in moments where researchers engage in processes of "seeing in and around theory" in order to worm through it (p. 8), a method in line with crip episteme emerges. This method promotes the notion of tangling the linear through models that tend to overwhelm discussions of the body and corporeal realities (Shildrick, 2009).

\section{Disability as cultural project: Crip epistemologies and cultural locations}

Currently, the most explicit link between disability studies and cultural theory is offered by Snyder and Mitchell (2006), who theorize cultural locations of disability — a key concept in addressing how the problem of intellectual disability is culturally and socially made in Western contexts, and how people are made both subjects and objects through this construction and research related to it. They argue that cultural spaces have been set aside for labeled people often against their will — including particular charity systems, institutions, and media representations (p. 3). These locations form the foundation of a modernist project that pits culture against nature and the body against society; here, the body is constructed, and dominant discourses are internalized (p. 4, 7). The cultural model of disability resists modernist conceptions of the body and instead locates disability as a site of phenomenological value synonymous with processes of social disablement (p. 6):

... such an emphasis does not hide the degree to which social obstacles and biological capacities may impinge upon our lives, but rather suggests that the result of those differences comes to bear significantly on the ways disabled people experience their environments and their bodies (p. 6). 
Through the cultural model disability emerges as a "tool of cultural diagnosis" (p. 12); or, as Eagleton (2000) writes, the process of culture choosing "us" before we choose "it" (p. 28$)^{48}$. When disability is a cultural location that "hovers indecisively between fact and value" (Eageleon, 2000, p. 13), it tends to also queer normative paradigms by surfacing in unexpected places, such as crip epistemologies ${ }^{49}$ (Kafer, 2013; Shildrick, 2009, p. 5).

Yet, the contemporary politics of intellectual disability currently remain divisive, continually relying on medicalized representations to divide the self from the other, and the mind from the body — to defamiliarize the otherwise familiar. Dolmage (2014), Titchkosky (2008), and Robert McRuer (2013) argue that it may be important for disability studies to move beyond monitoring cultural representations of disability by ranking its appearances as "good" or "bad" or "right" or "wrong" on the basis of political correctness ${ }^{50}$. Dolmage (2014) suggests that one way to push past singular readings of disability locations is to invite everyone to be impacted by representations of disability because “disability's constructedness of rhetoricity reveals how all bodies are constructed" (p. 101). This argument points to cracks in disability studies while simultaneously presenting a re-orientation of thought about the body, language, and rhetoric that

\footnotetext{
${ }^{48}$ For example, Kuppers (2007) describes the disability culture that chose her as a force resisting modernity: "For me, ... disability culture is the difference between being alone, isolated, and individuated with a physical, cognitive, emotional, or sensory difference that in our society invites discrimination and reinforces ... isolation - the difference between all that and being part of community" (Kuppers, 2007, p. 90).

${ }^{49}$ Crip epistemologies aim to subvert contemporary understandings of disability that are often reduced to normative standards - to those expectations of representation that subscribe to normativity versus those that do not. This type of normative dynamic (understandings that fit in/don't fit in), Shildrick explains, is a binary of difference that does not suffice in understanding disability as a mode of being in the world. "Certainly many disabled bodies do transgress the morphological conventions of Western modernity and thereby disturb entrenched socio-cultural determinations of proper bodily form," Shildrick (2009) writes, "but that is too limited in scope to explain the anxiety that disability evokes" (p. 18).

${ }^{50}$ A motion Carla Silva and David Howe (2012) undergo in attempting to validate, and thus complicate, the perceived "badness" and "goodness" of the "supercrip" in relation European Paralympic advertising campaigns.
} 
seems to fit crip epistemologies. Only in the last few decades have researchers tried to understand disability as another variation of humanness - a degree of involving people with real thoughts and needs. And, only over the past few years have crip epistemologies started in/forming, in their exploratory way, disability-based thinking.

The problem that emerges with new ways of reading/locating disability is that to force society to read/locate/understand disability differently is to acknowledge disability as different. The risk here, as Shildrick (2009) outlines following her Foucaultian analysis of queer, crip, and disability ontologies, is that "there is no clear-cut trajectory insofar as the very moment of speaking out risks generating a new category subject to discipline and regulation” (p. 65). It is noteworthy to remember the inseparability of power and knowledge as established by Foucault (1979): we are governed by codes of knowledge (often medical codes) whose power is found in their ability to dissolve into an "underlying essence, a metaphysical notion, or an empty catchall" that then positions both power and knowledge as taken-for-granted, naturalized culture and aids social control (Dreyfus \& Rabinow, 1982, p. 13, 129). In other words, power and knowledge work as tools to keep normality in place, and to keep its abstract, dominant discourses circulating (Carlson, 2010; Mills, 1959; Foucault, 1979). We might be reminded that, as Foucault explains in Madness and Civilization (1973b), the purpose of constructing madness was to develop a distinction between madness and sanity, and then to keep madness in place as part of the cultural imagination. Here, even resistant moments such as the social model and crip epistemologies are tied up in a discursive cycle that produces and circulates power and knowledge. That is to say that any new discourse constructs its own normativities that earn resistance. "In short," Shildrick (2009) explains, "no account, whatever its provenance, can claim final authority, but will always generate a challenge to its own limits and legitimacy" (p. 42). 
Vignette: The next few moments

Eventually I round down to the part of the informed consent form involving pseudonyms. "So, that means you can use your real name, or you can choose a different name." I try to explain that the benefit of using your real name is that you may get some real credit for your work, though I find myself cringing at the words "real credit" — as if I know what that really means. Sometimes words just spill out of my mouth. On the other hand, if you want to make sure nobody can identify you through the research - "nobody knows you're the person who wrote that thing, or said that thing" - you can make up a name.

"Like, a fake name?” somebody asks. I nod. "Like, my name could be Grandmaster B?" "Yes, if you want a pseudonym you could choose that."

"Okay. Where do I sign up?"

Another person across the table perks up. "I want to do a fake name," he says.

“Alright. Remember you have the option to use your real name too, if you want," I say.

“Can I use my rapper name?” he asks.

"I guess. What's your rapper name?"

He takes off his hat and gives me a serious look. What he says next wipes away any concern that this participant's real name might somehow be worked into a rap identity. "My rapper name is Justin Bieber." I bite my smile. He is serious. The other participants are laughing, but this man is not kidding around. Justin Beiber's name has also come up in the past; earlier the group voted to name themselves, and the title "The Justin Beibers" lost only to one vote. This participant is a fan of Justin Beiber, and I wonder if choosing the pop star's name will nevertheless compromise the participant's anonymity.

“Do you have any other names you could consider?” I ask him. 
"Yeah," he pauses. "Maybe not that one. I have to think about it."

Music is still seeping in under the closed door. Outside someone is singing "O Canada." One participant darts toward the door, his informed consent form in hand. He turns to me, "I gotta go," he slaps his hand to his chest patriotically. "This is my song."

\section{Disability and contemporary neoliberal interventions}

I would like to make clear that although this dissertation attempts to re-write certain assumptions about how disability comes to be in the world, and the possibilities of being in-relation-to disability, the real-world affects of globalization and neoliberalism on labeled people in Canadian contexts are not up for re-theorization, and are, instead, the context in which this thinking takes place. Therefore it is necessary to work through these types of poststructural theorizations in ways that account for locations of disability in prevailing locations of production, and to continue searching for what it is that "continues to impede the evolution of equitable conditions of possibility" (Shildrick, 2009, p. 1).

\section{Disability and ("entrepreneurial") citizenship}

The neoliberal agenda is inherently a normative agenda. The neoliberal agenda mirrors biomedical bodily constructs in its attempts to fix, remove, and individualize people understood to be hindering cultural "progress" and thus creates socio-economic conditions that bring up questions of citizenship. As Eagleton (2000) explains, culture has much to do with being a person and politics has to do with being a citizen — there is a difference between civil society (how people actually are) and the state (how privileged people wish to represent themselves and 
others) (p. 8). Approaches to citizenship in Canada, then, amount to conversations about rights and participation in society. In Canada, these societal rights and participation are a point of contention for labeled people who Prince (2010) calls "absent citizens" because their cultural locations tend to be outside of these spheres. Prince locates disability, including intellectual disability, in pockets of thought across the country — including government and charity-based organization thought — and assesses disability through "a politics of recognition" (p. vii) ${ }^{51}$.

Citizenship has much to do with how life experiences are managed as people access state and private services (Prince, 2012) ${ }^{52}$. In other words, citizenship is less defined by who you are than by your cultural location - your proximity to social safety nets and how many resources you cost versus how much you give back to the economy. "Neoliberalism promotes ... troubling notions of citizenship," Prince (2012) writes. "The personal tragedy, charitable, and medicaloriented notions of citizenship converts Canadians with disabilities, respectively, into citizens with spoiled identities, as supplicants and as sick patients" who are costly to healthcare and other state-run systems (p. 6). These notions are leftover ideas - modernist Enlightenment thoughts being dragged into contemporary disability discourse. Thus, neoliberal acknowledgement of citizenship in Canada holds up false rhetorical separations between the economic, political, social, cultural, and personal parts of disabled people's lives. These separations consequently downplay interconnectedness and intersectionalities which, in

\footnotetext{
${ }^{51}$ Prince coined this phrase because his analysis of Canadians' attitudes and beliefs about labeled people up to 2009 (using government reports such as the 1998 report, In Unison: A Canadian Approach to Disability Issues by federal, provincial, and territorial ministries of social services to describe how citizenship is framed and erased in processes of policy development) indicates that although attitudes toward labeled people are shifting (improving), Canadians are still reluctant to count labeled people as citizens.

${ }^{52}$ For example, applicants and recipients of state welfare services are often viewed as one-time visitors whose requests for help - via social safety nets such as food banks, the Ontario Disability Support Program, and homeless shelters - are processed through a wide web of administrative techniques that tend to ignore people's full social and economic experiences (Prince, 2012, p. 8).
} 
poststructuralist thought, are important in understanding how systems come to be and how they work on people today.

\section{Community living as neoliberal response to disability}

One life experience navigated through citizenship is employment. Participation in the workforce forms a large part of people's identities in contemporary Canadian contexts (Galer, 2012). Being employed is, for many people, a personal identity goal. This goal is, in part, driven by the notion that it is a personal responsibility to avoid, or remove one's self, from state-sanctioned incomes or social supports. Galer (2012) points to tension between Canadian disability politics and this neoliberal identity dilemma:

Whereas disability activists fight for the construction of empowered disability identity instilled with rights-based protections, many people with disabilities identify with the [neo]liberal individualism upon which participation in the capitalist labour market is largely based (n.p.).

Harvey (2005) goes even further, arguing that because neoliberalism's goal is to bring all people into the domain of the market, it is responsible for much of the "creative destruction" that he describes as "ways of life and thought, reproductive activities, attachments to the land and habits of the heart" (p. 3). This location outside of mainstream employment also describes the setting for this research, which takes place in a Community Living Toronto day program. Community Living mandates are often informed by the Independent Living Movement (ILM).

Acknowledging these mandates is important because the research that will unfold hereafter takes place under the ambitions of Community Living agendas. As Dossa (2005) describes, core 
principles of the ILM include rights-based notions of living outside of traditional patient roles and institutions to instead become independent consumers ${ }^{53}$.

Indeed intellectual disability, and identity politics within disability studies as a theoretical concept, is informed by citizenship, human rights, and the socio-economic circumstances in which people find themselves. Prince (2012) argues that Canadians generally do not think of disability in a way that combines economic and rights-based thought. Common messages about disability and employment are served up in a "soft" politics of recognition rather than in a "substantive" politics of redistribution (p. 20). Even while a social model-led shift has occurred in Canada in understanding disability as a socio-political concept, policy related to employment support for labeled people remains individualistic (Jongbloed \& Crichton, 1990 in Shier et al., 2009 , p. 64$)^{54}$. Prince (2012) also points out that much Canadian disability activism is closely connected to the state through mainstream political activities, as well as through dependence on federal and provincial governments for funding ${ }^{55}$. What we know is that in spheres of employment, labeled people have not historically been seen as worthy of investment (Dowse, 2009, p. 377).

53 “"The latter would lead to empowerment of individuals through choices such as where they lived, how they spent their money, and what opportunities to pursue for gainful employment. What is overlooked here is that disabled people have restricted choices dictated primarily on financial constraints," Dossa explains (2005, p. 2532). The financial constraints, of course, develop because disability is "Othered" and thus people with intellectual disability labels are considered unemployable members of the contemporary deserving poor. Therefore they remain candidates for, and often recipients of, provincial welfare programs.

${ }^{54}$ Michael Shier, John Graham, and Marion Jones (2009) recall many stories to this end as articulated by 56 people with intellectual disabilities in Regina and Calgary. Their work suggests that securing employment in the labour market is dependent on "normate" perceptions of labeled people, despite policy (both constitutional and institutional) protection. Again, labeled people are left behind as "absent citizens" (Prince, 2010).

55 "The disability movement has some faith in the efficacy of public action for alleviating poverty, tackling inequalities, and promoting accessibility," Prince writes (2012, p. 15). However, he points out that "in contrast to service organizations, such as charitable agencies and self-help groups, disability movement organizations are political in outlook and not therapeutic, of the disabled rather than for the disabled ..." (italics mine) (p. 4). 
Neoliberalism was an attempt to avoid the catastrophic conditions that threatened the capitalist order during "the great slump" of the 1930s (Harvey, 2005, p. 9). Failure to work was — and still is - read as individual failure to fit into society by meeting the needs of capitalist progress. Or, worse, failure to work has been read as a person's fault for "slowing" down the progress of other household members who are hindered from working because they must care for dependent family members, implicating those in-relation-to as also liable for disability's apparent shortcomings (Galer, 2012; Snyder \& Mitchell, 2006; Taylor, 2004). As capitalism has evolved so too has impairment and perception of disability (Ignagni, March 7, 2015). There are some Marxist lines of thought that suggest disability as a concept — "disability" as a way of labeling and arranging people and bodies — is the result of modern capitalism (Russell and Malhotra, 2009, in Galer, 2012; Snyder and Mitchell, 2006) ${ }^{56}$. Consider, for example, the "Fundamental Principles of Disability" statement by the UPIAS in 1976, which is foundational to social model ideology. It states,

... the particular form of poverty principally associated with physical impairment is caused by our exclusion from the ability to earn a living on par with our able bodied peers due to the way employment is organized (UPIAS, 1976, in Barnes, 2000, p. 442).

The social model, as a materialist perspective, links impairment and disability to "modes of production" or social organizations of work (Barnes, 2000, p. 444). So too Canadian disability activism is rooted in this historic, rights-based, socio-economic struggle.

\footnotetext{
${ }^{56}$ This rise of industrial capitalism in the early twentieth century called on particular bodies to work (often physically, linking the social model's emphasis on physical disability to neoliberal capitalism). To paraphrase Wendell (1996), the awards of these struggles, including inclusion in social arenas such as employment, are charged with the strength of the cultural demand that everyone meet particular, modernist bodily standards (p. 47).
} 
Today, however, many sectors of our economy have become known as the "information economy" or the "creative economy" (Florida, 2005). In this type of economy employers are increasingly concerned about recruiting innovative, well-educated, technology-savvy people to work in high-tech, knowledge-based, creative-content industries that drive much economic growth (Florida, 2005). These days, technological development is usually applauded for advancing "progress." As Dowse (2009) explains, information technologies strengthen political projects on a global scale as well because of the international web presences of advocacy organizations (p. 572). Therefore, a skill such as technological literacy is an important part of today's globalized neoliberal and “entrepreneurial citizenry" (Wisniewski, 2012) — an important part of being employable with a particular impact on people labeled as intellectually disabled:

Those whose intellectual impairment is deemed by bio-medico-psychological assessment to be so significant that no technology of agency or citizenship will effectively equip them for productivity are relegated as the 'burden' of carers, including families and service providers (Dowse, 2009, p. 577).

Not only do labeled people have to contend with the physical barriers of work: inaccessible environments, transportation, and communications systems, and so on as Colin Barnes (2000) names. Now people need creative, technological skills to work. Further, as the skills people need to become employable evolve, what it means to experience disability also changes if we think about lack of access to technology and lack of literacy in the UPIAS's terms of disability as "loss or limitation of opportunities to take part in normal life of the community on an equal level with others ..." (UPIAS, 1976, in Tregaskis \& Goodley, 2006). There's that emphasis on normality once again. Normalcy has made its way from pre-modern thought to contemporary critical disability studies thought; it is written into the core principles of disability activism and disability studies. 
The question we are left with, then, is whether or not the neoliberal interventions so often promoted in the name of progress are truly beneficial. It could be argued, for instance, that Community Living models, such as those employed by Community Living Toronto (CLT) whose mission is to change "the lives of people with intellectual disability by giving them a voice and supporting their choices where they live, learn, work and play," do their work through neoliberal agendas (“About us," Community Living Toronto). Because of CLT's emphasis on independence and access to personal, private property and work-related life choices, Community Living movements identify people as outside of the market and strive to bring them into the market in the name of inclusion, participation, independence, and agency. It is important to keep CLT's mission statement in mind moving forward in order to contextualize the participants in this study. Their writing takes place at a CLT day center, which is where many of the participants spend the whole work week, or part of it, because of their exclusion from the labour market. CLT is one of their primary cultural locations, and it is the only location they occupy during the course of this research. While I suggest that this cultural location does work in the interests of the participants mentioned here, it must also be viewed through a critical lens by identifying that it symbolizes tension between contemporary neoliberalism, disability politics, and research; CLT resists notions of disability as a personal problem and a private issue while at the same time striving for personal/individualized normalcy. Certainly, it is difficult to critique notions of impairment as personal problem while simultaneously striving for individualized normalcy.

To wind down I turn to S. Swenson (2008), who explains that disability rights embrace neoliberalism while at the same time fighting against it — always working within neoliberal frameworks (p. 627). Taylor (2004) makes this point as well, reminding us that disability does not have the "cool" factor of sexier movements like Black Power. "Many of the supports we 
fight to fund were privatized many years ago, and by us" (p. 627). In other words, encouraging people to have "normal" lives, "normal" jobs, and to be "normal" citizens without questioning the socio-economic conditions of possibility for us to recognize lives as "normal" is connected to efforts to normalize the body. Yet, the re- thinking of normality involved in overturning this type of cultural imaginary is colossal, and neoliberalism's conceptions of the body hold the same determining authority as did pre- modern/faith-driven conceptions of the body and the secular-biomedical faith in modern understandings of the body. To this end, Duggan (2004) makes an important observation:

Neoliberalism's avatars have presented its doctrines as universally inevitable and its operations as ultimately beneficial in the long term - even for those who must suffer through poverty and chaos in the short term. In other words, neoliberalism is a kind of secular faith. Its priests were elected by no one, and are accountable only to the global elites whose interests are promoted by its policies (p. xii).

\section{"Giving voice" and being on the "winning” side of neoliberalism}

It is not uncommon for researchers to be referred to as "giving voice" to those they research, and the action of "giving voice" is connected to neoliberalism. As Davies (2014) points out in his bibliographic review of neoliberalism, "distinctive neoliberal policies are those which encourage individuals, communities, students, and regions to exert themselves competitively, and to produce 'scores' of who is winning and losing" (p. 315). This act of "giving voice" comes from participatory homes of speaking with and colonial hopes of speaking for — it is a way of assimilating the "losing" others into the realms of the "winning" normates.

Disability activism and research often aims to produce those on the "winning" side of the neoliberal social binary. For many labeled people across Canada, access to citizenship means access to social inclusion and self-sufficiency via education and employment "rather than the alternatives of shelter workshops or voluntary service masquerading as competitive and fair 
wage-based work" (Prince, 2012, p. 11). Therefore a push toward normalization — a push toward giving and thus having voice — is a way of advocating for people experiencing low access to labour market participation (Harris et al., 2012, p. 824). Yet, as Sherene Razack (1993) demonstrates in her paper about what can happen when stories are treated uncritically, the act of telling a story (or "having voice") is not automatically empowering.

The problem of "giving voice" is a problem of agency. Some research is fuelled by the ambition to "give voice" where there is a real or imagined lack of perspective, particularly if oppressed people — presumed to be silent or silenced — are in the equation. To have voice within material, humanist discourses is to have agency — "to take oneself up as a knowable, recognizable identity, who 'speak for themselves' ..." and can rationalize and explain the moral choices behind their actions (Davies, 2000, p. 56). This voice is also expected to perform well: it's not enough to break silence; the silence must be filled with normative articulation and expression in order to be read-able and therefore productive. Any failure to access normative speech is subject to immediate pathological intervention, as Erevelles points out when she discusses verbal language (March 12, 2015). This assimilative view of language is a normative view that serves, again, to construct disability. Indeed, it is not linguistic incompetence or "untranslatability" that creates disability, but rather cultural locations of intolerance toward “untranslatability” (Erevelles, March 12, 2015). Emancipatory research approaches are often invested in the notion of "giving voice." Implicit in this impulse to "give voice" is the idea that not having a voice negates human subjectivity and citizenship ${ }^{57}$; what follows is an impulse, as Erevelles describes, to break the silence. Drawing on the Arudhati Roy's (2004) words, Erevelles

\footnotetext{
${ }^{57}$ For oppressed groups in particular — such as labeled people who are routinely asked to explain themselves to non-disabled people by fronting invasive questions such as "What happened to you?" or "What's wrong with you?" — the onus is on them, as object, to "voice" their particular positonalities and ways of being in the world (Ignagni, March 7, 2015).
} 
(2015) cautions that "there really is no such thing as the voiceless" when people are deliberately silenced and "preferably unheard."

Breaking silence is another method of keeping up with normalcy. And the pressure to be normal is the work of a broader neoliberal movement that attempts to keep up with capitalism. Neoliberalism is an attempt to re-make personal and social life by letting inequalities drive personal notions of worth and agency. As Davies (2000) explains, agency is synonymous with being a person; without agency the subject is lacking full normalcy and constituted as other, or opposite (p. 56). This perspective sets up the prospect of silence as a problem assigned to particular persons, and "giving voice" as a solution — rather than acknowledging silence as "the absolute limit of discourse" or "the other side" of discourse that remains related to all discourse, as Foucault (1978) suggests. In other words, rationalistic reactions to intellectual disability refuse to accept silence as valid presence and instead the subject/object seemingly without voice is immediately discredited as apart from normative human conditions.

When Foucault (1978) paints silence as "less the absolute limit of discourse" than the "other side" of it which has its own functions in relation to the power-discourses that form our socio-cultural understandings of the world and being in the world, he is suggesting that silence not be taken as invisible nothing-ness but rather that it be explored as a site of validity (p. 27). I pull on Foucault's words here in order to pressure the perceived goodness and utility of "giving voice" as a research action, and to suggest that receiving silence may be a less invasive method of research with a crip edge. "Giving voice" makes the researcher the hero of her own story (Lather, 2007, p. 38), running contrary to a cultural model of disability praxis that would rather silence disabled research objects than allow the researcher such trump power. From a feminist 
poststructuralist position, the project of "giving voice" is an outdated mode of assimilation into normative discourses:

All rights-based equality claims arising from the recognition of the limits of the modernist model of sovereign selfhood, ... are double-edged in their putative appeal, offering material gains at the cost of normalization and the covering over of difference (Shildrick, 2009, p. 11).

And from a crip perspective, "giving voice" simply (or complexly) isn't an ambition that fits people literally and figuratively without voice. The notion that "voice" can be given, and that the giver can (let alone should) position herself in the privileged position of imparting such a gift, potentially overlooks more complicated ambitions to re-think constitutions of agency.

The potential value of "presence" over "voice"

Perhaps a more useful approach to being in-relation-to people who are read as lacking "voice" is to focus on the invisibility of voice not solely as manifestation of personal deprivation but as one of multiple ways of being with its own value in its location on the "other side" of dominant discourses (Foucault, 1980, p. 27). Further, perhaps sliding away from the privileged act of "giving voice" is to re-direct focus on what is taken when "voice" is given, as well as what happens when bodies refuse to adopt "voice" as offered and instead remain apart from normative discourse and thus outside of common understanding; that means focusing on the failure of the “giving voice” project itself(Visweswaran, 1994, in Lather, 2007, p. 38).

In attempting to rethink discursive constitutions of agency rather than "give voice," researchers can re-orient themselves to the project of human-based research through affect, as well — through feeling presence rather than absence when given access to the apparently voiceless subject; through allowing authorship in multiple forms, including silence, and realizing that 
humans are made up of straying lines of meaning that sometimes disappear (in this research these lines will be known as "untranslatable" types, later); and through understanding that any individual can "go beyond the given meaning in any one discourse and forge something new" even if the new "something" remains unknown, unrealized, or manifests as what "might be" (Davies, 2000, pp. 66-67).

It is through all of these types of re-thinking that disability is finally pushed into the postmodern, which makes room for the polysemic "intertextuality" of disability — the understandings and queries of how disability, even in moments of silence and invisibility, is approached and received (Barthes, 2007, p. 82). Following Jacques Derrida's (1976) concern with ways of thinking about how meanings are established through presence and absence, the feminist poststructuralist thread that tugged us through modernity can, with the aid of some postmodern perspectives, move forward with the realization that although normativity needs disability to hold up its own definition just as discourse needs silence as its "other side," disability is a cultural arrangement that transgresses materialist notions. In other words, any attempt to transgress materialist notions that compound and build the phenomenon of disability — an attempt such as "giving voice," for example — undermines consciousness, ways of being, the nature of reality, and the lived-in body as "unmappable" (Jameson, 1991). In moving into an era where it is no longer possible to tell singular, unified stories about society and the body, disability empiricism transforms again. We drop the preoccupation with giving voice, and instead trouble traditional epistemological foundations of rationality by making space for presence where "voice" is sometimes absent. 


\section{Chapter 5: Necessary interruptions: Triple labeling, research ethics, \& vulnerabilities}

Exploitation and compassion live side by side, often in the same person, at the same time. - Vernon, 1979, p. 36

Researching intellectual disability is a way of confronting the limits of research, the constraints of researchers, and the strain of the researched. To borrow Lather's (2007) words, research involving intellectual disability forces researchers to confront "things that are easy to walk over" (p. 54). There is lots of room for vulnerability to emerge here, and it does. Therefore it is important to distinguish between vulnerability as a label institutionally imposed on certain bodies and vulnerability as an affect of being tied up in this label. From a feminist poststructuralist perspective, these "things" that can be overstepped not only include the people involved in the research, but also the changing positions people occupy, relationships that form and diminish, trust-building that is never quite solid, and the precarious spaces between and beyond traditional empirical approaches to research that build on old knowledge about the self, the other, and the

body. Researching labeled people, even when the research is primarily directed at the label itself, is, in many ways, a clumsy dance between exploitation and compassion as Vernon suggests in the epigraph above.

Vignette: Naming the participants; naming the research

Raymond decides he doesn't have any questions. He'd like to sign the informed consent form now. Three of the other group members form a line behind him. I didn't even see them get up, and I realize a video camera would come in handy if it were allowed, and if I'd thought of it sooner. One by one, I read through each consent form. Some people agree to sign on the spot, 
others don't. Ross gets up and hands me an already-signed form. "Yeah, I like it, I do," he says, nodding and smiling. "Uh, what are your plans for Thanksgiving?"

"For Thanksgiving?" I'd forgotten about the holiday, too caught up with everything to notice context, detail, description. So much for observational participation. Phenomenology forgotten. I cringe. Am I supposed to be doing phenomenology right now? Well, shit.

"I'm going to spend Thanksgiving with friends, " I say.

Once again, ABBA's "Dancing Queen" fills the room. Notebooks are spread across the table, and bits of paper seem to be flying as each writer spreads out his and her scraps, books, and words. Chairs are squeaking outside as people set up tables for a turkey lunch. The scent of gravy hangs in the air. Our door is closed, but many people who walk by gaze in at us through a window that faces into the hallway.

"With friends?" someone else asks, then, stopping short, "How do you spell Grandmaster $B ?^{\prime \prime}$

Right. I haven't spelled that yet. I turn toward the whiteboard. "Are you saying Grandmaster B or Grandmaster P?"

"B"

"P?"

"B, as in butterfly."

As I'm writing on the board, another voice comes from behind. Mr Clark Kent has chosen his pseudonym and written it on the form. "Okay I'm done," he announces. "You should take a picture." 
"Can we write a poem?" Grandmaster B has chosen his fake name, as well, and written it on the informed consent form. I lean over to sign it, feeling as though I am leaning into a windstorm of overlapping conversations. The two women in the room are silent.

"For Thanksgiving," Ross continues, "with my family."

"Yes, what kind of poem?" I ask.

"It will go like this," Grandmaster B takes a breath: "Sun will shine on you always be there for you love will always be around you."

Triple-labeling in disability-based research

With empirical dangers at hand, such as the many risks of being involved with research, it is no surprise that labeled people are commonly labeled "vulnerable" and their competencies called into question. While all people who participate in research experience various degrees of risk, as Van Den Hoonard (2002) points out, even though some people are indeed vulnerable, "in some cases this judgment cannot stand the test of reality" (p. 14). Because intellectual disability, vulnerability and incompetence are typically synonymous concepts for institutional/government ethics protocols, labeled people have been — and continue to be - excluded from knowledge creation about their own lives (Ignagni \& Church, 2008; Goodley \& Moore, 2000). In other words, under formal ethical research procedures disability is brought into being as a taken-forgranted vulnerability. This triple labeling (as intellectually disabled and vulnerable and incompetent) may be protective, and may be imposed as a result of "moral panic" (Fitzgerald, 2005, in Holland, 2007, p. 899). Still, the eclipse of these labels - disabled, vulnerable and incompetent - is a paternalistic construction of intellectual disability that informs ethics policy. This construction may not be representative of the multiple lived realities of people who may (or 
may not) wish to participate in research about themselves, but do not wish to conform to normative informed consent procedures.

For instance, Van Den Hoonard (2002) suggests that informed consent forms tend to exaggerate risk (such as the risk of boredom, which applies in many life situations that do not require arduous paperwork), and the effect of waxing poetic over the form overcomplicates the researcher/participant roles and power relations. Further, someone for whom reading and signing an informed consent statement is not an accessible process based on literacy features (and/or the inaccessibility of the paperwork) is not necessarily incompetent or vulnerable. This kind of paperwork may be exhausting or intimidating. What's more, a person's ability to consent can fluctuate, and this fluctuation is rarely accounted for through one-time-only consent procedures (Ellem et al., 2008, p. 504). Such statements in other contexts have been viewed as too formal, and/or as carrying Westernized colonial undertones as Linda Smith (1999) explains in her work on decolonizing methodologies. Thompson (2002) argues that for researchers concerned with justice, there must be processes of "informing-for-consent," which means that researcher must be informing during each stage of the research and must understand that consent fluctuates (Tymchuk, 1997 in Thompson, 2002, p. 95). Further, he suggests that informed consent forms should be tailored to each participant based on her or his comprehension and decision-making skills (p. 97).

Arguably the procedures that accompany the informed consent process are more suitable for health- or science-based research than areas of social science where research might be incomplete without the participation of people. Researchers pursuing any angle, however, may hold views on disability contrary to institutional protocols if they understand intellectual disability as a materialist, culturally constructed label imposed on people otherwise capable of 
risk-taking (including providing consent) without expert evaluation (or assumption) of vulnerability and in/competence. Nevertheless, researchers are tied to the institutional procedures that govern their work, and the effect is that researchers' praxis ends up (re)producing the institutionalized expectations that determine their positions (Evans et al., 2009, p. 899; Rapley, 2004; Van Den Hoonard, 2002).

For example, the first steps of this project involved communicating through a series of emails with people from Ryerson University's REB outlining their concerns for my proposed research protocol. I highlight this experience in order to offer an outline of this project's methods, and to point out that they are embedded in the risks of triple-labelling. On Sept. 17, 2013, the REB emailed me and outlined 18 concerns about my research relevant to each section of the protocol, most of which are simply too lengthy to draw out here. I had some difficulty responding to these concerns. For example, in the email, the REB representatives pointed to "cognitive" ability directly when they asked if I had suggested a three-week recruitment process "due to the cognitive abilities of potential participants" (Sept. 17, 2013). I attempted to explain that because I only meet with potential participants once per week, a three-week recruitment process would give me time to hand out the informed consent forms, and respond to anyone's questions in the following two sessions before the forms would be collected:

While three weeks may seem like a long time, it is important to remember that I only have contact with potential participants once per week. The participants do not have access to me, nor I to them, via email, telephone, or any other method .... The three-week routine is meant to give people ample opportunity to be introduced to the idea, and opportunity to develop any questions. The goal here is not to put anyone on the spot .... It is important to remember that my committee, the REB, and CLT staff have been familiarized with this project for months or longer, and I feel it is only fair and respectful to allow participants some time to get used to the idea, formulate some questions, and be in touch with me, my supervisor, an REB representative, or CLT staff - which could, in some cases, be conversations that need to be scheduled in advance. (Jones, Comments to the Chair, Application for Ethics Review of Research Involving Human Participants, 2013-269). 
The values inherent in many of the REB's concerns are embedded in the paternalistic shades of dis/ableism described earlier (Campbell, 2008). The Board's concern that a three-week recruitment process could be a response to "cognitive ability" suggests an assumption that the potential participants are too slow to make immediate decisions. The REB seemed to be suggesting that although they required weeks of briefing on the project, potential participants would be expected to perform on-the-spot consent-based decision making. On the whole, the three-week recruitment phase was designed to reflect an understanding that labeled people may not be immediately given the opportunity/autonomy to participate on the cultural assumption that they are non-writers, or that they may experience undue pressure to participate if the people around them think of them as "good" writers (Ellem et al., 2008, p. 501). The three-week recruitment timespan was meant to give people time to make informed decisions based on how they felt they may or may not fit into the research.

Also, the REB expressed concern that people would not be able to — or are not "normal" enough to - demonstrate, articulate, or possibly even feel discomfort without my constant monitoring of their behaviour. The REB seemed concerned that writing might be an upsetting activity for people whose perceived "cognitive ability" seemed so low that they may not display signs of being upset. I countered this suggestion by pointing out that participants may speak, write, or think about thoughts of discomfort in the same way one might in many research projects, daily conversation, or writing exercises - research always involves risk (Holland, 2007, p. 899). Here, the REB also requested an outline for each writing session, which was, for me, a peculiar task of imagining as the group did not then and does not now abide by any such schedule. At any rate, I suggested to the REB that our research sessions would be structured as follows: 
Using the example of a scheduled session, below, the researcher might attempt to open a conversation about a recent, specific instance in a story and how it emerged in the writing this type of question is based on an experience and/or a moment rather than on generalizations about the story itself.

Week 23 - 9:30 a.m. to 11:00 a.m.

1. Greetings and check-in

2. Review of "Things to Remember" section of informed consent form

3. Activity: Analysis

O Choose some excerpts of your own writing that are meaningful to you, and discuss why.

4. 10:30 a.m. break

5. Activity: Analysis continued

6. Check-out

When I wrote out this 24 -week schedule I knew that because I had never before asked potential participants to adhere to a writing schedule with firm parameters it would not likely be well received. However, I did not feel it would strengthen my case under any circumstance to reveal my "professional intuition," as the REB would later call it, that such procedures would be entirely ignored and rendered useless (Sept. 17, 2013). As Holland (2007) points out, one of the inherent implications of this kind of concern is that the researcher automatically poses a risk to participants (p. 898). Yet, from a disability rights/crip perspective, concerns about risk must be balanced against a person's right to participate, including right to risk (p. 899). It has even been suggested that past abuses in biomedical research have created a "moral panic" that streaks through ethics review processes and creates barriers for nonmedical researchers, though arguably, in my case, the reaction was less panic-driven and more problem-oriented (Fitzgerald, 2005 in Holland, 2007, p. 899). 


\section{Navigating research relationships}

"Can I sign now?"

"Um, yeah, you can. I just want to make sure you understand - "

"I do understand."

"... Can I just go through it with you?"

- Field notes, Dec. 4, 2014

As with all relationships, the dynamics of friendships and researcher/participant relationships are uncertain. It is from within these relationships that researchers capture the data needed to "undertake our thinking," to identify possibilities and meanings, and to practice our work (Lather, 2007, pp. 18-19). Relationships are in constant motion, and the path toward ethical understandings of the Other is indirect and constantly shifting. Their movement places relationships in a position of unreliability and fragility, yet they are often the basis of empirical research and are, as Lather (2007) repeatedly describes, the spaces where researchers "get lost" in praxis.

Friendships, which are a deepening of the researcher (subject) and participant (object) relationship, are rife with ever-changing dynamics, unspoken questions, and moments of wonderment. In research contexts, researchers move away from fieldwork and toward institutions that propel them in career building. Participants remain in the field or move away from it to continue with their respective lives, with or without emancipatory impact from the research. Ellis (2007) calls this shift a "split" in researcher identity (pp. 10-11). One way to mediate this "split" is through reconsidering processes of informed consent. A strategy such as "process consent," for example, involves the researcher checking in from time to time with participants to ask whether or not they want to continue with the research, and to remind them that their interactions are part of formal research (Grafanaki, 1996 in Ellis, 2007, p. 23). As 
Smith (1999) points out, asking for consent only once, perhaps through an informed consent form, implies that consent is constant — that it cannot come and go (p. 136). The intention of "process consent" is to avoid secrecy, to gauge participants' perceptions and interpretations of the work at hand, and to develop an answer to a question Thompson (2002) recommends all researchers ask themselves repeatedly throughout the research: "How can the researcher tell if participants understand that quitting the research will not affect their relationship with the researcher/institution?" (p. 103).

Assessments of competence also re-route this discussion toward relationships. Ellis (2007) holds that researchers naturally become friends with those they study, which is dangerous because the achievement of institutional ethics approval may leave researchers with a false sense that they are actually doing ethical research as these friendships develop. In this way, informed consent procedures tend to place risk in front of the study rather than throughout and following the research. Indeed there is no guarantee that researchers will do the "right" or ethical thing. with or without the informed consent process, before, during, or after the research process/relationships (patterson, 2008, p. 24); institutional approval for ethical research does not equal ethical research, but simply assumes researchers to be ethical (Somerville, 2006, p. 5). To this end, Thompson (2002) argues that friendship is an ongoing emotional risk for research participants, and he suggests researchers can reduce risk by not investing "too much" in a relationship that may not be mutually beneficial (p. 100).

Under the cultural model, which values non-hierarchical relationships (presumably including friendships), outsider researchers are greeted with suspicion. This model asks of researchers: Are you trying to help? And it criticizes any attempt to "help" as a misconception that labeled people are not capable of helping themselves (Snyder \& Mitchell, 2006, p. 190). 
Further, for triple-labelled people, a real research risk can be the researcher's ableist perception that participants may be competent enough to participate in the research but too incompetent to understand output data and research conclusions. Below, Ellis (2007) recalls this dangerous naïveté in her self-reflexive account of doing auto/ethnography in two fishing communities as a graduate student. Some community members later angrily confronted Ellis. To them, her research appeared to exploit secrets that were cultivated during moments that blurred the lines between research and friendship.

Did I say before any interaction, 'Hi, nice to see you again. Now remember I'm a researcher'? Talk about inhibiting a conversation. I felt uncertain about when and who I should remind because the boundaries of this peninsular community, and who was included in it, were ambiguous. Likewise, my role was unclear even to me. Although I was a researcher, I also saw myself as a friend to many people there, and sometimes I felt and acted like family. ... It embarrasses me now; however, at the time I sometimes found myself thinking that because most of the people with whom I interacted couldn't read, they would never see what I had written anyway and, if they did, they wouldn't understand the sociological and theoretical story I was trying to tell (p. 8).

As it turns out, thinking of research as a peninsular activity — as isolated, un-alive, and unable to move outward from the researcher and into the hands of the researched - is a great ethical risk that the relational model would urge researchers to consider.

Acts of "process consent" may help alleviate such risks (Ellis, 2007; Smith, 1999). Smith (1999) points out that asking for consent only once, perhaps through an informed consent form of the kind I was expected to use in this research, implies that consent is constant - that it cannot come and go (p. 136). "Process consent" tries to avoid secrecy by reminding participants of research intentions and asking for consent repeatedly before, throughout, and following fieldwork. Thompson's (2002) key question, above, was reiterated to me by the REB in the September 17, 2013 email response to my application for research: 
What is the evidence that informs your professional intuition that the group members are all competent, and able to understand the nature of the research project and what it means to be able to take action and leave the group at any time, returning if and when they choose to...? (September 17, 2013)

I believe this question comes from an important place of concern ${ }^{58}$. The REB's question here is significant in securing the safety of participants, ensuring empathy for participants, and assessing participants' interpretation of research situations. Yet, the question is problematic; certainly there are people for whom reading responses to stress can be difficult — triple-labeled or not. The “correct" answer to the REB's above question assumes, and relies on, the researcher's willing and accurate assessment of participants' competence. It also implores the researcher - in this case me - to somehow demonstrate institutional qualifications ("professional intuition") to judge potential participants as in/competent.

Such professionalized understandings of in/competence are essentialized understandings of humanness (Rapley, 2004). While intellectual disability is understood as a "historically continuous, clinico-medical, thing-in-the world that can be "diagnosed"' by type (p. 31), competence follows as a quantifiable personal attribute that persons "carry around with them" to be uncovered by researchers (p. 50). Assumptions about defective competence are often assumptions about practical performance — such as "what it means to take action to leave the group" - rather than understandings of an individual's internalized, abstract knowledge. Rapley's (2004) writing is particularly relevant in this area for his linkage of competence with morality. He roots competence in Enlightenment thought as a high order of reason and

\footnotetext{
${ }^{58}$ Again, research subjects must be fully informed, capable of making decisions, and free of coercion and manipulation. In many ways the REB's question was simply reflective of Ryerson's Policy on Research Involving Humans (Senate Policy No. 51).
} 
rationality, while incompetence connects to lack of "good work habits" and being outside the category of "the fully ethical, confessing, human subject" (Das, Naglieri and Kirby, 1994, in Rapley, 2004, pp. 49, 76). Rapley's (2004) literature review also points to psychological research that determines in/competence and constructs a "speakable truth" about certain persons ( $\mathrm{p}$. 209). As Goodley and Rapley (2002) reiterate, "truths do not emerge out of thin air. They are tied to particular institutions (and related research practices) such as medicine, psychology and social work - the "psych-complex"' that local research ethics protocols are searching for to validate through researcher claims of participant competence (p. 132).

The cultural model approach prefers a more nuanced interrogation process of both researchers and participants; it would ask Thompson's (2002) question differently: How can participants tell if the researcher knows what she is doing, and whether or not they would like to engage with her? This rephrasing echoes Smith's (1999) troubling of the common ending to methodological reports that leave us with more questions than answers questions such as: Whose research is it? What form will it take? Who will it serve? In her overview of the relationship between post-colonial research methodologies and indigenous peoples, Smith also takes aim at the researcher:

Is her spirit clear? Does she have a good heart? What other baggage are they carrying? Are they useful to us? Can they fix up our generator? Can they actually do anything? (p. $10)$.

Discussions around the concept of competence, choice, and risk also depend on the created notion of the Other, for whom risk is always involved - that is to say that it takes "competence" to diagnose incompetence (p. 11). And, along a more ontological vein, Mike Evans (2009) and his co-authors ask, "why would research with 'Others' mean they are no longer produced as 'Others'?' (Fischer, 1997, p. 4 in Evans et al, 2009, p. 899). 
Such questions are useful both in allowing REBs to do their due diligence, and to opening up questions of humanness: Is it acceptable for me to explain that the "professional intuition" that informs my judgment of others' competency is one stemming from a critical disability studies paradigm that considers labeled people to be human and therefore capable of independent decision making? Is it okay for me to suggest that the wider problem here might be my own incompetency in understanding their sometimes alternative or silent means of communication if and when participants do choose to "take action and leave the group"? What kind of space is offered here, if any, for me as a student and an applicant, to insist on Smith's (1999) conviction that competence is contextual when I cannot necessarily be relied on to "fix the generator," as she might demand?

And with that, I, as a researcher, am positioned in a place of competence in comparison to my potentially incompetent subjects before anyone is even invited to participate. Yet, such questions are primarily useful because relationship building around the informed consent process as outlined by institutional entities relies on positivist traditions of Othering triple-labeled people as incompetent objects of research rather than people who have a right to become involved in a research process on their own terms. Indeed, the informed consent process tends to disempower "vulnerable" populations by discrediting their judgment and handing the responsibility of assessing participants" competencies over to the "experts" who must work within the restrictions of the very institutions that disavow the participants by claiming they are vulnerable and incompetent in the first place. In response to the REB's question, I attempted to delicately explain my "professional intuition" as one that assumed humanness in the face of intellectual disability: 
... the evidence that informs my professional intuition that the research group members are all competent and able to understand the nature of the research project and what it means to take action and leave the group at any time ... spans beyond institutional qualifications and into my personal experiences living and working alongside people with intellectual disabilities. My background in Critical Disability Studies informs my understanding of adults with intellectual disabilities as competent human beings able to understand the nature of a research project and as capable decision-makers when offered the time and opportunity to proceed with informed decision making (Jones, 2014, Comments to the Chair).

In many ways I feel lucky to have gotten away with this response; after responding to the REB's 18 email-based inquiries my research proposal was accepted and the research could begin. In upcoming conversations of informed consent, it is important to recall that qualitative research remains bound by institutional protocol that protects the knowledge industry of the university. Informed consent continues to promote core assumptions associated with the medical model: the objectivity of researchers and the naïveté of the researched. The perpetual exclusion of people who do not subscribe to these informed consent processes re-inscribes disablement (Thompson, 2002, p. 96).

\section{Reaching for informed consent in cultural locations of supposed incompetence}

Disability is a category of human bodily variation that is discursively constructed as quasihuman and abnormal through modernity's faith in interventions aimed at fixing, regulating, and managing deviant bodies (Garland-Thomson, 2013). One of the supposed characteristics of disabled people that disqualifies them from humanness is incompetence - especially if they are understood to be without language and therefore objects to be spoken for (Carlson, 2010; Prendergast, 2001). For people labeled with intellectual disabilities in particular, issues of competence play an enormous role in the process of obtaining informed consent. As Smith (1999) points out, discussions around the concept of intelligence, discipline, and achievement 
depend on the created notion of the Other (p. 11). It is through the modernist meta-narrative of normalcy that a fascination with the abnormal emerged, and most certainly people labeled with intellectual disabilities are at risk of becoming objects of this fascination for the dominant, ableist groups pushing them into categories of abnormality, of Otherness (Carlson, 2010). Undoubtedly, risk is involved in research that includes any "Othered" person or population. Social norms establish the viability of a subject, and in our Western context establishing norms comes at the cost of setting one concept apart from another. The modernist, eugenic myth of normality is a cultural meta-narrative that influences our understandings of our proximity to intellectual disability and preconditions contemporary life (Wendell, 1996).

However, as Thompson (2002) attests, competence is not an "all-or-nothing phenomenon" (p. 98). A radical re-understanding of competence through the cultural model might employ a relational ethical perspective to suggest that some people have degrees of competence that are higher in some areas and lower in others, and therefore require new methods of inquiry, and new methods of granting consent. Perhaps, for instance, disability scholars can observe Othered groups' techniques. For example, the research method called kanohi kitea, credited to Te Aekotuki (Smith, 1999), involves "the seen face" that is present in the community - the idea is that the researcher "come out" to things, make herself recognizable, involve himself before, during, and after the fieldwork (Smith, 1999, p. 119-120). Another potentially suitable method is that of discovering. Discovering is about learning about Western science and technology and making it work for a particular group. Smith (1999) explains that this method concerns the social construction of knowledge, and the nature of knowledge imposed upon bodies. The relevance to disability is especially evident in her brief discussion of "ethno-science," which allows space for "writing back" to science — through writing about encounter with science — as Bérubé (1998b), Devaney \& Molenhuis (2013), Ferris (2013), 
halifax (2009), Rice et al. (2015), and Wendell (1996) have done. It is important to note that such methods also offer opportunities for communities and groups to go rogue and proceed with research without an institutional stamp of approval. And it may be that the most meaningful locations for disability-based, person-involved research are outside of the institutional processes that currently guide much disability studies work. Falling in line with these approaches, the cultural model might adopt the research dilemma as an ethical challenge in establishing competence and therefore re-understanding informed consent as the performance of a cultural myth — the myth being that an entire group is incompetent, and therefore lacks the human civility that would deem the people in it available for decision making until proven otherwise by a researcher whose competencies are also unstable.

The making of triple-labeled folks as located in "obviously" undesirable” and vulnerable locations is a sinister process that ensures intellectual disability continues to emerge as the work of "experts" (Snyder \& Mitchell, 2006, p. 21). For example, as an early theorist of occupational therapy, Kielhofner (1985) wrote that people with intellectual disabilities fake behaviours to indicate competence beyond their means through actions such as pretending to read a menu in a restaurant (p. 387). Decades later, with the intention to re-specify competence as an ethnomethodological form of intersubjectivity that is negotiated rather than essentialized as a bodily characteristic of normality, Rapley (2004) and Goodley (2011) reviewed similar research assertions that use discourse analysis to assess competence. In one instance, Goodley and Rapley (2002) coined the term "acquiescence bias," pointing to segments from a 1981 study of people with intellectual disabilities wherein people were deemed acquiescent based on answers to unsuitable (or trick) interview questions. When interviewees answered "yes" to questions such as “do you know how to fly an airplane?" they were cast as unreliable, and this unreliability and 
dishonesty were said to be characteristics of intellectual disability (Sigelman et al., 1981 in Goodley, 2011, p. 111). The longevity of "acquiescence bias" is demonstrated in Kathleen Ellem et al.'s (2008) life history research involving ex-prisoners with intellectual disabilities. Ellem and her co-authors describe operating in and around assumptions that participants/coresearchers could not accurately tell their own stories:

The researcher interviewed a man who told a story of attaining employment in more different areas than was humanly possible in a short time. To question him on this, in order to get a more accurate account, may have been seen as threatening to his own sense of self and competence (p. 500).

The researchers ultimately dealt with this dilemma by including the man's "community worker" in the interviews - though that came with its own risks of putting pressure on sensitive content and reducing the participant's comfort. Here the researchers acknowledged that deferring to nondisabled outsiders (such as caregivers) contributes to participants' perceived lack of control over their own lives (Thompson, 2002, p. 102). Ellem et al. (2008) further argued that although labeled people's intellectual impairment may affect the accuracy of some details obtained during an interview, overall the life-changing experience of imprisonment is not one easily forgotten or misunderstood (p. 501). The point is that decades after "acquiescence bias" was established, researchers are finding ways to resist this kind of persuasive disablement and pointing out the problematics of engaging triple-labeled people in research rather than dismissing them altogether.

As Goodley (2011) points out, the conclusion that labeled people are acquiescent rather than, say, polite and amicable when faced with unreasonable questions from strangers, points to preconceived ableist conclusions inherent in processes of Othering (p. 111). Similarly, Kielhofner's (1985) subject looking at a menu may not have intended to "fake" behaviour, but was simply participating in the normative social behaviour of looking at a menu. Of course, we 
will never know. And our ongoing ignorance is the result — the risk — of triple-labeling. Yet, from an interpretivist viewpoint, there is no need to know; there is no absolute truth to strive toward. Following Rapley (2004), competence is not something that should be located within individuals, but is a product of social and relational networks. These examples illustrate how the identity of intellectual disability still drags around the politics of outdated, individualist research notions of incompetence and vulnerability when people are barred from participating in research about their own lives because they are not trusted to engage, or critique, processes —including that of obtaining informed consent.

The ongoing exclusion of people who do not subscribe to these institutional processes reinscribes wider discourses of disablement associated with positivist thinking, including notions of researcher objectivity and untrustworthiness of the researched Other (Thompson, 2002, p. 96). Untrustworthiness is compounded by institutional marks of incompetence and vulnerability that tend to always-already disempower "special populations." These notions also seep into social discourse. For example, in a team-authored report that includes individual accounts of research, Caroline Vanderkinderen (2013) describes reaction to her research-based handwritten conversations with an institutionalized participant who called himself "Jimmy, the criminal, the beast of the park":

...people who heard of my research, being located both in and out of the university system, more than once asked me ... why I worked with this 'dangerous man' who was, for sure, 'lying'? They tried to convince me — while assuming that I was a naïve and credulous researcher - that his story was irrelevant and that he was manipulating me since I was not allowed to forget that 'he is a psychopath and we all know what psychopaths do' (Vanderkinderen, Roets, \& Van Hove, 2013, p. 2-3).

The purpose of these examples is to demonstrate that even in the hands of exploratory research and firm qualitative critique, disability emerges and re-emerges as the work of "experts" invested in somehow (re)presenting the docile body. This (re)presentation seems almost necessary in a 
cultural landscape of unbelonging where triple-labeled bodies are "deliberately silenced" (Erevelles, March 12, 2015) and researchers struggle to find ways to present Otherness and invisibility as possibility where few precedents of such possibilities have been set. 


\section{Chapter 6: Re-making the body in dis/postmodernity}

The modernist development of intellectual disability is a defect of Enlightenment reason and its invasive application through disciplinary discourses and technologies — forces under which many still work, live and die (Harvey, 1990, p. 14). Labeled people in particular exist under diagnosed categories of humanness, their bodies often rendered outside of intelligibility. This ontological category directs subjectivity development toward a familiar, taken-for-granted state of unhealthy-abnormal and fails to acknowledge phenomenological processes of becoming. By using disability as an object against which all subjectivities and bodies are discursively developed (Titchkosky, 2013, July), modernity churns up ontological questions that morph into none other than what Bauman claims all modernist projects to be: an assault on what it means to be human (in Tester, 2004, p. 118).

However, postmodern disability theorists offer a new perspective. They tend to challenge the rigidity of these bodily understandings and focus instead on embodiment and the task of deconstructing disability and impairment (Clare, 2013; Davis, 2013b; Kuppers, 2002). One question Carlson (2010) asks to this end is, "What place do persons with ... intellectual disabilities have within discourse, and how can their interests be addressed in ways that don't perpetuate certain forms of oppression and marginalization?” (p. 9). Such an ontological question realizes that there is no one way of being; however, we are the core of what Fredric Jameson (1991) describes as the contemporary “unmappable,” in sharp contrast to Titchkosky’s (2002) earlier movements of "mapping" disability. Where we once recognized intellectual disability through material analysis of the body that rendered visible the social interests that support the construction of intellectual disability, the postmodern unmappability of the contemporary 
embodied subject sheds light on sometimes-untracable consciousness and ways of being inrelation-to as exploratory moments of unsettled discourses and knowledges.

Departing from modernity's establishment of disability as a “degraded point of difference" (Titchkosky, 2013), postmodern approaches to disability are generated on the principle that reality is a discursive project (Titchkosky, 2002, p. 102). Postmodern theory frames disability and the body as culturally constructed/located and discursively developed, moving it beyond "concrete abstractions" and Cartesian binaries of normal/abnormal and $\operatorname{mind} /$ body that fail to explain human experiences (Iwakuma, 2002, p. 77). If we carry on with feminist poststructuralist notions that discourse constitutes culture, and that the body and the subject within culture are discursively constituted in a myriad of ways that transcend identity politics, then disability becomes something of a modernist myth open for deconstruction. This deconstruction of disability via re-imaginings of the body has been praised as "the ultimate postmodern concept" (Corker \& Shakespeare, 2002, p. 15; Price \& Shildrick, 2002, p. 74).

\section{Dismodernity and a new ethics of the body}

The question which modern philosophy asks in relation to science is not intended either to contest its right to exist or to close off any particular avenue to its inquiries. Rather, the question is whether science does, or ever could, present us with a picture of the world which is complete, self-sufficient and somehow closed in upon itself, such that there could no longer be any meaningful questions outside this picture.

$$
\text { - Merleau-Ponty, 1964, p. } 43
$$

Contemporary questions of ontological difference transcend the still-well-established mind/body split. Thinking through these questions relies on understandings that there has been a shift in modernist thinking of the embodied self as stable and independent while at the same time postmodern notions of the embodied self as dependent and never complete are grounds for 
exploration (Shildrick, 2009, p. 10). In addition, the categories of the body are "in crisis" as feminist poststructuralists, in particular, shovel through how such categories emerge and whom they include and exclude (Lather, 2007, p. 73). Thus, with a collapse of the subject, and with doubt toward what it means to be a categorized human whose knowledge could count as valid in any kind of categorization, postmodernity focuses on the uncertainty and directionlessness of social life and identity (Richardson, 2000). One of postmodernism's main accomplishments is the deconstruction of the universal (Titchkosky, 2002, p.110; Corker and Shakespeare, 2002, p. 3; Lather, 2007). Postmodernism rejects the idea of a single reality or truth while challenging traditional hierarchies and hegemonic systems of knowledge, and therefore pairs well with poststructuralism, which foregrounds the limits of sense-making efforts that build rational forms of explanation, according to Lather (2007, p. 5; Barnes, Mercer and Shakespeare, 1999, p. 36).

One way that disability has been re-conceptualized as a topic of postmodernity is through Davis's (2010/2013b) theories of dismodernity, which rely on notions of intersectionality, interconnectedness, and interdependence. Davis's starting point for this theory follows a long line of cultural studies literature concerned with identity politics. Davis refers to the realization that we may be unsure whether or not we are ready to resolve disability identity, or if we're only beginning to figure it out (Davis, 2013b, p. 263). This uncertainty reads as a response to Merleau-Ponty's 1948 radio talk about the limits and usefulness of scientific knowledge in the face of perception, in that modern science is often consulted - its "solutions" understood to help us form a full picture of the world, but its resolutions always inscribing an incomplete image of the world, and thus a suspiciously incomplete image of the self.

Davis (2013b) suggests that in its fluctuations — its in/visibility, its eventual appearance and potential disappearance, its everlasting manifestations or its technological addenda - 
disability is, in itself, an identity which can capitalize on its own instability as it differentiates from the ever-shrinking category of "normal" because it relies on both perception and science to bring it into being (p. 271). Davis's realization is reflective of Tom Shakespeare and Marian Corker's (2002) "ideology of disembodiment" that suggests that postmodernity has affected our sense of self and place, causing loss of meaning and confusion as we try to navigate individualistic cultures wherein the natural, unified, hidden essences of the self ought to be discovered and realized but continually evade us (McRobbie, 1985). Instead such notions block us from creating the hybridized, complex, and unconventional selves with multiple life possibilities, which Davis (2013a) argues are at the core of disability identity politics in postmodern contexts. The body in a provisional state is, in many ways, the contemporary context in which disability and all bodies are located:

The fortunes of techno-science continue to disrupt the fixity of defining disability and normalcy especially within the arenas of law and bioethics. Whilst anomalous bodies are undecidable in being open to endless and differing interpretations, an essentialised disabled body is subjected to constant deferral — standing in reserve, awaiting and escaping able(dness) through morphing technologies and as such exists in an ontologically tentative or provisional state (Campbell, 2008, unpaginated).

Through the framework of dismodernity, Davis (2013b) embraces the loss or absence of truth and selfhood by allowing the social self — marked by discourses, constraints, and dispositions - to emerge in an era where bodies rely on remediation. This type of remediation includes prescription drugs, mechanical addenda, memory exercises, and other examples that breath life into Trend's declaration that "the pathological is normal" in contemporary Western society (Trend, Sept. 25, 2013). Dismodernity attempts to trouble the act of categorizing bodies without re-categorizing them. From the perspective of this research, a promising point of dismodernity, with its wide scope of potential participants, is its apparent inclusion of those who remain invisible and its attempt to trouble the act of categorizing without re-categorizing. 
Through these motions, dismodernity suggests that our traditional ways of conceptualizing the problem of disability — and intellectual disability — is the problem.

\section{Calling for a new "ethics of the body"}

In order to begin re-thinking the body non-reductively and in dis/postmodern terms Davis (2013b) calls for a new ethics of the body that goes beyond the "dead end" of identity politics and toward discourses that value those who transgress normative boundaries of bodily encounters with the world (p. 275). His call appears to align with feminist poststructural ethics that argue that morality is connected with ontology, because, as Scully (2002) writes, "being cannot be separated from the moral context in which being occurs" (p. 56). This new ethics entails considering discursive inscriptions of corporeal realities and new means of knowledge production - an ontology that replaces the decorum of power and docility with a revision of concepts of normalcy and what Titchkosky (2013) calls a restricted version of humanness. "What we need now," Davis (2013b) explains, "is a new ethics of the body that acknowledges the advances of science but also acknowledges that we can't simply go back to a relatively simple notion of identity" (p. 271).

Specifically, Davis links this new ethics with body economy that involves the symbolic production of the simulated body, either for liberation or oppression. Following Jean Baudrillard (1994) dismodernity emphasizes that ontological and epistemological truths are fundamentally flawed. Here, theories of representation work against the real; not only do we have no access to the original body because it does not exist, but we have no need for the "real" in opening up space for political engagement amid what Kuppers (2002) describes as an endless cycle of discourses (p. 184). Trend (2013) speaks in the framework of dismodernity when he says that 
ableist culture buries its anxieties about disabilities in the distractions of maintaining the body. Such bodily productions include care of the body, care for the body, and care about the body (Davis, 2013b). Each mode echoes the medical model in that medicine is constantly in the business of reconstituting normality and abnormality in order to produce the "docile body" through self-imposed structures (Scully, 2002, p. 48; Mallet \& Slate, June 17, 2014; Wendell, 1996, p. 87).

Briefly, following Davis's (2013b) descriptions, care of the body is a "requirement of citizenship" we perform by buying products and addenda to conform to social standards of normality, including everything from skin moisturizer to pacemakers and other posthomanist visions that fit into cyborgian lives (Haraway, 1991; Kuppers, 2002). This mode contributes to what Bauman calls "the privatization of the body" (as cited in Davis 2013b, p. 274). Care for the body involves our engagement with healthcare industries (which Davis calls "disability industries") that are largely supported by the attendance of disabled people (2013b, p. 274). Caring about the body involves developing discourses that consider particular embodiments and the environments inscribed on them (p. 274). These methods of self-care are disciplinary practices that are preconditions for normality, and thus for participation in social life (Wendell, 1996, p. 88). We can recall, here, the notion of care as an individual quest in postmodernity a notion that that emerged in pre-modernity and carried into modernity that is now lived out in contemporaneity.

Thinking in terms of cultural locations of disability based on what bodies "tend to do" and "can do" (Ahmed, 2006, p. 56), I am reminded that these disciplinary actions of caring of, for, and about the body are so pervasive that "those of us who can learn to be or seem 'normal' do, and those of us who cannot meet the standards of normality usually achieve the closest 
approximation we can manage" (Wendell, 1996, p. 88). Finally, I use the term "embodiment" very intentionally in this writing because I am following Merleau-Ponty, who suggests the body is not a physical and/or intellectual tool of productivity but "a group of lived-through meanings" all interconnected and unconsciously taking account of surrounding environments (1962, p. 153). Here, postmodernity assists in restoring our concern with the body and our orientation toward what the body can and does do. Merleau-Ponty (1964), along with feminist scholars such as Butler (1999), Cixous (1979) and Donna Haraway (1990), teach us that the lived body is no longer "the ideal epistemic agent" but instead is indistinct from, and thus is, the knowing subject represented in particular ways in particular contexts (Schwandt, 2007, p. 23). With embodiment, the consciousness of the body and its participation in epistemology is important: "Embodiment cannot be completed," Iwakuma (2002) explains, "as long as s/he is conscious of, for example, pushing a wheelchair for transportation or is making an effort to flip a page while using a prosthetic arm" (p. 81). Therefore, Davis's caring about the body means caring about the meanings associated with the individualized body, and the impact these have as we go through processes of meaning-making in the world.

Indeed, in our neoliberal consumer culture, dismodernity suggests that individualized fear of impairment brings the body into consciousness because impairment inevitably takes place on our bodies or in-relation-to our bodies. Here we find ableism alive again, even in a dis/postmodern context that leaps away from the material world at times. Labels of impairment not only classify, but go on to establish "new sets of normal" - essentialist knowledges about the body that are drawn from the cognitive and social authority of biomedicine (Mallet \& Slater, June 17, 2014). Following Wendell (1996), individuals produce themselves as subjects in part through self-maintenance. In doing so, people establish a sense of identity (as in, "I can take care 
of myself") paradoxically through conformity (as in, "I need to be just like everybody else") (Price \& Shildrick, 2002, p. 68). This preoccupation with the body is an extension of the modern, Western scientific goal of control over nature. It reflects the myth that we can control our bodies, or that perhaps someday we will have the freedom of such control.

This myth suggests that through human action we can have the bodies we "want" and therefore avoid what Wendell (1996) calls "the rejected body" — the body interpreted as disabled (p. 91, 94). As we have recently seen played out in Canada, the myth is in motion in decisions about physician-assisted suicide that, at times, aim to secure the problem-riddled notion of "choice" as an alternative to seemingly faulty embodiments (Bach, July 13, 2015). As Michael Bach (2015) and Janet Price and Shildrick (2002) point out, the subject who experiences bodily transformation never does so in isolation; those around her are part of the story, thus relationality is of heightened importance in thinking through disability in dis/postmodern contexts (p. 69). In spite of the contemporary "unmappability" of the cultural context (Jameson, 1984/2006), and the possible dissolution of the subject amid a hyperreal daily reality (Baudrillard, 1994/2006), something of culture is always-already inscribed upon the body, subjectivity, and those in-relation-to the body.

\section{Locating disability discourses in dis/postmodernity}

It is this space between the subject and the construction of the surrounding world — the space Merleau-Ponty (1964) called "the chiasm" of inseparability between bodilyness and being-inthe-world — where disability discourse exists (Price \& Shildrick, 2002, p. 74). Thus, concepts that emerged in the earlier discussion about modernist conceptions of the body, such as positionality and "self" and "other" dynamics, retain their importance in dis/postmondernity though their contexts can be re-framed here. 
For example, dismodernity also reflects Foucault's explanation of government as an activity concerning one's relation to one's self, one's relations to others, and one's relations to institutions — processes of relating that employ normalizing technologies such as selfimprovement products and interventions like rehabilitation (Tremain, 2005, p. 8). In dismodernity, unlike modernity, the body's familiarity is not taken for granted and instead is defamiliarized through the "ideology of disembodiment" (Davis, 2013b). As Merleau-Ponty (1964) writes, the modernist sentiment of "I have a body" has given way to "I am my body" and "I live my body" (p. 198). And it is from this active starting point of living the body and being in-relation-to the lived body that we gradually prepare to move out into the epistemic realms of research by narrowing in on intellectual disability as a modernist myth up for postmodern deconstruction.

Corker and Shakespeare (2002) explain, “disabled people did not exist before [modern] classification although impairment and impairment-related practices certainly did" (p. 8). We have a habit of carrying disability through time and thought. Stockholder (1994), meanwhile, points out that one important question to ask in considering a cultural story of disability leading up to present understandings of it is simply: Why? That is, why does intellectual disability exist? Why has the mistreatment of labeled people been accepted so passively? (p. 166) And why does this mistreatment continue in contemporary cultural contexts without mass reaction to its blatant injustice? One answer to these questions can be found in a consideration of the humanness of certain people or, in Stockholder's (1994) words, the victimization of people because "social commentators convinced many that the victims were intrinsically inferior because they were subhuman, unfit for survival or not human at all” (p. 166). Were I to take Stockholder's assumption out from past tense and suggest that people carrying the label of intellectual disability continue to be treated as subhuman under a eugenic cultural imaginary, 
and continue to be found in cultural locations of disability that disavow their humanness, I would find myself straddling a conversation that neither fully belongs in the realms of modernity nor completely in the space of postmodernity. The answer to the notorious "Why?" leads, again, to a space wonderment and un-belonging.

Questions of ontological difference transcend the mind/body split, while at the same time this dualism continues to inform how we make meaning and how we make each other mean. However, moving toward postmodernity with a pre-established subject — one who is ahistorical, pitiful, uncultured, deviant, undesirable, unorderly, irrational, and unwanted among other characteristics modernity has inscribed on labeled bodies — risks maintaining the certainty of identity on which "theoretical elaboration[s]" are built (Shildrick, 2009; Foucault, 1978, p. 31). For example, to interpret intellectual disability as undesirable and non-relatable "Otherness" risks flattening the nuances of intercorporeality by fulfilling normative demands of static bodily categories and by undermining the "processes of becoming" that ensnare the always- unpredictable subject (Shildrick, 2009, p. 129). The motion of "becoming" brings subject development into question through certain theoretical expressions, such as intersections of feminism and queer theory that might re-understand disability through performativity (Butler, 1999), orientation (Ahmed, 2006), or "uneven forces of cultural representation" that promote political discrimination (Bhabha, 1994, p. 171).

Postmodern expressions of the body also employ post-humanness through cyborgian/hybrid narratives (Haraway, 1990) and through topics of interspecies communication (Salomon, 2013, June). Moreover, Davis (2013b) carries forward modernist notions of identityformation in claiming disability as "the identity that links other identities" through globalized dependence (2013b, p. 265). In other words, as our ability to classify and make distinctions about the body grows, the modernist notion of normal (or human) embodiment is pushed to the fringes 
of society to occupy a minority position though it is never entirely erased (Scully, 2002). Modernist conceptions of the body operate in the same breath as postmodernist conceptions of the body. As Davis (2013b) and Trend (2013) have pointed out, pathology is the new normal; modernist disability is what we all have in common in a postmodern context.

\section{The body and intellectual disability}

Price and Shildrick (2002) call the postmodern turn "a breakdown in normative certainty," explaining that the characteristics of the embodied subject in postmodernity include disarticulation, instability, and provisionality — all descriptors commonly linked to the modernist construct of intellectual disability (p. 68). Labeled people are still subject to the classical, medieval, and Enlightenment thinking that made way for modern scientific thinking about the body. In the present, however, Enlightenment categories of rationality and normality are suspect, and the truth-based knowledge that taught us our cultural triumph over nature and allowed us to read the body in particular ways through science and through research praxis are derailed in favour of poststructural knowledge (Lather, 2007). A new type of body is forming: the unstated, never rational, fluid, incomprehensible, and, following Berger (2014), dyes/articulate self embedded in the mirrored other. Yet, this body exists in the "collision of humanist and posthumanist assumptions in efforts to voice and make visible" that tend to uphold research involving people, especially where abstractions and untranslatability may be involved (Lather, 2007, p. 77). This unstable state of being is one this research expects to encounter as it aims to encounter labeled people.

Importantly, Davis (2013b) invites readers to wonder whether widening the umbrellas of disability identity will break that category into smaller subcultures (in the case of seniors, for example, whose subjectivities might provoke questions such as "do we/how do we distinguish 
between aging populations and disabled populations?”) or make the category of disability disappear all together (p. 272). Titchkosky (2013) appears to take on this challenge of wondering when she advocates for widening categories of disability to include even the uncategorizable.

She explains,

By opening this human horizon ${ }^{59}$, I am not simply suggesting that more and more people be included in it — that more people be regarded as productive types; individuals of worth; use-full citizens, or any other neo-liberal rendering of human as, again, a body of functions. Instead, I am trying to suggest that we open the category itself - human - to reflection, consider how it is operating via the degradation of so many, and try to imagine human differently (Titchkosky, 2013).

Here, Titchkosky demonstrates a self-in-relation mindset rather than a modernist self-inopposition perspective. This is why taking up a conversation about intellectual disability in light of postmodernity is important: postmodernity gives us a new way — including new language — to conceptualize humanness in a contemporary context where humanness can be understood as secondary under the label of intellectual disability.

However a moment of caution: moving toward postmodernity with a pre-established subject in mind risks maintaining the certainty of identity on which "theoretical elaboration[s]" are built (Shildrick, 2009; Foucault, 1978, p. 31). Philosophy and social theory risk overwhelming, or taking over, the already-established body that is up for grabs theoretically, so to speak (Goodley, 2011). For example, popular in current disability theory is phenomenology's concern with being in the world with others (Price \& Shildrick, 2002; Titchkosky, 2013). Following Merleau-Ponty (1964), Shildrick remarks that the interweaving of bodies constitutes subjectivity when "we are of [the world] rather than in it" (in Shildrick, 2009, p. 26).

\footnotetext{
${ }^{59}$ It should be considered here that "horizon" may take on the colloquial meaning of new opportunities. However, the word may also refer to an "encompassing frame of reference, without which any account of even single perception would be incomplete" (Spiegelberg, 1982, p. 146 in Iwakuma, 2002, p. 80).
} 
In The world of perception (1964) Merleau-Ponty describes orientation as the relation between different points in objective space "and a central perspective — the body" (in Ahmed, 2006, p. 8). Merleau-Ponty thus positions the body as a "central perspective," or, as Ahmed rephrases it, as "here," which is a "place to begin" as the world "unfolds ... over there" (p. 8). For Merleau-Ponty it is through the body that people begin to gain access to the world, making the body "the ground level of all knowledge" (Hughes \& Paterson, 1999, p. 601). The point is that while these postmodern "emancipatory vision[s]" of the body are tempting because they carry the effect of freeing us from rational, individualistic pathology that impinges on subjectivity formation, these visions sometimes seem plausible only for theoretical subjects (Erevelles, 2001, p. 94). Further, these visions always only take form from the body — that is, theory begins in the body - so when the body is forgotten these visions lose their shine. In short, this effect is that of Merleau-Ponty's (1964) reversibility: we are in the world and the world is in us; trying to separate our bodies from the world is the distance of rational thinking.

\section{Ontological differences}

This discussion takes an intentional turn from the promising prospects of dismodernity's reevaluation of identity categories to the dangerousness of wondering about intellectual disability identity. So, the shift from modernity to postmodernity is one that must be approached with some caution. I understand that disability discourse must be received and analyzed in order to understand the cultural locations of disability that allow it to emerge — this is the difficult motion of "mapping" the apparently unmappable (Barthes, 2007, p. 82). The effort here is not to regress into modernity, but to lend some stability to disability in its postmodern context by imagining a space for re-discovering the culturally constructed and discursively instituted body. As Angela McRobbie (1985) points out, postmodernity does not mean we have to do away with 
the subject, but rather that we have to query its presence, processes, and production (p. 528). In this case we begin with the notion that "Disability is lived, and it is lived as something other than a negative add-on to personhood" (Titchkosky, 2013).

Following Berman (1982), though, I still worry that part of the lived, or the action of living out disability, means people continually undergo inescapable normalization strategies that attempt to make disappear their bodies under the tight grip of modernist discipline. Yet we still try to make the world our own, theorizing disability as if we can have it both ways: as if we can both live through it and reject its experience, and being satisfied when its problem status disappears (or is solved) in a postmodern multiplicity of (theoretical) possibilities (p. 13). And because these possibilities are largely invisible, or exist primarily in the imagination of theorists, postmodern approaches risk being lost in abstraction. Lather (2007) compares the abstraction of postmodern research to the stringiness of some historical research, suggesting that each can hold dangerous undertones:

It's not the theories that are the problem, it's not the universals, it's not the symbols, it's not the language. It's the power that gets attached to them that becomes the problem. So yes, we are always talking meta, always bumping things up, always talking abstractness at some level and coming up with theories. We have to do that. But then it is like how power gets connected that's the enemy. And the problem is that historically research has been used in such oppressive ways that it has almost become synonymous with powerover - with abuse of power. It's a particularly problematic practice, one of the ways that abstractions become abusive is by making other ways of knowing invisible (p. 57).

Later in her writing, Lather goes on to say "dialectics is inadequate in coming to grips with our time and what it might mean to try to make a difference in it" (p. 75). Here, the riskiness of re/conceptualizing the body begins to spill over from theory to praxis as we re-revisit Foucault's (1973c; 1973d) dynamic of knowledge and power that is alive in our processes of formal, institutional meaning-making through silence and invisibility. 
As Dolmage (2014) notes, prematurely pushing bodies into the looseness of postmodernity risks incorporating "untroubled bodily norms in an unchallenged realm of abstraction" (p. 6). Yet, postmodern understandings of disability — what we might call a postmodern model — open new, critical questions about embodiment and "provide fodder" for critical and cultural approaches to disability (Carlson, 2010, p. 9). Therefore, although I recognize the usefulness of postmodern theory, my concern centers on how we might avoid inadvertently shaping "abusive" abstraction, and on how we might reacquaint ourselves with those still banished from social view — whose ways of knowing are made invisible (Lather, 2007, p. 57) - under the "trauma of modernization," before undergoing any attempt to reshape the self/selves in relation to others (Berman, 1982, p. 35; Brunswick-Cole \& Goodley, 2014). And so I exit this particular conversation of the dis/postmodern turn on late modernity's notes of worry and hesitation that accompanied the wonderment that brought me here. 


\section{Chapter 7: Expressive writing and phenomenology as methods of un/knowing the body}

There is so much we don't know, and to write truthfully about a life, your own or your mother's, or a celebrated figure's, an event, a crisis, another culture is to engage repeatedly with those patches of darkness, those nights of history, those places of unknowing. They tell us that there are limits to knowledge, that there are essential mysteries, starting with the notion that we know just what someone thought or felt in the absence of exact information.

- Solnit, 2014, pp. 87-88.

Because this project is about the experiences of writing, and because experiences tend to be unorderly, it seems imperative to show the reader this project's methods by storying them and letting them unfold as living action rather than tucking them into a late section as only a stale list of procedures. In this way I aim to do the work through the dissertation writing rather than summarize what is to be done, or what has already happened.

This research takes writing to be both a gesture (Vernon, 1979) and a system of thought (Spivak, 2011, p. xxxiii) in its interpretive approach. This approach is informed by poststructuralism and phenomenology — methodological strategies that are reinforced by the theoretical perspectives outlined in the opening of this project. This research intends to produce textual expression of the experience of intellectual disability in order to transcend our notions of the phenomenon to this point. Until now intellectual disability has unfolded as a modernist, materialist construction assigned as a problem to particular bodies that are commonly understood as ahistorical people with impaired minds and/or as theoretical subjects in postmodernity (Carlson, 2010; Michalko, 2009). Described below is a lived encounter with one participant named Ross who, while under the guise of informed consent, challenged the project's methods. My encounter with Ross demonstrates what methods are used in this research, and how these methods sometimes play out quite loosely. 
"Why did you choose the colour red?" I ask Ross, turning the voice recorder in his direction. Last week I made a note to follow-up with Ross because he wanted me to take a photo of his notebook as he left the room. Our sessions end at noon, when lunch is served, and last week the pull of hunger was stronger than Ross's desire to be part of the research. In the last session we worked through a writing activity: "If I was a colour, I would be the colour ... ".

"I don't know. I know," he begins. "I think red is like a, let me hear my voice. I don't know. What's that? I know, what's that?" Ross points at the voice recorder. When I listen to a recorded version of this conversation a few hours later, it is muffled by laughter from five other group members. I can't tell where the topic of red ends and the topic of the voice recorder begins. The voice recorder flashes a red light when it is recording, and I wonder if there is a connection. I've explained the utility of the voice recorder several times as per my proposed week-by-week research schedule. The voice recorder, I tell everyone routinely, lets me hear everything again; I listen to recordings of our conversations after we leave these sessions so that my notes are accurate.

"Do you want to see how it works?" I ask.

"Yeah, yeah I want to see how it works," he repeats my phrasing often, so I try to stick to open-ended questions during informal interviews and conversations.

I pick up the voice recorder and hold it near my mouth. I point at the digital volume unit meter that jigs back and forth as we speak. "The louder you talk the higher these bars go." I suggest he speak louder to "see" the sounds of his voice through this auditory measurement. After a few moments I gesture toward his notebook. His letters are made of large, dangling lines, like spiders scattered on a page. "Do you want to talk any more about your writing?”

“Yes I do, I like to," he says. “Um, I like asking questions. I like to... do something, and 
I," he laughs, picking up the voice recorder, "and I like to do something uh, and I like to."

"Would you like to ask me some questions?"

"Yeah, yeah, yeah." We adjust the microphone so it picks up his voice. "I have a question for you," he says. I explain that when I answer, he can point the microphone toward me.

"I like to, I like to," he begins, laughing. "I like to ask questions, in my notebook I sort of I sort of I can do this up and I can write anything I want. Anything I want. I can use something in my notebook I like to do something write anything I want. I like so I can hear ... I like to I like to um, I like to answer the questions so I can do something [inaudible] I like to write anything I want so I can write I would like to write in my notebook yes, uh, yes, Halloween Friday [inaudible] do something write it in my notebook, I like to. Good, good. I like it. Good." "Is that a question?" I ask.

"Yeah, it's a question. Answer the question. Yeah, yeah, uh huh." Ross is leaning over his notebook, pointing the recorder at my face.

"You want me to answer the question?" I begin to laugh. The other participants are watching. Flora is laughing softly, and Mr Clark Kent is banging his fists on his chair in a fit of giggles. I can hear his high-pitched sounds on the audio file I transcribe afterward.

"Answer the question, yeah," Ross insists.

"I'm afraid I didn't catch the question," I say. "Can you ask me again?"

Specific methods are at play in this reflective narrative account: recording, transcribing, participatory observation, unstructured interviews/conversations, data gathering through observation, lived experience descriptions, storytelling and writing, written reflections, CAP writing, and (almost) individual and collaborative textual analysis. Each of these actions emerge 
both intentionally and unintentionally, saying much about the research approach, the approach of researcher, and the approach of the participant(s) to the research. These collective methods, and perspectives toward them, make up my reflections on the experiences within this project; such reflections in turn act as a primary text for consideration. By relaying everyday experiences anecdotally with an emphasis on recorded dialogue, as above, I attempt to wriggle into the cultural location of disability in order to notice the shifting of things - how things feel against stringent methodologies, how participants may or may not subvert methodological restrictions. Plus, not only is dialogue more inviting and accessible, it protects against overconceptualization of study results (Church, 2014). This type of writing is a way of getting over the "romance of voice" and the temptation to "give voice" (Lather, 2007, p. 36) in exchange for presenting a lived experience that is sometimes without explanation and lacking conclusion, as is the imperfect nature of the empirical world and recordings of it.

This study uses my reflections on the experience of a writing group as its primary text, and secondarily looks at participants' testimonies of this experience and their written work to illustrate the boundaries and categories of intellectual disability as a cultural, contextualized, relational phenomenon. As Ahmed (2006) writes, the latter experience must take place in order for the former analysis to appear (p. 38). In other words, because labeled people are so often outside of the privileged place of rhetoric, researchers must "grant rhetor" by making space for writing, and conversations about it, to exist (Prendergast, 2001). For example, analysis of the moment played out above might take into account the critically participatory parts of this research, which understands this project as laced with too many restrictions to ever really be categorized as participatory. Even when space is not necessarily made for collaborative moments of production and interpretation, inside of and outside of writing, Ross, a participant, offers a change in research direction in his motion of turning the recorder around on me, the 
researcher. The research branches into participatory realms because this kind of interaction is allowed, though it remains outside of the research agenda.

Further, Ross gives me the task of attempting to make sense of that which I don't understand: his spoken words. Speech can be considered a form of writing because neither form of language is perfect and both forms ground the body in text (Derrida, 1976). Thus, Ross's gesture of speech, which surrounds his writing and which I attempt to direct toward his writing by making his writing the subject of our conversation ( "do you want to talk any more about your writing?"), highlights the imperfections in both people's communication processes not because of his actions but because of my inability to understand, to translate, the thoughts he has articulated at my request. Thus, we are both dislocated, positioned somewhere outside the realm of understandability, or, as Homi Bhabha (1994) might have it, "otherwise than modernity" — though never apart from modernity (p. 181).

To follow Bhabha's thinking would be to expand the scene: The conversation takes place in a day program institution for people with intellectual disabilities. The building, with its whitewashed cement-brick interior and a boardroom at the back where the writing group meets, is a suburban office building. It stands with the purpose to house people with intellectual disabilities during the day while their caregivers work. So Ross, and I, and the other participants are in the place we're in because of a modernist understanding of our lives that separates us as "they" who must be occupied while "I" work, using "their" work as my subject. We are caught up in a modernist dynamic that describes our wider cultural location, and a brief moment of wonderment kindles the question: How did we get here? (p. 9). Zoom in on that dynamic to the conversational encounter of dislocation, which positions us all as research objects, or as the researched upon, amid, say, Derrida's (1976) questioning of the idealization of both speech and writing in modernist contexts that would suggest there are, in this case, questions of culture, 
context, and relationality embedded in the dialogue and perhaps answers to match (Dertscher, 2005, p. 10). I could, and will, continue with this type of analysis in a later section more pointedly geared toward analysis. My point here, however, is that the methods in this research expose moments of mis/understanding and re-position all involved. Generally speaking, these are the moments that belong to the original phenomenon of intellectual disability that gives rise to the experience in question (van Manen, 2002, p. 9).

Methods and (some of) what happens when they're introduced

The purpose of attending to writing experiences and attempting to interpret them with the guidance of participants is to upheave moments of mis/understanding and move them out of the realm of wonderment and into more concrete handling of insider/outsider politics and never-tobe-known meanings discovered in the lived experience descriptions that provoke wonderment. It is worth pausing, here, to explain that lived experience descriptions are a phenomenological technique coined by van Manen $(1990,2002,2014)$ aimed toward capturing the meanings of lived experiences. To continue with the example above, the methods are still at play during this particular encounter with wonderment. Below the encounter rolls along until it dissolves, and I am stuck in a place of unknowing that is instigated by Ross and picked up by the voice recorder.

"I'm afraid I didn't catch the question. Can you ask me again?"

"Yeah, okay.” Ross pauses, looks away.

"What is the question, Ross?"

"Well, I can listen to my voice, so I do, I write in my notebook I do."

"That's good. So, what is your question to me?" 
“My question, I like to, to. I like to I do answer the question, I do," Ross releases a hearty laugh.

“Well I'm not sure, I'm not sure of the answer," I say. The other participants have put their pens on the table, and writing has come to a halt.

"Not sure of the answer," Ross repeats.

"What do you want me to talk about?" I have no idea what he wants. I imagine that sometimes, when the situation is reversed and I am asking questions about the participants' writing, they feel the same way. I am playing a guessing game, and guessing is a sure sign of wonderment. I jot this down in my notebook, followed be a question mark as if to say, 'Are you seriously going to try to theorize this?'

"I like, answer the question in my notebook I do. Yeah, yeah, okay, anything I want to. Yeah. Okay."

"Are you asking if you can write anything you want?" I ask, while at the same time he says, "I can do, I do."

"Yes, " I say. "You can write anything you want in your notebook."

The mood has changed now. Things are still, almost solemn, and I can't quite figure out how or when the atmosphere changed. On the recording there are no longer traces of laughter, and Ross's tone is firm, matter-of-fact. "Yeah, it's okay," he says. "Okay, okay."

"Do you want to talk any more about writing?"

"Not talk no more, yes please."

"Do you want to go back to writing now?"

"I'd like to go back to, I'd like to go back, to writing I'd like to, yes." Ross returns to his writing, and begins humming along and making joyful-sounding "oo-ey oo-ey oo- $h$ " sounds as he writes. He does not look up for the remaining hour of the session. 
My notes from this day say: "No answer on red?"

I take specific tools with me into these experimental moments: a voice recorder to catch everything verbally articulated, including those phrases that scurry into speech too quickly for me to catch with shorthand notes; notebooks for each person, including the researcher, though my pages are arguably the least filled at the end of each session because I spend most moments in conversation rather than in observation; pens, which I tote around in a plastic sandwich bag to be distributed by Ross at the beginning of each session; whiteboard markers of various colours (orange and purple are most popular) for occasional group writing on the boardroom whiteboard; and a camera to photograph participants' writing (with their permission — I never remove their private notebooks from their possession, optting to photograph a page instead).

This research also requires place and permission to make space for writing. To this end I try to demonstrate my respect for the organization and the people who allow me to occupy this space each Friday: I show up early, chat with staff, chat with participants, and back down from any open critique. This research takes place in a sprawling, one-story industrial office building at the intersection of two busy streets in the east end of Toronto. On 4 Overlea Boulevard, the JS Manson location of Community Living Toronto provides space for people with intellectual disabilities to occupy on weekdays; there is a television in the heart of the building, a common area where people gather on breaks to play Wii games, surrounded by a handful of offices for staff, a classroom, a production room for workshop duties, and a boardroom where the writing group in question meets every Friday morning. And here is a tally of the details built up so far: The group, which eventually named itself "Once Upon a Time," a name that stuck for some but was met with puzzled looks by others, began in July 2013 with me at the helm. Our 90-minute meetings begin at 10:30 a.m. The meetings became topics of research after approval from Ryerson University's REB in February of 2014, followed by approval from CLT supervisor 
Judy Endacott, who works on-site but does not normally attend the research sessions.

The research began with a three-week recruitment phase that spread through the duration of the fieldwork. The project was originally pitched to the REB with an eight-week recruitment phase that would allow current, non-research participants time to decide whether they would like to continue writing under research surveillance or not. The elongated timeline also intended to make time for participants and their supporters (CLT staff, caregivers, family members, friends) to thoroughly review all documentation and contact the researcher indirectly through an institution-based phone number. The same week the Ryerson phone number was established the recruitment flyers were distributed en masse in order to meet project deadlines. The following week, those who showed up to the "Once Upon a Time" group were given informed consent forms. From then on, any wanderers-in were told about the research verbally and given a consent form to take home and peruse if they chose to do so. One regular participant entered the research in the fourth week, and another in the seventh week. The former person requested that she and I go through the six-page document together. Using our fingers to point at the words on the informed consent form, we read through the six-page document together. She agreed to take the form home for further consideration alongside the new supervisor working at her group home whom she believed would help her with any questions. I circled my research phone number and assured her that I could make photocopies of the form as per her request, as I did with all other participants. When we reached the section of the form focusing on anonymity and pseudonyms, our conversation played out like this:

Chelsea: So, if you decide to be part of the research you can be known as and when I write my report I will refer to you as However, if you want you can choose a different name, and when I write my report I'll put a different - 
Participant: My name's gonna be Prince, uh, Prince Diana. You can call me that.

C: Okay, that sounds good. Now, one thing to think about with your name,

P: My name's not

C: Okay.

P: Prince Diana. My morning staff always call me that because I don't like to be called my last name. My first name is Prince Diana.

C: Prince Diana or Princess Diana?

P: Prince Diana.

C: Okay.

P: Okay.

C: Now, can I just mention one more thing?

P: You're doin' it again. Prince Diana! [Participant puts her head in her hands, stomps her foot under the table.]

C: Sorry.

$P$ : Don't call me that!

C: I'm sorry.

P: It's okay.

C: Prince Diana?

P: Yeah?

C: Can I mention one more thing to you? [Participant puts her head down on her notebook]

C: Are you feeling like you'd like to get back to writing now?

P: I'm trying. But.

C: Okay, then I'll keep it short. If you want to use your real name, it allows you some 
authorship. So people can look at your writing and say, 'Hey, I know who wrote that.' But if I show them your writing and say Prince Diana wrote this, they might not know who wrote that. P: Well that's my name. That's my name. My sister always called me that. But my name Prince Diana. 'Cause my roommate never heard me saying that to me. My roommate never say that to me.

C: Okay.

P: But the other guys don't know.

C: Okay. So, Prince Diana, this is a form for you to take home. You can fill it out now or - P: I'll take it home.

This conversation alludes to the difficulty in explaining the complex nature of pseudonyms. Indeed for some people a pseudonym is protective and freeing in the writing process. For others, it acts sinisterly in denying authorship to particular works. In Prince Diana's case, she became visibly upset when I referred to her using her given name. Certainly her frustration is reasonable: Really, how often must the researcher be told a person's name before referring to a participant correctly? However, when she spoke the words, "You're doin' it again. Prince Diana!" the participant demonstrated a large degree of anger by putting her head in her hands and stomping her foot. She seemed adamant that Prince Diana was not only her chosen name for her research, but also a larger piece of herself that would be present now. The opportunity to become Prince Diana seemed to trump any explanation of its risk, and I felt compelled to comply in order to prevent the participant from becoming distressed. In the dialogue above, the vulnerability of both the researcher and the subject is exposed in relation to the tools of the informed consent form and the optional pseudonym. 
I recruited seven participants in total for this research, following the sample guidelines presented to Ryerson's REB which, in short, restricted the sample to labelled adults with intellectual disabilities of any gender who attend JS Manson and would be willing to participate. Four of these people are "regulars," meaning they show up and participate in expressive writing on a weekly basis. Other participants are involved in the research on a spotty basis, joining the group only now and again before finding somewhere else to go. The research was originally pitched as a 24-week project, but because of the tight timeline fieldwork was reduced to 15 weeks. Fieldwork took place between October 2014 and February 2015, followed by much re/writing.

\section{A brief note on encountering methodologies}

In moments of re/writing there is tension between explaining methods and methodology. Explaining what we did is more difficult than explaining what happened. Lather (2007) chooses "getting lost" as a methodology, and as a way of knowing, that shifts toward "the end of narrow scientificity" and thus removes researchers from the position of knowing or "being in the know" to the position of being lost in questioning and "epistemological indeterminacy" (pp. 24). There is no doubt that much of this research involves "getting lost," not only in the motion and direction of the research but sometimes (maybe oftentimes) in its explanation. Lather's feminist post-poststructural approach seems fitting for the ways in which the phenomena of intellectual disability is approached from a perspective of wonderment, which attempts to linger in the affect of questions it evokes, rather than to find answers with which to wipe its hands clean and carry on. Sometimes those moments of wonderment swoop me backward in the methodological process, and instead direct my attention toward arriving here rather than being here. Methods are what we did; methodology is the multiple orientations toward what 
happened, which will be performed throughout this writing as pieces of data. Or, as Price (2012) writes: "Methodology is not a prescription, but movement, improvisation, movement" (p. 181). Though I turn my attention now toward methodology over method, both "what we did" and "what happened" in this research can be summed up as the movement and improvisation of writing. 


\section{Chapter 8: Moving beyond research ethics: Relational ethics and labeled people}

To ask what makes certain possibilities impossible for us is to press our uncertainties and to calculate the apparatuses of our capture. What would it mean to create a different space in which to undertake our thinking, an aesthetic space, a political space? What would it mean to create new solidarities, fragments of other possibilities, to experiment differently with meanings, practices, and our own confoundings?

- Lather, 2007, pp. 18-19

Tensions between positivist, medicalized research models and the social model create challenges in finding a suitable paradigm that might fit the values of disability studies researchers who are attracted to person-based research. However, one model that may be appropriate in some cases is Snyder and Mitchell's (2006) cultural model of disability. We can recall that this model emphasizes personal, social, and cultural contexts of resistance toward positivist, biomedical standards of normality and suggests that disability emerges as a result of a person's active disenfranchisement from experiences afforded to others (such as research participation) (p. 4).

The model also assumes that disability-related work by non-disabled researchers skews understandings of disability, and therefore calls for qualitative inquiry that includes the input of labeled people without the objectification of people as objects of research. Snyder and Mitchell (2006) include disability studies approaches as potentially objectifying:

The institutionalization of disability studies is just that - a formal cultural ingestion process that churns out more knowledge about disability while resisting reflexive inquiries about whether or not more is inherently better (p. 185).

In an attempt to pursue research without further overanalyzing a labeled/diagnosed population, Snyder and Mitchell advocate moving away from person-based research while simultaneously remaining in proximity to communities of activists. They suggest that textually-based analysis is the only absolute remedy to the exhaustion of people-based research practices in part because texts only exhaust the researcher and therefore are of little threat or risk to labeled people, and in 
part because all people interact with disability through this domain (Davis, 1995). The task of disability studies, then, is to cultivate media and textual critics, as well as historians who can best analyze past and present culture (Snyder \& Mitchell, 2006, pp. 201-202). Herein is the model's downfall: the cultural model privileges the textual/discursive at the expense of the material. Yet, there is value in this model because validity in the cultural model of disability is in experiential forms, such as those embedded in arts-based research where the body, and the constant threats against it, becomes the phenomenological site of evaluation.

Because the cultural model's highest ethical standards involve adhering to the material/textual binary that characterizes positivism (Adams St. Pierre, 2014, p. 12), its application to person-based research is difficult. It is necessary to find new approaches to ethics that may fit this model when people are, in fact, involved in such studies. One approach to incorporating the cultural model in a person-based study is offered through Ellis's (2007) notion of relational ethics. Ellis separates relational ethics from procedural ethics (such as those outlined by ethics committees) and from ethics in practice (situational ethics that deal with unpredictable moments during field research) (2007). She explains that relational ethics requires researchers to "[act] from our hearts and minds, acknowledge our interpersonal bond to others, and take responsibility for actions and their consequences" before, during, and following field research (2007, p. 3). In so doing, relational ethics urges researchers to move beyond institutional and personal standards of ethics in practice (Bergum, 1998 in Ellis, 2007, pp. 4-7). Because assessing competence and the procedures of informed consent (filling out forms, for example) involves people, relationships become a crucial and inevitable element of the informed consent process under a relational ethics framework. 
Relationship building involves consideration of the role of the researcher as that of researcher-as-friend, or the "friendly façade" that comes with meeting others — through personal conversations over coffee, and so on, that end with "be in touch soon," as Tom (1996) describes (in Thompson, 2002, p. 99). Researcher/researched relationships often come with certain questions: whether or not it is possible to be friendly without being a friend, what friendships ought to look like under institutional surveillance, and who will benefit from the friendship. Relational ethics aims to consider these questions and thereby reconsider how personbased research is conducted. Therefore, person-based research might not be entirely disposed of as the cultural model suggests. Rather, I posit that it is possible to preserve the principles of the cultural model — to still reject research frameworks that use its subjects as objects — by including a relational ethics approach built on amending the framework and aimed at a similar goal of alleviating risk toward people whose bodies and experiences have been, and perhaps are still, appropriated by researchers.

As relational ethics pertains to intellectual disability, it is clear that intellectual disabilitybased research is a cultural location of disability wherein researchers map out their work using the supposed characteristics of labeled people that disqualify them from humanity. These include presumptions that certain people are incapable of using their minds and worthy of ableist colonization: they do not imagine; they do not invent things or have histories; they are unintelligible; they have no language and must be spoken for; they do not know how to make the most of their lives and must be shown the way by non-disabled people (Smith, 1999, p. 25; Carlson, 2010). A relational ethical perspective suggests that some people have degrees of competence that are higher in some areas and lower in others, and therefore might take issue with using "professional intuition," for example, to gauge the competence levels of others, 
challenging informed consent as the performance of a cultural myth. This myth, or metanarrative, suggests that an entire group should be labeled as incompetent, and therefore not human enough for independent decision-making, until proven otherwise by a researcher whose competencies are not in question — although they always ought to be.

Vignette: (Still) beginning research

A question rings from the other side of the table: "How do you spell Grandmaster B?"

"I'm gonna be Clark Kent," someone else calls out.

"Uh, I like Ross," says Ross without looking up, his pen speeding along a lined page.

Raymond cuts in and hands me his form. "What's that?" he points at the front page.

"Should I read the form to you?"

"Yeah," Raymond nods, eyes wide.

I read the form aloud, word for word with Raymond hovering nearby. He sits down. He stands up. He sits again. Sometimes he walks out of the room so I stop reading for a minute. When he returns I start up again. Other participants have started writing. Flora, predictably quiet, has opened her SpongeBob Squarepants book and begins copying the text using her purple pen. Sharon, across the table, works on a pad of paper and often copies the words - including the publisher's copyright information - from a book of fairy tales. Ross is working through his genealogy. Another participant continues ripping paper from his notebook like a human shredder. Everyone is sitting now, and for a moment we are quiet even if the room is not; the song "Pretty Woman" is seeping through the wall. Normally this would be a good time for a dance break. Sometimes I bring my iPad and we listen to a couple of songs halfway through our writing session. Sometimes Flora and I are the only people who dance in these moments. 
"Can you take a picture of this?" a participant holds up the ripped paper where he's written "October 10, 2014." I explain (again) that besides photography not being permitted under the research guidelines until all informed consent forms are signed, I don't have a camera today. I regret not packing my gear. It might have been fun to try out the voice recorder and the camera, simply so participants could get used to them being in the room. For a moment I can't remember why I thought that would be unethical. "Okay," he says, looking down at the page. "I'll write a fresh one. For the camera."

Disability research history: A select overview

When the social model of disability emerged in the United Kingdom in the 1980s as "disability studies' big idea" (Hasler, 1993 in Shakespeare, 2006a, p. 29), it brought with it a new branch of disability-based research methodology. This new methodology aimed to respond to communitybased activism, thus establishing an epistemological foundation for disability studies (Goodley \& Moore, 2000). In resisting positivist, medicalized research, disability-based researchers began qualitatively accounting for (by means of including) oppressed people (or people thought to be oppressed) in research (Barnes, 2003). Emancipatory principles were foundational to emancipatory disability research frameworks (Barnes, 2003, p. 10). Oliver (1992) referred to emancipatory research as a radical new approach to research embedded in a three-stage history of disability-related research: the positivist stage, the interpretive stage, and the emancipatory stage (p. 102). Contemporary disability-related research remains unlabeled, and has not yet been added to this pile of stages. However, in 2006, the focus of disability-based research shifted sharply toward rights-based critical disability theory with the drafting of the UN Convention on the Rights of Persons with Disabilities. This convention still acts as a template for research on 
policy, practice, and citizenship (Stanton \& Clare, 2012, p. 1013). Disability inquiry continues to hold on to a rights-based approach, sometimes called the human rights paradigm, but has since evolved into a cultural experience heightened by crip activism and epistemologies wherein labeled people are reclaiming, among other things, the words that have defined disability culture (Longmore, 1995; Linton, 1998; Ignagni \& Church, 2008, p. 627).

Although principles of inclusion are foundational to participatory and emancipatory frameworks popular in disability-related research (Johner, 2013; Johnson et al., 2014; Jones, 2008; Knox et al., 2000), they still reflect normative goals of research and result only in various degrees of success. For example, in 2000 Goodley and Michelle Moore charted a plan for accessible dissemination of participatory research involving a troupe of labeled theatre performers. The plan included a paper illustrated by non-disabled "experts" and called for "contextualized activism" - an exchange of skills and an advancement of political goals (p. 869-870). The researchers concluded that, ultimately, their cartoon-like data made the process "difficult to sell” (p. 879) ${ }^{60}$.

Further, in cases where disability-based research involves people, researchers have noticed several ethical problems as well, such as limits to accountability (Barnes, 2003), and researchers' unwillingness to challenge institutional control of disability production (Barnes, 1992; Shakespeare, 2006a). Colin Barnes (1992) specifies six main issues pertaining to researchers (rather than participants): researchers' lack of empathy for participants, researchers' overuse of talkative/verbal participants, researchers' secretiveness about their intentions,

\footnotetext{
${ }^{60}$ Generally, they wrote, academic audiences found the work to be an unviable research contribution because it didn't meet the normative standards of research procedures and dissemination. This work has since been use to demonstrate arts-based work that risks a "slip into available interpretive frames that foster construction of intellectual disability as childlike and cute" (Ignagni \& Church, 2008, p. 630).
} 
researchers' tendency to focus on the present during observation, and researchers' interpretations of certain phenomena not matching the participants' interpretations of the same phenomena. In later writing, Barnes (2003) also suggests that research dissemination may principally benefit researchers rather than those whose lives they profess to improve, and he questions the emancipatory nature of documenting the experiences of disabled people. After all, social scientists were researching disability long before the social model entered academic discussion (Barnes, 2003, 7-10). Specifically, Barnes refers to Erving Goffman's (1968) exploration of the imposition and meaning of stigma on persons who might be labeled disabled, and Foucault's (1979) writing about formations of subjectivity under circumstances of institutionalization. What's more, Snyder and Mitchell (2006) suggest that if universities can be credited with producing influential cultural beliefs about disability (both medical and social), they can also be credited with producing career-“experts" who justify and validate these ever-changing beliefs, ensuring the difficulty of resistance (p. 19). They argue that, regardless of policy, researchers still consider labeled people as "perpetually available" objects of exploration and normative explanation (p. 28). Barnes (2003), for instance, has outlined issues of accountability to disabled people when, as Davis suggests in his theorization of dismodernity (2010/2013b), disability identity remains in flux for many.

A poststructuralist could carry this argument further and suggest that by subscribing to institutional labels of vulnerability, and disciplinary/institutional actions of emancipation, researchers are re-circulating discourses that socially construct intellectually disabled individuals as vulnerable and in need of emancipation. This discursive de/construction places researchers in a tricky situation. Ellis (1998), who has found herself in similar scenarios, uses stigma as a concept in locating herself through her ethnographic research. "I doubt I would be able to move outside of the category of minor bodily stigmas without first immersing myself within it," she 
explains in justifying her non-traditional research method of placing two stigmatized people together to show knowledge rather than positioning a non-stigmatized/non-disabled researcher with a stigmatized subject in order to argue or prove a point (pp. 523-524). All this to say that the positivist understandings of research ethics that code present-day qualitative research play a large role in orienting us toward intellectual disability, and this orientation continually "turns toward" (Ahmed, 2006) notions of stigmatization and subjectivity/Other formations. When our past and current understandings of the stigmatized body point toward intellectual disability, we are stuck in a discursive cycle of dis/ableism that informs our research and drives our conceptions of ourselves in-relation-to research subjects.

Qualitative, post-positivist research still has not shaken its positivist undertones. And the research carried out and written up here is not excluded from this drawback. Further, some argue that qualitative research of various methodological stripes - participatory, ethnographic, actionbased, and so on — have not produced real social change that forwards the self-declared interests of labeled people ${ }^{61}$ (Ellis, 2007; Oliver, 1992; Snyder \& Mitchell, 2006). Therefore, this research attempts no such feat; it is exploratory rather than emancipatory.

Vignette: Attending to details

Raymond is the only non-regular attendee. He attended the expressive writing group during its beginnings, nearly two years ago. Since then he's been on hiatus doing other activities on Friday mornings, such as art and cooking. In the past he's come by with the latest copy of Hello Canada magazine. Back then, he wrote about the new royal baby, Prince George. Raymond wrote with

\footnotetext{
${ }^{61}$ Snyder and Mitchell (2006) count several examples of participatory action research projects, including some of their own, as representing the "modern disability research industry" that fails to promote the objectives of labeled people and, therefore, slides into an oppressive paradigm by "adding to the research mill" rather than deconstructing oppressive social structures (pp. 200-201).
} 
great, wide-armed gestures and squeals of excitement. Today he walked into the room with squeaky sneakers and the recruitment flyer in hand. He pointed to the flyer and simply said, “This.”

I dodge from person to person, trying to find out if any further individual explanation of informed consent is needed. I will proceed with rolling consent, and with weekly reminders of consent. Right now I'm not sure everyone understands even though (and because) all of the forms are signed.

I explain, again, that people can take their forms home and return them next week, or in a few weeks. They can show their forms to caregivers and people they trust. "Staff?" Sharon asks — her only word spoken to me today. Yes, I explain, and they can call me. "You can call me." They can call Anne. "You can call Anne." They can call Judy, the supervising staff person at this site. "You can call Judy."

One group member holds up my whiteboard marker. "Can you write out the date?” Raymond walks back into the room. I didn't realize he'd left. His song is over. "I'll do it," he says. I hand him the blue marker. He walks up to the board and begins a row of small, shaky lines: $R-A-Y-M-O-N-D$.

“It's October tenth," I say.

"How do you spell that?" the participant asks.

“Here's another marker, I'll put it on the board." I pull out the purple marker. I bring this marker as a nod to Flora, who writes almost exclusively in, and about, the colour purple.

“Wait__ " Grandmaster B, a man nearly twice my size with a green army jacket and a thick band of chains around his neck, catches me by the arm " - I'll write the ten."

"I want you to take a picture of this, " Mr Clark Kent - who has decided against his previous pseudonym of Justin Beiber — holds up a few lines about basketball. 
“Take a picture of this too," Grandmaster B tears a sheet of paper from his notebook. The poem has been ripped from his notebook. His writing method usually involves ripping a piece of paper out of his notebook before he writes on it. Often, after he has written, he scrunches up the paper and throws it in the garbage. Taking photos will be as much an act of preservation as it is an act of data collection.

“Oh, okay, okay," I start up again. "I have something to say to everybody again, if you wouldn't mind listening for just a second. I can't really take pictures until the research has started; today I just wanted to fill out the informed consent forms."

At the other end of the table Ross picks up and puts down his pen repeatedly. He is usually the first person in the boardroom each Friday. Some days I arrive to find him sitting at the end of the table hunched over his notebook, writing. He burns through notebooks. Because Ross's prolific mind cannot be contained in a 50-page spiral for longer than a few weeks, I am constantly requesting new notebooks for the group in my weekly updates to Judy. Once, Ross and I counted how many pages he wrote in an hour-and-a-half sitting - twenty, all covered in names and addresses of relatives listed in his long, blocky print. Ross almost never participates in planned writing activities, preferring instead to release the same words again and again, as if he is reciting a genealogy of relatives and their homes in Toronto, England, and Heaven. Ross looks down at his notebook, and then up at me. As a researcher I am also an annoying adversary that pauses the writing in the name of protocol.

Reconciling research

To continue moving forward with the cultural model of disability in hand, it is important to recognize the need for emergent methodologies under this model. To reiterate, the cultural model emphasizes personal, social, and cultural contexts of resistance toward positivist, biomedical 
standards of normality. It demands qualitative inquiry that includes input from labeled people (Snyder \& Mitchell, 2006). This model differs from the social model of disability in its willingness to acknowledge and explore impairment in medicalized contexts. Unlike the social model which traditionally differentiates between impairment and disability, the cultural model understands impairment to be both human variations in encountering environmental barriers "and socially mediated difference" that may bring disabled people to group identities and phenomenological reflection (Snyder and Mitchell, 2006, p. 10).

And, as Barnes (2003) suggests, at the extreme end of this cultural approach, consulting with people about their histories and lives is never enough:

Recent trends to consult with disabled people on their desires, such as 'emancipatory research' and 'client-centered care,' do not evade the social problem at the heart of disability: if disabled people are subject to the internalization of dominant definitions and values of disability just like those who are nondisabled, then asking clients about their personal goals is not a practical solution to more human models of intervention (p. 8).

Here we detect echoes of what Shildrick (2009) has been suggesting all along: there is a "shared responsibility" to understand and transform the social imaginary, and repeating norms that make up the hegemonic frameworks of our contemporary experiences is an insufficient way of moving forward (pp. 5-8).

Rather than digressing into debates over whether the cultural model of disability presents a methodological paradigm suitable on all fronts, or whether qualitative research should involve labeled people at all, let us work with a realization that underlies the contemporary ethos of disability-based research: ethics are both situational and institutional. Ethical procedures enforced by institutions such as universities, where qualitative disability-based research continues to develop, have been found to constrain inquiry involving disabled populations that may not see themselves as "vulnerable" but are judged as such by the institutional policies that govern research, no matter the theoretical approach that informs them (Holland, 2007; patterson, 
2008; Van de Hoonard, 2002; Smith, 1999). Again, Ellis (2007) draws a distinction between relational ethics, procedural ethics as defined by Guillemin and Gillam (2004) and situational ethics in practice (p. 4). Relational ethics organizes around values of respect, dignity and connectedness between researchers, participants, and communities. In so doing, relational ethics urges researchers to move beyond institutional and personal standards of ethics, and also to move beyond paradigms, such as the cultural model of disability, that suggest avoiding human-based research is the most ethical move forward (Bergum, 1998 in Ellis, 2007, p. 4, 7; Snyder \& Mitchell, 2006). A relational ethics approach is not dissimilar to Somerville's (2006) call to include what she calls "the ethical imagination" in all research endeavors, which includes the mystical imagination, the moral imagination, and the scientific imagination. These ways of thinking intend to proceed with research whose approach is not about finding ultimate truths, but embracing the indirect path to multiple realities and modes of knowledge creation.

The tensions between positivist research traditions and the social model create challenges in finding a suitable paradigm that might fit the values of researchers attracted to disability-based research (Oliver, 1992; Barnes, 2003; Goodley \& Moore, 2000; Longmore, 1995). In order to focus on both sides of this conversation — the situational and the institutional — we must begin in the center of this tension and continually try to navigate and (re)form the research as it unfolds. 
Research roles: Vulnerable subjects, vulnerable observers

'Who am I to write this?' is a necessary question, but not necessarily a paralyzing one.

- Burman, 2011, p. 290

The role of researchers working with labeled people has much to do with being stuck in questions of living, working, and making meaning ethically in institutional contexts. Researchers must be alert to the interweaving issues of relationship building; often, this means attending to power dynamics related to a member of the dominant group (non-disabled researchers) studying others who have less power. This is, again, a discussion of positioning, and of orienting toward intellectual disability where ethical implications are bound up in efforts to (re)connect with the always-already situated and interconnected. This process is one of relationship building, which can be met through techniques of relational ethics that are useful under a cultural model of disability perspective toward the research at hand. For instance, the earlier ethics-based email conversation between the REB representatives and myself hinges on the assumption that the potential participants in the research are immediately vulnerable. People carrying the label of intellectual disability are routinely made objects of research "vexed about the question of vulnerability" (Behar, 1996, p. 5; Carlson, 2010; Snyder \& Mitchell, 2006). Their positioning in this way constructs them as prime examples of "vulnerable" subjects given that vulnerability is a commonly assumed characteristic embedded in the phenomena of intellectual disability.

Vulnerability is discursively constructed as a flagpole that marks the way for nondisabled people to orient themselves toward intellectual disability. Arguably, however, the takenfor-granted pre-condition of vulnerability as applied to intellectually disabled subjects is a characteristic constructed by the ableist ethical processes surrounding their potential participation in research. In her reflection on news coverage of Hurricane Katrina in 2005, Titchkosky (2008) 
describes the word "vulnerable" as particularly insidious in its effect of individualization and its implication of opposition; she asks: if one person is "vulnerable," is the other "strong"?

Vulnerable can be used so that people do not have to imagine how the intersections of some social differences are made to appear as if natural, like unwanted storms. ... From this more social perspective, vulnerable can draw attention to daily life as it is tied up with collective ways of interpreting embodiment. A very deep vulnerability lies in the ease with which we can forget that embodiment is always a mediated social phenomenon. Embodiment appears through intersecting interests of self and of others (Titchkosky, 2008, p. 4).

That the very procedures by which I enter research involving labeled people are already built on a hierarchical dualism that establishes the subjects of research as vulnerable objects means agency is taken away from the participants before the research even begins. The labeling of particular people as "vulnerable" by policies that do not actually encounter these people is an example of a collective way of interpreting embodiment, as Titchkosky (2008) explains - a problem recognized by institutional authority only if enough individuals seem to have it (p. 57). It is through the intersection of the apparently invulnerable researcher and the apparently vulnerable researched that intellectual disability is once again constructed via discursive practices make it an undeniable problem of encounter.

Consider, as well, that ethical implications of qualitative research involving persons with disabilities who are commonly labeled as "vulnerable" involve both situational challenges and ethical responsibilities embedded in exercises of power (Somerville, 2006, p. 5). In some cases, emergent paradigms in the field of disability studies, or imposed on disability-based research, can contribute to the formulation of emergent methodologies whose ethical considerations deviate from those of traditional, positivist research methods. However, a conversation focusing on the ethical implications of person-based qualitative research is a wide one that invites investigation into understandings of culturally constructed concepts of disability, vulnerability, 
competence, and normality inscribed in the Western cultural imagination that guides institutional conceptions of ethics that, for better or for worse, guide researchers' qualitative processes.

Considering that universities are institutions of knowledge-power production under institutional surveillance locally (such as through Ryerson University’s Research Ethics Board) and nationally (such as through the Tri-Council Policy), disability-based empiricism exists at a point of tension between the institution's role in producing research that meets its ever-evolving standards of ethics and the qualitative researcher's empirical investigations of humanness and knowledge-creation. Indeed, institutional ethics regulators enforce policies in response to traditional, positivist methodologies commonly informed by biomedical approaches that have harmed — and undoubtedly continue to harm — people. Yet, some researchers also perform resistance to the institutionalized ethical codes, responding to the potential dangers of the positivist approach (patterson, 2008). For example, in 1992 Lather met with six other women to discuss her research involving women living with HIV/AIDS. She recorded the conversation in her 2007 book, Getting lost: Feminist efforts toward a double(d) science (pp. 49-57). In this conversation, Lather describes feeling suspicious of emancipatory efforts, and in turn the women facing her pick away at Lather's outsider positioning and ask her to explain her expectations if they are somehow transgressing emancipation:

Janet: What do you expect from them [the participants], what are they going to do for you [the researcher]?

Patti: At minimum they are going to tell stories.

Janet: No, I mean to you - you P. Lather. Do you want them to save you from your emancipatory intentions?

Patti: Well, ... that goes back to the larger questions that are huge on the ethics end of it and on the politics end of it. Sometimes I say, why do empirical work at all? What does it mean to use other people's lives as data? (pp. 51-52)

That closing question — "What does it mean to use other people's lives as data?" (italics mine)

(p. 52) - helps us land again at the foundational notion that through our work we make each 
other mean as opposed to only being the effects of discourse (Titchkosky, May 7, 2014). Postpositivist qualitative researchers operating under new paradigms and suggesting new methods and methodologies experience active tensions (both institutional and situational) in deciding what constitutes emancipatory and ethical research involving people and how to make meaning.

Lather (2007) does not go on to explicitly answer her own question, but she does expand on her interest in the ethics involved in her "double gesture" of getting beyond performing whatever text announces (p. 49). Her greatest fear in the doubling of gestures is "that I will kill them with my high theory, that I will eat away their stories ... somehow do them injustice ..." (p. 51). Arguably, a cultural model of disability can lead to alternative methodologies of researching disability by transgressing the assumptions involved in emancipatory research and, instead, introducing and/or including methods that are interactive (that is, including people) and mutual (that is, not necessarily power imbalanced). Thus the ability of these methodologies to match the ethical standards outlined by the institutions that oversee such research remains unresolved. And, as donna patterson (2008) attests, there is no guarantee that researchers will do the "right" or ethical thing with or without institutional surveillance (p. 24); institutional approval for ethical research does not equal ethical research, but simply assumes researchers to be ethical (Somerville, 2006, p. 5).

\section{Ethical decision-making}

One of the most complex aspects of any empirical approach to research with others is making ethical decisions about what to say, whether to say it, and how to say it (Richardson, 1994 in patterson, 2008, p. 19). As patterson (2008) explains: 
What have learned is to be careful in wording ethics applications - to provide possible questions, to avoid qualitative terminology or words such as assessment. Have learned to reshape what am doing mindful of REB's guidelines. Suspect am not alone in learning to give my REB what they want and no more. Experience a consequent closing down rather than an opening of ethical dialogue [sic] (p. 21).

Such struggles are at the heart of tensions in Westernized "research culture" that ties knots between ways of knowing the self and ways of knowing the Other (Smith, 1999, pp. 2, 8). The effect of the "research culture" of the university institution on researchers who are motivated to keep up with the institutions' motion not only to protect privileges already in place, but also to rise to a position of privilege, has been acknowledged in some cases. In other words, students often have to conform in order to earn a job, and this deserves more attention than there is room for here (Smith, 1999, p. 129; Ellis, 2007; Holland, 2007)

Early frameworks of disability-based research that boasted emancipatory and participatory outcomes are now understood to contribute to the unethical objectification of labeled people in research, despite their inclusive mandates (Snyder and Mitchell, 2006). In part, these troubled dynamics stem from frameworks that continue to position researchers as "experts" or "knowers," and triple-labeled participants as "subjects" and "vulnerable," as discussed in earlier sections of this work. In contemporary disability-based research, methods that claim to be empowering, emancipatory, and truly participatory are viewed with suspicion. They may even be rejected if and when they are thought to interfere with the emergent disability-based research agenda of using qualitative methods (such as arts-based inquiry) that attempt to employ empirical evidence and first-person perspectives as valuable and meaningful contributions to knowledge that situate labeled people as experts in their own lives (Ignagni \& Church, 2008; Holland, 2007). 
The difficulty in moving beyond traditional disability-based methodologies, however, appears to be an institutional struggle wherein researchers are bound by the same institutional strategies that tend to disempower labeled people (Snyder and Mitchell, 2006). Holland (2007), for example, offers an account of the ethics committee at the University of Canberra rejecting her application to interview people diagnosed with "mental illness" (p. 8). Holland also writes about adapting her language to reflect the ethics committee's understanding of "mental illness" (to use her language). Her adaptations included using words that carried overtones of diagnostic, biomedical interpretations such as "patient" rather than the group's own terms that have been re/claimed to resist passive diagnostic labels, such as "consumer/survivor/ex-patient," or, more simply, c/s/x (Holland, 2007, p. 987). The committee cited several reasons for their decision, including Holland's decision to disclose her personal past experience of mental illness. In response to the ethics committee citing the disclosure of Holland's previous experiences as a psychiatric c/s/x as "not appropriate," Holland writes:

This form of transparency is a central precept of emancipatory and qualitative research and is essential ... . Failing to identify myself in this way would have been a form of deception, from my point of view, and no amount of ethical advice to the contrary would change my reality (p. 903).

Holland's writing is important because it highlights tensions between the idealized processes of qualitative research and an ethics committee's resistance to post-positivist research involving people (Van Den Hoonard, 2002, p. 3).

For some researchers, the difficulty in moving beyond traditional disability-based methodologies is an institutional struggle. Researchers striving to empower their participants perhaps their friends — are bound by institutional strategies that tend to disempower everyone involved (Snyder \& Mitchell, 2006). Institutional resistance to emergent qualitative, disabilitybased research is increasingly common in disability studies literature: Church et al. (2006) 
tolerate "being managed" by a corporate bank during their reflexive ethnographic exploration of the work-learning relations of disabled employees in the corporate financial sector (p. 70, 8182); Titchkosky (2011) outlines a fights for or against access that begins with the Universal Symbol of Access on a workplace bathroom door that only opened an inaccessible 24 inches, and ends with her call to uncover meaning by drawing on the "say-able" (p. 40-42); Goodley and Moore (2000) recall resistance from academic colleagues about their decision to present and publish an illustrated translation of a participatory theatre project with labeled people, and their fear about losing funding for future projects; Ross Gray (2000) describes the difficulty of extending beyond traditional researcher roles in person-centered contexts to include positionings such as "worrier," "two-bit-hustler," and "conveyor of hope" — these remnants of research positionings are unaccounted for in institutionalized processes of informed consent; patterson (2008) describes her fear that qualitative researchers must satisfy the academy rather than seek new knowledge after suggesting to her university's REB and the Tri-Council that people be called "participants" rather than "human subjects." patterson suggests that perhaps many more accounts of institutional barriers to research go unrecognized:

Seems almost easier not to speak about this, just in case — am left wondering how much else of a similar nature is not spoken of, hidden, 'lost in the shuffle' because those involved have not been able to find a way, an ethical way, to approach and speak about such matters [sic] (p. 19).

The "hidden" side of contemporary disability-based research, or disability-based research attempts, points to a muzzling of qualitative researchers attempting to work with "vulnerable" triple-labeled populations. While institutional ethics guidelines play a role in protecting researchers, participants, and the disciplines and institutions under which research takes place, some person-based research has hit a dead-end. Some researchers do not make it through the 
informed consent phase ${ }^{62}$. Others may turn away from institution-based research and engage in community-based research, which has its own ethical processes and demands "subjective rigour" (such as knowing when to stop researching and how to admit bias) (Ontario Public Research Interest Group, 2014). Importantly, as Holland (2007) points out, researchers in the humanities and social sciences continue to make significant contributions to this field outside of the constraints of research ethics committees (p. 896). What is hidden, then, remains invisible. A sense of silence exists in dead-end disability-based research that characterizes this type of research in the context of contemporary, institutionally-directed qualitative research climates.

\section{Taking up "the ethics of ethics"}

The encounter with other perceivers continually assures me that there is more to any thing, or to the world, than I myself can perceive at any moment.

- Abram, 1996, p. 39

The empirical dead-ends that characterize intellectual disability research do not represent a turn away from person-centered research as the cultural model suggests. Rather, they are an avoidance of institutional research protocol that excludes certain populations, and in this reorientation toward research we are confronted with relational ethics. I am suggesting that perhaps, rather than turning away from research in student-based work contexts, or rather than leaving parts of our curiosities unaddressed and pointing to gaps in the literature, we reposition ourselves as something other than knowers in relation to the people from whom we hope to learn.

\footnotetext{
${ }^{62}$ Holland (2007), for example, dropped her project when she refused to meet the ethics board's requirements. And, as patterson (2008) points out, such studies are difficult to locate as they are unlikely to ever be published
} 
However, charting a person-centered research course from within institutional confines, as some researchers must, may work if using the objectives of a cultural model under the guidance of a relational ethics approach. These frameworks may serve to reform person-based research by discrediting institutional assumptions under which researchers work: for example, that some people cannot make decisions or take risks, and that researchers have no past or future relationships with participants and vice versa (Ellis, 2007, p. 5). Although tricky, culturalrelational approaches could increase the vulnerability of the researcher through demands of flexibility, circumstance, reflection, and confrontation by the people she or he chooses to research - (somewhat) leveling out the imbalanced power between researcher/researched that currently informs research ethics policy. By taking up "the ethics of ethics," including those embedded in the informed consent processes, researchers may re-frame long-held notions of incompetence and vulnerability by supporting "talk back" motions about, and amid, research on some people's lives (Somerville, 2006, p. 5). Whatever the approach, researchers who come face-to-face with triple-labeled participants situate themselves amid considerable tensions and a disquieting history that continually shapes current cultural locations of research and disability.

Vignette: Collecting informed consent forms

"Hold on a minute, one word at a time," I scramble to get Grandmaster B's words onto the whiteboard. For several weeks Grandmaster B came to expressive writing group and wrote nothing. Often he would sit down, wipe his nose with the back of his hand, and then rip up bits of paper until he got bored enough to leave. And I don't mean to be presumptuous about his feelings; he would literally say, "I'm bored. I'm doing art instead," and walk out the door. 
Then, one day, Grandmaster B curtly asked if he could tell me a poem. When he spoke his poem aloud I wrote it on paper and he began copying the words into his notebook. Much of his poetry emerges in this way: he speaks the poem, then I write it on the whiteboard or on paper in clear, capitalized, printed letters. Then he rips out a page from his notebook and copies his own poem on to the paper, either to keep or rip up. We have clear conversations announcing that even though I am doing some of the writing, he is the "real" writer, the "real" poet. Once Grandmaster B gets through the first two lines of this poem — and, indeed, the line structure is determined by how much space is on the white board at any given moment when poems erupt he hands it to me. "You should keep this for your research."

"Thank you. Maybe I will. But why don't you hold on to it for now?"

"You didn't write it." Grandmaster B says, launching us both into a non-linear conversation.

"No, I didn't," I confirm.

"But you wrote it on the board."

"Right."

The poem on the board is longer now, and it says something like this:

SUN WILL ALWAYS SHINE ON YOU

ALWAYS BE THERE FOR YOU

LOVE WILL ALWAYS BE AROUND YOU

"So, you wrote it?" he asks me. 
"No, I would say you wrote that poem," I respond, trying to hand over some degree of authorship. "I just put it on the board. But my putting it on the board was part of your writing process, you know what I mean?"

"Because I suck at writing."

"I wouldn't say that." I try to speak softly, patiently. I often tell Grandmaster B that he is something of a poet. I say it because I believe it, but I wonder if it will sound paternalistic if I hear myself say it on the voice recorder one of these days. He speaks in poetry, and he is the only person who specifically requests readings of Shakespeare texts from time to time.

Mr Clark Kent pushes his notebook in front of me. Everyone has learned over the months that sliding a notebook over my own, or simply holding it near my face, tends to be a good way to pull me out of whatever I'm doing. Sometimes raising a hand or calling my name isn't enough, depending on how many people are doing the same thing. I'm aware that I have become the focal point of the room. The attention I asked for at the beginning of the session has not, and likely will not, lull. I wonder how much of this spotlighting is associated with the informed consent forms and how much of it is just usual routine for participants who are used to having the only nondisabled person in the room directing everything. I'm used to this spotlight - too used to it. Redistributing power can seem impossible in some moments, and I admit that micro-managing can sometimes simply be easier so I just do it. I worry that I am not the ideal researcher for this type of work. I also don't know how to re-orient everyone toward any other focal point right now. "I think I'm done," Mr Clark Kent says. He's written a few words about friends pushing him around. "Can I take a picture of you?" he asks, digging an iTouch from his pocket.

"I'd rather you didn't," I say.

"Okay, sorry about that." 
"That's okay." Am I modeling proper consent procedures? Or am I just being difficult?

I look around the room. Ross is writing. Sharon has her head down on the table;

occasionally she has a little snooze in writing group. Raymond is in his chair, looking at a blank piece of paper. Flora is churning through her SpongeBob text, one purple word at a time.

"My poem is about my girlfriend," Grandmaster B says, redirecting my attention once again.

"Okay, thanks." I want to hear more about Grandmaster B's writing, but in this story I can see that some participants, specifically the two women in the room, are fading into background characters. Everyone at this point has filled out the informed consent forms without opting to take them home, to my surprise. I assumed it would take weeks to collect the signatures, that people would want to consult with outsiders. I have either failed to give enough credit to my participants and their understanding of this research or I have failed to explain it properly. I try to tally up bits of the morning that might count as non-failures as the warm smell of gravy wafts into the room. Turkey dinner is only minutes away, and the clatter of utensils is calling. Out of the corner of my eye, I see Flora look at her watch. Sharon lifts her head. "Is this how you spell it?"

"Spell what?" Spelling is always the thing. People want to know how to spell things properly, again and again. I imagine it will be conversations like these that the voice recorder will pick up most. There will be days of silence broken only by, "Is this how you spell it?" I walk over to Sharon's notebook, where she's written "rasing."

"Rasing?" I ask. "What does that mean?"

"Like, rasing," she says. Right.

"Raisin?" 
"Reason," she says, more slowly this time so I can catch the word.

"Oh, reason," I say, and spell it, slowly, letter by letter, moment by moment. Meanwhile, Grandmaster B pulls up a chair beside me. He rips his poem out of his spiral notebook and holds it in front of my face, so close the page grazes my nose. I ask him to lower the poem and wait a minute, please. He holds the poem steadily until Sharon and I work through "r-e-a-s-o-n.” Then I turn toward him.

"What will your teacher say?" he asks.

"My teacher?"

"This one," he points at my supervisor's name, written on the informed consent form on my lap.

"Oh, Anne?"

"Yeah, Anne. What's she gonna say?"

I pause. "I truly don't know." 


\section{Chapter 9: "Why writing?": Reflections on method, motion, and writing as intellectual disability}

... Such a science of writing runs the risk of never being established as such and with that name. Of never being able to define the unity of its projects or its object. Of not being able either to write its discourse on method or to describe the limits of its field.

- Derrida, 1976, p. 4

To write is to reflect; to write is to research. And in writing we may deepen and change ourselves in ways we cannot predict.

- Van Manen, 2014, p. 20

I have been asked, "Why writing?" Why choose writing as a method instead of painting, performing, or any other arts-based method that might end with some sort of spectator display? After all, participatory and emancipatory methods tend to have a climactic end-point, and much research involving labelled people falls under those categories. Mine doesn't, and I'll say more to that end later. But, I might be asked in the meantime: Don't you want to show off the work? Shouldn't there be some sort of public reading? Shouldn't there be some sort of closure — some sort of ending as our Western ways of understanding writing have taught us to expect? (Smith, 1999) Still, no. I do not intend to display this research for the sake of display. And I choose writing for its unpredictable invisibilities, and, more pointedly, because writing and intellectual disability are not separate concepts in the context of this research; writing is intellectual disability, and thus writing is more a way into a phenomenon than a ceremonial result.

Writing is the primary method here because so much of it is invisible, though its invisibleness is often overshadowed by visible language representations (signs) and a common understanding of these representations known as literacy. Visible/visual communication takes the form of writing: the sign, the word, the discourse, the logos — otherwise defined by Heidegger (1962a) as the manifestation of "what one is 'talking about' in one's discourse" made accessible 
to the recipient (p. 54) — read through logocentric lenses (Derrida, 1976). Paradigmatically, writing is a representation of speech acts thought to be suitable for visual representation and communication (Olson, 2009, p. 6, 9) — though Derrida (1976) has written otherwise, suggesting that writing is a process in and of itself that does more than step in and signify the phonetic (pp. 40-41). More briefly, David Olson (2009) offers a critical account of the history of writing. "To tell the history of writing, even in its paradigmatic sense," he explains, "it seems essential to begin with a more comprehensive view of writing as the use of created visual marks ... for communication and expression" (p. 6).

While an extensive review of Olson's work is not possible in this chapter, it should be stated that he traces writing in the West as a modernist form of rationality symbolic of the leap from pagan mysticism (magic and the invisible) to the Protestant Reformation. Modernity is also associated with a liberal recognition that each person should be allowed opinions and forums to express those opinions, including through language and writing (p. 14). However, Olson also suggests that in order to understand the conditions of possibility for writing to arrive as it does currently — visible, logocentric — "we must set aside our literate prejudices, our tendency to assume as natural and obvious that language is an object available for inspection; that we have a natural consciousness of language" (p. 9). 
A note on functional writing

I wake up and find myself swimming in a medium given to me. It's like waking up immersed in a pool of water: I have to keep myself afloat with the actions of my body. I speak because I am immersed in speech; my gestures are a form of treading water.

- Vernon, 1979, p. 14

'Did you bring any of those, um, what do you call those things in a book?' 'Poems?'

'Yeah, those.'

- Field work notes, Feb. 6, 2015

If the body is implicated in language, then we can also hold that bodies have been excluded from language and that language has excluded bodies. This exclusion is evident in the action of labeling. As Hannah Arendt (1998) suggests, speaking both to the limitations and the impact of language, "the moment we want to say who somebody is, our very vocabulary leads us astray into saying what he is; ... his [sic] specific uniqueness escapes us" (p. 181).

Yet, despite this exclusion by type - for some bodies are allowed access to language and some are not (Prendergast, 2001) — Vernon seems to suggest, in the passage above, that being a human being means being immersed in language: meaning that to be human is to be part of the bodily gesture of language and the wider, overshadowing discourses in which bodies operate. Restated from a poststructural feminist perspective, the way people use the resources (language) available to them is, as Triantafillia Kostouli (2009) explains, also the way they re-articulate and circulate their own meanings and reveal their power to re-configure, re-write, and improvise subjectivities (Dyson, 2002, in Kostouli p. 1-3). For Vernon (1979), this involvement evokes the effect of drowning. Here, Vernon specifies an immersion in speech, which serves as a reminder of the links between speech and writing as systems of thought referred to by Derrida (1976) as the normative (ableist/audist) demands of phonocentric and logocentric society, respectively. As H-Dirksen Bauman (2004) points out, Derrida recalls the fallacy that "language is speech," and 
speech is linked to identity - a fallacy that renders people outside of normative realms of language/speech "Other" (p. 244). It is the fallacy that we become human through language, and outside of language we are something else. "Historically, we humans have identified ourselves as the speaking animal; if one cannot speak [participate in language] then he or she is akin to human in body but animal in mind," Bauman writes (p. 244). Vernon (1979) seems to suggest otherwise — that we are human all along, and as humans we are implicated in language and discourses and we must sort our way through somehow. Also we may be reminded of Arendt's (1998) notion that speech (meaning something wider that pulls toward language) and action (meaning relationality) are "the modes in which human beings appear to each other" (p. 176). All this to say that Western traditions favour functional communication, such as understandable talking and writing, over non-phonetic writing and the phonetic ruptures of the body that are less understandable, and that these functional types of communications impact subjectivity formation.

Logocentrism is an important concept in understanding functional language because it refers to the understandable and to the action of striving toward understandability, sense-making, and normativity in language acts (such as writing). Derrida (1976) calls this type of writing "nothing but the most original and powerful ethnocentrism" that imposes order on both writing and truth (or Arendt's action), which is ultimately the "debasement of writing" (p. 3). As Kostouli (2009) summarizes, social realities are constructed by language, and knowledge is constructed by discourse (p. 108). Perhaps it is no wonder, then, that Vernon's (1979) feeling is the sensation of treading water, an act of resistance and recovery from the suffocating weight that pushes the body downward: language. 
Arriving at writing

Prior to the modern visible there is a type of "preknowing" in the gesture of writing, a type of knowing you cannot know until you have written (Cixous, 1993, p. 38). That is not to say that other methods don't sludge through certain types of invisibleness as well. As Merleau-Ponty (1964) points out, while science — language — has established itself as the modern way of knowing, "painting, poetry and philosophy have forged ahead boldly by presenting us with a very new and characteristically contemporary vision of objects, space, animals and even of human beings seen from the outside, just as they appear in our perceptual field" (p. 45). For instance, Jenna Reid and Danielle Laudry explain that in their course-based practice of Internetbased mad art displays students are given a choice whether or not to publicly display their artists' statements. When students choose not to explain their art, the effect is a collaboration of madness-based art-making that uses art to establish new ideas that don't resemble disciplinary boundaries, and "that's good, but without explanation we miss many of the intricacies [artproducers] want to explore," Reid says (Reid \& Laudry, Feb. 27, 2015). And certainly, as a visible form of expression, normative writing excludes much.

Normative writing tends to exclude this type of pre-knowing, or at least language often falls short in acting an adequate mode of expression. Therefore it is important to recognize, as deaf studies scholars have in conceptualizing the concept of Deaf Gain, that an effective response to the violent normalization of disabled people's experience can be found in reframing disability experience, and representations of it, as a form of diversity that can be counted as a contribution to culture (Bauman \& Murray, 2013, p. 247). Deaf Gain "is the notion that the unique sensory orientation of Deaf people leads to a sophisticated form of visual-spatial language that provides opportunities for exploration into the human character," Bauman and 
Murray (2013) explain (p. 247). Deaf Gain emphasizes the study of language and the important cultural and anthropological contributions signing (rather than writing or speaking) communities make to the study of language, and supports the notion that Deaf people's visual orientation toward the world is an important way of knowing and meaning-making in an increasingly visual culture (p. 248). By writing we can understand that normative words are only "an arbitrary relation to the thing represented" (Olson, 2009, p. 7), or, in other words learning from Saussure's grand lesson that words are signs not directly associated with their signifiers except through association (Derrida, 1976) — writing moves away from the ambition of writing and away from normalization.

Perhaps most central to this project is the notion that normative writing, in its logocentricity, and dressed in its costume called "literacy," tends to exclude particular bodies. Ahmed (2006) explains that our orientation toward particular objects, including bodies, texts and even the objects of writing (paper and pencil, for instance), has much to do with the "nearness" of these objects (p. 52). In the writing involved in this project, participants are given space and time to write in order to bring them nearer to the possibility of writing that is not otherwise presented — to make writing reachable is the only way to make writing possible, and the action of writing produces writers as subjects, making the body a tool for an additional type of expression (outside of other arts-based forms and outside of restrictive notions of literacy) (pp. 52-53). Ahmed goes further, reminding us that bodies "tend to do" what they are oriented toward: the work they already have to do, and the effects of that work and its repetition; "what bodies 'do' leads them to inhabit some spaces more than others" through action or inaction (p. 58). The inaction of writing signified by the absence of literature written by triple-labeled people points toward barriers they may face in attempting to write rather than any apparently natural aversion to writing. This silence is the other side of a larger discourse that pegs triple-labeled 
people as non-writers (Foucault, 1978). Therefore I do not advocate for writing as the most efficient method of inquiry. However, for the purpose of exploring how intellectual disability emerges through writing, I must create space for writing, which is another way of saying that I must create a space to repeat the action of writing and produce writers. By orienting participants, and the research, toward writing this method becomes a now-possible form of embodied expression that leads us into invisible realms that are historically and commonly out of reach for triple-labeled participants. As Ahmed (2006) contends: "The point is simple: what we 'do do' affects what we 'can do"' (p. 59). The idea behind choosing writing as a method is to find out what happens when triple-labeled people occupy space as writers in the nondisabled domain of writing.

\section{Writing as motion}

Writing is the bodily gesture that, according to Cixous (1993), we descend into with difficulty "as we would the earth or the sea, positioning our bodies in such a way as to approach the unknown" (pp. 5-6). Writing, in its particular reflexiveness that winds through the internal and spills into the external, is a bodily movement that takes place between the semiotic and the symbolic (Kristeva, 1984). The semiotic tends not to be tolerated by the logocentric norm; writing by people who live as they write tends not to subscribe to the way writing should be (Cixous, 1993, p. 115). Un-understandable writing is a type of action that plunges the writer (the do-er, the knower) into the invisibleness of "the cultivated domain" of consciousness to the same degree as understandable or "translatable" writing sweeps writers away (Cixous, 1993). Both forms transport writers to the same, invisible place of explosive thought, but only one type — the "translatable" or understandable — emerges alive, with potential to be passed forward to recipients (readers); usually only the "translatable" has an audience (Field, 1934b, p. 12). 
This research deals with two types of writers: those who move into writing's invisible, mysterious realms and emerge with sometimes "untranslatable" scribblings, and those whose scribblings come from a similar place but can be exploited for social and capital gain in a logocentric world where normative writing rules. The research follows Cixous's (1976) directive: "Write your self. Your body must be heard. Only then will the immense resources of the unconscious spring forth" (p. 880). At the same time, it also heeds her warning that writing by people who live the way they want to live (which is often by swimming against normative streams of thought) is rarely tolerated (Cixous, 1993, p. 115). Therefore this research is positioned in "the space between" freedom and restriction. The space between these two different types of discoursing ("letting something be seen," as per Heidegger) is reflective of cultural locations of disability, in particular those cultural locations of the dys-/articulate (1962a, p. 55; Berger, 2014; Snyder \& Mitchell, 2006). The space between is also writing.

So, back to the opening question: Why writing? Because writing is a gesture that always demonstrates cultural location, and where we are located "gives us a certain take on things" because perception involves orientation (Ahmed, 2006, p. 27). In this case writing demonstrates cultural locations of intellectual disability by inviting the reader to attempt to understand "untranslatable" writing and sort out her or his (often troubled) relation to it. 
Narrowing writing toward method and motion

As sure as you can think some mysteries in only one language and not another, so too can people think untranslatable mysteries.

- Cixous, 1993, p. 3

Here, I focus on writing as a method to address the fourth research question of this study, which follows Cixous (1993) and van Manen (1990) in asking what it would mean for "untranslatable" expressive writing to be read as reflecting the pre-verbal sensations present in the lifeworld.

Figuring out "what it would mean" involves approaching writing somewhat phenomenologically, since phenomenology allows readers to feel out writing not only for its signifier but also in an effort to get behind it and to become involved in the invisible (Ahmed, 2006).

In this case, the invisible invites gestures of writing scribed by triple-labeled people. This scribing could be better called cultivating, constructing, building, or edging toward. Following Heidegger (1971), building, dwelling, and thinking are one process that works as testimony to poetic ability if poetic writing is not perceived logocentrically but thought of as the primordial "ability to take measure of the world" (Hofstadter, trans., 1971, p. xiv). Further, by reflecting the pre-verbal sensations of the lifeworld, reading invisible or "untranslatable" writing in this way allows us to encounter writing not as something that refers to intellectual disability as object, but as intellectual disability. In short, let me restate that expressive writing is intellectual disability. Writing, in this way, allows for the object to become human. Through writing, "an inner space opens up, a space we call the subject; and into that space, herded together in order to exist, come joy, disgust, love, or puzzlement," and in this turning-over, in this transformation, the subject becomes subjectivity (Vernon, 1979, p. 30). Again, disability brings all cultural endeavors into being, and writing is one cultural endeavor that brings intellectual disability into being 
(Titchkosky, 2008, p. 4). Thus, the question of "what would it mean ... ?" is met with methodological meaning-making processes that adopt writing as way of re-encountering intellectual disability as presence inside of, and outside of, invisibility despite degrees of un/translatability.

Another reason why writing is useful as method and motion is because it triggers the eruption of the subject and opens up new social and ethical possibilities for the subject inrelation-to. The space between the many sides of personhood that form our personal ideas of subjectivity is a deep, unconscious space that we may access in several ways, including through writing. To demonstrate, van Manen (2002) notes the difference between producing words ("silently chewing them and then spitting them onto the keyboard, onto the computer screen") and writing, which is an unconscious process (p. 1). Because writing is singular, and because when one writes there is no response - especially to the obfuscated, non-normative forms of language confronted in the act of writing — there is no "other" (Vernon, 1979, p. 28). Writing brings us in-relation-to rather than into terms of separation; we do rather than desire. In writing, Vernon (1979) explains, "the Other becomes dislocated and lodges partly in me, partly in language itself. A gap opens up .... This gap is what we call the subject” (p. 28). To rephrase: writing makes room for the subject to appear without objection or scrutiny from outside. Through writing, those who are objects of research emerge as subjects by the marks, or absence of marks, on a page. What follows in a writing group, where writing takes many forms — an individual task, a group endeavor, this research project, my/your personal habit, a grouping of new types of literacy — is writing in-relation-to: a willingness to give up ownership of the text and thus a willingness to give up ownership of 'my' body (Price \& Shildrick, 2002, p. 65).

We may understand writing as a wide communicative gesture that is intellectual disability and thus a gesture that can nudge us into a phenomenological exploration of "what it 
would mean" for "untranslatable" expressive writing to be read as reflecting the pre-verbal sensations present in the lifeworld - a process that involves not only our head and our hands (a position embodied by participants and researcher alike, here), but the entire sentient body as it is funneled into expression (van Manen, 2014, p. 20; Vernon, 1979). Writing is a way of expressing creativity in the face of constraints, both internal and external. Thus writing is an act within and against the discourses that build intellectual disability, and even the discourses that build logocentric expression. Writing is, following van Manen (2002), a temporal experience that carries the body in an ebb and flow pattern against and away from the lifeworld within which its concept is structured:

To write is a solitary experience, a solitary and self-forgetful submersion into textual reality. ... Strangely, in the space of the text our experience of language seems to vacillate between transparency and impenetrability. One moment I am totally and selfforgetfully entering this text - which opens up its own world. The next moment the entrance seems blocked; or perhaps, I am re-entering the text with an acute awareness of its linguistic obscurity and darkness (p. 3).

Following Solnit (2014), it is a movement into "patches of darkness" and unknowing that invites us to writing (p. 87). And here, in writing, the body is propelled into recognizing its own falseness and the falseness of normative, authoritative knowledge (p. 88). This propelling of the body through the motion of writing is depicted another way by Cixous (1976), who describes l'écriture feminine as woman's gesture. One of her many metaphors is flight: "Flying is woman's gesture - flying in language and making it fly" (p. 887).

We are reminded again, then, that writing is also closely linked to speech and to reading; these are one in the same process (Cixous, 1991; Derrida, 1976). Writing and reading are gestures that allow expression — be it normative sign-making or non-normative movement — to "draw us in" in order to create autonomous works so singular they can, at times, be indecipherable (van Manen, 2002, p. 4). Writing and speech can be considered synonymous because each gesture 
calls into question the idealization of its form (Derrida, 1976). As Dertscher (2005) explains,

What is attributed to 'writing' must be attributed to 'speech': in both there is some delay, some lack of satisfaction, some possible discrepancy from what is imagined as the originating idea, or consciousness (p. 10).

We return then to the paradigmatic understanding of writing as representation of speech acts both in its visibility and its invisibleness (Olson, 2009, p. 6). Writing, therefore, is a blended method that means more than one thing. Because of writing's swing between cultivating individualistic subjectivity and subjectivities in-relation-to, this method lives in a larger, interpretive and participatory methodological sphere.

\section{The political edge to writing}

Returning to the question "Why writing?" Rosalind Jones (1986), in her explanation of l'écriture feminine, offers another reason to write:

We are more likely to write, and to reach each other's writing, if we begin by working against the concrete difficulties and the prejudices surrounding women's writing than if we simplify and idealize the process by locating writing as a spontaneous outpouring from the body (p. 229).

The "concrete difficulties and prejudices" to which Jones refers are the markings of the sociopolitical contexts in which all writing takes place. Olson (2009) explains that writing has always been a political act involving writers with political and creative motivations leading up to the realms of modernity where expression, reading, and interpretation are valuable aspects of literacy and thus valuable aspects of writing. These modes of expression and understanding are taught in social institutions (such as schools) and are wide-reaching globally and in the West, where this research takes place and where writing is an active type of social practice. For example, In his historic account of writing, Olson (2009) concludes that the history of writing is a story of ongoing discoveries of increasingly abstract and rebellious language (p. 12). 
Consider, then, that with writing by triple-labeled people we may "locate" writing as an expression "of the body" by engaging in culture within ourselves: by making time and carving a physical and ideological space for a particular type of writing to emerge. This means writing by engaging in the semiotic and embedding a political imperative in this writing by working against ableism by letting go of ableism and allowing writing to emerge as a spontaneous outpouring of the equalized body. Giving attention to this type of writing motion involves political economy, "or an uneven distribution of attention time between those who arrive at the writing table, which affects what they can do once they arrive," and - Ahmed (2006) notes in brackets, which I will remove to uplift the significance of this repetitious message - many do not arrive at the (literal and metaphorical) writing table because they are not allowed there based on the ongoing labour of other "attachments" (p. 32). For example, Prendergast (2001) describes the separation of normalized discourse from another, seemingly opposing, type of discourse demonstrated by her friend Barbara whose selfhood is impacted because she is labeled as schizophrenic:

Barbara's 'rich lifeworld' accounts have over the course of time I've known her involved CIA drug-testing at parties she's been to, visions of Jimi Hendrix visiting ward B3, and detailed descriptions of thoughts that have been projected into her head by outsiders. They consist of a number of things I don't believe in, though more significantly her doctors don't believe in them. Initially, talking to her about these subjects, I felt the privilege of suspending my disbelief long enough to consider that, well, she might be right. She might be a canary in the mines, more sensitive to the vagaries and possibilities of the technological, political, and spiritual present than I am. ... she has an experience of certainty I can't even approach (p. 55).

That Barbara's subjectivity and selfhood (as "carrier" in Sontag's reading) (2001) is perceived of as other than normal somehow affirms that her stories (her prose), as well, should be located outside of normative realms of possibility.

As Sontag (2001) predicts, the ostracized side of this subjectivity equation leads to the death (or "pathetic fate") of it all; there is no prose Barbara could articulate that could pass as normal since her body is diagnosed as "outside of language" (Berger, 2014, p. 32). Presumably 
Barbara's ticket to normality would be an ability to construct "normal" stories or erase her current lifeworld. Crucially, labeled people have life experiences that are routinely disavowed as lacking, abnormal and invalid because of their untranslatability. Yet, collectively, labeled people have accumulated a significant body of knowledge (a cultural corporeality) that could be further developed (Wendell, 1996, p. 73). Giving time and concentration to writing, then, is a way of resisting a political and social economy where labeled people are intentionally positioned under erasure and away from deep-thinking work (including research about themselves).

Additionally, through writing, the expressive takes unpredictable shapes. Some of these shapes are political: all may write if the understanding of writing is broadened to include untranslatable and invisible works/worlds. However, non-disabled people are too often permitted to appropriate disability in their writing, while disabled writers are understood to be regressing when they fall into the realm of semiotic expression that tends to oppose the functional/symbolic. This schism represents the space between intellectual disability and (to borrow from Mairs, who overturns concepts of lack) those without its label (Mairs, 1996 in Mintz, 2007, p. 36). Indeed, looking back at Jones's (1986) assertion, writing by people marked with intellectual disabilities can be communicated through the body, and can also be a conscious response to dis/ableist realities (p. 230). This movement away from normative writing involves shedding all of its structures, all of its ceremonial milestones such as public readings and publications. Nonnormative writing involves making space to write, to enter the invisible, without tangible reward. However, as mentioned earlier, the inherent discrepancy present throughout this project is the reality that this writing will end in reward likely for only one of the many writers involved. This violent imbalance, so inherent in research, will, at least, have some purpose in highlighting cultural locations of disability. 
There may be some recourse, however: writing cannot tell us everything. In many cases it may tell us nothing, because it is not always writing's intention to communicate despite paradigmatic understandings of writing's purpose (Olson, 2009). Indeed, it is through this firm attempt to use writing as a way to create meaning-embedded discourse that discourses become linked to power because they present certain relationships/meanings as "true" and normal, thereby excluding other forms of knowledge from "truth" or normality (Kostouli, 2009, p. 102). However, in the context of research that does not seek logocentric "truth" (Derrida, 1976, p. 3) and does not desire to know everything under the pretense that not everything needs to be known — or, written another way, the pretense that not every problem needs to be solved and that presence without explanation holds validity — writing should not tell us everything. Instead, as Vernon (1979) explains in reference to poetry, writing "brings us through what can be said to the verge of what can't be said" (pp. 83-84). And, what can 't "be said" is that which calls for space and presence. In Lather's (2007) words,

... texts that do justice to the complexity of what we try to know and understand include the tales not told, the words not written or transcribed, the words thought but not uttered, the unconscious: all that gets lost in the telling and representing (p. 13).

Thus, throughout this research I take up writing as method of telling and representing that finds out about itself as it goes along because writing is intellectual disability; some of what writing finds out has a political edge, some of it less so. Writing works through first thoughts and re-writing, through letting go and returning, and by noticing when words are not enough and when metaphor is no longer sufficient. The limits of language are part of writing, the edges of expression from which we fall toward other methods. Here, in this space that is endless and that also has limits, I stick to writing as method/ology and movement so that I can reflect, research, and change in ways I cannot predict (Van Manen, 2014, p. 20). 
Returning to the research

My research does not focus on writing about disability, simply for the reason that not all disabled people will be interested in writing about disability. My group-driven approach nevertheless attempts to situate triple-labeled people into a group where some may find it difficult to understand the writing of others. Still, disability is not an inevitable topic in this context. Also, during the "Once Upon a Time" meetings, time is taken to explain meanings, which gives community-based readings an inclusionary dimension that is lacking in individual reading and writing (Pollard, 2007).

Further, little is known about the everyday literacy levels of adults with intellectual disability, making even recruitment for this project difficult: it was not unusual for staff pull people out of the group or discourage them from joining by saying, "but he can't read" or "Her? No, she doesn't know how to write.” Though, to her credit, Judy Endacott made a point of ensuring each person at JS Manson received a recruitment flyer regardless of any outsider's expectations of individual literacies. Under the guise of functional language, this recruitment dilemma calls for a reimagining of what literacy means, and thus a re-thinking of writing that can be explained briefly. Of course, I don't always succeed at this task. For example, in one transcribed instance a participant was writing and a new staff member, unfamiliar with the procedures of the "Once Upon a Time" writing group, came into the room and looked over the participant's shoulder: 
Staff: What are you guys doing here?

Participant: I'm writing something.

Staff: I'm talking to Chelsea. Did you forget? [Looks over the participant's shoulder at her notebook.] You're writing something, that's for sure.

Chelsea: At this very moment, $\square$ and I are going over the informed consent form, because part of this group has to do with research. But generally speaking we all come together and write about different topics. We call it expressive writing because some of the writing, like is very expressive. The goal is not to label any writing 'right' or 'wrong.'

Participant: Thank you for coming.

Staff: Wow, I'm being thrown out.

Participant: Yeah. [Looks down at her notebook and keeps writing.]

The staff member's comment, "You're writing something, that's for sure," was spoken sarcastically, as if to suggest that the participant was writing something bizarre, or something not to be taken seriously. Nobody explained to the staff member that the participant's loops and swirls were potentially something more (and in fact this writing was later described by the participant as a story about a family member). Also, from what I recall, I failed to recite my "schpeel" properly because I was a bit taken aback; most of the staff at JS Manson are aware of the confidential nature of this research project and rarely enter the room without knocking. Still, there are instances in research where situational ethics rule and the responses to them are imperfect. 
Expressive writing as method

... I had read many descriptions of the contents and habits of the 'unconscious mind' which by definition was something I could never by unaided effort know in myself. But I had not realized that no man's land which lay between the dark kingdom of the psychoanalyst and the cultivated domain of my conscious thought was one which I could most profitably explore for myself.

- Milner, 1987a, p. 12-13

Certainly there are some benefits to using functionalistic approaches to transcend traditional understandings of literacy, including the major benefit of social participation, a normative perk the social model continually works toward (Shakespeare, 2006a). Still, we are implicated in language and thus we are implicated in risk. Language remains the grand organizer of the logocentric and phonocentric world, and it is the organization of these modes that remains exclusionary by and for certain bodies (Derrida, 1976).

As such, normative communication is ableist communication. These normative modes of communication manifest in understandable, or translatable, language gestured through intelligible and non-temporal writing. Derrida (1976) explains that this type of sense-making writing points to a particular metaphor:

A writing that is sensible, finite, and so on, is designated as writing in the literal sense; it is thus thought on the side of culture, technique, and artifice; a human procedure, the ruse of a being accidentally incarnated or of a finite creature (p. 15).

Here, Derrida points to writing as a metaphor for civilized culture (not dissimilar to Eagleton's chronicling of culture's dominance over notions of nature) (2000): as "technique" and "finite" descriptions of a modernist approach to communication that aligns with already established notions of normality and excludes its perceived opposites, including intellectual disability. We are reminded again, then, that language is part of the body and language has a particular knack 
for being simultaneously inclusive and useful, on the one hand, and exclusionary and inept, on the other.

Yet, as Vernon (1979) emphasizes, for as much as language organizes the world, the world resists language (p. 16). To understand non-normative or non-written language as a possible gesture of resistance, or as a possible gesture of presence, requires researchers to move beyond the comfortable organization of language that emerges in ableist writing and discourse. To only rely on writing that "makes sense," so to speak, is to ignore the invisible, to undermine the world's resistance to its normative organizational structures. And sense-making means working under the assumption that the human's job is to stay afloat in the oppressive world-sea of language for fear of drowning, to follow Vernon's earlier metaphor. Presence is that space somewhere between drowning and floating, where some people hover all of their lives. Ignoring this positioning of particular bodies in-relation-to language is an act of disavowal; ignoring is one way that we make meaning and make each other mean (Titchkosky, May 7, 2014). The work of expressive writing, then, is located in moments of presence that fall somewhere between the language modes of utility and expressive gesture.

Expressive writing is a method of writing that allows writers to lean toward writing as a work of pleasurable and present gesture. The gesture doesn't necessarily need to be communicative, though sometimes understandable language appears. Gestures need not take the form of some type of normative message to be observed, transcribed, interpreted, and regurgitated through analysis and presentation, either. Rather, some gestures don't translate easily into discourse and therefore don't circulate easily. Expressive writing is a non-normative form of writing that does not subscribe to form and genre; expressive writing can be "untranslatable" and difficult to decipher. In this study, expressive writing methods are wide- 
ranging: being in a space where writing is happening, making motions on paper with a pen or pencil, contemplating, using symbolic words to translate thoughts, using other symbols, lines, and spaces to gesture, speaking aloud and having someone else write words, sitting quietly and being present, and introducing yet-to-be-discovered actions that correlate with the intentions of an expressive type of writing. Other gestures also emerge that fall under the category of expressive writing, such as flipping through pages and stopping to re-write over something written in the past, drawing, ripping pages, folding pages and storing them in a pocket. These are some of the gestures of expressive writing I have witnessed, and no doubt there are more that have been missed or are yet undiscovered.

Expressive writing involves the intention to make space for unpredictable and not-yetknown movements of writing. Expressive writing is a way of negotiating the invisible space of discovery Marion Milner (1987b) references: poetic bursts available through acknowledgement of the unconscious as a place where expression may emerge. Expressive writing is a type of writing that represents the eruption of consciousness, a visit to the invisible "space between," and expression that transcends or does not quite match with normative modes of writing that would explain themselves and leave little time for wonderment. And, in the analysis of this gesture, I read such expression through the non-normative lens of l'écriture feminine and then phenomenologically reflect on the writing as a gesture of triple-labeled bodies living through the mark of a particular phenomenon called intellectual disability. 
Vignette: Notes from December 12, 2014

Today's activity is somewhat easy, but it requires a bit of structure. We're moving into the functional, not in order to fix or solve, but simply to get through at least one activity promised to the REB. Sometimes the functional and the expressive overlap - simple as that. It's fine. I tell myself it's fine. Not much I can do about it.

Step one: make a list of nouns. Step two: list some verbs. Then pair the words together in whatever way you choose and make sentences. Then paragraphs. Then stories.

"Anyone know the difference between a noun and a verb?" I ask. Perhaps not a great entry-point.

“Oh, a nun and a bird,” Mr Clark Kent says, perhaps picking up on the intonation of my verbal words.

I write "noun" on one side of the whiteboard and "verb" on the other, as well as plain language explanations of each ("a person, a place, a thing” and "action words," respectively). I use the people and things in front of me as examples: Flora, JS Manson, table.

Sharon immediately names "table" as a noun. Owen takes me through a suggestion that is difficult for me to hear; I can't make out his words. I ask him to spell it, and he spells " $S$ - $A$-VA-T-N-A-R-M-Y” before I realize he's saying "Salvation Army." Mr Clark Kent takes his time thinking of a person. Often when he is put on the spot he balks a little, offering a lot of "um," and "I think it's..." in ways he doesn't when I suggest he write in his notebook. "Um, I think she wasn't here," he says softly. I invite him to make up a person, someone imaginary, when Flora looks up from her book and says, "chairs."

“Great, thanks. So now I want to think of some verbs, ” I begin. Ross's head is in his notebook. I say his name three times but he does not look up, so I let him continue writing. A few 
moments later, he begins to hum. I ask specifically about the Salvation Army: What's it like there? What words do you think of when you think of the Salvation Army? Sharon offers "crowded" so I write that down, alongside the word "people." Mr Clark Kent points out that chairs have legs, so I suggest we could call them "four-legged" or "tipsy," and he agrees.

"What you need in a sentence is a noun and a verb, " I say as I attempt to explain the next part of the exercise. I try to keep the technical writing lesson to a dull roar. Sharon points to her notebook and from the front of the room I can see that she's written, "Salvation Army crowded." She suggests the sentence, "The chair has four legs."

I ask if anyone would like to grab the whiteboard marker and write a sentence on the board. Ross bolts up - apparently listening, I guess — and walks toward the board. Mr Clark Kent is in the way, already writing. He's writing a sentence about "a nice, wonderful, lady."

“Chelsea, this is finished," Ross says, trying out a dead whiteboard marker. I tell him to forget it, throw it in the garbage. I sit down and slump my shoulders. I realize how arduous it can feel to dwell in the functional, even if the expressive sometimes nags for structure, and even if you promised functionality.

Notes on expressive writing as gesture

... Language voices the body, but ... this voicing or writing of the body is never perfect, or even a nearly perfect communication: to embrace the writing of the body is to embrace difference, in a Derridean sense - it is to continually fail to signify, when failing to signify is our only means of meaning making.

- Dolmage, 2014, p. 106

This notion I've been repeating is that expressive writing is a gesture of bodies implicated in language. And, as Dolmage directs above, this type of gesture - language that voices the body imperfectly — is one that relies on Derrida's concept of difference, which, in brief, refers to "the 
interplay of presence and absence" (Wolfe, 2008, p. 114). This view of writing as gesture comes from Vernon (1979), who dwells on gestures. He explains that “the gesture with meaning doesn't just clothe the meaning, but rather is its body, its existence" (p. 18). Vernon demonstrates this concept with examples which I will try to rephrase through my own experience: when, in the research-based "Once Upon a Time" writing group, I slump my shoulders this not only represents a performance of what weariness could be, it is weariness. Here, the sign and the meaning are the same; there is no gap between the in/voluntary sign and the signifier in gestures. I am both absent and present. Perhaps my mind is absent and my physical body present, but because these two aspects of humanness are one in a poststructural feminist understanding of embodiment, the absence and presence do not happen in opposition to one another but paradoxically in the same motion that we might label "dreariness." Similarly expressive writing is a gesture of the mind, even when the gesture is withheld for whatever reason. To write down a squiggle of lines that make no normative sense and leave the reader perplexed does not represent what writing could be; it is writing. As Vernon (1979) proposes, "[t]hrough gestures, our speech incorporates the silent, unspoken presence of the world, but in such a way that it remains silent, unspoken" (p. 20). I take this to mean that the body can be part of the world — can have presence and value - in invisibility and in absence. The body can be both present and absent all at once, and expressive writing is a method of mapping the presences and the absences.

Expressive writing, then, becomes a tool in a wider deconstruction of text and intellectual disability, both being culturally situated concepts with a certain degree of self-created authority or cultural authority. From a methodological perspective, however, questions emerge about how and when to record and provide evidence of invisible gestures. Therefore, in this study, participants' writing and reflections of their experiences are paired with the researcher's 
observations and lived experience descriptions for analysis in order to cover some of that un-seeable, or easy-to-miss, territory. This pairing attempts to transcend the material/textual binary that characterizes much research; we are material and immaterial in the gestures of making meaning and making text (Adams St. Pierre, 2014, p. 12). This shift in thought toward the methodological — toward the question of why what happens happens (and what happens next) — also pulls us back to the methodological intentions of this chapter, and moves us forward into questions of how the research ought to, or ought not to, be done. 


\title{
Chapter 10: Necessary interruptions: On not being participatory, emancipatory, or transformative
}

\author{
Rather than evoking nostalgia for a lost world of certain knowledge, to engage and \\ transvalue these shifts is to move toward a thought of dissensus rather than consensus, a \\ dissensus not easily institutionalized into some new regime of truth. This is about the \\ 'ruins' of methodology, the end of transcendent claims and grand narratives: \\ methodology under erasure. \\ - Lather, 2007, p. 2
}

The methodological choice of group-based expressive writing is both institutional and situational, and thus carries a somewhat false underlying impression of participatory and emancipatory approaches. This misconception could stem from an outsider's imagining of a writing group where people, called "participants" or "co-researchers" rather than "subjects," can and do write for purposes that will enrich their lives. In this fantasy, which speaks to the limits of knowledge, writers are also happy, productive learners who attain skills to apply in the functional, symbolic realm. The writers think of ideas and execute them with the support of the researcher and the group. Their pages are full of insight and at the end of this project all readers gain a new, cemented perspective on disability from the magic that has emerged from participants' minds. This fantasy is the supercrip-esque stuff of real-life organizational mantras pledging to "see the ability" and let people with disabilities teach "us" to paint/write/draw/act “outside the lines" (Canadian Down Syndrome Society, 2014). The language of doing things outside of the lines reminds us of Ahmed (2006) — as if everyone involved could simply reverse gears and change the direction of the linear orientations that led us to our present perspectives.

This work is not innocent, nor does it come with any expectation of a happy, transformative ending. One way to hemorrhage innocence is to declare that the work is not, and will not become, participatory or emancipatory. This declaration makes some sense, given that 
the work has always been riddled with an air of cynicism. Originally, in an assignment for Anne MacLennan's 2012 research methods course, the project was pitched as a triple threat: participatory, emancipatory and transformative. Some of the intentions of the project then, and now, remain the same: valuing participants by including a reading of their cultural history; understanding participants as "knowers" involved in knowledge creation rather than as simply objects of research (Ignagni \& Church, 2008; Goodley \& Moore,Fper 2000); acknowledging that disabled people are not "perpetually available" for research (Snyder \& Mitchell, 2006, p. 28); allowing as-autonomous-as-possible writing processes for people involved (Mertens, 2010, p. 26); understanding and adopting feminist instruction that knowledge is culturally derived and therefore critical self-reflection is necessary (Harding, 1993 in Mertens, 2010, p. 25-26; Oliver, 1990, p. 101-102, Siebers, 2010, p. 333); deciding that the researcher must be a presence in the lives of community members, with a useful agenda that potentially gives back rather than only taking data (Smith, 1999); and, working with the inclusion of multiple, evolving methodologies (as per transformative research, specifically) (Mertens, 2010, p. 33). Still, these aspects of the work do not make it participatory, emancipatory, or transformative.

Participatory, emancipatory, and transformative paradigms have a feel-good quality that I, as a researcher, want to follow. Disappointingly, though, this research doesn't always feel good. I'll explain this by starting at the beginning: Participatory, transformative, and emancipatory paradigms emerged gradually in disability studies beginning in the 1980 s, as the social model's limitations were becoming apparent. Scholars began to suggest that the social model fails to represent the diversity of experiences, and instead centers mainly on white, male, physical disability experiences (Shakespeare, 2006b, p. 267; Mertens, 2010, p. 27; Oliver, 1992, p. 101). In response to such limitations of disability studies' leading paradigm, feminists advocated for 
stronger inclusion of experimental influences and identity politics within disability studies that have since expanded the field significantly (Morris, 1991; Crow, 1992). These feminist influences propelled disability studies toward participatory, emancipatory, and transformative paradigms, echoing those in critical feminist perspectives whereby researchers wishing to reexamine theories attempt to include, reflect on, re-imagine, and explore women's experiences through various methods, including reflexive, arts-based research (Hesse-Biber \& Leavy, 2007; Mertens, 2010, p. 22; Oliver, 1992, p. 105, 111).

Oliver chronicles the history of disability-related research in three stages: the positivist stage, the interpretive stage, and the emancipatory stage (Oliver, 1992, p. 102). Indeed, a contemporary researcher wishes to be at the emancipatory stage or beyond in order to keep up with the field. Disability studies has always sought to distance itself from the first, positivist stage which includes medicalized research. In disability studies' circles (or, perhaps more accurately, those circles with social modelist leanings) medicalized research is believed to objectify and oppress people, treating "disability paradoxically as both a ... mystery and a preoccupation that promises to yield knowledge about nondisabled bodies" (Snyder \& Mitchell, 2006, p. 28). The non-medical focus of disability-based research shifted sharply towards rightsbased critical disability theory in the years leading up to the 2006 UN Convention on the Rights of Persons with Disabilities (CRPD), which acts as a template for research into policy, practice, and citizenship (Stanton \& Clare, 2012, p. 1013). The tension between positivist research models and the more interpretivist social model creates challenges in finding a suitable paradigm that might fit the values of researchers attracted to disability-based research (Oliver, 1992; Barnes, 1992; Barnes, Mercer, et al., 1999; Goodley \& Moore, 2000; Synder \& Mitchell, 2006; 
Longmore, 1995$)^{63}$.

Because the field of disability research is continually unstable, my optimistic 2012 pitch for this research now has gaping holes, which emerged, in particular, when the research proposal encountered the ethics review process outlined earlier. And, because the idea for this research came solely from the researcher, and because the execution of the idea is policed by Ryerson's REB quite stringently, this research fails to feel good under the labels of participation, transformation, or emancipation. The research has gone from being idealized in what it could be, to being understood as a project with a negotiable amount of institutional freedoms and constraints. To look at some tangible examples: it is clear that although people are allowed to write anything they want, participants work with notebooks that are potentially under surveillance by staff and people in their home lives, not to mention with a researcher who requests to photograph them and use them as part of the research. Further, each person writes separately, and my own fieldwork notes indicate that there is little communication between participants. Primarily participants speak to me and do not engage with other writers in the room, deflating much of the hope of fostering an encouraging (feel-good) group dynamic or transformative normative, interpersonal social skill-building.

In response, I attempt to orchestrate group writing activities, knowing that this gesture carries an uneasy risk involved in deviating from the day-by-day, hour-by-hour research schedule offered to the REB before the beginning of the project. One example of a group activity

\footnotetext{
${ }^{63}$ Critical disability inquiry in particular continues to hold on to a rights-based approach, sometimes called the human rights paradigm, although this branch of disability studies has since evolved to focus more broadly on cultural experiences - again nodding toward cross-cultural feminist paradigms (Smith, 1999) - wherein people with disabilities are reclaiming, among other things, the words that have defined a disability culture and (often medicalized) language that has worked against people with disabilities in the past (Dolmage, 2014; Longmore, 1995; Linton, 1998; Ignagni \& Church, 2008, p. 627).
} 
is word association. In doing word association participants use multi-coloured whiteboard markers to think of words as fast as possible (these are what Natalie Goldberg called "first thoughts" in her 1986 book Writing down the bones, which is a staple tool in "Once Upon a Time" meetings) and write them on the board. This activity is met with some participation, though usually several members of the group remain hunched over with their heads in their books working on what I call "independent writing projects ${ }^{64}$." Further, there is no participatory element in constructing the agenda, or plan, for each writing session. The potential for this type of participation was immediately negated with the REB's demand for a detailed research schedule. Finally, participatory, transformative, and emancipatory work shares the quality of allowing people more freedom of choice than this project can, or does (Mertens, 2010). On paper, people in this project can stop writing and leave the research at any time, though it is fair to say that this right is regularly usurped because JS Manson has a set schedule of events, and part of its mandate is to teach employability (read: functional) skills such as committing to a project. People who leave the writing group are sometimes (not always) quietly ushered back into the room by staff monitoring the outside common area.

Further, the contexts under which this research takes place - under the institutional gaze of Ryerson University's REB and the organization CLT — lead to a work environment where the researcher is positioned at the head of the project, thus bursting any fantasies of transformation via collaboration. This project involves a researcher and participants, and, unable to squeeze out of this relationality, fails to include people in participatory or emancipatory manners. For example, I would not go so far as to label the participants "co-researchers," as is

\footnotetext{
${ }^{64}$ Sometimes I am allowed to read these projects, other times not. Therefore it is difficult to gauge the accuracy of my labeling though we can detect the power dynamics in the room as being less than participatory when I am the one doing the labeling.
} 
common in participatory community-based research where groups that include a research mandate and researchers work toward a common, sometimes emancipatory, cause (Hande et al., 2014). Further, although my ontological standpoints and methods are similar to those in critical disability studies traditions, I am less interested in the previous rights-based paradigms and instead lean towards arts-informed research, including writing and storytelling whose transformative powers are yet unsettled (Gray, 2000). In many ways, this research began with particular methodological ambitions and has unfolded in opposing directions. The research is both less than its prospective, name-able ambitions and also more nuanced than it was when it hatched with certain degrees of naivety. Thus, it does not feel good to label the work as anything other than what it is, although what "it is" is uncovered only through a process of thinking-out key principles of the work. The label for this work doesn't emerge easily in the literature despite helpful alternative discussions on methodology such as those offered by Lather (2007) and Smith (1999). It seems most accurate, at this point, to describe the research based on what happened, rather than what it might be called.

\section{Edging toward (and away from) arts-based inquiry}

Key principles of this ambiguous methodological agenda include understanding research and analysis as politicized packages that deserve acknowledgment, the sharing of knowledge among participants, and the understanding that knowledge is socially and culturally derived, and that therefore exploratory, creative, critical self-reflection about the research is necessary (Harding, 1993 in Mertens, 2010, p. 25-26; Oliver, 1992, p. 101-102; Siebers, 2010, p. 333). Therefore, under the right circumstances, one somewhat suitable way to describe what happened in this research might be arts-based inquiry. Arts-based inquiry's defining elements include everyday knowledge creation, methodological integrity (a commitment to expressive writing as a form of 
knowledge), creative inquiry processes (relying on common sense and responsiveness rather than the stringent rules of positivist research), and the presence of the researcher (Coles \& Knowles, 2006, pp. 61).

On the other hand, arts-based inquiry is also tied to a moral, change-making purpose and audience transformation. To truly participate in arts-based inquiry I ought to work with the explicit intention to reach audiences outside of the academy (Coles \& Knowles, 2006, p. 61). Therefore, unless my audience is the participants themselves - and this can't be so, because the writing I present here is inherently inaccessible, even though I will share it with them - this work simply doesn’t fit arts-based methodology and, at most, uses arts-based inquiry as a methodological enhancement rather than a stand-alone methodology (p. 60). What's more, artsbased inquiry rings suspicious for some advocating for disability-related paradigms because the arts tend to serve the interests of medicine and arts-based clinical practice rather than critical disability research, as demonstrated by the "helping" professions incorporating literacy and creativity into their therapies (Ignagni \& Church, 2008, p. 628; Pollard, 2012). Nevertheless, my work draws on principles of both feminist and disability studies while employing expressive writing as a method of inquiry. Specifically, I approach my inquiry on the basis that this research has the potential to fill the epistemological and ontological needs of both researchers and triplelabeled participants, who, through non-normative storytelling, can critique knowledge of disability and link this knowledge to production.

Further, choosing an arts-informed method, such as expressive writing, may increase the diversity of research about people with intellectual disabilities and remove barriers to accessing such research (Ignagni \& Church, 2008, p. 634). Stories that may emerge, especially those of “self-change," can help disabled people reclaim their experiences from medical understandings. One downfall to this epistemological approach, as Ignagni and Church (2008) articulate, is that 
these stories often recall the acquisition of disability and form narratives of individual achievement, placing most of its literature outside of my scope because my sample includes the non-normative writing that is difficult to narrate (p. 629). Disability studies research has the potential to begin one way with a conscious aim to unfold in another, all in order to achieve transformative ends. Yet, the research isn't wholly an arts-informed project either. It is still something other — something new and untested, but not necessarily in a desirable way. And, so, this research is re-categorized, or perhaps more suitably, un-categorized.

\section{Un-categorizing the research}

At the risk of regression by Oliver's (1992) rankings, this work is better understood as interpretive, hesitant, and critical, leaning toward potentially participatory arts-based inquiry.

Disability studies currently engages in similar critical, exploratory approaches by understanding discrimination as systemic and structural, urging researchers to focus on participant experiences and intersectionalities (Mertens, 2010, pp. 22-25). Generally speaking, however, disability studies research strives to be transformative and consequently necessitates participatory methods, so it is a puzzling place to find myself working as a disability-based researcher: outside of participatory paradigms but also outside of positivist paradigms. In working with a group of writers carrying labels of intellectual disability, part of the intention of this research is to create a space for the intersections of personal writing experiences under the assertion that researchers can learn from their own writing processes and from others' experiences (Mertens, 2010, p. 26; Ignagni \& Church, 2008, p. 62).

However, the research also moves beyond its new re-categorization. In negotiating the ethics of this work, the research is shoved back into an interpretive stage where old questions are made new: What does it mean to do research with triple-labeled people? What are the 
ethical implications of outsiders attempting to (re)connect with those "always already" situated in cultural locations of disability? As disability and conceptions of it are temporal and constructed, how can those not (yet/anymore/ever) marked with the lifelong label of intellectual disability orient themselves toward the phenomenon in an effort to connect with those already facing that direction? What foresights follow? Snyder and Mitchell (2006) caution researchers to think about situationality, which is what pulls this research backward into what Lather (2007) calls "dissensus" (p. 2). Indeed, the methodology here is "under erasure" (p. 2).

This research is not meant to uplift, or to subscribe to the modernist notions of progress that brought the researcher and the participants to their respective points of orientation toward intellectual disability. Here, the final research question is meant to be cracked open: What would it mean for "untranslatable," expressive writing as a communicative tool to be read, in some cases, as reflecting the pre-verbal sensations present in the lifeworld (Cixous, 1993; van Manen, 1990)? This question is an invitation into a phenomenological reading — or a phenomenological approach to reading — accompanied by poetic response-writing. So, writing as method; writing as discovery (Richardson, 2000). Still, an arts-based method, but neither participatory nor performed. Can this type of thinking assist in widening expectations of cultural participation and unbinding intellectual disability from contemporary invisibleness? Could such experiences expose the untranslatable utterances of the body as "bodily presences" meant to be felt and present rather than as foibles to be corrected, hidden, and disavowed (Abram, 1996, p. 89)? And, further, could the inclusion of such writing in academic discussions about intellectual disability nudge researchers toward spaces of unintelligibility that offer a valid interpretation of experience? 
Given the new parameters of this project, the work must leave room for slow thinking, disagreement with itself, and entanglement in the unknown — here, wonderment rings again that would fail to provide answers, or produce a feel-good product, or end in any particular direction of gratitude for uplifting all of us and setting us straight, or in the right direction, on the topic of intellectual disability. This interpretive research works in the realization that there is no right direction, only presence and absence. 


\section{Chapter 11: Moving into a phenomenological approach: Gathering and explicating moments}

Yet that which remains hidden in an egregious sense, or which relapses and gets covered up again, or which shows itself only 'in disguise,' is ... the Being of entities, .... This Being can be covered up so extensively that it becomes forgotten and no question arises about it or about its meaning. Thus that which demands that it become a phenomenon, and which demands this in a distinctive sense and in terms of its soundest content as a thing, is what phenomenology has taken into its grasp thematically as its object.

- Heidegger, 1962a, p. 57

Once, during a two-hour "Once Upon a Time" writing session, Prince Diana handed me a piece of paper filled edge-to-edge with "+" and "o" symbols in blocky, blue-inked scrawl. The text was indecipherable to me. I asked Prince Diana if she would help me understand her writing. She simply pointed at the page, shrugged, and said, "It's a poem about my grandmother riding a bicycle."

Normatively speaking, Prince Diana failed to successfully write a poem about her grandmother riding a bicycle based on any perception of the text as "untranslatable" or ununderstandable (Cixous, 1991, p. 3). To report most accurately to an audience that may hold normative writing to the highest, or only, standard: the participant penned a full page of shapes and symbols that say nothing clear or coherent. This understanding of the text is also an orientation toward it - a logocentric, symbolic, masculinist orientation (Derrida, 1976; Cixous, 1991). As I established earlier through Vernon (1979), who suggests that doing a thing is the thing itself, orientation toward the text is also an orientation toward the person from whom the text emerged, or the person we might understand as tied to this text. In other words, how Prince Diana's text is read is also how Prince Diana is read. To interpret the text as un-understandable is to interpret the person in the same, discounting way. Such an approach would demonstrate a particularly ableist perception of the type this research tries to avoid in its ambition to widen 
expectations of cultural participation, and to unbind intellectual disability from the contemporary invisibleness discussed in earlier sections.

Living in a context where the un-understandable lacks value, the corporeal realities of the un-understood (the "dys-articulate") are constantly placed in the same separate human category that manifests through segregatory social practices (Berger, 2014). Such practices include eugenic practices and approaches to language and the body discussed earlier that draw lines between normal and non-normal ways of being. The movement in this part of the research, then, is a shift out of the many eugenic realms of invisibleness and disappearance, away from bodily absence, and toward what Abram (1996) calls "bodily presences" (p. 89) — moments where the body is not necessarily meant to be known as understandable, but is meant to be felt and present. In other words, this research pushes writing, and thus the body, towards moments where foibles are not meant to be corrected, hidden, or disavowed, but are instead intended to be understood as part of the unknown fabric that makes up our lived experiences. This movement toward unintelligibility is facilitated by a phenomenological approach to understanding intellectual disability as cultural phenomenon through the experience of writing.

Consider, for example, bracketing any normative perception of Prince Diana's writing. Bracketing is a concept from Edmund Husserl, one of a handful of pioneering phenomenologists whose writing is influential in this section. Bracketing involves putting aside past knowledge of a phenomenon (intellectual disability) and rendering it non-influential in the context of the research (Giorgi, 1997 in Vagle, 2014, p. 67). For Husserl (1991), bracketing is tied to the significant need to distinguish between the pre-phenomenal being of experiences ("their being before we have turned toward them in reflection") and their being as phenomena (in van Manen, 
2014, p. 95). Bracketing is a process similar to that the process of empathy, which requires a person to step outside of herself, as described by the artist Anna Deavere Smith (2006):

To step outside you must suspend opinions and judgments. It doesn't mean that you are devoid of them. It means that you can control them long enough to watch, listen, and feel. You store what you have learned, and then you do what you will with what you have gathered (p. 23).

Husserl's transcendental phenomenology is oriented toward the correlative terms of intuition and givenness. Intuition, in this sense, represents immediacy, and givenness provides a measure of phenomenological comprehension (Moran, 2002, p. 7). As Dermot Moran (2002) explains, “ ... the character of the intuiting corresponds to the character of the giveneness or manifestation" (p. 7). In Husserl's words,

... when objects are intuited, thought of, theoretically pondered on, and thereby given to us as actualities in certain ontic modalities, we must direct our theoretical interest away from such objects, not posit them as realities as they appear or hold in the intentions of our acts (in Moran \& Mooney, 2002, p. 69).

For example, under present circumstances where intellectual disability is presented to us as an always-already set, familiar object — as an undeniable diagnosis or an unchangeable way of being ("Other") stuck in a particular circumstance (over there) - phenomenology calls us to segregate our ideas of this apparent "reality" of embodiment and perceived impairment, as well as our acts that follow its meta-narrative, such as paternalistic assumptions of vulnerability and incompetence.

Therefore, reflecting on Prince Diana's writing through bracketing leads a reader to understand the text for what it is: a series of pen strokes across a page; "o" and "+" shapes carrying unknown — but not completely absent, because the shapes are present — meaning. This type of observation could lead to an examination of the rhythm of the writing, its shapes and motions; perhaps we can visibly see figures in the writing that lead us to other thoughts and associations. From this perspective whereby brackets move the writing away from ableist 
assumptions, Prince Diana has created an abstract form of expression potentially carrying multiple meanings. Bracketing, to borrow Ahmed's (2006) words, means apprehending something as if one had not encountered it before (p. 25). The motion of bracketing seems to ask: What is the object when it is no longer familiar? (p. 35). In working through the phenomenon of intellectual disability, bracketing can mean encountering a text as what Husserl calls "the thing itself" by imagining it as detached from the circumstances by which it arrives, not for the sake of neglecting interconnectedness (Shildrick, 2009), but rather for the sake of positioning a thing the writing - in such a way that it can be freshly perceived and not bogged down by the cultural circumstances from which it emerges.

\section{Turning toward a phenomenological approach: Bracketing and orientation}

A phenomenological approach recognizes the space between what is normally called, or perceived of, as fact, or truth, and the intentions and orientation toward, or away from, a text and thus a body. Further to the motion of bracketing, Heidegger's (1962a) notion of "seeing through the facts," (p. 57) mentioned above, is, following Husserl, another way of recognizing the banality of everyday pre-phenomenal experience and pausing to reflect on its phenomenon. "Seeing through the facts" allows recipients of a text to take it up differently — to re-orient toward it, or, as Ahmed (2006) might contend, to stray from the straight, normative line(s) that so often lead us toward everyday taken-for-granted perceptions of phenomenon as it presents itself for our inevitable perception. For Ahmed (2006), the concept of "orientation" allows us to rethink how concepts reveal themselves to us, and how we "find our way" through what we are facing (pp. 6-7). 
A phenomenological approach also relies heavily on orientation, meaning "the intimacy of bodies toward their dwelling places" (Ahmed, 2006, p. 8). In other words, orientation toward intellectual disability has much to do with where intellectual disability is situated socioculturally, and the positioning of writing suggests that intellectual disability remains "untranslatable." In Prince Diana's case, and in the cases of many of the other participants in this research, a normative orientation toward the text will push away from it, disregard it, and scuttle the body — the person from whom the text emerged — out of the normative cultural imagining of writing as belonging to a eugenic, segregatory cultural space. This shift in cultural location marks the writing as indecipherable and therefore abjectly worthless. A phenomenological approach, then, perches itself in the push-away motion and pauses to reflect on what is happening, bracketing the rest.

Importantly, however, Ahmed (2006) cautions that the thoughtful motions of bracketing and orientation may lead to the removal of important avenues of thinking, including cultural circumstance and interconnectedness/intersectionalities - even if that type of neglect is not its intention (pp. 33-14). Ahmed's caution: remember that how a thing comes to be is not unimportant (pp. 33-34). Bracketing, she warns, "creates a fantasy that we can do without what we put to one side" and "clears the philosopher's table and allows him to do his work" in the absences of the familiar goings-on within the brackets that the philosopher depends on to do the very work of bracketing (pp. 31, 33-34) ${ }^{65}$. Thus, we recall the purpose of the earlier "mapping"

\footnotetext{
${ }^{65}$ Ahmed breaks down her thoughts in the first chapter of Queer Phenomenology (2006) when she imagines Husserl writing about his children and setting aside (apparently "transcending") the highly feminized labour outside himself that keeps the children occupied while he writes. I would suggest, following the thoughts of Erevelles (2005), that this fantasy strings researchers along into postmodern territory, where the imagined sets the parameters for our thinking while the objects of our imaginations remain in the very real world of navigating multiple forms of oppression.
} 
of particular subjectivity formations, including those of triple-labeled people, and of pushing the idea that materialization of the body matters (Erevelles, 2015; Titchkosky, 2008) — especially when it comes knowledge creation about bodies commonly understood as familiar, lacking "Others" whose presences and absences are highly implicated in language.

\section{Phenomenological starting points}

In addition to bracketing and orientation, helpful starting points include the question of what a phenomenon is and what it means to take up a phenomenon. In writing about intellectual disability as phenomenon, I take a phenomenological approach by centering my inquiry on the notion that a phenomenon is that which is not taken for granted. Because a phenomenon is something that emerges, or is lifted into emergence or being (in Heidegger's terms), the concept of phenomenon is broad:

The phenomena of phenomenology are to be understood in a deliberately broad sense as including all forms of appearing, showing, manifesting, making evident or 'evidencing,' bearing witness, truth-claiming, checking and verifying, including all forms of seeming, dissembling, occluding, obscuring, denying, and falsifying (Moran and Mooney, 2002, in Vagle, 2014, p. 20).

Further, drawing on Heidegger, Vagle (2014) explains that phenomena are "the ways in which we find ourselves being in relation to the world through day-to-day living" (2014, p. 20), or the ways we are brought into being, specifically the ways we are brought into being in relation to ourselves and others (Shildrick and Price, 2002).

Phenomena also include experiences in which we find ourselves. For instance, when I am with the "Once Upon a Time" writers I find myself in multiple ways of being: sometimes feeling frustrated, sometimes yawning and making evident my tiredness, sometimes laughing, sometimes "truth-claiming" by answering the common question of "How do I spell this right?" and so on. In all these ways, I am in-relation-to others for whom ways of being brought into 
being are highly un-knowable in any "truthful," essentialist fashion. On both the research side and the participant side of this project, however, even the most prosaic moment or encounter can be loaded with affect and ordinary variety. For example, the purple white-board marker Flora uses often makes her smile because of her fondness for the colour, and when she smiles I am glad to have a recordable reaction; a change in attitude indicates a change in direction during the particular group experience of brainstorming words and writing them on the board. As a researcher I am not interested in describing the properties of the group (although I have mentioned the location, the number of participants, and other specifics in the methods section), but I am interested in the difficult task of capturing the essence of the group — the sensed significance of finding ourselves in this state of being that is buried in ordinariness - and digging up the essence of its affect that gives way to wonderment. The phenomenon, broadly understood, is the "way in which we find ourselves," and it is taken up through a phenomenological approach to understanding what happens when the researcher is positioned inrelation-to others and their texts.

\section{Thinking phenomenology, thinking methods}

A phenomenological approach also follows van Manen's guidance $(2014,1991)$. He asks researchers to reflect and describe the phenomenon in all its confused, imperfect essence. Further, this research considers Heidegger's (1962) directive that the invisible/hidden can become the forgotten, and that phenomenology demands that the forgotten be lifted into being. Phenomenology, then, is not only an entry point into the space between a mash of seemingly nonsensical text and a poem about someone's grandmother riding a bicycle; phenomenology is a 
reorientation toward that (forgotten) which can be taken up (described) through countless perspectives (of being).

In this study, the reorientation into an invisible writing space occupied by the texts and lives marked with intellectual disability is a movement that backs away from normative interpretations of writing as much as is possible (and, indeed, this gesture isn't always possible). Instead, this research looks toward wonderment as its "dwelling place," as a place to position its encounters between the semiotic on-page expression (again, "+" and "o" signs indicating ununderstandable language from a labeled source) and the clearly symbolic explanation of that expression that serves as a sometimes-glance into the invisible, or as Dolmage (2014) highlights, "the space between" ("it's a poem about my grandmother riding a bicycle").

Methodologically speaking, this research does not, and cannot, take a "proper" phenomenological approach. In part this downfall is based on the researcher's proximity to phenomenology as a new method deserving of much more exploration than fits into a dissertation timeline. On the sly, however, I also suspect that anyone engaged in crip writing might be pleased with this work's failure to be "proper." Similar to queering narratives, crip writing, in the unpaginated words of Jim Ferris (2007), refers to the centering of reading and writing on those bodies that are off-center, apart from the norm "where there is even more to feel." That this research is off-center, and that it deals with people whose bodies are strategically placed on the tail ends of the normative bell curve (Davis, 2010; 2013b), suggests that perhaps an off-target approach to phenomenology is not entirely undesirable.

This research understands phenomenology broadly and shakily, and therefore does not claim to be doing phenomenology but instead takes a phenomenological approach. A phenomenological approach should be understood less as a method with steadfast rules, and 
more as an attitude toward experiential phenomenon (Van Manen, 1990; 2014, p. 26). Adopting an attitude (of any type) toward experiential phenomenon is necessary given phenomenology's concern with the ways in which things appear to us through experience - the given reality that our lives are experiential and thus experienced through practical, everyday engagements with the world. Thus experience is inherently meaningful (Etough and Smith, 2008, p. 180). As Van Manen (2014) explains,

phenomenology is more a method of questioning than answering, realizing that insights come to us in that mode of musing, reflective questioning, and being obsessed with sources and meanings of lived meaning (p. 27).

The work here, then, refers to precarious processes of description and reflection on how the phenomenon of intellectual disability appears to consciousness.

Often phenomenology is characterized as a "turn toward" objects that are given to consciousness (Ahmed, 2006, p. 25). Consciousness, as per Edith Stein's (1989) explanation, refers to "the sphere forming the basis of all our investigation" (p. 231). Or, as Moran and Timothy Mooney (2002) explain, consciousness in phenomenology is linked to "the how of appearing" (p. 5) and "the manner objects are constituted in and for subjects" (pp. 1-2). Phenomenology's experiential elements of receiving phenomenon and orienting in or away from its direction/directive offer accounts of consciousness and meaning that require a change in orientation within and between human encounters. Following Husserl, this re-orientation searches in a "zig-zag fashion" not dissimilar from Somerville's (2006) metaphor of constellation-style ethics, where thoughts and scenarios "move from star to star" and can be connected by particular patterns that are tied to wonder and uncertainty (pp. 78, 81). The truth "the thing itself" — beyond its actualities is embedded in experiences during their presentation and is therefore never straightforward (Husserl, 2002, p. 69, 74). 
Therefore, the actualities of intellectual disability that have been chronicled through biomedicine and accounted for as the body lacking normality or, more specifically, "normal" mind-function (Carlson, 2010), can be read as the actuality of problem. Thus, intellectual disability is presented as familiar problem in need of solution. For the purposes of this project, a phenomenological approach attempts to bracket its phenomena and the actuality of problem attached to it in order to exclude the notion of problem, and thus to experience intellectual disability as other things, including presence.

\section{Intellectual disability and phenomenology}

Intellectual disability can be approached through the phenomenological concept of embodiment. Dolmage (2014) calls embodiment "a phenomenology defined not by boundaries, but by openings" - one of the key openings being language that exchanges between bodies (p. 111, 114). As Paterson and Hughes (1999) point out, phenomenology offers an opportunity to transcend modernist, Cartesian dualisms that posit the body as "passive precultural object" (p. 597). Specifically, Paterson and Hughes argue that the body can undergo a mode of "dysappearance" from the social sphere ${ }^{66}$, making certain moments of disability inevitably

\footnotetext{
${ }^{66}$ Paterson and Hughes write about pain, explaining that pain is often pushed toward the charge of medicine, not politics or society, leaving it outside the realm of disability-based discussions ( $p$. 603). To extend their case, it could be argued that intellectual disability also tends to "dysappear" into seclusion, as a matter - a problem - to be dealt with somehow else or swept to the bottom of disability hierarchies. For example, the writing of a person who communicates nonneurotypically tends to "dys-appear," to become the Other or somehow be positioned outside of being, when it is simply not considered writing because it is not understandable to the normative reader. This disavowal occurs when one encounters prejudicial assumptions against her work assumptions that it is invalid, non-credible, impossible to understand, and that the writing, the text, cannot be what the writer claims it to be because the text cannot, or will not, be recognized as such by a normative recipient. For example, if Prince Diana's poem about her grandmother riding a bicycle is taken to be worthless based on disableist assumptions it is immediately disavowed and shoved to the realm of the actualities of intellectual disability that have been chronicled through biomedicine and accounted for as the body lacking normality.
} 
invisible and thus, thinking of Heidegger (1962), forgettable and outside common understandings of being.

Further, the process of "dysappearance" is linked to processes of subjectivity, and subjectivity is linked to cultural location (Snyder \& Mitchell, 2006). Exclusion from communication, then, is not the problem of the communicator, but a convention relating to the norms of communication and the hostility toward those whose bodies are understood as noncommunicative in cultural contexts where disability-based institutions police and colonize people's lifeworlds (Erevelles, 2015; Paterson \& Hughes, 1999, p. 603, 607). Indeed, the lifeworld of an individual is always-already bound by social and historical context. Paterson and Hughes (1999) write, “... when one is confronted by social and physical inaccessibility one is simultaneously confronted by oneself; the external and the internal collide in a moment of simultaneous recognition" (p. 603). The only way to study human life is to do so through cultural and socio-historical meanings that position intellectual disability in particular cultural locations (Eatough \& Smith, 2008, p. 180).

This research is also a cultural location of disability. Thus, the role of researcher is once again brought into question because it is the researcher who prompts these particular moments of inaccessibility that confront both text and the self. The researcher is also the single party that brings intellectual disability into this investigation at all, calling it a taken-for-granted label assigned to some bodies, often at birth, that sticks throughout the lifespan. The notion that intellectual disability exists and is regulated as part of each person's everyday life through moments of encounter or experience makes intellectual disability as a phenomenon. These encounters trigger a type of wonderment that situates the moments less as fact than as phenomenon — wonderment, in all its invisibility, illuminates intellectual disability's resonance. 
And so a phenomenological approach calls for a return to wonderment. Wonderment serves as a necessary point of departure for this investigation because it is a concept designed to describe a particular, guttural feeling that is experienced by some people during encounters with intellectual disability whether abstractly or through one's own subjectivity and relation to the other. Wonderment is an entry point into Berger's (2014) “dys-appearance” through thought, through taking notice of the absence, the lack, or the invisible and querying its source.

Instructions for doing phenomenological research: Max van Manen's hermeneutic (and pedagogical) approach

Van Manen (2014) begins with wonder. He describes wonder as "that moment of being when one is overcome by awe and perplexity ... when our gaze has been drawn by the gaze of something that stares back at us" $(2002$, p. 5). Phenomenology takes form through various motions of staring back. It is not only the return of the gaze that unfolds a phenomenological approach, but the acknowledgement of the gaze and the attempt to appreciate the compulsion to respond to it. Further, embedded in the task of the phenomenological approach is another mission of rooting the unpredictable realms of wonder and thereby experiencing the affects of wonderment. Through van Manen's (2014) agogical approach, which focuses on "doing" phenomenology rather than philosophizing about phenomenology, my senses are guided toward my initial and ongoing understandings of phenomenological approaches to inquiry (p. 23). Here, data gathering, findings, and explications of the research overlap and blend with one another. The phrase "data gathering" is borrowed from Vagle (2014), who uses this language instead of "data collection." He explains that this language is useful in its effort to express something less solid than the collection of data. He writes, "['data gathering'] makes me feel as though we could just as easily be taken up by the data then doing the taking" (p. 78). Further, a particular 
conversation with Ann Fudge Schormans led me to reconsider what I call "data." Fudge Schormans helped me realize that every movement which is thought, evoked, remembered, and recorded under the guidelines of the REB can contribute to the gathering of knowledge with the title "data" (July 8,2014$)$. This is the nature of an approach, rather than a hard-and-fast rational method. In what follows, my leaning toward van Manen's writing is an attempt to learn from, and perform, research in the spirit of his conviction that phenomenology can be taken up as a broad approach to doing meaning-making inquiry rather than a goal-oriented project with clean and decipherable results that emerge only in rational patterns (van Manen, 2014, p. 16). Again, we are reminded of Titchkosky's thought that we may not only be making meaning, and we are not only the effects of discourse, but also make each other mean (May 7, 2014).

From van Manen's (2014) perspective, a phenomenological approach is an opening, a type of foyer into the vast schools of thought in all their "lack of singularity, certainty, and finitude" (Vagle, 2014, p. 52). The wide corridors of phenomenology are intimidating, but the state of wonder in which they begin is inviting. Through this phenomenological invitation, van Manen's (2014) promise that "phenomenology is more a method of questioning than answering, realizing that insights come to us in that mode of musing, reflective questioning, and being obsessed with sources and meanings of lived meaning" encourages researchers to enter into a state of wonder rather than turn away from it (p. 27). To closely paraphrase Vagle's (2014) summation of van Manen's phenomenological approach (because it is perhaps as close to an instruction list as I will find given phenomenology's open-endedness), doing research through a phenomenological approach means a range of things: studying lived experience; explicating phenomena as they present themselves to consciousness; studying essences; describing experimental meanings and moments as we live them; attending to the practice of 
thoughtfulness; searching for humanness; and poeticizing and poetic response-writing (p. 56). The latter three points infiltrate my thinking, and this work, most loudly. Attempts at thoughtfulness, attempts at understanding humanness, and attempts to poeticize our goings-on reach toward what it might mean for "untranslatable" expressive writing to represent the lifeworld and attend to bodily presence. These steps contribute to uplifting the contemporary invisibleness of intellectual disability. In this sense, a phenomenological approach is an interpretive action-approach - a movement toward unintelligibility and thus a doing of research inside and outside of the traditional bounds of research.

Van Manen's (2014) action-based work focuses on what he calls "phenomenology of practice," which refers to the kinds of inquiries that serve professional practitioners and branch into the situational understandings of everyday life (p. 15). Van Manen's commitment to the study of lived experience emphasizes the active and interpretive doing of phenomenology as never final (Vagle, 2014, p. 56). Lived experience is the stuff we live through before we take a reflexive view of it, and the reality of our ongoing living — being alive - means lived experience is continual:

For the researcher it is important to realize that experience, as we live it from moment to moment, is always more complex, more nuanced, more richly layered than we can fathom, and meanings emerging from reflecting on lived experience are always ambiguous, enigmatic, and ultimately unfathomable (van Manen, 2014, p. 42).

Finally, van Manen (1990; 2014) also consistently urges learners of phenomenology and phenomenological approaches to consult core texts; the literature of "true research" requires us to move into phenomenological approaches authentically (2014, p. 22). Therefore, following the necessary explanation of descriptiveness and lived experience description that was promised earlier, this writing will branch into a brief exploration of philosophical approaches to phenomenon in terms of relationality and corporeality. These approaches will be underscored 
through concise accounts of the works of influential thinkers: I begin with Husserl's (1970) transcendental phenomenology, and move into Heidegger's (1962b) ontology and notions of being in the world and "everydayness." Heidegger's posits are later re-routed by Price and Shildrick (2002) toward thinking that can be applied specifically to the relationship of nondisabled research and disabled participants, including ideas of "being-in-the-world-with-others" and "becoming-in-the-world.” Merleau-Ponty's (1979) conceptions of perception and "bodily consciousness," as well as theinseparability of "flesh" and embodied perception, follow. This discussion reminds us that the body is embedded in every word.

\section{Describing (vs. demonstrating) characters (participants)}

Because this dissertation is formatted somewhat normatively because normative writing aims to demonstrate and prove, unraveling the characters through description rather than through demonstration is another small way of cripping the dissertation. Here, the characters have been, and continue to be, written out one at a time, as they are encountered, instead of introduced in a list, as is a common protocol for researchers writing up participant-involved findings. The purpose of this method of writing is to reveal the characters as humans who enter and leave the research narrative at different times, whose improbable presences are both known and unknown, and to avoid a clinical list of names (categories) and identifiers (symptoms) that would echo the historic place of research objects.

The data has been gathered gradually, as relationships have gradually formed and "split" in this research process (Ellis, 2007). The goal of this research is not to generate knowledge about a particular group of people engaging in a particular practice of writing, but to nudge 
researchers toward cultivating and developing a flexible type of wisdom that can be practiced in our existential, everyday encounters with intellectual disability. Choosing description over demonstration where possible aids encounter and discourages taxonomy. Thus, in this research I ask questions whose answers have to unfold through trial and error: What is the lived experience of being next-to intellectual disability in the context of creating and un/understanding text? And, further, how can this experience be described most effectively?

\section{Lived experience description: Prince Diana}

There are several forms that can "open up" aspects of a phenomenon: poetry, fiction, freewriting, and others (Vagle, 2014, p. 90). One particular avenue into van Manen's (1990) approach is lived experience description, which attempts to describe a moment as it happens rather than through surrounding commentary. The use of lived experience description in this project is an attempt to isolate the moments of descriptions that are phenomenological, and to discard those that are not. The challenge is in telling the difference, and shaving off moments of commentary that fall out of the realm of lived experience description. Below is a short example of description, which is followed by an adaptation of the writing to match the intentions of lived experience description. In another, more linear context we might call this the first data sample, or the first case study, or the first demonstration of a writing-based experience of wonderment that could be easily overstepped (alluding to Lather's earlier caution that there are moments in research that are easily ignored) (2007, p. 54). The scenario below elevates an otherwise invisible moment of bodily presence to part of the lifeworld, and demonstrates how data is gathered and explicated. 
"Don't tell anybody okay?" Prince Diana aims her pen at her notebook. "I want that to be our secret, okay?"

Prince Diana is talking to another JS Manson "client" who has wheeled into the boardroom. He handed her a drawing of two stick people beneath a pulsing yellow sun - a gift, I think. The man made an appearance in this writing group several months ago, though Prince Diana wasn't around to flirt with back then. During that time, I handed him some paper and a pen and he immediately fell asleep. Today, the man says he wants to stay.

"Alright, fine then, you can stay," Prince Diana speaks to her paper but her words fly in his direction.

"Did you want to join us for writing?" I ask the man. He has not signed an informed consent form, and as far as I know he is unaware of the research.

"Write what?" he asks. I hand him two pieces of paper ripped from my notebook and a pen. I explain the group, its research and non-research sides. He agrees to write with us for today, and maybe again next week. He doesn't want an informed consent form.

The man asks Prince Diana what he should write. She dismisses him: "I'm writing a poem about grandmother, so I have to finish this."

A staff member knocks on the door and waves me into the hallway. She whispers her directive in my ear: Prince Diana and the new guy are not supposed to sit together because of "inappropriate touching." I comply. This issue has come up in the past. Not that I have actually witnessed "inappropriate" anything. I'm more concerned about staff trying to separate people, reading participants' notebooks to check up on them, and reporting them - I've witnessed more breaches of conduct to that end than anything else. I'm told later that Prince Diana "has a history" of hugging and cuddling people. Then, I'm told, she has a tendency to go back to her 
group home and report to staff that she has been abused - repeatedly hit or beaten - by her snuggler. Accepting Prince Diana's affection apparently comes at a price, but I really don't know what's true and real here. Perhaps the danger is not inherently in the cuddling, it's in a memory or a perception of the cuddling that is distorted enough to put her partners at risk. The other danger is in the gossip surrounding Prince Diana and my obvious inability to navigate it.

Prince Diana is not the only person to carry this particular quality. Mary also has a history, according to staff rumour. Staff censor her writing. She used to write tame romance stories about men at JS Manson, exploring fictional encounters of romantic touching and kissing. This was put to a stop when, one morning, I arrived to find a staff person reading her journal. Mary was nowhere in sight. She had apparently sent a love note to someone, and when he did not reciprocate she called the police and reported being inappropriately touched.

The grey areas here are absurdly endless.

Phenomenological lived experience writing attempts to work through memory and interpretation in order to notice the remarkableness of usually unremarkable, ritualized experiences. In this type of writing I attempt to attend to meaning that belongs to the original phenomena and gives rise to the experience itself (van Manen, 2002, p. 9).

As Moran (2002) emphasizes, the descriptiveness of the phenomenological approach seeks to "illuminate issues in a radical, unprejudiced manner, paying close attention to the evidence that presents itself to our grasp or intuition" (p. 1). In observing and describing the phenomena of intellectual disability, it is a phenomenological prerogative that drives the discovery toward the things themselves or, in other words, intellectual disability as it shows itself "what is self-given, and not something that is a representation of an outer world" (Moran, 2002, p. 6). It is via this descriptive route of understanding intellectual disability that I sense its essence 
is somewhere between its representation (meaning the person carrying the label and the things they do) and the observation of this representation through any writing, including my own here. Somewhere between the lines of this text is a sensation, and I call this sensation wonderment. In this case, the wonderment is a pause, a brief illumination of, researcher-participant-staff relation — the unspoken, unwritten, and implied that is unresolved. The story might be re-written in a way that emphasizes the presence of this sensation more phenomenologically in the passage that follows, which attempts to investigate the scenario as lived rather than as conceptualized in response to van Manen's (1990) instructions (paraphrased by Vagle above), and reduce the narrative to "what is self-given" (Moran, 2002, p. 6).

Prince Diana is writing when a man enters the boardroom and hands her a drawing of two figures and a round, yellow sun. "Don't tell anybody, okay? I want this to be our secret," she says.

The man wheels into a space at the table next to Prince Diana, who does not look up from her writing. When he asks her what he ought to write, she waves her hand dismissively and says, "I'm writing a poem about grandmother, so I have to finish this."

A staff member knocks on the door and beckons me toward her. We stand together in the hallway and she whispers a warning that Prince Diana and the man are not supposed to sit together because of "inappropriate touching." I look into the room; they are sitting next to each other, writing silently. The staff member explains to me that Prince Diana "has a history" of inviting people to snuggle and later reporting that she has been repeatedly hit or beaten by her snuggling companions.

When I enter the room again, I ask if I can take a seat between them and they nod. I sit between these participants for the remaining 40 minutes of our session. 
With lived experience description researchers must be careful not to cut out certain necessary elements of writing such as tension. Without tension phenomenological accounts fall flat:

A powerful phenomenological text thrives on certain irrevocable tension between what is unique and what is shared, between immanent and transcendent meaning, and between the reflective and the pre-reflective spheres of the lifeworld (van Manen, 2014, p. 68).

Again, however, we are reminded that any kind of description, including lived experience description, can "inevitably do violence to lived experience" by bringing that experience to an abrupt "halt," applying a permanent identity to it, or by remodeling the experience as something other than what it was via a distorted angle or orientation (van Manen, 2014, p. 105). Arguably, there is a whole realm of investigation up for grabs in the first version of the story, where themes of sexuality, deviance, and eroticism rise to the surface. In the second version of the account these themes are forgotten, yet the re-writing works to bracket the pre-suppositions embedded in the first version of the story (van Manen, 1990; Vagle, 2014). By reducing this description to a part that is specifically research-oriented — that focuses on the relationship between the researcher, the researched, and the non-researched as a troubled triad — this lived experience description explication of the data demonstrates the hidden dynamics at play.

What is left of the story is a re-imagining and a re-writing of a scene based both on memory and gathered data. This scene is a "contact zone" where "what emerges is not a mirror of oppression or promise but a residue of all the moments of watching and waiting in the mode of the potential, or the very problem of a moment of poesis" (Stewart, 2007, p. 77). Poesis, of course, is tied to making and to poetry, and thus the account is a gesture toward intellectual disability as phenomenon and as presence — a gesture that might otherwise be hidden. As Vagle (2014) points out, “sometimes letting writers just write provides even 'better' phenomenological data" than that which would be found by sticking to a particular form or method, even one that 
could be called upon to "open up" aspects of a phenomenon (p. 92). Writing and re-writing descriptively, with the support of lived experience description writing, is a method of data gathering and data explication here. The data emerges and re-emerges via interpretation that is never fully complete, and that never has a solid end point even though it does shed light on what it finds in "the space between" (Dolmage, 2014).

\section{Digging into essences}

Finally, a phenomenological approach gives in to the essence of phenomenon and attempts to dig it up, to describe it. Husserl (1970) instructs:

The phenomenology must bring to pure expression, must describe in terms of essential concepts and their governing formulae of essence, the essences which directly make themselves known in intuition, and the connections which have their roots purely in such essences (p. 66).

Husserl dwells in essences. Moran and Mooney (2002) pull a claim about phenomenology from Husserl's 1913 edition of Logical Investigations when they explain that in phenomenology, facts are disclosed to consciousness "in such a way that the essences of those facts and their intertwined laws can be exhibited, as well as the modes of our access thereto" (Husserl, 1913 in Moran \& Mooney, 2002, p. 6). The essence of something is not an experience perceived as "real" fact, but rather the expression of "empirical fact," the stuff that is known through intuition and "the connections which have their roots purely in such essences" (Husserl, 1913, in Moran \& Mooney, 2002, p. 6). Trying to dig up the essence of something is a game of opposites whose expression "zig-zags" between description and the things referred to by the symbolic (Zhok, 2012, p. 102; Husserl, 2002, p. 70). The game begins by recognizing the factuality of a thing, and then attempting to separate that factuality from the non-temporal (that which does not change) 
and that which is not dependent on "the particularities of factual experiencing" (Zhok, 2012, p. 102). Following Sedgwick (2002) and Stewart (2008) this supposed game leads to weak theory. Weak theory is theory that "becomes undone by its attention to things that don't just add up but take on a life of their own as problems for thought"' (Stewart, 2008, p. 72). That essence doesn't quite "add up" and therefore it weakens its own ontology — and weak ontology, Stewart posits, is situated in the middle of essences (p. 77).

Importantly, essence can be a material, tangible part of a phenomenon though it may not necessarily be tied to (named) language and its boundaries may not be identifiable (Stewart, 2008, p. 107). Yet essence is not a social construction; it is not the stuff out of which the problem of intellectual disability is made if we think of labeled individuals as people whose bodies are located in cultural locations of disability. Essence, rather, is "the moment itself when an assemblage of discontinuous yet mapped elements throws itself into something" (Stewart, 2008). In this sense - discontinuous and mapped, familiar and unfamiliar - I think of intellectual disability as essence because of its broad permanence as applied to particular bodies. Intellectual disability is recognizable label rooted in materialist understandings of the body as problem; however it is also an abstraction with unclear boundaries and unmanageable presences. Intellectual disability is like an aura that hovers around only certain people in particular cultural locations, and it is a phenomena that dips into the familiar and unfamiliar. And as intellectual disability moves back and forth between these realms its motion is identifiable but ungraspable - a type of sensuous essence that emerges immediately and re-emerges in reflection. Intellectual disability is "what stands firm as individual experiences unfold" throughout this research (Zhok, 2012, p. 119). Describing intellectual disability, then, is not unlike seeing only one side of an 
object, particularly when description is linked to the intangible, such as essences and modes of humanness. 


\section{Chapter 12: Reflections on Mary, Owen, and Flora's writing}

This research attempts to present "untranslatable" expressive writing not only in its finished form, but also in the moments where it emerges, and in the relational elements of writing that come to pass during this process of meaning-making via expressive writing — the moments that might make intellectual disability mean.

By thinking in terms of actions and moments, I aim to move outside of the logocentric elements of writing and to understand the action of writing as a communicative tool. That there are essences to be taken into account — or read — through the motion of writing means that for "untranslatable" expressive writing to be understood as reflecting the pre-verbal sensations present in the lifeworld it must be understood as meaningful motion (Cixous, 1993; van Manen, 1990). Therefore the data gathering for this project involves dwelling somewhat in the writing itself, but also in the process of writing and the interpersonal engagements that come up because of writing. This type of phenomenological data gathering and explication takes the form of description and, following van Manen (2014), lived experience description writing. These forms of writing force the process of re-writing into data gathering, and re-writing widens perceptions and expectations of cultural participation by calling up from unconsciousness that which is overpassed or left invisible in the first few rounds of observation. These "bodily presences" that, I will argue here, can be felt as present rather than as problem (Abram, 1996, p. 89) are part of the triple-labelled writing process inherent in academic discussions about intellectual disability.

The data gathered here does the work of taking up, as Vagle (2014) posits. It has been compiled over 14 weeks of unstructured conversation, note taking, listening, descriptive re/writing, and expressive reflection. Every week this work was done in a paper notebook, except for in one instance when I brought my laptop to a "Once Upon a Time" meeting to show 
participants photographs of their writing and to read them excerpts of my dissertation draft which included their names or anecdotes about them. On that day I took notes on my laptop, which made the notes less accessible than when they were taken on paper because paper notes are more easily passed around for participants to flip through and/or read. The goal of collecting this type of data in these bare-bones ways is to find out as much as possible about a brief experience of being in-relation-to those in-intellectual disability, even when the gathered data emerges and waits as something of a mess to be sorted through in (ironically, perhaps) the name of intelligibility.

What follows are three writing samples called "Reading writing," so named because the work involved in gathering and explicating the writing is a reading of experience. Some writing samples include photographs of participants' writing, while others include re-writings and memory gatherings. These samples are meant to demonstrate moments of experience where writing provokes the emergence of intellectual disability as a phenomenon. The first sample comes from Mary, who demonstrates how the self is discursively constituted under contemporary disciplinary readings of the body. The second is derived from Owen's writing process. Owen's (re)writings — or text*, as I will come to name them — open us up to the actions of "finding things" we may have never "thought or felt before" and direct us to the unknown (van Manen, 1990, p. 13). The final example is that of Flora's language and writing experiences, which land somewhere outside of modern expectations of research participation, forcing us to give in to intuition and descriptiveness. Flora also shows us how disappearing can be a way of arriving at, and starting from, the limits of knowledge. 
Participant writing sample 1 - A poststructuralist reading of Mary's writing experience

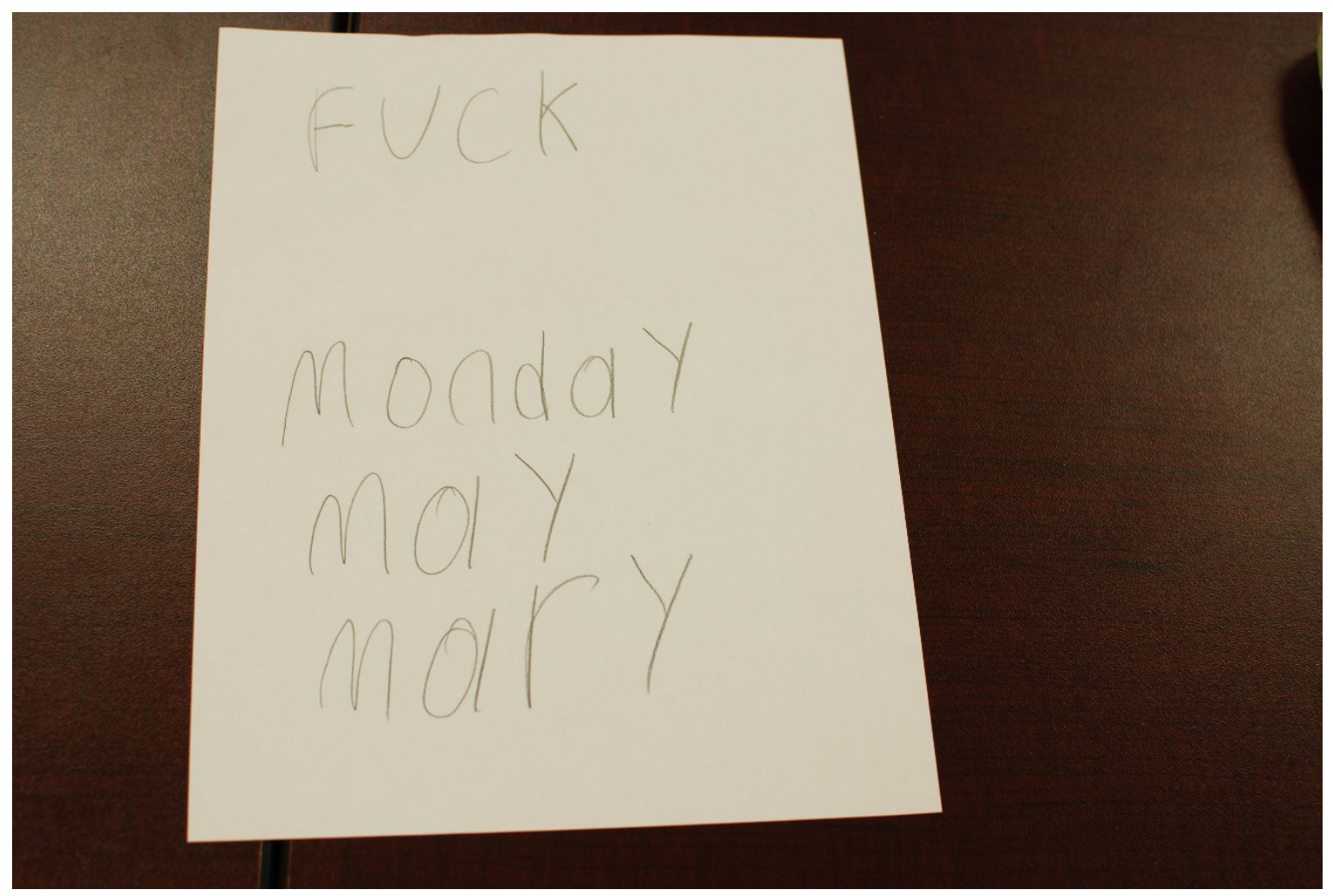

Image description: Participant writing sample 1 - Image shows a white piece of paper on a brown tabletop. The words "fuck," "Monday," "May" and "Mary" are written on the paper. The letters in the word "fuck" are capitalized, and this work is the topic of the dissertation analysis. The other words are written in lower case, and these are words Mary used on January 9, 2015 to demonstrate the un/ease of spelling to the researcher.

As Davies (2000) explains, agency has much to do with personhood. From a poststructuralist perspective, the person — the subject — is the effect of a "mutually constitutive web of social practices, discourses and subjectivity; it is the tissue of social relations" (Henriques et al., 1984 in Davies, 2000, p. 55). We are only ever brought into existence and into meaning through available discourses. In more humanist lines of thought, agency has to do with a person being in relationship with the normative lines of society, which act upon them as people go through individual struggles for personhood and citizenship, as Prince (2012) outlines in his analysis of 
citizenship, or more specifically "absent citizenship." These individual struggles are encapsulated in particular circumstances — geography and government, for instance — wherein freedom and individuality mean "the ability to choose and decide" (Bauman, 1990, p. 21). Eagleton (2000) reminds us that culture is a form of subjectivity at work within everyone, and that being a person is linked to freedom and normality — concepts that are the offspring of modernist notions of civilization (pp. 8-13). As Bauman (1990) points out, others affect our freedom, and the material conditions in which we find ourselves creating writing, living through experiences, and making meaning. These encounters can be narrowed; they can become more personal and closer to the ground when detected in moments.

To be labeled as someone with an intellectual disability is not a matter of free choice because this label is often "the territory" of one's personal freedom: we are born with the label or not, and it has much command over our lives (Bauman, 1990, p. 24). Therefore, one's agency one's sense of self and personhood in this world - is captured by experiences of subjectivity, with subjectivity constituted by contradicting discourses; "one can only ever be what the various discourses make possible, and one's being shifts with the various discourses through which one is spoken [or written] into existence" (Davies, 2000, p. 57). The contradictions and conflicts within these discourses have concrete, material effects for disabled people. Therefore, the act of writing combines both poststructural instability and humanist coherency as it relates to a person's agency and forms a person's subjectivity, as Mary — whose citizenship positions her in a day center that is the location of this research — will demonstrate.

There are several advantages to being in-relation-to Mary and her positioning as an intellectually disabled writer. One advantage is her large and fascinating portfolio of writing, which features several forms too extensive to dive into here: love letters, narratives about 
flamingos and other pink things, rolling rhymes, a thick stack of reference pages where words are spelled several different ways, a hidden diary kept at home tucked away where staff won't find it, a collection of perpetually unfinished word search games. Another advantage for me, as a hearing person, is that Mary speaks verbally using language and diction I can understand. She also communicates using American Sign Language (ASL) and uses her skills to support two other participants in the research group whose ASL skills are far above my own. During one fieldwork day (Dec. 5, 2014) she wrote a secret letter to one of the participants. I wasn't allowed to read it. "Do you worry that staff might read it?" I asked her. She shook her head no. I asked her how she planned to keep it a secret - confidentiality can sometimes be hard to come by for triple-labelled people — and she told me that she and one of the ASL-speaking participants had a sign-language-based system to pass things between backpacks.

Also, Mary almost never participates in my planned writing activities. She has no patience for ethics protocol and often moans and mumbles when I begin our sessions by asking how people are, and by describing a writing activity. My fieldwork notes reveal that she repeatedly tells me, in various turns of phrase and body language, that my activities are "silliness" and that she should just be allowed to write of her own volition (Feb. 4, 2015). I owe her many thanks for her frequent demonstrations that the research doesn't entirely unravel when participants don't play along with institutional protocol.

Below is a lived experience description of one writing encounter with Mary, based on fieldwork notes from January 9, 2015:

Mary is packing up her stuff. She has a pile of crossword puzzles, blank pages, and Disney colouring books that fit into a crinkly plastic bag. The sound of the rustling bag fogs up the transcription and makes me squirm when I listen to the recording and make notes later. Mary 
sighs loudly several times. She clicks her pens, closing them for the day. Her chair squeaks across the floor as she gets up to leave the table. I am trying to listen to Flora talk about a Toronto Raptors game. Mary stops at the doorway and gazes at everyone.

"See ya," I say, trying not to sound flippant (and probably not succeeding). Mary is allowed to leave whenever she'd like, and I don't want to sound anything but neutral about it. The research session started about 10 minutes ago. When she needed help spelling something and I told her to wait, Mary put her head in her hands, sighed heavily, and began packing.

The rest of the participants continue writing.

Less than three minutes pass on the voice recorder.

Mary is back.

"Is it alright if she returns?" A staff person asks me as she ushers Mary into the room. Of course it's all right, I assure her.

's bringin' me back," Mary says, wide-eyed. The staff person watches Mary find a seat at the table.

"Mary understands that we all sound out words to spell them," the staff person says.

"But if it's a hard word I don't want to do it," Mary says.

"Mary," the staff person says, "we respect what you do and do not want to do, but we do not want you walking out of group, please. Unpack your stuff. Start to participate. Stay positive, Mary; I believe in you. Chelsea, feel free to let me know if there are any issues."

In this moment, attention needs to be oriented toward the specific ways an "intertextual world of social practices" (created out of the prospect of writing and Mary's decision not to write, rather than through any particular writing activity) underpins particular identity positionings (Kostouli, 2009, p. 102). First, Mary is being read and explained as not positive, which immediately implies 
that the "appropriate" and/or "correct" way to write is from a standpoint of positivity. Thus she is positioned as something opposite of a "good" writer/participant. Further, her individuality is called into question and her action of leaving the research is linked to attitude rather than to her right to do so. I too am put in an uncomfortable position when it is implied that I should voice "any issues" to staff members. Mary's control over her own situation has dissolved, as has my control over the situational ethics of my own research project; the power relations have quickly shifted from Mary making her own decision to leave the research to staff escorting her back into the room and verbally passing control over to me. (And, suddenly, I am in the position of researcher-in-wonderment).

The transcription reveals that I didn't say anything (if memory serves me correctly I think I nodded my head). I said nothing because I didn't know what to say ${ }^{67}$. I understand that Mary is allowed to leave the research at any time. And in fact the REB protocol should ensure her ability to do so; it should protect her from participating against her will. However, I also understand that staff roam this day center and part of JS Manson's rights-based, independence-driven agenda involves making sure participants stick to their commitments; if Mary has signed up for writing today, she is expected to write. The immediate surveillance at the day center is more direct, and perhaps stronger, than the REB's surveillance.

From a poststructuralist perspective, Mary's "choice" to leave the research at any time is a rational one based on her desire to leave. Because desire is integral to the discourses through which personhood is constituted, Mary's desire in this moment creates her subject position as one who has made a decision to leave (Davies, 2000, p. 57). Her decision, however, conflicts with humanist notions of choice. Although it is written — sanctioned, basically — in the REB

\footnotetext{
${ }^{67}$ And I am reminded of Goodley and Rapley's (2000) readings of “acquiescence bias" when I retrospectively re-assess my own actions here.
} 
protocol and in the signed informed consent agreement that Mary may leave the research at any time, Mary's choice to leave conflicts with ostensibly rational and coherent thought that suggests her choice is wrong because it is made on the basis of lack - in this case not only lack of normative participation patterns and seemingly correct desire, but also lack of a "good" attitude. So I say nothing, because I know that although Mary's freedom is restricted now because she cannot leave the room, at least under my watch she doesn't have to participate/write. My hope is that Mary can at least exit the activity if she cannot exit the room. The story continues a few moments later:

Mary holds up a page of paper for me to see. On it, she's written the letters " $F-U-C-K$." Idon't say anything. "That's her, right there," Mary says. Then she rips up the paper. "If you see that, you're gonna tell her, and I don't want that."

“I'm not going to tell her. That's okay.” I say.

“Do you know sign language?” she asks. When I shake my head no, Mary begins to sign something I don't understand. I go and sit beside her, and I ask if I can take a photo of what she's written for my research. "It's four letters," Mary explains. "That's how mad I am ..., you know what those letters mean. That's how mad I am. When I leave the room I mean it for real, and I don't want [staff] bringing me back."

In my reading of this situation, Mary demonstrates that she does have an understanding of herself as being discursively constituted by contradiction. She is aware of her rational desire to leave, and she is also aware of how this desire has been misinterpreted, and thus she is stuck in this research group. This reading is also phenomenological in the sense that it points to the intersubjectivity of human experience, and a shared account of writing that formed the basis of a 
particular social interaction that not only pointed out the place of intellectual disability but also put it in its place (Withnow et al., 1984 in Madjar \& Walton, 1999b, p. 4).

Consider that Mary also subverts my interpretation of her constitutive self by ensuring that she can add a discourse to the mix that I don't understand when she signs a message (perhaps to herself, or to others; her audience is unclear to me). In this way she ensures that I will miss out on data by using linguistic knowledge to resist and modify both of our positionings (Kostouli, 2009, p. 103) — she becomes knower and I become the one that will never quite understand what she is speaking, and thus I remain in a position of lacking clarity in my analysis. With these actions, Mary subverts and re-invents the power relations she works within.

Our conversation continues below. I have abbreviated some of the dialogue below to reduce the length of this encounter, and I have chosen to step out of LED writing and into pure dialogue writing in order to avoid tampering with Mary's points and in an attempt to let her dialogue explain the situation.

Chelsea: Does it help you to write it down?

Mary: Can Ijust say something? I'm gonna show you something on this paper. Like, you know like, let me put 'Monday' down. That's an easy one to spell, but 'Saturday' is too long. I wouldn't know how to spell that, right? But the thing, well, for the months - you know the months? - well 'May,' that's a month, that's easy to spell, but the month 'January,' that's a long one. That's kind of hard for me to spell so I would be asking for help and stuff like that. I know how to do the easy ones and say, 'Mary, ' I can spell my name, that's easy. ... you get what I'm saying? 
C: I get what you're saying. However, there are a few things I need to think about too. So, like, sometimes I need to talk to other people, not only you. So sometimes if you need help you might have to wait, okay?

M: That's the problem with me. Like, if I make a mistake in [someone 's] name or in 'January' or say 'Saturday' then it wouldn't make sense. ...

C: Who do you want it to make sense for?

M: It can be somebody at home. It can be somebody at here I go to talk to, right? Or it can be family, somebody in the family of mine. Or it can be somebody here. It can be anybody.

C: So are those all the people who read what you write?

M: Yes.

C: And you want to make sure they understand it?

M: Right. I want these people to understand my writing, and know what I'm saying. I don't want them to think I do crazy writing and make mistakes on purpose.

C: Right. Okay. Well, sometimes, even if we make a mistake, people can still understand.

M: Well some people don't.

C: Does that happen, sometimes people don't understand?

M: Yes.

C: And what happens when people don't understand?

M: They say I'm a clumsy writer. They think I don't write good, they call me crazy, and they just think my writing is garbage. People, some people, say that. Like, some, for instance, some people at home say it. Some people here say it. Or some people at $\square$ say that. And not everybody says it; it depends on who the person is. Like $\square$ would say it. And $\square$ would say it. And $\square$ would say it. Or - somebody. 
C: So, let me make sure that I understand: you want to make sure that you write everything correctly so that nobody says negative things about you or your writing?

M: Right.

Here, Mary describes the disciplinary power under which she writes. This type of disciplinary power is the work that goes into producing intellectual disability. Mary is under constant observation as her writing gradually moves out from her own gaze and into the sight line of the people who surround her (Foucault, 2003, pp. 47-48).

If we think about writing as moments that can possibly tell us something about the lifeworld, a phenomenological reading of the happenings that lead to Mary's writing moments exposes her as present in the interpretation of her own writing. Ahmed (2006) suggests moments can be read as happenings, and that happenings bring something to the situation; something arrives (p. 40). And what arrives "is shaped by the conditions of its arrival," including past encounters such as those Mary describes where she is labelled as "clumsy" and "crazy." If Mary is arriving at writing under social conditions that interpret her cultural location as always-already lacking rationality to participate in normative writing, arguably Mary's writing process and her deep concern for spelling (even more than the text she produces) reveal the social realities of the people in this writing group, which Kostouli (2009) might call a "learning community" (following notions of literacy as a community/group-based understanding of language) whose social realities are constructed by language accuracy/correctness (p. 108). In other words, the phenomena of intellectual disability "appear" or "arrive" in anticipation of both writing and normative readings of text — "the arrival only becomes an arrival insofar as it has happened; and the object may 'appear' only as an effect of work that has already taken place” (Ahmed, 2006, p. 40). In Mary's case, intellectual disability reveals itself (“arrives") because writing, or more 
specifically spelling errors, is about to happen and has happened, and intellectual disability is the result of those errors that have happened and have later been taken up as apparent evidence of Mary's lack.

Further, following Prendergast (2001), Mary's concern, which she articulates in the above transcript, solidifies the notion of rhetor being "granted" only to those who write - who represent meaning and language — in understandable and correct normative terms. Here, Mary's text takes "the shape of social action," as Ahmed (2006) argues all objects do if/when we look not only at the thing itself but also at its conditions of arrival that give the writing its specific shape (p. 41). Or, put another way, the actions performed on the object (Mary's writing) affect its subject (Mary, the writer) (p. 43). It seems as though, for Mary, there is little possibility of reversibility: her body/her writing cannot be separated from the rational thinking that determines its validity (Merleau-Ponty, 1964). Thus her concern about spelling/accuracy is very real in that she can easily be diagnosed as "outside of language" and thus disavowed (Berger, 2014, p. 32).

On this day, Mary went on to write a letter to her mother. She asked for assistance with spelling only once. When I step out of the room and leave the recorder on, she sounds out words that I hear during the transcription later. Whatever else she wrote she did not show me; there was no grand finale that would serve to display the cheerful participatory nature of her writing and my research because in the elongated moment that we might call her writing process, Mary and I distanced ourselves from each other as I tried not to push her toward writing and as she turned toward it as a solitary experience. What was once a research space intended to give time and concentration to writing as a way of resisting a political and social environment where triplelabelled people are excluded from deep-thinking work has changed shape and become a place where Mary is stuck, obligated to write. Hardly emancipatory, hardly leaning toward closure. 
Instead, we are left with opened-up embodied expression that evidences the wide communicative gesture that is intellectual disability where we are both obligated to dwell for another hour or so in the familiar "that's just the way it is" sensation of wonderment.

One lesson we can take from this encounter with the question of what it would mean for "untranslatable" expressive writing to be read in the lifeworld is that expressive writing is made by more than one person; it has a whole social history attached that "arrives" when, in this case, pencil meets paper. The writing process itself is a response to dis/ableist realities (Jones, 1986, p. 230). This brief glimpse of context is available not necessarily in the text itself, but in the moments wherein the text emerges and intellectual disability as a phenomenon begins to rear its face and come into contact with the research and its subjects. Still following Ahmed (2006), I suggest that what is missing from this analysis as a result of a methodological shortfall is a tracking of the effect of multiple conditions of labour on the writer (p. 42). A poststructuralistphenomenological approach built on observational analysis would benefit from more context and history. For example, formal interviews and/or life histories with someone like Mary could work to better understand her proximity to normative notions of literacy and the steps institutionalization has taken (such as training, education, and instruction) to configure Mary as intellectually disabled. 


\section{Reading Writing: Owen}

Participant writing sample 2 - Queering and cripping text

One part of the fourth research question that informs this study asks if phenomenological reading, accompanied by poetic response-writing, could assist in "widening expectations of cultural participation and unbinding intellectual disability from contemporary invisibleness." In attempting to confront this aspect of the wider research question, I turn to Owen's writing.

I offer no image of Owen's writing because he indicated in his informed consent form that he did not want me to take photos of his writing. However, during the "Once Upon a Time" research sessions he often asked me to take photos of his writing anyway, and the ethical lines became blurred; I have images of his writing, taken on his request, stored in my research files that defy the informed consent agreement but make sense given Owen's rolling consent. I look at these images to jog my memory as I write. One image shows a spiral notebook filled with words from top to bottom. Owen's letters stretch three lines tall, and on average he writes two or three words per line, making his writing resemble stanzas. He blots out words he does not want with black ink, by spiraling his pen over each letter. The effect of these rounded, bobbing blots is of black clouds floating between words, and I name them "clouds" when I re-imagine his writing.

On January 16, 2015 Owen read his writing aloud to the group in his soft voice that I sometimes strain to hear. At the end of each session I ask writers if they would like to share their writing, and Owen is one of a handful of participants who often walk or wheel to the front of the boardroom and read their work aloud. Owen grips his paper tightly, and rarely looks up as he reads. The words come out of his mouth monosyllabically, one after another like the rapping, 
syllabic drip, drip, drip, of a leaky tap. He reads the words that fill his page, and I jot down what I hear:

I went to go out somewhere with friends at a group home walking straight in the parking lot solving blank stuff and moving theatre separate kiss cards.

In his notebook, Owen's words are spread something like this, including certain "clouded" areas, with each line hitting the edge of the page's margins:

I went to
go out some
were with
fridens grop
home walking
starts (cloud)
ParKing Lot
(cloud) sovesy bring
(cloud) (cloud) staff
(cloud) (cloud) and
movie thererd
CinxenBix gived
carDs Owen

What I hear through the transcription and what is written on Owen's paper are not the same text, and what is lost in translation is difficult to measure: Did he improvise and speak off script? Or did I mishear certain words that aren't written down like "at" and "kiss"? Can the shapes of Owen's words as they appear on these pages tell us something about intellectual disability? Working through the idea that all creative practices are embodied, affect-related processes, Wendelin Küpers (2011) suggests that phenomenology can help to "re-remember" the marginalized body in light of a separation of body and consciousness (Styhre, 2011 in Küpers, 2011, pp. 101, 105). What follows in this example is that I have, in a queer way that is closely aligned with crip ways, found some of what I am looking for in writing as I seek meaning and experience. 
Phenomenological perspectives aim to dig up "the experience as it is for the person living it rather than as diagnostic labels might lead us to expect" (Madjar \& Walton, 1999b, p. 6). While Owen's writing does not reveal his experience of being triple-labelled, it does tell us something about meaning-making and how meaning is also re-made of intellectual disability through re-writing. By writing down Owen's writing in a way that is different than his own written work, I make Owen mean something other than the discourses he presents and the always-already frameworks within which he exists. Following Vagle's (2014) directions, describing intellectual disability through writing and rewriting as a method of gathering data is an ongoing process that urges researchers to think about language through description (p. 59).

We might, following Küpers's (2011) reading of Merleau-Ponty, understand the motion of re/writing as creative practice in that it is an embodied motion and a situated nexus of action (p. 102). Below is a lived experience description gathered from a December 12, 2014 "Once Upon a Time" research session that serves as a re-written representation of an experience that opens up space for particular action-based processes, such as listening and reflection.

From across the table I ask Owen what he is writing about, and he begins folding up his page. He tells me his writing is private; he doesn't want to share it with the group. Later, when I ask if anyone would like to read their writing aloud, Owen raises his hand to volunteer. He speaks the words on his page: "Back door walking up the stairs the front door back door. Open inside a chair. Sit in there, a table. Owen wants to know about coffee, the staff."

"What is that story about?" I ask.

"Oh, it's about the group home. About ours," Owen says, folding the page and putting it in his shirt pocket.

"Can you tell me a little bit more about it?" 
"Hm?"

"Can you tell me a little bit more about it?"

Owen doesn't say anything.

I try again. "Can you tell me anything else about it?"

"Uh, I have nothing to say."

"Okay, alright."

In reflecting on this conversation I try to take a tip from Kuppers (2007), who teaches us about listening. "Listening," she writes, "I am always seeing around the edge, always aware of the smoke screens and narratives, and what emerges in the act of reading as an embodied luscious, heart-opening performance of meaning making” (p. 94). In this way, Kuppers takes up listening as a motion of cripping - a way of getting out from behind fixed forms. I am not privy to the form Owen's writing takes on the page. I can only hear what he says and imagine the spaces between words, and how they might fall either on the page or into the air. His words draw me in, as van Manen (2002) says words will when he emphasizes that reading and writing are similar processes (p. 7).

Owen's reading edges on being an unremarkable experience, something taken-forgranted with not enough evidence (that is, no visual representation) to support its validity. In order to challenge this motion and to suggest that Owen's writing in this case is remarkable, or at least worthy of remarks, I suggest that there are ways to get "inside" this text without seeing it phenomenological ways of re-writing that allow us to broaden the understanding of what "really" happened in normative terms and give space to the creation of what van Manen (1990) calls possible worlds, or a possible experience of this text that also points to possibilities in human experience (p. 70). Van Manen refers to this process as poetizing when he writes, 
We must engage in language in a primal incantation or poetizing which harkens back to the silence from which the words emanate. What we must do is discover what lies at the ontological core of our being. So that in words, or perhaps better, in spite of the words, we find 'memories' that paradoxically we never thought or felt before (p. 13).

Yet, it is also important to recognize that there is danger in re-writing participants' words danger in accidentally implying that my interpretation of things is how things "really" arrive (Lather, 2007, p. 13). And through my observations of this particular writing process, I consider Roland Barthes's notion that violence of this type is possible, because in modernity rational language is favoured and notions of reality tend to be granted to texts that are upheld by "the real" - by hegemonic discourses that give texts authority and social function $(2007$, p. 83$)$. The risks laid out as they are, here is how I heard Owen's writing:

Black door
Walking up
the
stairs
the front door
back door
Open
inside a chair
Sit
in there a table
Owen wants to
know about
coffee
The staff

In some ways this re-writing, and thus re-reading, of Owen's words is a way of experiencing his writing pre-reflexively, or bracketing it, because the original is unknown. One characteristic of a phenomenological approach is that it tends to describe the depth of an experience without offering an explanation of the scope of the process at hand (Madjar \& Walton, 1999b, p. 14). 
Another way of understanding this process is in saying that phenomenological approaches are always retrospective rather than introspective (van Manen, 1990, p. 9). What we know about Owen, for example, is that his writing is spoken and interpreted by others, thus slashing a division between the original, "real" text and what is understood and taken away from this experience. Yet the text that appears here is a result of Owen's "real" concentration and very "real" writing. Thus Owen's text is a plural text because it has several irreducible meanings (Barthes, 2007, p. 84).

Owen's text is also the result of labour, including Owen's labour and the labour of those whose literacy teaching has helped form Owen's writing process (Ahmed, 2006). For example, this text points to familiar objects of encounter such as coffee, tables, and chairs, and suggests that these objects hold meaning and memory in the experience described. As was also demonstrated by Mary's writing, the motion of bringing together understandable words is a motion of literacy that is taught and learned; the text is both the effect of work and also what allows us to work (Ahmed, 2006, p. 50). And as we also learn from Ahmed (2006), objects are not just props or material things, they support the actions for which they are intended; learned meanings of the objects Owen names may point toward actions such as drinking, writing, and sitting - although what these actions really mean to Owen remains unrevealed (pp. 46-47). What also remains unknown is why he is writing and what that means to him; the introspective is hidden even though I have tried to pull it out by asking for more information about the text. Therefore, the irreducibility of meanings here can be attributed to Owen's resistance to reducing (explaining) his text with any particular reading, opening up a new idea of text.

Further, now that we have gotten "behind" the text, as Kuppers suggests (2007), we might, in line with queer theory, "slant" it (Ahmed, 2006, p. 65). Using Merleau-Ponty as her 
starting point, Ahmed (2006) describes the "queer moment" which is similar to the moment of writing the results in Owen's text:

By implicating the queer moment, in which objects appear slantwise and the vertical and horizontal axes appear 'out of line,' we must be overcome not because such moments contradict laws that govern objective space, but because they block bodily action: they inhibit the body such that it ceases to extend into phenomenal space (p. 66).

Owen's text appears "slanted," "altered," and "out of line" by a myriad of factors: the mismatch between the sound of the words and their shape on paper, the unclear explanation of meaning, the tampering (intervention) of the researcher's re-writing. Therefore, we could suggest that Owen's "text" take an asterisk, as in "text"," to give the word a greater range of meanings, some of which are fluid, hidden, resistant toward binaries, changeable over time, and sometimes attributed to more than one body in the process of meaning-making (Tompkins, 2014, pp. 26-27).

The meaning structures embedded in this text feel just slightly out of grasp, lodging the research again in a sense of wonderment. A phenomenological approach considers the possible meanings of lived experience, which push the research more tightly into the "space between" experiencing intellectual disability and being in-relation-to intellectual disability (Dolmage, 2014; van Manen, 1990). If we think of Owen's text as text*, we uncover the silence within the writing without necessarily "outing" what exists in that space. Instead we may even go further to suggest that the meaning should not, and could not, be revealed by the rational discourses that shape this research project, and thus follow in the footsteps of researchers whose thinking takes them outside of such structures (Gray, 2000; halifax, 2009; Holland, 2007; Reid \& Landry, 2015; patterson, 2008). In re-thinking Owen's work not as something to overpass because much is un/under-explained or untranslated by both researcher and participant, we thoughtfully re-engage with the text in a "heedful, mindful wondering" (van Manen, 1990, p. 12). 
By re-engaging with the text this way, we also re-engage with intellectual disability as a site of meaning that is wider than expectations of its label, including poetizing, that draw intellectual disability out of invisibleness while simultaneously intending to respect the unknown. Ahmed (2006) explains that "the failure of objects to work could be described as a question of fit: it would be the failure of subjects and objects to work together" (p. 50). In other words, as a researcher I make a choice for Owen's writing to "fit" because to call his text* unresearchable, or invalid, would be in equal part an unwillingness to include his writing and acknowledge the labour and meaning that potentially dwells in the text*. This ambition to respect the unknown brings to mind Ahmed's (2006) distinction between "using" something and "perceiving" something, such as the writer's experience of text* — "using" being possessive and intending a thing for a purpose such as problem solving, and "perceiving" being more in line with notions of bracketing and experiencing that phenomenology tends to privilege in focusing on the ordinary in order to reveal meaning, rather than asking the ordinary (the writer or his text*) to do the work of revealing meaning (p. 48).

What's more, Ahmed (2006) clarifies that the "failure of something to work" or, I'll suggest, to "fit," would lead to "failed orientation: a tool is used by a body for which is not intended, or a body uses a tool that does not extend its capacity for action" (p. 51). Again, to take up Owen's writing as unfit for this research because of its "untranslatability" (Cixous, 1991), or because of the researcher's unwillingness to explore the unknown, or for any multitude of reasons, is to emphasize not only the failure of the research but the failure of Owen's body, his self, within the research. This disavowal would be a form of disability disavowal not unlike the exclusion experienced by many triple-labelled people who face institutional barriers embedded in REB guidelines and academic research expectations, as outlined earlier in this dissertation. By 
re-orienting toward Owen's text as text*, we move beyond the normative expectations of what the phenomena of intellectual disability and text can or should do and instead focus on what they are doing, even as sometimes unknown and ultimately unsolvable. 
Participant writing sample 3 - Disappearing and reaching a limit of knowing

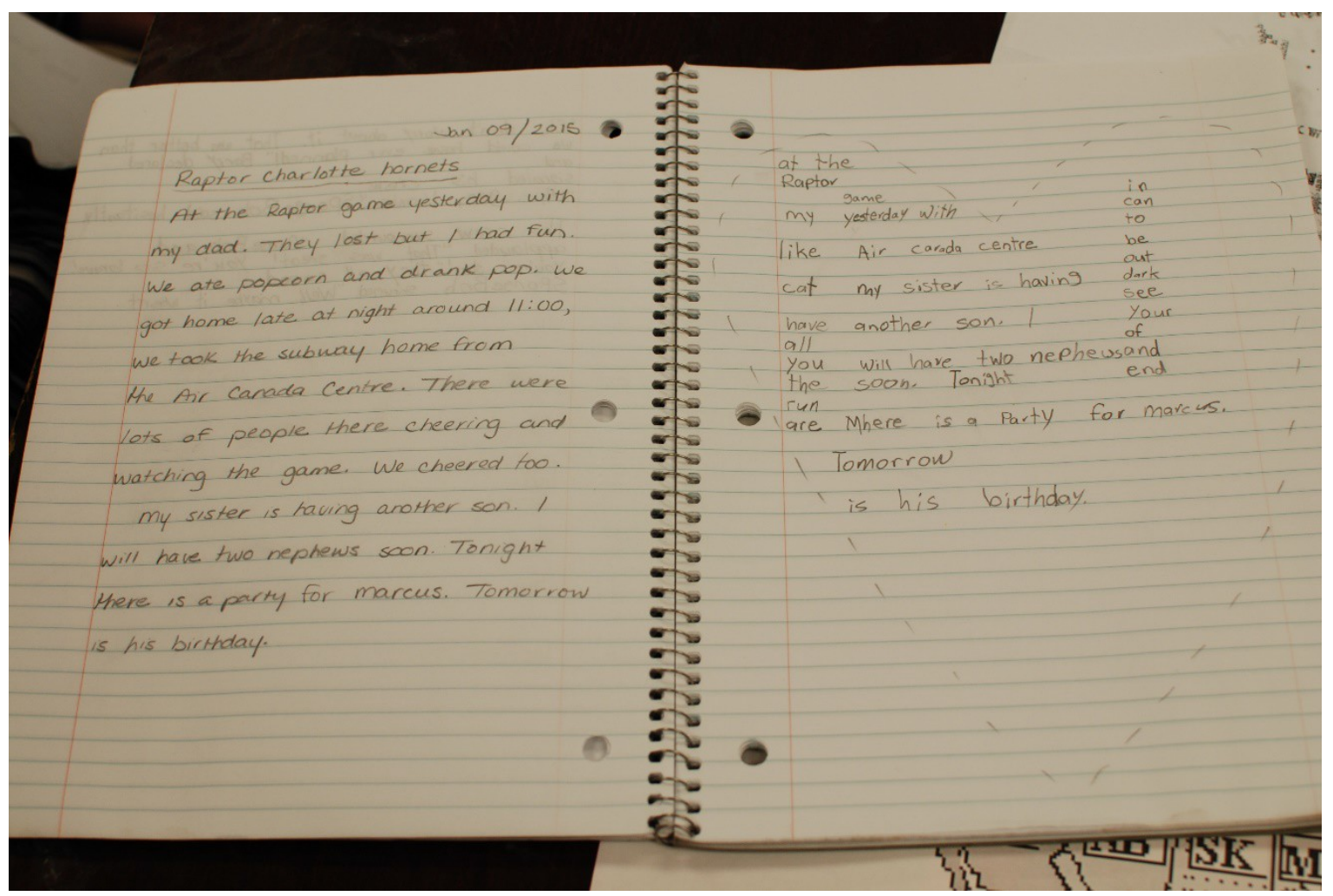

Image description: Image shows two pages of a spiral notebook. The first page, dated January 9, 2015, is filled with the researcher's printing. The researcher has written two paragraphs of words dictated by the participant, Flora, on the topic of a Toronto Raptor's basketball game and the news that her sister is expecting another baby, thus making Flora an aunt twice over. The second page is a work of shape poetry. Flora has drawn a heart and filled it with words copied from the first page, such as "Raptor," "you will have two nephews," and "cat."

Husserl's early work attempts to debunk notions that logic should be paired with linguistic and philosophical discussions. In the introduction to Logical Investigations Husserl (1970) begins by quoting Mill, who, to summarize, suggests that philosophizing without language is an impossibility - that language is necessary for thought (p. 65). Husserl suggests this assertion is rash against other "modes of cognition which come into play in their utterance and in the ideal 
possibility of applying such propositions, together with all such conferment of sense and objective validities as are essentially constituted therein" (p. 65). This statement already leads us away from the straight line of the normative, toward a queering or cripping of language, because Husserl guides us off route, suggesting that although science relies on verbal expression with its "grammatical clothing," phenomenology is concerned with something other, or something else (p. 66).

Perhaps this "something else" is also that which Derrida (1976) advocates for in the second chapter of Of Grammatology. Here, Derrida points out that "the possibility of writing" is the possibility of history — that people without writing are considered ahistorical (p. 27). He points to writing as a modernist construct ("the domain of science") with a system of thought, speech, and writing, wherein writing the meta-narrative of writing names it the "figuration" of language (and he repeats the above metaphor of writing as the "clothing" of language) (pp. 33, 35). By critiquing the systems of thought, language, and writing that present us with contemporary discourses and circumstances, both Husserl (1970) and Derrida (1976) point us in the direction of a "pure phenomenology of the experiences of thinking and knowing" that doesn't necessarily block language but requires us to look beyond, within, and around it (p. 66). I now look to Flora to demonstrate some of these experiences "off route" of language that sometimes arrives dressed up in rational, translatable language, sometimes not. These experiences take place through motions that involve normative writing and other types of writing, specifically drawn letters and shapes in the air.

Flora's writing process involves much routine. She has never missed a "Once Upon a Time" session in the three years the group has been operating, nor has she missed a research session. She often arrives early and sets up her purple notebook carefully before asking to go to 
the washroom. Flora has told me that her favourite colour is purple, and purple things such as her backpack and grapes have been topics of her writing. Most often, however, Flora copies wordfor-word out of a book called SpongeBob Squarepants Superstar (Auerbach, 2001). Often when I open our sessions by asking how people are doing, Flora shyly shakes her head and doesn't answer the question. Flora is best described by her inter/actions; as the old creative writing adage goes, she is a "show-don't-tell" kind of person whose writing moments often outnumber her written and spoken words. Below is a short lived experience description from my October 24, 2014 field notes that demonstrates Flora's presence in the research:

Grand Master B and I work through one letter at a time. "You doing okay, Flora?" I call over my shoulder. She nods and smiles.

"The front door and the money plants," she says in words so soft I ask her to repeat them. I want to confirm what she's said for the voice recorder.

“Are those things purple?” I ask. She smiles and shakes her head. "Do you want them to be purple?" Flora lifts her head and nods. I urge her to imagine and write up those items as purple if she wants. Later I sit next to Flora, and we brainstorm some ideas. She also wants to write about her upcoming birthday. We think about purple presents, buffets, fruit salad, and Chinese foods I don't know how to spell.

As a final point of positioning, it is important to note that Flora is often in the background of my field notes. Consider the interaction below noted from November 7, 2014. My notes remind me that the group is working on a task to write something about what happened in childhood, with the idea of digging up memories as building blocks for present stories. At one point the 
conversation touches on the landmark childhood event of "being born," which sets the context for the brainstorming excerpt below.

Ross says he remembers being a baby, which gets a lot of laughs. Flora pulls out a picture of herself as a baby that she carries in her wallet.

"What do you think you did as a baby?" I ask. "I've

never been a baby once," Mr Clark Kent says. I

laugh. "I find that hard to believe."

Flora approaches me as I stand at the front of the classroom. She shows me a charm bracelet given to her for her birthday over the weekend. I'm not sure what she is trying to tell me. In the meantime the men are debating whether or not it's possible to remember being a baby.

Part of my purpose in choosing to throw a spotlight on Flora's writing experiences is to pull her presence out from the background, even only a little. Flora's writing is often the white noise on my voice recorder, yet her presence is constant and unique.

Flora's writing in the image that opens this section follows another document she wrote titled "Good News Flora" that describes the news of her sister's pregnancy and Flora's anticipation of becoming an aunt twice over. On that day, Flora slid her notebook in front of me. This motion, I have learned from its repetition over the research period, is a way of asking if we can write together. When we write together, Flora frequently whispers words near my ear and I write them down as dictated, or sometimes I attempt to form sentences and ask for her approval before writing them in her notebook. Then, Flora often copies my writing (which is really her 
writing, but accommodated) onto another page. On this occasion she gradually and quietly spoke words that I stitched into clunky sentences:

At the Raptor game yesterday with my dad. They lost but I had fun. We ate popcorn and drank pop. We got home late at night around 11:00. We took the subway home from the Air Canada Centre. There were lots of people there cheering and watching the game. We cheered too. My sister is having another son. I will have two nephews soon. Tonight there is a party for [first nephew's name]. Tomorrow is his birthday. (Field notes, January 9 , 2015).

This document was the beginning of a pile of writing focusing on her new nephew, including a three-word poem written after participants were asked to close their eyes and write three words that described their thoughts. Flora wrote, "Happy, funny, two," and told the group she was thinking of her new nephew. These are examples of Flora's possible entry points into normative, logical modes of writing, which tend to be the most counted forms of participation because they are measurable and verifiable.

However, Flora also communicates in several ways that seem to transcend words and normative understandings of writing, driving us away from the modernist thought-to-languageto-writing pattern that denotes normative communication hierarchies. For example, Flora uses her finger to trace letters, shapes, and entire words in the air. I realized only upon reviewing my data that the evidence for this is scarce, though I often see her repeating this motion — a motion that constitutes what her body does, following Ahmed (2006). I have only noted these movements twice in my field notes and transcriptions. Here, I am reminded of the limitations of research, given that I only have a voice recorder to capture our sessions and it fails to record things done in silence, and of the limitations of my own (jumpy) memory. Below is one instance of Flora's air-writing method, observed (and remembered) on January 30, 2015, as the research days come to an end and I review the photographs of everyone's writing with each participant. 
Flora agreed to show me her notebook in case there were other pictures I would like to take for this research.

Flora and I flip through her book. Some of Flora's older entries are written in purple pen that bleeds through the pages, so all of her writing is backed by bright pink ink blood.

On one page she's written the names of stores at a plaza called Gerrard Square, and she tells me that Gerrard Square no longer has a Toys R' Us. When I ask her if she likes to go to these places - Fairweather, Suzy Shier, Bell — she nods. Flora writes the numbers "7” and "2" in the air with her finger. "The 72," she whispers.

"You take the 72 bus there?" I guess. She nods again. Flora often writes numbers in the air, or on the table, using her finger. These numbers are literally invisible, and dependent on what the reader/recipient can imagine and remember.

Then, Flora writes "1979" with her finger on the table. "Sheep," she says. "What do you mean?"

"Year of the sheep," she says, pointing to herself. "I'm sheep."

"Oh I see," I say, although there is nothing left to see; the numbers have disappeared.

In this exchange, there is work being done that can be considered both beyond writing and part of writing: guessing, imagining, shaping, "seeing" the invisible. Much of this writing is intuitive, fleeting, and uncounted, yet it contributes to Flora's overall collection of work. It also relies on the reader/recipient to be in-writing in order to access its fleeting messages. As we will recall from Vagle (2014) and van Manen's (1990) instructions, being in-writing and being inintellectual disability includes describing, attending to, and reflecting. The researcher is called on 
to observe, recall, and mull over her own memory in order to include Flora's writing experiences in any final project, and in doing so another experience of making meaning out of intellectual disability emerges (van Manen, 1990).

In his declarative statement about returning to "the things themselves," which this dissertation has hinted toward and can finally expand upon now, Husserl (1970) argued that logical concepts must begin in intuition:

... they must rise out of an ideational intuition founded on certain experiences, and must admit of indefinite reconfirmation, and of recognition of their self-identity, on the reperformance of such abstraction. Otherwise put: we can absolutely not rest content with 'mere words,' i.e. with a merely symbolic understanding of 'words,' ... which are set up in pure logic. Meanings inspired only by remote, confused, inauthentic intuitions - if by any intuitions at all — are not enough: we must go back to the 'things themselves.' (p. 67)

With Husserl's words, we learn that returning to the "things themselves" does not mean accepting that the roots of a phenomenon are satisfactorily found in "mere words" or in our understandings of language (p. 67). Often, these roots are in the communicative body that calls out to us, so that we orient ourselves toward or away from it and read the body's givenness as text (Pruska-Oldenhof, lecture, May 13, 2011). Husserl, therefore, is suggesting that we reach even more deeply into the invisible to experience intuition and experiences, and the the space between these invisible moments and the "abstractions" they become are molded into logos, into words. It is by bending further into the text, or perhaps by bending past the text all together, that we challenge and subvert normativities by denouncing them as unsatisfactory in claiming and demonstrating particular phenomenon, including intellectual disability.

I find significance in Flora's writing because much of it is invisible background work that is only realized through the work of imagining. Flora's motions of writing, including writing in the air with her finger, are examples of experiences that cannot be "worked over," as Merleau- 
Ponty (1964) puts it, and emphasize gesture as possibility — as "a flesh of things" (pp. 130,

133). Merleau-Ponty (1964) describes the type of movement that is involved in following

Husserl's foundational command:

To return to the things themselves is to return to that world which precedes knowledge, of which knowledge always speaks, and in relation to which every scientific schematization is an abstract and derivative sign-language, as is geography in relation to the countryside in which we have learned beforehand what a forest, a prairie or a river is (p. ix).

Or, as Abram (1996) explains, we do not return to the things themselves unless we tap into the untranslatable "inner world" and its mysteriousness, which is never fully captured by Western science and philosophy (p. 10). In part, this directive means being open to wonder, and thus wonderment, and considering wonder and its affect to be the condition of possibility for opening new modes of representation (Rubenstein, 2008, p. 8). This kind of thinking turns moments into happenings (Ahmed, 2006). And, when things are happening, the body becomes a subject that calls to us again, and reminds us of the multiple modes of being in the world that constitute particular actions, just as Flora reminds us of the flexibility of the motion of writing and in doing so allows intellectual disability to "arrive" as a new mode of possibility.

When intellectual disability "arrives" again as a new mode of being, and being inrelation-to those who must imagine, remember, and "see" in order to orient themselves toward the phenomenon of intellectual disability in this context, new challenges emerge. One of the challenges of taking a phenomenological approach to this phenomenon, and to the moments of wonder and wonderment it carries along with it, rests in making things stand out in new ways (Madjar \& Walton, 1999b, p. 2). This re-making sometimes requires "apprehending human experience as it is lived in the context in which it occurs and which it helps shape" (p. 3), meaning that the research must question assumptions and engage in interaction by bracketing conceptual schemas (p. 8). With Flora's writing we are faced with the ordinary (basketball 
games, family events) and, at times it seems, obligated to feel the extraordinary. Perhaps "extraordinary" is too strong of a word. Perhaps Flora's writing does not move beyond ordinary at all, and instead finds value in not quite reaching a state of ordinariness because it does not hit all of the normative requirements needed (in fact, the air-writing never even hits a page, making it near-impossible to consider for, say, conventional publication). Ordinary writing, according to Cixous (1976), is “marking writing," meaning it is writing run by a political, masculine (and I'll add ableist) economy to uphold hegemonic norms. It is difficult to leave such marks on Flora's combined ink-and-air-writing, because it disappears and subverts the social spaces where our subjectivities are weaved and webbed. And with that, Kumar's (1994) observation that both subversive and normative discourses "develop in tandem, each speaking to the other continuously" is realized (in Dossa, 2005, p. 2528).

With this realization, we can re-enter the invisible by returning to the active verb disappearing — or, dys-appearing (Berger, 2014) — which held a rather negative space earlier. Disappearing, and the risks tied to it, also serves another purpose: disappearing, as an action working as the silent "other side" of discourse (Foucault, 1978), leads us into the "unknown territory” of what Merleau-Ponty (1964) calls “the world of perception.” O’Neill (1979) explains that bodies are physical and communicative and therefore moral; they are forces we orient ourselves toward (p. 16). Therefore, when the body is disappearing in research, and in writing, because of ableist expectations and understandings of what its motions ought to be in neoliberal research contexts, the body no longer calls to us. Instead the disappearing body sheds its context and history, and takes on an invisible hole that is its cultural location. This kind of disappearing could be twisted into subversion, but I believe it is more likely the motion Lather (2007) refers to when she writes about "things that are easy to walk over" and advocates for researchers to slow down 
and pay attention to these things, or these people as the case may be (p. 54). However, the disappearing in and of itself can be an action that calls to us - a happening we may orient ourselves toward and strive to acknowledge and understand. I contend that part of making each other mean is catching what would otherwise disappear. To write Flora into spaces where she might too easily disappear means regarding both invisibility and silence as a legitimate form of presence. Further, to acknowledge Flora's disappearing as a way of arriving at intellectual disability is to throw a spotlight on an invisible happening in "the space between" that constitutes a precarious phenomenon (Dolmage, 2014).

Merleau-Ponty suggests there must be a place for such data, or "the confused beginnings of scientific knowledge" if we want to picture the world "as it really is" (pp. 41, 40). It is not enough to concentrate on the limits of our knowing; it would not be enough for me to stop here and say that I can't understand Flora because her writing is sometimes impossible to record given the REB-approved technology (voice recorder) at hand. As Cixous (1976) explains, writing takes us into the other and into the "space between" where meanings are never explicit but sometimes detected, and sometimes difficult to decipher when mismatched with normative styles of understanding (p. 883). We find intellectual disability in Flora's writing processes through the reminder that phenomena are constituted by both presence and absence, and perhaps in her case absence rings louder than presence.

Therefore, as a means of closing this section of writing and returning to the original research questions, I suggest that in order to expose and take part in experiences as "bodily presences" to be felt and present (Abram, 1996, p. 89), we must make the actions of silence/silencing and disappearance/disappearing observable and notable as part of our praxis. Both silence and disappearance constitute the phenomena of intellectual disability and we must 
consult our senses - our perception — if we want to know what silence really is (MerleauPonty, 1964). "The task," Lather (2007) writes, "is to meet the limit, to open to it as the very vitality and force that propels the change to come" (p. 37). We find intellectual disability at the supposed limits of our knowing. 


\section{Chapter 13: Keeping intellectual disability open: Interruptions, insights, and afterthoughts}

No investigation has the right to present its results as the totality, as complete; Western intelligence has too long exploited this pretension and has too often presumed that knowledge was finite and fully attainable.

- Stiker, 1999, p. 2

There is still worry and hesitation riddled throughout this writing. Only now, near the end point, there is more ease toward the prospect of approaching the unsettled phenomenon of intellectual disability with wonder and wonderment — and a willingness to leave it unsettled.

This project began by watching my brother, Kevin, write. It is fitting, then, that I find myself typing these words as he sits a room away, watching television. I don't see him write much anymore. Perhaps he doesn't want to write. Or perhaps he has no space to write. I can't tell. I don't mean to complicate what might be very uncomplicated. However, it seems only one of us is on the way to arriving at the "winning" side of writing and reaping its normative awards. And maybe that's okay. Kevin has his own life and personhood to attend to outside of this dissertation - a life of deep thinking that I am only in-relation-to.

I can't simply capture the present and resolve it. And so, beneath the shadows of nearby deadlines, I attempt to disconnect sistering and research, even though they are always connected. I re-direct myself away from Kevin's story and back to this project, realizing a clear gap between my thoughts and Kevin's — our "space between" wavers in unresolved wonderment somewhere between my laptop and the television. I will always be embedded in dilemmas of positioning.

There is still worry. However, I'm losing time with my hesitation.

This project ends by writing back to myself quickly. Did I do what I said I would do? In the ways I said I would do it? Did I reach any "space between"? Earlier I wrote about "the space 
between" as a location derived from Dolmage's (2014) writing. Glimpsing through a lens of wonderment I've tried to read "the space between" as invisible essence, or situation, where we know presence and absence, where we understand and where we don't understand. Silence, unknowing, and un-belonging are words that might characterize "the space between" as an insipidly silent space (the "other side" of discourse, as Foucault explains) (1978, p. 27). Here, we fall into moments where there's nothing to say, where the uncomfortable is familiar and where, outside of research circumstances, we instinctively flee. And by being present in these moments we experience a phenomenon — we are, hopefully, in-intellectual disability just as sure as we are in-writing (Vagle, 2014). We can both study and feel the lived-out affects of being inrelation-to. And even if — or as — we bolt away from "the space between," we feel wonderment at our accidental rediscovery of things, and our rush to brush them off as "natural" and unworthy of reflection.

Wonderment is the particular feeling, or unsettled affect, that is absent from literature about intellectual disability but strongly associated with the phenomenon itself. Wonderment is both passive and responsive in that it is a motion that participates in ableism on one hand and resists it on the other. Because this study and the research questions attached to it are crafted using gestures of wonderment, the explorations here are unraveled loose ends. But there was never any closure expected, other than that of the form. Rather, this work aimed to interrogate the way things are here, in a contemporary Western location, where disability is something all cultural endeavors bring into being (Titckosky, 2008, p. 4). Positioning myself here, attempting to write a normative ending in "the space between," is intentional and also incidental. No matter which way I write it, the wonderment here still leaves us in the dark. Therefore, I have come to understand "the space between" as the place we enter when we feel we have reached a limit in 
our understanding (Lather, 2007). This limit could orient us away from the phenomenon of intellectual disability, or toward it.

In other words, the limits of knowledge and understanding can be taken as a starting point. Starting at the limits helps us reconsider what is possible: presence, absence, silence, unknowing, and un-belonging can flag the way forward. And moving forward, as Shildrick (2009) emphasizes, is a project in re-understanding and transforming the cultural imaginary (p. 5). And so, ironically, this research actually ends at a highly unresolved beginning — another opening.

\section{Summary of research goals}

The overarching goal of this dissertation was to broadly confront the phenomenon of intellectual disability by moving into the invisible moments where it arrives and builds subjects out of all of us as knowers and un-knowers. This confrontation involves explicitly linking people carrying intellectual disability labels with knowledge production about themselves by making space for writing and writing within that space.

Writing remains important in contemporary contexts because of its links to language, discourse, and silence as the "other side" of language, however contested (Derrida, 1976; Foucault, 1978; Husserl, 1970/2002). Certainly we need to think about language in a broad context. Even though language is often understood as a skill in contrast to a lack of language (signified by silence), rather than as a part of our identity formation, language is mapped on our bodies. Language provides identities, the way we understand ourselves, the way we understand others and "Othering" (Erevelles, 2015). In order to understand language and silence outside of the skill/lack binary so embedded in present modes of communication we must also continue understanding that the body is implicated in language and in silence. The body is so deeply 
entrenched in these motions that triple-labeled people must operate under meta-narratives that over-rationalize vulnerabilities and suggest they are not human, or worthy of participation in humanness, without language. This research did not quite strive to overturn that myth. There is nothing to prove; of course triple-labeled people also carrying intellectual disability labels are human. What was left to do — as bodies "do do" (Ahmed, 2006) — was participate in humanness. Thus, we wrote.

We, the researcher and the participants, began writing in ways that make sense and don't make sense. We wrote to meet one of the primary goals of this research, which was to write in this way without disqualifying "untranslatable" writing as invalid or lacking legitimacy. This work involved understanding both language and writing as modern technologies that make things happen (Grant, 1990). In response we adopted the method of expressive writing to characterize what we were doing. As the researcher I glimpsed into the expressive writing processes of several participants throughout the study. Among others whose names appear throughout the vignettes are Ross, who turned around the research methods by researching the researcher; Prince Diana, whose poem about her grandmother riding a bicycle directed us to useful and important normative mis-understandings; Mary, whose subjectivity was being built alongside her own troubled processes of building text; Owen, who authored a text* that was layered with meaning and never quite pinned down; and Flora, whose writing methods overturned normative, modern expectations of valid communication processes. In a move to ensure that the dissertation did not put an onus on participants to perform any kind of transformative outcome, however, I chose to include their contributions as exploratory additions to the research rather than as the crux of any argument. I remained aware, though, that these textual representations are important 
to share because triple-labeled people are at risk of being considered unreliable narrators of their own stories if their stories are excluded from research about themselves.

Intellectual disability comes from language and we can make sense of it by creating and mapping expressions of intellectual disability that repeatedly give the phenomenon shape and place. And, although we are the effects of discourse, we also make each other mean (Davies, 2000; Titchkosky, May 7, 2014). Therefore the primary intention of this work was to make space for triple-labeled people, and those in-relation-to them (including the researcher), to make meaning using the practice-based method of expressive writing. The motion of expressive writing throughout this body of work is one of pleasure, process, performance, presentation, and positioning — of working and doing as the body does "do," following Ahmed (2006), to offer something that can be read and deconstructed as phenomenon in particular cultural locations where intellectual disability is both familiar and unfamiliar. The work in this space, then, was the work of contributing to conversations about themselves and ourselves - both in-relation-to others and in-intellectual disability — and recognizing that sometimes there is no difference between the two selves.

Nevertheless, the participants involved in writing this dissertation are still often read as lacking mind processes — a reading that follows them and others in their cultural locations of dys-/disarticulation though pre-modern, modern, and then postmodern understandings of intellectual disability (Berger, 2014). The participants' writing builds and carries experiences that land somewhere between the textual and the material, and somewhere outside of an easily categorizable research paradigm (Adams St. Pierre, 2014). This was a modernist research project with postmodern fantasies. Modern conceptions of disability operate at the same time as postmodern conceptions of the body unfold. The ways in which bodies are made, and meaning is 
made, are the result of familiar discourses and discursive practices, vulnerabilities, the politicization of bodies and the political disorientation that confuses bodies, cultural locations of phenomena such as intellectual disability, and meaning-making in relation to everyday experiences. Yet, the research cautiously (with worry and hesitation) turned toward postmodern thinking to help re-insert the body into the research process, thus also re-vamping the process of being-in-the-world-with-others and being in-relation-to using relational ethics (Ellis, 2007; Shildrick \& Price, 2002).

Theoretically speaking, Foucault (1979) frames critique as a practice of freedom and discourses as ever-circulating. Derrida (1976) uses deconstruction as a way of pointing at the taken-for-granted, familiar order and re-reading it through the cultural imaginary. To take up these processes in relation to their phenomenon is a way of studying the lived-out affects of being in-relation-to. Yet, many of the material conditions under which this research took place speak to modern processes (such as following research ethics protocol) that serve to preserve intellectual disability as an individualized problem awaiting a solution rather than a taken-forgranted part of a modern, eugenic social order. As Titchkosky (2011) summarizes,

While disability is undoubtedly a problem within the sciences, including the social sciences, how this problem of disability has been made obviously beyond question remains quiet in the general silence of science. Asking how problems come to make an appearance ... recasts the problem of disability by dislodging it from its taken-for-granted embodied moorings (p. 131).

The work here aimed to defamiliarize intellectual disability for the sake of bringing more awareness and comprehension of the self and the "Other" to our cultural memory and our cultural imaginings. So, using Foucault's (1978) notion of discourses and Derrida's (1976) subject de/construction, among other ontological concepts and approaches including phenomenology, the research opened a space of empirical experience where intellectual 
disability can and should arrive and be (re)discovered and (re)understood as intercorporeality and presence rather than problem.

Finally, this "space between" the textual and the material makes the body both visible and invisible. We, meaning the writers, the researcher, and the readers, followed a textual pathway toward these experiences that continued to implicate us in the "shared responsibility" of the socio-cultural imaginary where this reading of words and bodies takes place (Shildrick, 2009, pp. 7-8). Re-experiencing writing helped us reconsider Otherness as a consolidation of possibility rather than a static state of being. By considering the ways in which bodies are made, we hold up bodies — people — as presence with social meaning rather than as familiar absence. In this way, we retain a focus on discourses and how they build and drive our experiences of routine engagement with the body, disciplinary technologies, and disavowal of the "Other" while at the same time centering intellectual disability as a cultural, contextual, and relational phenomenon as per the cultural-relational model's expectations.

\section{Insights: Remarks on the research process}

It all seems somewhat absurd until we begin to discern the silence in the writing - the cultivation of one's own being, from which the words begin to proliferate in haltingly issued groupings, then finally in a carefully written work, much less completed than interrupted, a blushing response to a call to say something worth saying, to actually say something, while being thoughtfully aware of the ease with which such speaking can reduce itself to academic chatter.

- van Manen, 1990, p. 8

Earlier in this writing I mentioned that part of this dissertation would be devoted to picking at ethical snags and "finding out if I get anywhere" — as if getting somewhere, or anywhere, was the goal. I believe I did get somewhere. Somehow, namely with the help of Lather's (2007) 
writing, I landed at the limits of my own knowledge and realized that the space of limits is often my own proximity to the phenomenon of intellectual disability, and that this proximity must be as good a starting place as any. The process of getting there, however, was one informed by a troubled turn toward phenomenology.

By explaining that this research was not participatory, emancipatory, or transformative I set out to make clear the vulnerable means by which we enter into research. Indeed, it remains difficult to challenge institutional modes of disability production, as Barnes (2003) warned, though I feel I have moved beyond Barnes's expectations of non-disabled researchers by not relying on talkative/verbal participants and by being transparent about my research and its intentions (as often as possible, and with the support of institutional privilege). This short list of supposed research attributes is rather incomplete. And anyway, good intentions don't equal innocent research because research is never innocent. No matter how hard I worked toward transparency, this research process never exempted me from navigating the precariousness of relationship building and situational and institutional ethics. And certainly the question remains as to whether this research adds to the "research mill" that continually objectifies disabled bodies or whether it deconstructs oppressive structures (Snyder \& Mitchell, 2006, p. 231). Further, it is clear that the research still benefits me, the researcher, most of all. And what's more, as Ellis (2007) points out, the research never really closes because the researcher must take responsibility for her actions even after the research is over. And so we can again locate a point of arrival here and now, at the limits of knowledge and understanding.

Yet, not an ounce of this process was meant to show anyone the path toward normalization or intelligibility, and this move is an achievement of the project. This project attempted to map modern and postmodern locations of disability (which can be outside of 
"mappable" intelligibility) using methods that revealed various vulnerabilities, including those of the researched and those of the researcher, as well as the thorny politics and praxis of not knowing and moving ahead anyway through the realms of ethics and affects and trials and errors. The project revealed wonderment as a tool for thinking through its own process, and it shone light on the process of triple-labeling as a modernist strategy of exclusion that can be resisted, in some small ways, by being open to flexible research methods and methodologies. Overall, the research questions served as signposts throughout this investigation, markers to keep this mapping not-quite linear but, instead, open to re-routing particular points in a constellation of thought and knowledge (Somerville, 2006). In an effort to organize some of these points, I attempt to directly confront the research questions below.

First research question: Where does disability come from?

As I have mentioned previously, the subjectivity of each person, regardless of personal embodiment, is deeply intertwined in a materialist cultural imaginary that shapes our corporeal realities (Shildrick, 2009). This entwining is important because, as Titchkosky (2008) writes, "disability is made to materialize, and it is often only intelligible, as a problem located in a certain number of individuals, and this is how disability is made to matter in, and for, community” (p. 66). Launching from Butler's (1993) point that materialization is what “"matters' about the body," Titchkosky explains that how disability is made, and made to materialize, is linked to where disability comes from. Therefore, the first research question sought to understand where intellectual disability comes from. It also sought to de-familiarize intellectual disability. De-familiarizing ourselves from intellectual disability by imagining its constructions and circulations as part of a wider cultural discourse of history and memory gives us more 
awareness and comprehension of the self in relation to the world (Bauman, 1990, p. 51). By tracing some of the embodied silence that has come to characterize intellectual disability since pre-modern discourses, this literature review planted roots in the phenomenon and offered broad strokes of context that might help us understand how disability is constructed, understood, and internalized in Western contexts where modern forms of thinking are temporary and governed by “concrete abstractions" (Stockholder, 1994; Harvey, 1985).

We know, for example, that intellectual disability is rooted in pre-modern and modern experiences of poorness and Christian values of charity and care. Despite being both static and dynamic, intellectual disability is still shot through with conceptions of lack - lack of history, lack of reason, lack of mind processes, lack of possibility, lack of normalcy, and moral lack (Carlson, 2010). The notion of lack contributed to the realization that intellectual disability means un-belonging: people carrying this label are both segregated and normalized as abnormal. In this sense, intellectual disability was also linked to modernist fears of abnormality. These fears are our primary "orientation toward" intellectual disability and our entry point into the ableism that characterizes the contemporary socio-cultural conceptions of disability under which this work takes place (Ahmed, 2006).

Intellectual disability remains one of our ultimate modern problems aching for a solution that might manifest as a return to normalcy. Some of these solutions have included eugenic technologies such as institutionalization and "newgenics" (Ignagni, personal communication, July 8, 2015). Disability hierarchies have also emerged, and they serve to bring order to bodily categories and certain bodies' proximities to normality. After all, meta-narratives of normality are the preconditions for modern life (Wendell, 1996). Therefore, by framing intellectual disability through "cultural splitting" — language/silence, normal/abnormal, non- 
disabled/disabled, mind/body — we come to understand intellectual disability as the result of a prevailing eugenic mindset that places particular bodies in particular cultural locations, including the location of the dys-/disarticulate that disappears, silences, and makes absent (Berger, 2014; Wendell, 1996, p. 85-86). This cultural location is one allocated to the preservation of the docile body.

Much of the work here is about considering our proximity to intellectual disability, given its ordinariness and its extraordinariness. The circumstances under which we make contact with disability are both familiar and discontinuous. Given the fluidity of disability, in all its post- and dis-modern nature (Davis, 2013b), the question of orienting the self, or myself, toward a corporeal reality that cannot be one's own or my own, but has constant implications for my life and the lives of others is an ethical quandary that lives throughout the pages of this dissertation. If the vignettes are the situational and institutional moments peppered throughout the writing, then the ethical dilemmas are the salt that follows. These ethical knots are also the makings of wonderment as it occurs in moments where I am not sure whether I am allowed to comment on personhoods and subjectivities other than my own, though sometimes I comment anyway. After all, Titchkosky (2008) teaches us that disability is present everywhere and thus it works to bring everything into being — so why turn away? (p. 4).

As the project continued to wonder where intellectual disability comes from, it became important to understand that intellectual disability has historically tended to emerge alongside the objectification of the body. For most people becoming a medicalized subject is unavoidable (Hughes, 2005). Still, biomedicine seeks to naturalize abnormality, in particular, in order to hold up modernist norms and the governing power of medicine (Stiker, 1999). Intellectual disability comes from eugenic mindsets that are the outcome of positivist biomedical knowledge, which 
uses diagnosis and categorization to establish departures from any imagined norm and to pose solutions to the problem of disability (Davis, 2013a). We know that eugenic thought and modernist technologies, such as institutionalization, position people in society in ways that are useful to modernist ambitions of production and progress.

The power of eugenics is oppressive rather than productive, while the power of institutionalization is productive rather than oppressive (Titchkosky, 2008). For instance, in neoliberal Canada, citizenship, or what Prince (2010) calls “absent citizenship," is reliant on participation in the labour force and the literacy skills this often entails. People with disabilities, in turn, become subject to advocacy movements that habitually place normalcy as their core ambition (Prince, 2012). They are also the targets of power/knowledge relations which often take the form of biomedical interventions. We can count "giving voice" as one of these interventions that relies on fantasies of assimilation and normalcy. Meanwhile, crip epistemologies do something different by working outside of neoliberal contexts and attempting to reclaim disability (Kafer, 2013; Linton, 1998). We can recognize both past and contemporary intellectual disability as a state of $u n$-belonging, wherein people are both segregated and normalized. Therefore, disability comes from cultural circumstances where people are expected to be productive under oppressive circumstances.

Second research question: How do we orient toward intellectual disability?

The research question about how we orient ourselves toward intellectual disability not only aimed to point out the cultural location of the phenomenon, but also intended to critically interrogate the process of orientation - primarily toward modernist locations that stem from the problematization of the labeled body. The question also asks how we perceive disability, since 
perception and orientation are closely tied (Ahmed, 2006). The question, moreover, serves to query how the problem of intellectual disability is the socially constructed site of particular bodies, and, at times, serves to construct people and the perceptions of ourselves and others that follow.

Let me return here, if only briefly, to hook's (1992) explanation of the invasion of the "Other" in order to re-establish the starting point for how I attempted to orient the research toward intellectual disability (p. 368): the active "self" connects to, and takes, experiences of the "Other" that heighten the "self's" experiences and leave the "Other" behind, possibly unchanged (p. 380). In the case of intellectual disability as phenomenon, we can understand that intellectual disability is a myth open for investigation and deconstruction — which sometimes puts triplelabeled people at the core of the research as the "Other" (unknown) to the "self" (knower). This research tried to avoid completing this type of conquest. Instead, it aimed to connect the "self" and the "Other" and understand what resistance takes place through this connection. This study also demonstrated how people with intellectual disabilities are made both subjects and objects through research about their corporeal realities. In retrospect, however, I will venture to say that this research failed in its prospective orientation here, and in fact slid through the entire invasive process described above, and now closes at an advantageous point for the researcher and almost (though not entirely) leaving the "Othered" participants behind (though they may be changed it will be hard to investigate that without another round of research ethics protocol).

My location as non-disabled, normative, privileged researcher in-relation-to is another orientation that remains largely uninterrogated amid the larger, rational meta-narrative of disablement that Shildrick (2009) claims researchers inevitably write within and through. The focus on intellectual disability as socio-cultural phenomenon was polarizing, orienting this 
research away from its also non-disabled end. Yet, the research had to be finished. And it had to be understood in normative terms. All this for many taken-for-granted reasons that work to sustain the normative and "retrace" its "straight lines" that mark all bodies and drive us to perform our humanness in particular ways (Ahmed, 2006, p. 66). I first attempted to understand how institutional ways of knowing rely on preconceived notions of vulnerability to establish triple-labeled individuals and place them on the outskirts of research knowledge and production. This realization helped me understand my own artificial positioning as a competent knower and a worrier, and a writer, and other roles not dissimilar from Gray's (2000) discoveries in his own research. These are the "hidden" motions of research that indicate what doesn't get done, and which dead ends trap us as we attempt to move along. There is no ceremonial ending.

Studying intellectual disability means entering into/engaging with cultural locations where the body is transformed into an object, and transcending the fixed network of centers and margins people often rely upon to understand the world (Shildrick, 2009, p. 149). It also means taking intellectual disability to be an active phenomenon that contributes to meaning making about the body, the self, and the other in particular contexts. And since intellectual disability is a cultural location available in many ableist societies, such as the one within which this work takes place, the objectification of the subject was difficult to avoid. It was for this reason that the participants' writing was tacked on to the end of this dissertation as icing on the cake, rather than as any substantial part. The goal behind this strategy was to make sure the research did not hinge on anything the participants would or would not do; as Ellem et al. (2008) have pointed out, for a researcher to act with justice she must "avoid imposing on particular groups an unfair burden of participation" (p. 500). Therefore, the research had to be strong on its own in case participants did not want their writing, or their writing experiences, appearing on these pages. 
Adams St. Pierre (2014) suggests that researchers have to recognize what is happening beyond their intentions: "qualitative methodology participates in and continues the centuries-old history of Cartesian knowledge projects — ferreting out what is known only in not being known — yet" (p. 6). With these instructions for perception at hand, amid this straight, Cartesian-riddled dissertation (for it only queers once in a while, and even then echoes of the radical and the crip are difficult to catch), triple-labeled people emerged: Kevin, Ross, Prince Diana, Mary, Owen, Mr Clark Kent, Flora, and GrandMaster B. Together we are still in- or in-relation-to intellectual disability and we engage in moments that produce intellectual disability; this is our orientation toward each other. What follows is the work of deconstructing and reconstructing which allows us entry into "the space between," which is a space of writing — writing for approval, writing for credit that isn't always shared, writing to put diploma in hand.

Overall, I move out of this particular project with the understanding that this research will always be situated in risky, imperfect institutional boundaries that give and take degrees of privilege. This privilege was especially felt when things seemed to fall into place - for example, when the informed consent forms were so quickly signed. Sometimes I wonder how things worked out so smoothly: Were there moments of oversimplification and miscommunication that I simply overlooked? Were there risks I failed to outline? Do I detect a hint of incomplete episteme? (Could these have been instances of me orientating away from important things?) Or perhaps ableism and non-disabled privilege simply worked together to rig me up as "expert" even in moments where I might have rejected the label. After all, intellectual disability remains the work of "experts," for whom intellectual disability remains an "obviously undesirable" state of being and/or cultural location (Carlson, 2010; Snyder \& Mitchell, 2006, p. 21). 
Finally, in order to make something of a new research process that combined cultural model intentions and relational ethics in research involving triple-labeled people this research tacked a phenomenological edge onto already poststructuralist intentions. The project attempted to perceive intellectual disability through a phenomenological approach that presented "untranslatable" writing as relational experience with moments of emergence and wonderment that amount to meaning making, and also making intellectual disability mean. I was interested in capturing the essence of the group (and my method was the incorporation of vignettes into the wider writing) and in pointing out the moments when the phenomenon of intellectual disability emerges in individual writing processes. I attempted to follow van Manen's (2014) steps for action-based praxis - the type of phenomenology that engages with what is unsettled and allows the processes at hand to keep moving. These steps involve turning toward intellectual disability and recognizing how it "commits us" to the world (Vagle, 2014, p. 27), investigating experience as lived, reflecting on unfamiliar and unintelligible experiences, writing and re-writing descriptively, maintaining interest, and thinking through it all in parts and wholes (van Manen, 1990, 2014; Vagle, 2014). Perhaps in orienting myself toward (expressive) writing as process I caught some of these essences along the way - if not directly, then on the periphery of the vignettes and the participant writing samples.

This type of research also took up the question of orientation/perception alongside the notion of bracketing. The latter meant I attempted to encounter intellectual disability as if it was a phenomenon that happened only during this research, and the former meant not turning away from moments of wonderment that are, in other circumstances, easy to abandon (Ahmed, 2006, p. 25). This phenomenological approach called for a return to wonderment that worked to ensure intellectual disability would not be taken for granted on these pages, and helped me establish a 
new way of orienting toward the insidious research processes that mark people as triple-labeled and thus outside of specific research paradigms (because of ever-shifting identity politics). Taking a phenomenological approach meant aiming for interpretation rather than explanation (van Manen, 2014, p. 43). Therefore, orientation toward intellectual disability also meant orientation toward familiarity, wonderment, and people with particular writing experiences. These motions relied both on notions of what disability supposedly is, and on the action of being present and attentive toward what is happening and how intellectual disability presently emerges.

\section{Third research question: What foresights follow?}

Intellectual disability is a cultural phenomenon that still too often offers a vague answer to Stiker's (1999) question: "how would we be if we were not the way we are?" (p. 69). Yet, the third point of inquiry here aims to bracket our understandings of disability as problem and instead (re)conceputalize intellectual disability as a phenomenon outside of current medical, neoliberal interpretations. This question asks us to imagine something that isn't yet happening that is, to imagine that the research, or research like it, could be transformative enough to rewrite a small piece of the world's normative script and re-cast triple-labeled people in another role as social actors in a collective cultural imagination.

This question also asks us to save some space for intellectual disability in our cultural imagination. The question asks us to understand intellectual disability as present, for better or worse, and to no longer accept the phenomenon as invisible. This is a question that begs us to include encounters (phenomenological or otherwise) with silence, the unseen, and the unknown past, present, and future in order to offer the self and the "Other" a vibrant encounter that holds history and context even in a short moment. 
Foucault makes the point that change comes from changing ourselves, and changing our bodies and ways of knowing so that we might gesture differently to that which is outside of ourselves (in Lather, 2007, p. 62). What I know now is that writing makes room for the subject to emerge where she or he might otherwise be hidden, or $d y s$-/disappeared. Writing is one way forward, because it is a movement that cultivates both individual subjectivity and intercorporeality. And when the subject emerges, the researcher is automatically in-relation-to the triple-labeled individual, thus the tone changes from theoretical to action-based material wonderment. In addition, this project highlighted that even without the promise of emancipation, participation, or ceremonial endings, giving time and concentration to writing is a way of resisting a neoliberal political economy where triple-labeled people are excluded from research and deep-thinking roles.

Moving forward, we can be assured that description of and reflection on the phenomenon of intellectual disability remains precarious given that every person, regardless of personal forms of embodiment, is implicated in the "shared responsibility" of the socio-cultural imaginary whose discourses shape our contemporary situations, and therefore also shape our lives and subjectivities (Shildrick, 2009, pp. 7-8). This research process is heavily reliant on cultural locations of disability, despite efforts to bracket, become re-oriented, and serve the study with intention. Part of locating intellectual disability, then, involves the process of finding the "Other" by recognizing the difference between presence and absence, or visible and invisible. Locating intellectual disability also means acknowledging that researching intellectual disability is a way of confronting the limits of research, the constraints of researchers, and the strain of the researched. At the same time, intellectual disability is a movement between the absence and presence of language. To ignore particular human proximities to language, or to suggest one 
can't write based on normative (literate) understandings of writing, is an act of disavowal.

Therefore, I am led to conclude here that the way forward is to leave the process unresolved, lest we run the risk of closing down possibilities of intellectual disability-based research.

Fourth research question: What would it mean for untranslatable writing to be re-read?

Re-reading "untranslatable" writing would mean keeping the processes and possibilities of intellectual disability unsettled, or as van Manen (2014) suggests, not putting the research down. Ultimately, what it means for "untranslatable" writing to be re-read is that this type of writing can be included in academic literature in line with crip and queer epistemologies that deviate from normative lines of inquiry and instead open themselves to new considerations of validity that play out in the resistance of rationality and intelligibility.

This research intended to produce textual expression of the experience of intellectual disability in order to transcend our notions of the phenomenon to this point; until now intellectual disability has unfolded as a modernist, materialist construction assigned as problem to particular bodies that are commonly understood as belonging to ahistorical people with impaired minds (Carlson, 2010; Titchkosky \& Michalko, 2009). In asking what it would mean for "untranslatable" expressive writing to be read as a communicative tool that potentially reflects pre-verbal lifeworld sensations, this question pointed to the need for inquiry with a phenomenological edge (Cixous, 1993; van Manen, 1990). The question introduced the expectation that cultural participation be non-normative, and suggested that in order for "normate" researchers to engage and find a way into inquiry about this type of participation we have to find a way into invisibleness. Phenomenology does that, though it is not the only way as I alluded to by mentioning crip expression/writing, mad art-making, and Deaf-gain. Further, we 
recall here a loose list of van Manen's (2014) instructions for engaging in phenomenology: study, explicate, describe, attend to, search, poeticize (Vagle, 2014, p. 56). These verbs are also the descriptors of the process of expressive writing, and the reading that follows. To understand writing as a motion that involves these gestures and more is to re-read intellectual disability.

This project oriented toward intellectual disability through writing as gesture, and writing as system of thought (Vernon, 1979). If we are thinking of intellectual disability as cultural, contextual, and relational writing then the methods of getting at the phenomenon are significant. We engaged in the gestures of writing and reading, and thus re-writing and re-reading, because so much of these processes are invisible, and because this type of engagement is a way of cripping this modernist form of communication (Olson, 2009). Normative writing tends to exclude particular bodies. Therefore the idea behind engaging in "untranslatable" or expressive writing is to find out what happens when the motion is within reach and when disabled people occupy space as writers - when writing becomes what we "do do" for a time (Ahmed, 2006, p. 270). The gesture of writing also includes pre-knowing, and therefore expressive writing uncovers our humanness (because to be human is to be implicated in language) and allows the invisible to move into visibility as we re-encounter intellectual disability (Cixous, 1991).

Finally, re-reading is also an orientation. As ideas of intellectual disability are circulated and re-circulated, our present orientation toward disability remains a modernist orientation: an unremarkable problem of mental lack often separate from the self, somehow further dulled in its embodied manifestation as a familiar part of the Other. The discourses that drive our experiences emerge through routine engagement with modernist, disciplinary technologies that uphold hegemonic norms and through the constant "cultural splitting" of the mind and the body (Wendell, 1996). Intellectual disability, as Wendell (1996) writes about disability in general and 
as the social model preaches, is the result of the social exclusion of a subject whose corporeality falls outside of modernity. On the outside of modernity, these bodies are the ones that are "deliberately silenced" and "preferably unheard" as they are interpreted by an ableist society (Erevelles, March 12, 2015; Carlson, 2010). Shildrick (2009) writes:

What is at stake, then, is not some simple opposition between categorical groups with and without socio-cultural capital [non-disabled and disabled people, respectively], but a discursive context in which a range of people - those who are disabled, those who are normatively embodied, disability scholars, and activists and allies alike - are caught up in the interplay of barely recognized forces (p. 83).

Re-reading is a way to turn away from "the interplay of barely recognized forces" and instead move in- or in-relation-to intellectual disability (p. 83). The first step in re-reading is defamiliarizing the familiar because unfamiliarity helps us deconstruct the always-already possibilities of social relations. We do this, in part, by writing and by being in-relation-to others rather than understanding them in terms of separation. Re-reading intellectual disability helps us to avoid the traps of desire and temptations to normalize that characterize insidiously invasive research processes that encompass both ableism and disablism.

Re-reading "untranslatable" writing helped organize a space and a discourse of intellectual disability outside of rationality. This motion meant to follow cultural disability studies' techniques of critiquing where disability "belongs" and pointing out how disability is put in its place - either by the surveillance of bodies, the refusal to understand value in the untranslatable, the easy imposition of research that puts particular, problemed bodies under investigation, or the quick isolation of unusual discourses. Part of what it means to include intellectual disability in academic readings is that the naturalness of the label becomes an object of interrogation and intellectual disability can be de-familiarized through "untranslatable" texts. The achievement of re-reading such writing is that it debunks any general assumption that people 
know what intellectual disability means — that intellectual disability is a vague, tragic lack embodied by a particular person and for a wider group of segregated people we are rarely at risk of encountering (Carlson, 2010). Such modernist notions are overthrown when, through rereadings, we are brought into the encounter by many texts that are neither generalizable, nor natural, nor ahistorical.

\section{Afterthoughts: Moving into memory}

It's as if the solid ground has given way, leaving us hanging like tender cocoons suspended in a dream world. As if the conditions and possibilities of a life have themselves begun to float.

- Stewart, 2007, p. 61

Far be it from me to introduce new concepts as the dissertation winds down. However, I am ending this dissertation at another opening. In this way I refuse to stop the cycles of knowing that keep up (and sometimes slow down) the work's momentum. And, being as we are at a crossroads between the limitations of knowledge and the researcher's responsibility to continue to attend to the project even after the research is over, I am working a lot with memory these days. And this could be useful work that returns us to a starting point: Titchkosky's (2011) politics of wonder, where wonderment arrives and where the actions of remembering and repeating help us understand how things take form (Ahmed, 2006). So, for a moment, I take memory as an entry point into another angle of this study that relies on memory.

As I was remembering Flora's writing, both on paper and in the air, I came across a set of notes written long ago titled "Useful Stein words." It is, simply, a list of potentially useful or thought-evoking words speckled throughout Edith Stein's (1989) phenomenological writing on the interpersonal, specifically from "On the Problem of Empathy.” I thought I might use Stein's writing in this project, but until now I simply couldn't connect with it — her thoughts did not 
seem to fit into my own construction of disability discourse. I realize now that Stein adds nuance to the experience of being in-relation-to, which can connect with the primordial act of expressive writing. Stein distinguishes between primordial and non-primordial experiences within the self that constitute the other: "I constitute myself in primordial acts and the other in non-primordial acts" (Moran \& Mooney, 2002, p. 230). Further, Stein brings the body into her work, and in fact relies on it when she refers to "parts of the living body" as "constituted as moving organs" and to the perception of the world as dependent on these "moving organs" (p. 234). Stein also teaches recognition of the other through perception of the body, which is not perceived as a physical object but as made up of complex experiences, which reminds me of how Flora "writes" when she chronicles close experiences such as going to a Toronto Raptor's game and her changing familial role.

The body is always engaged in the movement of approaching and withdrawing, while also being approached and withdrawn from (Stein, 1989). Stein writes in terms of the visual and tactile, explaining that these senses "call upon each other as witnesses" to the other, and that our perception is based on internal and external bodily orientation toward other phenomenon:

As long as I have my eyes open at all, [the body] is continually there with a steadfast obtrusiveness, always having the same tangible nearness as no other object has. It is always 'here' while other objects are always 'there' (in Moran \& Mooney, 2002, p. 231).

Even, she writes, if we lose the visual and tactile ("if we shut our eyes tightly and stretch out our arms") (p. 232) we will sense the other - the objects beyond our perception - through internal circuits that place the body as somewhere in the world, in space, thus contributing to the constitution of the self as an embodied being in place.

This effect occurs in memory: I can close my eyes and imagine Flora in front of me, shaping words in the air with her finger. In my mind, Flora is "here"; on the page, Flora is 
somehow "there." There is something about the perception of the air-written words that lingers longer than the words on paper. Perhaps it is that I need to attend to the words that float in the air by using memory work, and by imagining their appearance even when they do not emerge as tangible objects to be read. These types of words require a distinct and constant bout of attention because they arrive only for a moment and in a glimpse they can disappear. There is an almost enchanting quality about writing in the unperceivable way that memory is called on to build and hold on to something. By writing her words in the air Flora re-engages the reader with the text, and slips into a type of writing that calls up metaphor over evidence - the type of writing that constitutes experience but remains difficult to hold up and prove. Recalling Flora's air-writing in a formal way is like catching a snowflake on your tongue and attempting to describe the snowflake's shape based on its quick melting. Flora's words melt into the air and disappear, opening up a primordial and non-primordial exchange that constitutes the self and the other, and thus constitutes the emergence and disappearance of intellectual disability through disappearing text.

Husserl's phenomenology is also highly reflective and recollective. For Husserl, a person cannot reflect on lived experience while living through it; only in retrospect, when the experience has passed, can a person orient herself toward it and begin to think phenomenologically about it (van Manen, 2014, p. 94). Van Manen (2014) uses the example of anger to illustrate this point. He suggests that if one tries to reflect on his anger when he is feeling anger, the gesture of attempted reflection immediately changes the feeling of anger, thus phenomenological reflection is always reflection on an experience that has passed (p. 94). The lesson Husserl offers that can be funneled into this work is that inquiry should begin from beginnings that seem clear, rather than depart from existing bias and unexamined meta-narratives 
(van Manen, 2014, p. 93). Also, I attempt to practice my phenomenological approach by noticing the self-givenness of things - in particular the participants themselves, texts written by the participants, and my prejudices toward both — with the understanding that I will never truly understand these "things" that I research.

To take this re-reading further: I recall that the experience of reading intellectual disability through disappeared and remembered text is a pathic experience. To understand pathic experiences, van Manen (1999) points toward Heidegger's (1953) notion of befindlichkeit, which is taken up as "attunement" (1953). Here, Heidegger connects attunement to mood, and mood to a fundamental condition of being-in-the-world or being-there-with another. Befindlichkeit, or attunement, is a "stage" of observation or research that one finds herself participating in, rather than a deliberate research step. Or, in van Manen's (1999) words, befindlichkeit is the sense that we have of ourselves and others in situations, literally translating as "the way one finds oneself" in the world (p. 29). Attunement "pays respect to an understanding that is more doing than it is knowing" (Campagnolo et al., 2009, p. 20). Gian Marco Campagnolo et al. (2009) go on to explain that the discipline required for this type of attunement is "in life and not in words" ( $p$. 21). What makes a pathic experience then has, in part, to do with "letting something be encountered" (Heidegger, 1953):

Letting something be encountered is primarily curcumspective [sic], not just a sensation or starting out at something. Letting things be encountered in a circumspect, heedful way has - ... in terms of attunement — the character of being affected or moved (p. 129).

That things matter, Heidegger goes on to write, is a signal of attunement (p. 129). However, things can matter indirectly, in ways that are sensed or thought or felt rather than evidenced. In this sense, attunement leads to pathic understanding — understanding of that which is situated, 
relational, and embodied, and that is thus similar to the understanding this entire work has been striving to reach (van Manen, 2015).

In her book, Ordinary Affects (2007) Stewart opens a small vignette with the words, "Things have started to float" (p. 61). Moving forward I dare think her words are an accurate description of the change in cultural imaginary that has taken place for me throughout the process of writing this dissertation. Things are no longer as grounded as they once were. Even the opening research question, which asks whether intellectual disability is a culturally constructed problem or if individuals are a culturally constructed problem, is one rooted in material analysis rather than in the shaky impermanence of poststructural thought. So, things are still floating.

This "floating" is perhaps the condition for learning and for trust that Lather (2007) suggests we embrace in order to begin — or in this case, begin again — research (p. 31). Things float in spaces between the laptop and the television, experience and memory, past and present, writing and thought. I suppose being attuned to these floating things means realizing that they matter even when they meet the limits of knowledge and understanding. Attending to these things means not letting them drop, even when endings are beginnings and entire knowledge processes are left unsettled.

Vignette: Let them eat cake

I end this research session with a Natalie Goldberg (1986) reading that I promise will only take about two minutes. I tell participants that Goldberg is "gonna talk a little bit about writing," and someone says "okay." It's fine. Sometimes we need to set these things up.

I read two or three pages, and part of Goldberg's instructions include these words: 
... When you bake a cake, you have ingredients: sugar, flour, butter, baking soda, eggs, milk. You put them in a bowl and mix them up, but this does not make a cake. This makes goop. You have to put them in the oven and add heat or energy to transform it into a cake, and the cake looks nothing like its original ingredients. ... In a sense this is what writing is like. You have all these ingredients, the details of your life, but just to list them is not enough ... (p. 58)

The cake metaphor goes on for admittedly more than two minutes (my calculations were a bit off). When I am finished reading I look up from the book and ask, "Does that make sense?"

“Oh, kinda," Mary says. "I like the part about the baking."

"The baking? Yeah." I say. "Do you know what she means?"

“Not really," Mary says.

"Okay, well," I think about this for a minute. I wonder if I should explain the concept of a metaphor, or if I should just let the metaphor do its job. "Who here has baked a cake before?" Nobody responds.

After a few quiet seconds, Mary answers for the group, "Not really."

“Um, has anyone, um ... ” I struggle. "Who here has done any cooking? Practiced cooking in the kitchen?"

Silence.

“Worked with any food?"

Ross is shaking his head and frowning. People begin putting their stuff away.

"Okay well, when you bake you need to use ingredients, like flour and sugar, " I awkwardly try to paraphrase Goldberg. I feel unprepared. My notebook notes later reveal that I call this a "stupid ableist Marie Antoinette moment - let-them-bake-cake metaphor." I shouldn't have assumed that the participants necessarily have any baking or kitchen experience. I've lost my audience. Nobody seems interested in carrying on a conversation about food that 
could eventually evolve into a conversation about writing. It is nearly noon, and the research session is beginning to close down. Moments to write slip away.

"Do you have any thoughts about that?" I ask.

"Not really," Mary says.

"Okay. All right. Let's hit the road then." 


\section{Appendices}

Appendix A: Ryerson University Research Ethics Board Approval Letter

\section{RYERSON UNIVERSITY}

\section{RESEARCH ETHICS BOARD}

To: Chelsea Jones

Communication and Culture

Re: REB 2013-269: Writing disability: making space for people with intellectual disabilities Date: February 18, 2014

\section{Dear Chelsea Jones,}

The review of your protocol REB File REB 2013-269 is now complete. The project has been approved for a one year period. Please note that before proceeding with your project, compliance with other required University approvals/certifications, institutional requirements, or governmental authorizations may be required.

This approval may be extended after one year upon request. Please be advised that if the project is not renewed, approval will expire and no more research involving humans may take place. If this is a funded project, access to research funds may also be affected.

Please note that REB approval policies require that you adhere strictly to the protocol as last reviewed by the REB and that any modifications must be approved by the Board before they can be implemented. Adverse or unexpected events must be reported to the REB as soon as possible with an indication from the Principal Investigator as to how, in the view of the Principal Investigator, these events affect the continuation of the protocol.

Finally, if research subjects are in the care of a health facility, at a school, or other institution or community organization, it is the responsibility of the Principal Investigator to ensure that the ethical guidelines and approvals of those facilities or institutions are obtained and filed with the REB prior to the initiation of any research.

Please quote your REB file number (REB 2013-269) on future correspondence.

Congratulations and best of luck in conducting your research.

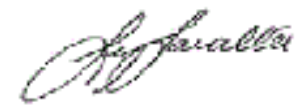

Lynn Lavallée, Ph.D.

Chair, Research Ethics Board 


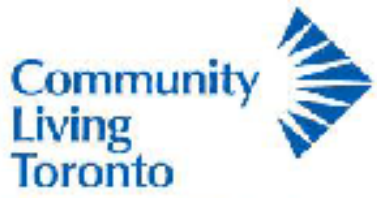

Whare chnirne charge the russ

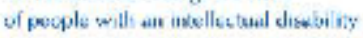

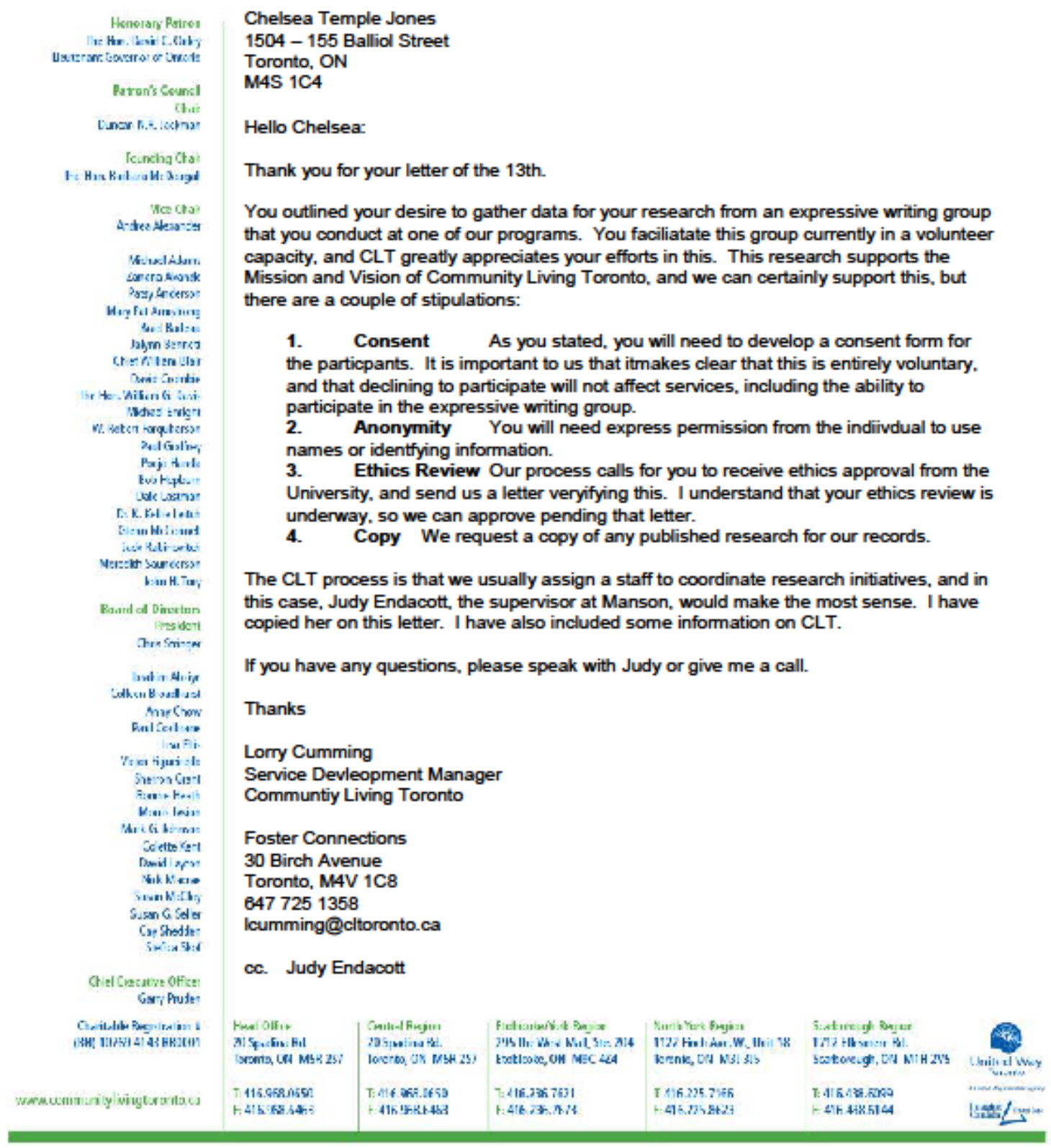


Appendix C: Informed Consent Form

\section{Consent Form for Ethics Review of Research Involving Human Subjects}

\section{Research Ethics Board Ryerson University}

You are being asked to participate in a research study. Before you give your consent to be a volunteer, it is important that you read the following information and ask as many questions as necessary to be sure you understand what you will be asked to do.

Title of Project: Writing disability: making space for texts by people with intellectual disabilities

Researcher: $\quad$ Chelsea Jones

Ryerson University doctoral student in the York-Ryerson Communication \& Culture Program

Email: chelsea.jones@,ryerson.ca

Phone: 416-979-5000 ex. 2604

Supervisor: $\quad$ Anne MacLennan

Graduate Program Director, York-Ryerson Joint Graduate Program in Communication \& Culture

Email:amaclenn@yorku.ca

Phone: 416-736-2100 ext. 33857

\section{Purpose of the Study}

This study is being done as part of the requirements to complete a Ph.D. in Communication and Culture through Ryerson University. The goal of this study is to create space for people with intellectual disabilities to write expressively without judgement or being told what kind of writing is "right" or "wrong" over a six-month period of weekly meetings. Another important goal of this research is to show other people — including people with disabilities and nondisabled people their writing, so that their writing can be included in research about people with intellectual disabilities, and so that we can learn about your thoughts. It is important to note that this is not a therapeutic group. This group is meant to be fun and creative, and it is important for me to ensure that I have asked for your informed consent to participate in the research aspect of this group. If you decide that you want to be part of the group, but you do not want to part of the research, you do not have to sign this form.

\section{Who can participate?}

This study will include five people. To participate, you must be:

1. a person who self-identifies has having an intellectual or developmental disability

2. 18 years of age or older

3. living in Toronto (for example, participants may commute from surrounding areas such as Mississauga or Scarborough) 
4. willing to join a research group that meets once per week for 24 weeks (approximately 6 months)

5. willing to participate in expressive writing (which may take many forms, including scribbling, verbalizing, drawing, etc.) and discuss some (not all — based on voluntary contribution and participants' comfort levels) of this writing during group meetings

6. willing to have your writing photographed by the researcher

7. willing to be recorded with a voice recorder during each meeting

8. a current participant in TACL's programming

9. familiar with the research and this informed consent agreement

Please note that if you write unconventionally, or if you communicate in ways other than through pen and paper (such as a magnetic speech board, sign language, or non-verbally), you may participate.

\section{Not Participating}

If you do not wish to be part of the research, you do not have to sign this form. If you are not part of the research group your work will be of equal value to those who are part of the research group, but your work will not be part of my final report. However, all members of the Expressive Writing Group will have their voices recorded for the duration of the research (12 weeks). If you are not participating in your research, I will not transcribe what you say and I will not use it for my final project. If you do not wish to have your voice recorded, you may decide to join the Expressive Writing Group when the group carries on as usual without the presence of a voice recorder.

\section{Description of Study}

People participating in this study will be asked to attend the writing group once per week for 12 weeks at JS Manson. During the writing group, participants will write and, if they choose, share their writing with the group for discussion. The group will last one hour. During this time, I will record the group's discussion with a voice recorder. Also, I will take photographs of people's work.

Members of the writing group who are part of the research will:

- Write creatively on a weekly basis for a 24-week period

- Be asked whether or not I can take photographs of their writing on occasion

- Have their voices recorded by a voice recorder

- Have some of their photographed work included in my final report

- Have some of the things they say during our meetings included in my final report

\section{What are risks?}

Risks occur when there is a chance that you may feel uncomfortable participating in research. In this research, the risks include:

\section{Feeling uncomfortable, meaning feeling excluded, bored, or as though the researcher is "in charge" of the group}


Before each group session, you will be reminded that your participation is voluntary. If you feel excluded, bored, or as though you do not have enough "say" in what is going on, or uncomfortable in any other way, you do not have to participate in the research group. If you feel uncomfortable, you can take a break from the group for a short time or a long time. Also, you are welcome to make suggestions and bring in activities for the group.

\section{Social risk}

"Social risk" means that although the group conversations are supposed to be confidential, it is possible that the conversations are brought up outside of the group. I will ask everyone in the group to please try their best to respect the privacy of others by not repeating conversations that occur during group time.

\section{The risk of forgetting that the research is voluntary}

You may discontinue participation, temporarily or permanently at any time, and your options will be outlined at the beginning of each group session so that nobody forgets. It is your choice whether or not you want to participate at any given time. Your choice will not affect what the researcher or anyone else thinks of you.

\section{Benefits of the Study}

You may not gain any direct benefit from being in this study. However, it will give you an opportunity to share your writing with others because I will write reports for my committee and potential conference presentations. The final report will be made available to you. The report may be published, in full or in part, and I may talk about the research at conferences. Hopefully, this will help interested people better understand people with intellectual disabilities.

\section{Confidentiality}

Only your writing and pictures will be shared in my final report and at conferences. Your name will not be shared, unless you wish for it to be shared, so your identity will remain confidential. This means that the only people who will have access to your personal information will be me, members of the research group, my supervisor, and the other people on my research committee. All audio recordings and photographs will be kept on my computer, and protected with a password for the duration of five years.

\section{Your name}

Your name will not be on any information, unless you choose it to be. If you wish, you can choose a pseudonym (a fake name). However, once the research is finished and I publish the final report (my doctoral dissertation), you will not be able to change your mind about whether or not your name appears in the research.

If you decide to put your real name on your notebook or your writing samples, I will block it out with a 
black block using computer software called Photoshop, so it will look something like this: "My name is Chelsea." Five years after the research is completed, I will destroy all of the information by permanently deleting it from my computer.

\section{Voluntary Nature of Participation}

Participation in this study is voluntary. This means you decide if you participate, nobody can make you participate. Your choice of whether or not to participate will not influence your future relations with Ryerson University, the Association for Community Living (TACL), or Chelsea Jones. If you decide to participate, you are free to withdraw your consent and to stop your participation at any time without penalty or loss of benefits to which you are allowed. Also, it is your right not to have your voice recorded during the sessions. It is also your right not to have your work photographed. Please tell the researcher if you do not want to be recorded, or to have your work photographed.

\section{At any particular point in the study, you may refuse to participate in any particular}

discussion or stop participation altogether. Also, if you choose not to participate in the research, you are still welcome to be part of the writing group.

\section{Things you to remember}

There are certain risks and responsibilities to remember about this study. I will review these points at the beginning of each research session.

1. Your participation is voluntary. That means you decide if you participate or not. You can leave the research group at any time. You have the right to choose not to participate in discussion, and you have the right not to have your writing photographed.

2. There may be some risks in participating. If you are upset by some writing or some aspect of the discussion, you are allowed to stop participating temporarily or permanently.

3. All information will be kept confidential as much as possible. The only people who will have access to the voice recordings of the discussions and the photographs of your work are the researcher and her supervisors. All information will be kept in a password-protected file on the rearcher's computer. It is important to respect confidentiality by understanding that someone may not wish to tell you whether they are participating in the group as part of the research project or just for fun. Also, it is important to remember that I will not tell you who is participating in the group as part of the research and who is participating just for fun.

4. Your name will not be on any part of the research unless you choose it to be.

5. The research is part of the researcher's education. In order to complete her $\mathrm{PhD}$, she needs to write about what we do during the research sessions. The researcher's final report (the dissertation) and other smaller research papers may be published in journals and books. The researcher will also need to talk about the research at conferences. The aim of this research is to show other people your work so they can learn about it. To respect your privacy, the researcher will never use your name in her papers or presentations unless you wish her to do so.

6. The researcher has agreed to share her final report with TACL, which means staff at JS Manson will have access to the report and may choose to read it.

7. There is no cost to participating, and you do not have to pay to participate. 


\section{Questions about the Study}

If you have any questions about the research before, during, or after this study, please ask. You may contact:

Researcher: Chelsea Jones

Email: chelsea.jones@,ryerson.ca

Phone: 416-979-5000 ex. 2604

Supervisor: $\quad$ Anne MacLennan

Email: amaclenn@yorku.ca

Phone: 416-736-2100 and dial extension 33857

If you have questions regarding your rights as a human subject and participant in this study, you may contact the Ryerson University Research Ethics Board for information.

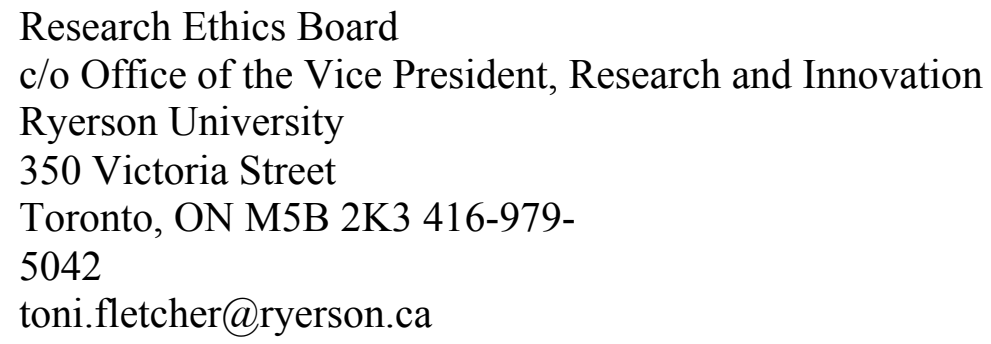

\section{Agreement}

Your signature below indicates that you have read the information. When you sign below, it means you have had a chance to ask any questions you have about the study. Your signature also indicates that you agree to be in the study, and you have been told that you can change your mind and withdraw your consent to participate at any time. You do not have to sign this agreement if you wish to participate in the writing group but you do not wish to have your work included in the research. You have been given a copy of this agreement.

You have been told that by signing this consent agreement you are not giving up any of your legal rights.

\section{Do you wish to use your real name?}

Yes

No, my pseudonym (fake name) will be:

\section{Do you consent to have your voice recorded during each session?}

Yes

No 
Do you consent to having photographs taken of your work upon the researcher's request? Yes $\quad$ No

If you wish to participate in the writing group as part of the research project, please sign here:

Name of Participant (please print)

Signature of Participant

Date

Signature of Investigator

Date 


\section{Reference List}

Abram, D. (1996). The spell of the sensuous. New York, NY: Vintage Books.

Adams St. Pierre, E. A. (2014). A brief and personal history of post qualitative research. Journal of Curriculum Theorizing, 30(2), 2-19.

Agran, M. (2011). Promoting literacy instruction for people with severe disabilities: Achieving and realizing a literate identity. Research \& Practice for Persons with Severe Disabilities, 36(3-4), 89-91.

Ahmed, S. (2006). Queer phenomenology: Orientations, objects, others. Durham, NC: Duke University Press.

Alamenciak, T. (2013, September 30). Huronia: Settled, but not forgotten. The Toronto Star. Retrieved from http://www.thestar.com/news/gta/2013/09/30/huronia_settled_but_not_forgotten.html

Arendt, H. (1998). The web of relationships and the enacted stories. In The human condition (2nd ed., pp. 181-188). Chicago, IL: University of Chicago Press.

Auerbach, A. (2001). Nickelodeon Spongebob Squarepants Spongebob Superstar. New York, NY and Toronto, Canada: Scholastic.

Barnartt, S. (1996). Disability culture or disability consciousness? Journal of Disability Policy Studies, 7(2) 1-19.

Barnes, C. (1992). Qualitative research: valuable or irrelevant? Disability, Handicap \& Society, $7(2), 115-124$.

Barnes, C. (2000). A working social model? Disability, work, and disability politics in the $21 \mathrm{st}$ century. Critical Social Policy, 20(4), 441-457.

Barnes, C. (2003). What a difference a decade makes: Reflections on doing emancipatory disability research. Disability \& Society, 18(1), 3-17.

Barnes, C., Mercer, G., and Shakespeare, T. (1999). Understanding disability. In Exploring disability: A sociological introduction (pp. 10-38). Cambridge, England: Polity.

Barounis, C. (2013). Cripping heterosexuality, queering able-bodiedness: Murderball, Brokeback Mountain, and the contested masculine body. In L. J. Davis (Ed.), The disability studies reader (4th ed., pp. 381-397). New York, NY: Routledge.

Barthes, R. (2007). From work to text. In S. During (Ed.), The cultural studies reader (3rd ed., pp. 81-87). London, England: Routledge. 
Baudrillard, J. (2006). The precession of simulacra. In M. G. Durham \& D. M. Kellner (Eds.), Media and cultural studies: Keyworks (pp. 453-481). Malden, MA: Blackwell. (Original work published 1994)

Bauman, H. L. (2004). Audism: Exploring the metaphysics of oppression. Journal of Deaf studies and Deaf education, 9 (2), 239-246.

Bauman, H.L. \& Murray, J. (2013). Deaf studies in the $21^{\text {st }}$ century: 'Deaf-gain' and the future of human diversity. In M. Marschark \& P. E. Spencer (Eds.). The Oxford handbook of Deaf studies, language, and education (Vol. 2, pp. 210-225). New York: Oxford University Press.

Bauman, Z. (1990). Thinking sociologically. Oxford, England: Blackwell.

Bauman, Z. (1999a). Culture as concept. In Culture as praxis (pp. 1-46). London. England: Sage.

Bauman, Z. (1999b). Introduction. In Culture as praxis (pp. vii-lii). London, England: Sage.

Bauman, Z. (2000). Liquid modernity. Malden, MA: Polity.

Behar, R. (1996). The vulnerable observer: Anthropology that breaks your heart. Boston, MA: Beacon Press.

Baynton, D. (2013). Disability and the justification of inequality in American history. In L. J. Davis (Ed.), The disability studies reader (4th ed., pp. 17-33). New York, NY: Routledge.

Ben-Moshe, L. (2013). The institution yet to come: Analyzing incarceration through a disability lens. In L. J. Davis (Ed.), The disability studies reader (4th ed., pp. 132-146). New York, NY: Routledge.

Berger, J. (2014). The disarticulate. New York, NY: NYU Press.

Berman, M. (1982). Introduction: Modernity-Yesterday, today, and tomorrow. In All that is solid melts into air: The experience of modernity (pp. 15-36). New York: Penguin Books.

Bérubé, M. (1998a). Foreword. In Simi Linton, Claiming disability (pp. vii-xv). New York: New York University Press.

Bérubé, M. (1998b). Life as we know it: A father, a family, and an exceptional child. New York, NY: Vintage Books.

Bérubé, M. (2013). Disability, democracy, and the new genetics. In L. J. Davis (Ed.), The disability studies reader (4th ed., pp. 100-113). New York, NY: Routledge. 
Bhaba, H. K. (1994). The postcolonial and the postmodern: The question of agency. In The location of culture (pp. 171-197). New York, NY: Routledge.

Biklen, D., \& Cardinal, D. (1997). Contested words, contested science: Unraveling the facilitated communication controversy. New York, NY: Teachers College Press.

Bingham, H., Kolanovic, D., East, J., Dunn, R., Yerrill, G., et al. (2011). A story a day: 365 fairy tales, rhymes, and other stories. Bath, England: Parragon Books.

Briant, E., Watson, N., \& Philo, G. (2013). Reporting disability in the age of austerity: The changing face of media representation of disability and disabled people in the United Kingdom and the creation of new "folk devils." Disability \& Society, 28(6), 874-889.

Brunswick-Cole, K., \& Goodley, D. (2014, February 3). Thinking about the human; thinking about disability. Nordic Network on Disability Research. Retrieved from http://nndr.no/thinking-about-the-human-thinking-about-disability/

Burch, S., \& Joyner, H. (2007). Unspeakable: The story of Junius Wilson. Chapel Hill: University of North Carolina Press.

Burroway, J., Stuckey-French, E., \& Stuckey-French, N. (2011). Writing fiction: A guide to narrative craft (8th ed.). Boston: MA: Longman.

Burman, E. \& Maclure, M. (2011). Deconstruction as a method of research. In Somekh, B. \& Lewin, C. (Eds.), Theory and methods in social science research ( ${ }^{\text {nd }}$ ed., pp. 586-294). Los Angeles, CA: Sage.

Burton, P. (2013, September 20). Huronia: Pierre Burton warned us 50 years ago. The Toronto Star. (Original work published 1960). Retrieved from http://www.thestar.com/news/insight/2013/09/20/huronia_pierre_berton_warned_us_50 years ago.html

Butler, J. (1999). Subjects of sex/gender/desire. In Gender trouble: Feminism and the subversion of identity (pp. 3-44). New York, NY: Routledge. (Original work published 1990)

Campagnolo, G. M., Curzi, Y., D’Andrea, V., Fele, G., Liberman, K., \& Viscusi, G. (2009). 2.3 Befindlichkeit. In Phenomenology and the social study of information systems: Conversations with Kenneth Liberman. Quaderno, 46, 21-23.

Campbell, F. K. (2001). Inciting legal fictions: Disability's date with ontology and the ableist body of the law. Griffith Law Review, 10, 42-62.

Campbell, F. K. (2008). Refusing able(ness): A preliminary conversation about ableism. $M / C$ Journal, 11(3). Retrieved from http://journal.mediaculture.org.au/index.php/mcjournal/article/viewArticle/46 
Campbell, J. (1996). “Growing Pains,” Disability Politics — The Journey Explained and Described. (n.d.). Independent Living Institute Library. Retrieved from http://www.independentliving.org/docs6/campbell1996.html

Canadian Broadcasting Corporation. (2014, February 24). Moose Jaw centre for mentally disabled to close by 2016. CBC News Saskatchewan. Retrieved from http://www.cbc.ca/news/canada/saskatchewan/moose-jaw-centre-for-mentally-disabledto-close-by-2016-1.1279044

Canadian Down Syndrome Society. (2014). Paint outside the lines for National Down Syndrome awareness week! See the ability campaign. Retrieved from http://cdss.ca/ndsaw/2014/10/national-down-syndrome-awareness-week-2014announcement/

Carlson, L. (2005). Docile bodies, docile minds: Foucauldian reflections on mental retardation. In S. Tremain (Ed.), Foucault and the government of disability (pp. 133-152). Ann Arbor: University of Michigan Press.

Carlson, L. (2010). The faces of intellectual disability: Philosophical reflections. Bloomington: Indiana University Press.

Chouinard, V. (1997). Making space for disabling difference: Challenging ableist geographies. Environment and planning D: Society and space, 15, 379-387.

Church, K., Frazee, C., Luciani, T., Panitch, M., \& Seeley, P. (2006). Dressing corporate subjectivities: Learning what to wear to the bank. In S. Billett, M. Somerville \& T. Fenwick (Eds.). Work, subjectivity and learning (pp. 69-85). Dordrecht, The Netherlands: Springer.

Cixous, H. (1976). The laugh of the medusa. Signs, 1(4), 875-893.

Cixous, H. (1991). Coming to writing. In Coming to writing (pp. 1-58). Cambridge, MA: Harvard University Press.

Cixous, H. (1993). Three steps on the ladder of writing (S. Cornell \& S. Sellers, Trans.). New York, NY: Columbia University Press.

Clare, E. (1999). Freaks and queers. In Exile and pride: Disability, queerness and liberation. Cambridge, MA: South End Press.

Clare, E. (2013). Stones in my pockets, stones in my heart. In L. J. Davis (Ed.), The disability studies reader (4th ed., pp. 497-506). New York, NY: Routledge.

Coleman Brown, L. (2013). Stigma: An enigma demystified. In L. J. Davis (Ed.), The disability studies reader (4th ed., pp. 147-159). New York, NY: Routledge. 
Collins, P. H. (1990). Patricia Hill Collins: Intersecting Oppressions. In Black feminist thought: Knowledge, consciousness, and the politics of empowerment (pp. 2-11). Boston, MA: Unwin Hyman.

Community Living Toronto. (2015). About us [Web page]. Retrieved from cltoronto.ca/about-us

Copeland, S. R., Keefe, E. B., Calhoon, A. J., Tanner, W., \& Park, S. (2011). Preparing teachers to provide literacy instruction to all students: Faculty experiences and perceptions. Research and Practice for Persons with Severe Disabilities, 36, 126-141.

Corker, M., \& Shakespeare, T. (2002). Mapping the terrain. In M. Corker \& T. Shakespeare (Eds.), Disability/postmodernity: Embodying disability theory (pp. 1-17). London, England: Continuum.

Davies, B. (2000). A body of writing 1990-1999. Walnut Creek, CA: AltaMira Press.

Davies, W. (2014). Neoliberalism: A bibliographic review. Theory, Culture \& Society. 31(7/8), 309-317.

Davis, L. J. (1995). Enforcing normalcy: Disability, deafness, and the body. New York, NY: Verso.

Davis, L. J. (2010). The end of identity politics: On disability as an unstable category. In L. J. Davis (Ed.), The disability studies reader (3rd ed., pp. 301-315). New York, NY: Routledge.

Davis, L. J. (2013a). Introduction: Normality, power, and culture. In L. J. Davis (Ed.), The disability studies reader (4th ed., pp. 15-28). New York, NY: Routledge.

Davis, L. J. (2013b). The end of identity politics: On disability as an unstable category. In L. J. Davis (Ed.), The disability studies reader (4th ed., pp. 263-277). New York, NY: Routledge.

DePoy, E., \& Gilson, S. (2013). Disability, design, and branding: Rethinking disability for the 21 st century. In L. J. Davis (Ed.), The disability studies reader (4th ed., pp. 15-28). New York, NY: Routledge.

Dertscher, P. (2005). How to read Derrida. London: W.W. Norton.

Derrida, J. (1976). Part 1: Writing before the letter. Of grammatology (G. Spivak, Trans.) (pp. 187). Baltimore, MD: Johns Hopkins University Press.

Devaney, J., \& Molenhuis, D. (Eds.). (2013). Mess: The hospital anthology. Toronto, Canada: Tightrope Books. 
Docherty, D., Hughes, R., Phillips, P., Corbett, D., Regan, B., Barber, A., . . \& \& Izzidien, S. (2010). This is what we think. In L. J. Davis (Ed.), The disability studies reader (3rd ed., pp. 432-442). New York, NY: Routledge.

Dolmage. J. (2014). Prosthesis. In Disability rhetoric (pp. 1-19). Syracuse, NY: Syracuse University Press.

Dossa, P. (2005). Racialized bodies, disabling worlds "they [service providers[ always saw me as a client, not as a worker." Social sciences \& medicine, 60 (2005), 2527-2536.

Down, J. L. (1997). Observations on an ethnic classification of idiots. London Hospital Reports, 3, 259-262. (Original work published 1866). Retrieved from http://www.neonatology.org/classics/down.html

Dowse, L. (2009). "Some people are never going to be able to do that." Challenges for people with intellectual disability in the 21st century. Disability \& Society, 24(5), 571-584.

Dreyfus, H. L., \& Rabinow, P. (1982). Michel Foucault: Beyond structuralism and hermeneutics. Chicago, IL: University of Chicago Press.

Duggan, L. (2004). "Introduction" and "Downsizing democracy" in The twilight of equality? Neoliberalism, culture politics, and the attack of democracy (pp. x-21). Boston, MA: Beacon Press.

Eagleton, T. (2000). Versions of culture. In The idea of culture (pp. 1-31). Oxford, England: Blackwell.

Eiesland, N. (1994). The disabled god: Toward a liberatory theology of disability. Nashville, TN: Abingdon Press.

Ellem, K., Wilson, J., Chui, W. H., \& Knox, M. (2008). Ethical challenges of life story research with ex-prisoners with intellectual disability. Disability \& Society, 23 (5), 497-509.

Ellis, C. (1998). 'I hate my voice': Coming to terms with minor bodily stigmas. The sociological quarterly, 39 (4), 517-537.

Ellis, C. (2007). Telling secrets, revealing lies: Relational ethics in research with intimate others. Qualitative Inquiry, 13(1), 3-29.

Engber, D. (Oct. 20, 2015). The strange case of Anna Stubblefield. The New York Times. Retrieved from http://www.nytimes.com/2015/10/25/magazine/the-strange-case-of-annastubblefield.html? $\mathrm{r}=0$

Erevelles, N. (2001). In search of the disabled subject. In J. Wilson \& C. Lewiecki-Wilson (Eds.), Embodied rhetorics: Disability and language in culture (pp. 92-111). Carbondale: Southern Illinois University Press. 
Erevelles, N. (2005). Signs of reason: Rivière, facilitated communication, and the crisis of the subject. In S. Tremain (Ed.), Foucault and the Government of Disability (pp. 45-64). Ann Arbor: University of Michigan Press.

Erevelles, N. (2011). "Coming out crip" in inclusive education. Teachers College Record, 113(10), 2155-2185.

Erevelles, N. (2015, March 11). Putting disability studies into research/theory/praxis: A student seminar with Dr. Nirmala Erevelles [Lecture]. Centre for Media and Culture in Education and the School of Disability Studies Student Advisory Committee to Ryerson University. Sally Horsfall Eaton Centre, Ryerson University, Toronto.

Erevelles, N. (2015, March 12). "Tongue-tied": Theorizing at the intersections of bilingual education, deaf studies, and disability studies [Lecture]. Centre for Media and Culture in Education. George Vari Engineering and Computing Centre, Toronto.

Erevelles, N. (2015, March 13). CMCE Disability studies works in progress session with respondent [Lecture]. Centre for Media and Culture in Education and the School of Disability Studies Student Advisory Committee to Ryerson University. Presentations by Mary Jean Hande and Fady Shanouda. Sally Horsfall Eaton Centre, Ryerson University, Toronto.

Evans, M., Hole, R., Berg, L., Hutchinson, P., \& Dixon, S. (2009). Common insights, differing methodologies: Toward a fusion of Indigenous methodologies, participatory action research, and white studies in an urban Aboriginal research agenda. Qualitative Inquiry, 15(5), 893-910.

Ferris, J. (2007, June). Crip poetry, or how I learned to love the limp. Wordgathering, 1(2). Retrieved from http://www.wordgathering.com/past_issues/issue2/essay/ferris.html

Field, J. (1981a). First questions. A life of one's own (pp. 19-33). New York, NY: Jeremy P. Tarcher/Perigee.

Field, J. (1981b). Prologue. A life of one's own (pp. 11-18). New York, NY: Jeremy P. Tarcher/Perigee. (Original work published 1934)

Filax, G. (2006). Social/legal production of sexual minorities in Canada. In Queer youth in the province of "severely normal" (pp. 75-104). Vancouver, Canada: UBC Press.

Florida, R. (2005). Introduction. In Cities and the creative class (pp. 1-21). New York, NY: Routledge.

Foucault, M. (1970). The order of things: An archaeology of the human sciences (A.M.S. Smith, Trans.). New York, NY: Vintage Books. (Original work published 1966) 
Foucault, M. (1973a). Doctors and patients. In Madness and civilization: A history of insanity in the age of reason (R. Howard, Trans.) (pp. 159-198). New York, NY: Vintage Books.

Foucault, M. (1973b). The great confinement. Madness and civilization: A history of insanity in the age of reason (R. Howard, Trans.) (pp. 38-64). New York, NY: Vintage Books.

Foucault, M. (1973c). Preface. In The birth of the clinic (pp. xi-xix). Taylor \& Francis e-Library, 2003. London, England: Tavistock.

Foucault, M. (1973d). Stultifera Navis. Madness and civilization: A history of insanity in the age of reason (R. Howard, Trans.) (pp. 3-37). New York, NY: Vintage Books.

Foucault, M. (1975). I, Pierre Riviere, having slaughtered my mother, my sister, and my brother...:A case study of parricide in the nineteenth century. Trans. F. Jellinek. Lincoln, NB: University of Nebraska Press.

Foucault, M. (1978). The history of sexuality: Volume 1: An introduction (R. Hurley, Trans.). New York, NY: Random House. (Original work published 1976)

Foucault, M. (1979). Discipline and punish: The birth of the prison. New York, NY: Vintage Books. (Original work published 1977)

Foucault, M. (1986). Docile bodies. In P. Rabinow (Ed.), The Foucault reader: An introduction to Foucault's thought (pp. 179-187). London, UK: Penguin Group.

Foucault, M. (1991). Governmentality. In G. Burchell, C. Gordon, \& P. Miller (Eds.), The Foucault effect: Studies in governmentality (pp. 87-104). Chicago. IL: University of Chicago Press.

Foucault, M. (2000). The abnormals. In P. Rabinow (Ed.), Michel Foucault ethics essential works of Foucault 1954-1984: Volume 1 (pp. 51-58). London, England, Penguin Group.

Foucault, M. (2003). 21 November 1973. In J. Lagrange (Ed.), Psychiatric power: Lectures at the College de France, 1973-74 (G. Burchell, Trans.) (pp. 39-62). Basingstoke, Hampshire, England: Palgrave Macmillan.

Foucault, M. (2006). Nine: 16 January 1974. In J. Lagrange (Ed.), Psychiatric power: Lectures at the College de France 1973-74 (G. Burchell, Trans.) (pp. 173-233). Basingstoke, Hampshire, England: Palgrave Macmillan.

Freeman, M., \& Vagle, M. D. (2013). Turning hermeneutics and phenomenology on one another: Implications for qualitative research. Paper presented at the annual meeting of the American Educational Research Association, San Diego, California, April 2009.

French, S. \& Swain, J. (2006). Telling stories of politics and hope. Disability \& Society, 21 (5), 383-396. 
Galer, D. (2012). Disabled capitalists: Exploring the intersections of disability and identity formation in the world of work. Disability Studies Quarterly, 32 (3), retrieved from http://dsq-sds.org/article/view/3277/3122

Gallagher, S. (2012). Phenomenology. Basingstoke, Hampshire, England: Palgrave Macmillan.

Garland-Thomson, R. (1997). Disability, identity, and representation: An introduction. In Extraordinary bodies: Figuring physical disability in American culture and literature (pp. 7-18). New York, NY: Columbia University Press.

Garland-Thomson, R. (2001). Seeing the disabled. In P. Longmore and L. Umansky (Eds.), The new disability history: American perspectives (pp. 335-374). New York: New York University Press.

Garland-Thomson, R. (2002). Integrating disability, transforming feminist theory. NWSA Journal, 14(3), 1-32.

Garland-Thomson, R. (2013). Integrating disability, forming feminist theory. In L. J. Davis (Ed.), The disability studies reader (4th ed., pp. 333-353). New York, NY: Routledge.

Gee, J. (1991). Socio-cultural approaches to literacy (literacies). Annual Review of Applied Linguistics, 12, 31-48.

Gilroy, P. (1993). The Black Atlantic as a counterculture of modernity. In Modernity and double consciousness (pp. 1-40). Cambridge, MA: Harvard University Press.

Gilroy, P. (2006). British cultural studies and the pitfalls of identity. In M. G. Durham and D. M. Kellner (Eds.), Media and cultural studies: Keyworks (Rev. ed., pp. 381-395). Malden, MA: Blackwell. (Original work published 1996)

Gilson, S., \& DePoy, E. (2000). Multiculturalism and disability: A critical perspective. Disability \& Society, 15(2), 207-218.

Goffman, E. (1963). Stigma: Notes on the management of spoiled identity. Englewood Cliffs, NJ: Prentice Hall.

Goldberg, N. (1986). Writing down the bones: Freeing the writer within. Boston, MA: Shambala Publications.

Goodley, D. (2007). Towards socially just pedagogies: Deleuzoguattarian critical disability studies. International Journal of Inclusive Education, 11, 317-334.

Goodley, D. (2011). Disability studies: An interdisciplinary introduction. London, England: Sage. 
Goodley, D. (2012). Jacques Lacan + Paul Hunt = Psychoanalytic Disability Studies. In D. Goodley, B. Hughes, \& L. Davis (Eds.), Disability and social theory: New developments and directions (pp. 179-194). Basingstoke, Hampshire, England: Palgrave Macmillan.

Goodley, D., \& Moore, M. (2000). Doing disability research: Activist lives and academy. Disability \& Society, 15(6), 861-861.

Goodley, D., \& Rapley, M. (2002). Changing the subject: Postmodernity and people with "learning difficulties." In M. Corker \& T. Shakespeare (Eds.), Disability/postmodernity: Embodying disability theory (pp. 127-142). London, England: Continuum.

Grant, G. (1986). Thinking about technology. In Technology and justice (pp. 11-34). Concord, Canada: House of Anansi.

Gray, R. (2000). Graduate school never prepared me for this: Reflections on the challenges of research-based theatre. Reflective Practice, 1(3), 378-390.

Grekul, J., Krahn, H., \& Odynak, D. (2004). Sterilizing the "feeble-minded": Eugenics in Alberta, Canada, 1929-1972. Journal of Historical Sociology, 17(4), 358-384.

Grekul, J.M., (2002). The social construction of the feebleminded threat: Implementation of the Sexual Sterilization Act in Alberta, 1929-1972. Edmonton, Canada: Department of Sociology, University of Alberta.

Guillemin, M. \& Gillam, L. (2004). Ethics, reflexivity, and 'ethically important moments' in research. Qualitative Inquiry, 10, 261-280.

halifax, n. v. d. \& Mitchell, G. (2013). (Nurse)-Writing with the wolves. Qualitative inquiry, 19 (5), 349-352.

halifax, n.v.d. (2009). Disability and illness in arts-informed research: Moving toward postconventional representations. Amherst, NY: Cambria Press.

Hall, S. (2006). Encoding/decoding, In M. G. Durham and D. M. Kellner (Eds.), Media and cultural studies: Keyworks (Rev. ed., pp. 163-173). Malden, MA: Blackwell, 2006. (Original work published 1980)

Haller, B., Blaser, A., Naidoo, V., \& Jones, C. (2013, June 28). Panel presentation. iTechnology as cure or iTechnology as empowerment: What does print media report? Panel: "Miracle" or Misrepresentation? Technology takes on Communication Disabilities. (Re)creating Our Lived Realities. 26th Annual Conference of the Society for Disability Studies, Orlando, Florida.

Haller, B. A. (2010). Representing disability in an ableist world: Essays on mass media. Louisville, KY: Avocado Press. 
Hande, M., Sing, J., \& Basualdo, M. (2014, January). Panel presentation for the Ontario Public Interest Research Group at the University of Toronto and York University. Research in action: Building accountable community research. University of Toronto, Toronto, Canada. http://www.opirgtoronto.org/node/201

Haraway, D. (1990). A manifesto for cyborgs: Science, technology, and socialist feminism in the 1980s. In L. J. Nicholson (Ed.), Feminism/postmodernism (pp. 190-233). New York, NY: Routledge.

Harris, S. P., Owen, R., \& Gould, R. (2012). Parity of participation in liberal welfare states: Human rights, neoliberalism, disability and employment. Disability \& Society, 27(6), 823-836.

Harvey, D. (1985). Money, Time, Space and the City. In Consciousness and the urban experience: Studies in the history and theory of capitalist urbanization (pp. 1-35). Baltimore, MD: The John Hopkins University Press.

Harvey, D. (1990). Part 1: The passage from modernity to postmodernity in contemporary culture. In The condition of postmodernity: An enquiry into the origins of cultural change (pp. 3-113). Cambridge, Massachusetts: Blackwell Publishers.

Harvey, D. (2005). A Brief History of Neoliberalism. Oxford, England: Oxford University Press.

Hayward, K. A. (2005). A hierarchy of disability: Attitudes of people with disabilities toward one another. (Ph.D., University of California, Los Angeles). Retrieved From ProQuest Dissertations and Theses (prod.academic_MSTAR_305002638).

Hebdige, D. (2006). (i) From Culture to Hegemony; (ii) Subculture: The Unnatural Break. In M. G. Durham and D. M. Kellner (Eds.), Media and cultural studies: Keyworks (Rev. ed., pp. 144-162). Malden, MA: Blackwell Publishing. (Original work published 1979)

Heidegger, M. (1962a). The phenomenological method of investigation. In Being and time (J. Macquarie \& E. Robinson, Trans.) (pp. 49-63). New York, NY: Harper \& Row.

Heidegger, M. (1962b). The worldhood of the world. In Being and Time (J. Macquarie \& E. Robinson, Trans.) (pp. 91-119). New York, NY: Harper \& Row.

Heidegger, M. (1953). A. The existential constitution of the there. In Being and time (J. Stambaugh ,Trans.) (pp. 136-131). Albany: State University of New York Press.

Heidegger, M. (1971). Poetry, language, thought (A. Hofstadter, Trans.). New York, NY: Harper Perennial.

Hesse-Biber, S. N., \& Leavy, P. (2007). Feminist postmodernism and poststructuralism. In Feminist research practice (pp. 83-109). Thousand Oaks, CA: Sage. 
Hocking, C. (2007). The romance of occupational therapy. In J. Creek \& A. Lawson-Porter (Eds.), Contemporary issues in occupational therapy: Reasoning and reflection (pp. 2340). Chichester, England: Wiley.

Hofstadter, A. (Trans.) (1971). Introduction. In M. Heidegger, Poetry, language, thought. New York, NY: Harper Perennial.

Holland, K. (2007). The epistemological bias of ethics review: Constraining mental health research. Qualitative Inquiry, 13(6), 895-914.

hooks, b. (1997). Wounds of passion: a writing life. New York: Henry Hold and Company.

hooks, b. (2006). Eating the other: Desire and resistance. In M. G. Durham \& D. M. Kellner (Eds.), Media and cultural studies: Keyworks (Rev. ed., pp. 366-380). Malden, MA: Blackwell Publishing. (Original work published 1992)

Hubbard, R. (2013). Abortion and disability: Who should and should not inhabit the world? In L. J. Davis (Ed.), The disability studies reader (4th ed., pp. 74-86). New York, NY: Routledge.

Hughes, B. (2005). What can a Foucauldian analysis contribute to disability theory? In S. Tremain (Ed.), Foucault and the government of disability (pp. 78-92). Ann Arbor: University of Michigan Press.

Hughes, B. (2012). Civilising modernity and the ontological invalidation of disabled people. In Goodley, D., Hughes, B. \& Davis, L. (Eds.), Disability and social theory: New developments and directions (pp. 17-32). New York, NY: Palgrave Macmillan.

Humphrey, J. (1999). Disabled people and the politics of difference. Disability \& Society, 14(2), $173-188$.

Husserl, E. (1970). Introduction to the logical investigations. In D. Moran \& T. Mooney (Eds.), The phenomenology reader (pp. 65-77). London, England: Routledge. [Original citation: E. Husserl, Logical Investigations, 1970, trans. J.N. Findlay, Vol. 1, pp. 248-266. London and New York: Routledge \& Kegan Paul/Humanities Press]

Ignagni, E. (2015, March 7). Policies and practice of intervention. Course lecture. Ryerson University, Toronto, Canada.

Ignagni, E., \& Church, K. (2008). One more reason to look away? Ties and tensions between arts-informed inquiry and disability studies. In A. Cole \& J. G. Knowles (Eds.), Handbook of the arts in qualitative social science research (pp. 625-638). Thousand Oaks, CA: Sage.

Iwakuma, M. (2002). The body as embodiment: An investigation of the body by Merleau-Ponty. In M. Corker \& T. Shakespeare (Eds.), Disability/postmodernity: Embodying disability theory (pp. 76-87). London, UK: Continuum. 
Jameson, F. (1991). The cultural logic of late capitalism. In Postmodernism, or, the cultural logic of late capitalism. Durham, NC: Duke University Press.

Jameson, F. (2006). Postmodernism, or the cultural logic of late capitalism. In M. G. Durham and D. M. Kellner (Eds.), Media and cultural studies: Keyworks (Rev. ed., pp. 482-519). Malden, MA: Blackwell Publishing. (Original work published 1984)

Johner, R. (2013). Disability and poverty: Stories that resist attitudinal barriers to inclusion. Canadian Journal of Disability Studies, 2(3), 31-54.

Johnson, K., Minogue, G., \& Hopkins, R. (2014). Inclusive research: Making a difference to policy and legislation. Journal of Applied Research in Intellectual Disabilities, 27, 7684.

Jones, A. R. (1986). Writing the body: Toward an understanding of l'écriture feminine. In M. Eagleton (Ed.), Feminist literary theory: A reader (pp. 228-231). Oxford, England: Basil Blackwell.

Jones, C. (2013). Interview with John Swinton. The United Church Observer. Retrieved from: http://www.ucobserver.org/interviews/2013/02/john_swinton/

Jones, C. (2014). Application for ethics review of research involving human participants, submitted to Ryerson University Research Ethics Board re: File REB 2013-269. Feb. 17, 2014.

Jones, C. (2014). Comments to the chair, Application for ethics review of research involving human participants, 2013-269. Online form.

Jones, S. (2008). From marginalization to participation and back again: Including people with learning disabilities in research ... but for how long? Disability Studies Quarterly, 28 (2). Retrieved from http://dsq-sds.org/article/view/95

Kafer, A. (2013). Feminist, queer, crip. Bloomington, IN: Indiana University Press.

Kielhofner, G. (1985). A model of human occupation: Theory and application. Baltimore, MD: Williams \& Wilkins.

King, T. (2015). The inconvenient Indian: A curious account of native people in North America. Minneapolis: University of Minnesota Press.

Kliewer, C., \& Biklen, D. (2007). Enacting literacy: Local understanding, significant disability, and a new frame. Teachers College Record, 109, 2579-2600. 
Kliewer, C., Biklen, D., \& Kasa-Hendrickson, C. (2006). Who may be literate? Disability and resistance to the cultural denial of competence. American Educational Research Journal, $2,163-192$.

Knoblauch, C. H. (1990). Literacy and the politics of education. In A. A. Lumsford, H. Moglen, \& J. Slevin (Eds.), The right to literacy (pp. 74-80). New York, NY: The Modern Language Association of America.

Knox, M., Mok, M., \& Parmenter, T. (2000). Working with experts: Collaborative research with people with an intellectual disability. Disability \& Society, 15(6), 49-61.

Kostouli, T. (2009). A sociocultural framework: Writing as social practice. In R. Beard, D. Myhill, J. Riley, \& M. Nystrand (Eds.), The Sage handbook of writing development (pp. 99-116). London, England: Sage.

Kristeva, J. (1984). The semiotic and the symbolic. In Revolution in poetic language (M. Waller, Trans.) (pp. 20-20). New York, NY: Columbia University Press.

Küpers, W. M. (2011). Embodied pheno-pragma-practice: Phenomenological and pragmatic perspectives on creative "inter-practice" in organisations between habits and improvisation. Phenomenology \& Practice, 5(11), 100-139.

Kuppers, P. (2002). Image politics without the real: Simulacra, dandyism and disability fashion. In M. Corker \& T. Shakespeare (Eds.), Disability/postmodernity: Embodying disability theory (pp. 184-197). London, England: Continuum.

Kuppers, P. (2006). Addenda, phenomenology, embodiment: Cyborgs and disability performance. In S. Broadhurst \& J. Machon (Eds.), Performance and technology: Practices of virtual embodiment and interactivity (pp. 169-180). New York, NY: Palgrave Macmillan.

Kuppers, P. (2007). Performing determinism: Disability culture poetry. Text and Performance Quarterly, 27(2), 89-106.

Lacan, J. (1977). The mirror stage as formative of the function of the I as revealed in psychoanalytic experience. In Ecrits: A selection. Trans. A. Sheridan (pp. 1-7). New York: W.W. Norton \& Co.

Lather, P. A. (2007). Getting lost: Feminist efforts toward a double(d) science. Albany: State University of New York Press.

Lavallée, L. "Re: REB 2013-269 Status.” Message to the author. 23 September, 2013.

Leavy, P. (2007). Essentials of transdisciplinary research: Using problem-centered methodologies. Walnut Creek, CA: Left Coast Press. 
Leavy, P. (2009). Method meets art: Arts-based research practice. New York, NY: The Guildford Press.

Lewis, B. (2013). A mad fight: Psychiatry and disability activism. In L. J. Davis (Ed.). The disability studies reader (4th ed., pp. 115-130). New York, NY: Routledge.

Library and Archives Canada, Censuses. (2015, February 28). About the Federal Census of 1871 (Ontario). Retrieved from http://www.bac-lac.gc.ca/eng/census/1871-on/Pages/aboutcensus.aspx

Linton, S. (1998). Claiming disability: Knowledge and identity. New York: New York University Press.

Longmore, P. (2003). Disability Watch. In Why I burned by book and other essays on disability (pp. 19-31). Philadelphia: Temple University Press.

Lyotard, J. (1979). The postmodern condition, 1. The field: Knowledge in computerized Societies. In The postmodern condition: A report on knowledge (pp. 3-6). Manchester, England: Manchester University Press.

Lyotard, J. (1999). Defining the postmodern. In S. During (Ed.), The Cultural Studies Reader (2nd ed., pp. 142-145). New York, NY: Routledge.

Mace, J. (1996). The significance of student writing. In J. M. Fitzpatrick (Ed.), Lifelong literacies: Papers from the 1996 conference. (pp. 67-70). London, UK: Gatehouse Books.

Madjar, I., \& Walton, J. A. (Eds.). (1999a). Nursing and the experience of illness: Phenomenology in practice. New York, NY: Routledge.

Madjar, I., \& Walton, J. A. (1999b). Phenomenology and nursing. In I. Madjar \& J. A. Walton (Eds.), Nursing and the experience of illness: Phenomenology in practice (pp. 1-16). New York, NY: Routledge.

Mairs, N. (1986, September 5). On being a cripple [Web log post]. Retrieved from http://thelamedame.tumblr.com/post/30938417648/on-being-a-cripple

Mairs, N. (1996). Waist-high in the world: A life among the nondisabled. Boston, MA: Beacon Press.

Malacrida, C. (2015). Introducing the Michener Centre. In A special kind of hell: Institutional life in Alberta's eugenic years (pp. 3-30). Toronto, On: University of Toronto Press.

Marks, P. (1999). Disability: Controversial debates and psychological perspectives. New York, NY: Routledge. 
Mawyer, R. (2005). The postmodern turn in disability studies. Atenea 25(1), 61-75.

McBryde Johnson, H. (2013). Unspeakable conversations. In L. J. Davis (Ed.), The disability studies reader (4th ed., pp. 507-518). New York, NY: Routledge.

McCabe, J., \& Holmes, D. (2011). Reversing Kristeva's first instance of abjection: The formation of self reconsidered. Nursing Inquiry, 18(1), 77-83.

McDermott, R., \& Varenne, H. (1995). Culture as disability. Anthropology \& Education Quarterly, 26(3), 324.

McKittrick, K. (2013). Plantation futures. Small Axe, 17(3), 1-15.

McRobbie, A. (1985). Feminism, postmodernism, and the 'real me.' In Postmodernism and popular culture (pp. 61-74). London, UK: Routledge.

McRuer, R. (2013). Compulsory able-bodiedness and queer/disabled existence. In L. J. Davis (Ed.), The disability studies reader (4th ed., pp. 15-28). New York, NY: Routledge.

McVey, D. (2008). Why all writing is creative writing. Innovations in Education and Teaching International, 45(3), 289-294.

Merleau-Ponty, M. (1948). The world of perception and the world of science [Video file]. Retrieved from https://www.youtube.com/watch?v=uf9TtYdxy3A

Merleau-Ponty, M. (1964). The world of perception (O. Davis, Trans.) (pp. 31-83). London, England: Routledge. (Original work published 1948)

Mertens, D. M. (2010). Research and evaluation in education and psychology: Integrating diversity with quantitative, qualitative, and mixed methods. ( $3^{\text {rd }}$ ed.). Los Angeles, CA: Sage.

Michalko, R. (2009). Coming face-to-face with suffering. In T. Tichkosky \& R. Michalko (Eds.), Rethinking normalcy: A disability studies reader (pp. 91-114). Toronto, Canada: Canadian Scholars' Press.

Miller, L., Whalley, J., \& Stronach, I. (2011). From structuralism to post-structuralism. In Somekh, B. \& Lewin, C. (Eds.), Theory and methods in social research $\left(2^{\text {nd }}\right.$ ed., pp. 586294). Los Angeles, CA: Sage.

Mills, C. W. (2000). The sociological imagination (Fortieth anniversary ed.). New York, NY: Oxford University Press. (Original work published 1959)

Milner, M. (1987a). 1957: The ordering of chaos. In The suppressed madness of sane men: Forty-four years of exploring psychoanalysis (pp. 216-233). New York, NY: BrunnerRoutledge. 
Milner, M. (1987b). 1960: The concentration of the body. In The suppressed madness of sane men: Forty-four years of exploring psychoanalysis (pp. 234-240). New York, NY: Brunner-Routledge.

Mintz, S. B. (2007). Unruly bodies: Life writing by women with disabilities. Chapel Hill: University of North Carolina Press.

Moran, D., \& T. Mooney (Eds.). (2002). The phenomenology reader. New York, NY: Routledge.

Morgan, M., Cuskelly, M., \& Moni, K. B. (2011). Broadening the conceptualization of literacy in the lives of adults with intellectual disability. Research \& Practice for Persons with Severe Disabilities, 36(3-4), 112-120.

Morris, J. (1991). Introduction. In Pride against prejudice: Transforming attitudes to disability (pp. 1-15). Philadelphia: New Society.

National Council on Ethics in Human Research (NCEHR). (1996). Facilitating ethical research: Promoting informed choice: Discussion document. NCEHR Communique. Retrieved from http://www.ncehr-cnerh.org/section2.html

Nunkoosing, K., \& Haydon-Laurelut, M. (2012). Intellectual disability trouble. In D. Goodley, B. Hughes, \& L. Davis (Eds.), Disability and social theory: New developments and directions (pp. 195-211). New York, NY: Palgrave Macmillan.

Odette, F. \& Rajan, D. (2015). Our right to be safe! Building safe communities for people with disabilities and Deaf people. Retrieved from http://www.cacl.ca/newsstories/blog/buildingsafecommunities

Oliver, M. (1990). Disability definitions: The politics of meaning. In The politics of disablement (pp. 20-34). London, England: Macmillan.

Oliver, M. (2009). Understanding disability: From theory to practice (2nd ed.). New York, NY: Palgrave Macmillan. (Originally published in 1990)

Olson, D. R. (2009). The history of writing. In R. Beard, D. Myhill, J. Riley, \& M. Nystrand (Eds.), The Sage Handbook of Writing Development (pp. 6-17). London, England: Sage.

O'Neill, J. (1985). Five bodies: The human shape of modern society. Ithaca: Cornell University Press.

Ontario Public Research Interest Group, University of Toronto (OPIRG-Toronto). (2014, January 30). Research in action: Building accountable community-based research [Event]. Ontario Institute for Studies in Education, University of Toronto, Toronto, Canada. 
Paterson, K., \& Hughes, B. (1999). Disability studies and phenomenology: The carnal politics of everyday life. Disability \& Society, 14(5), 597-610.

patterson, d. (2008). Research ethics boards as spaces of marginalization: A Canadian story. Qualitative Inquiry, 14(1), 423-428.

Pollard, N. (2007). Voices talk, hands write: Sustaining community publishing with people with learning difficulties. Groupwork, 17(2), 36-56.

Pollard, N. (2012). Communities of writing. In N. Pollard \& D. Sakellariou (Eds.), Politics of occupation-centred practice: Reflections on occupational engagement across cultures (pp. 146-161). West Sussex, England: Wiley-Blackwell.

Prendergast, C. (2001). On the rhetorics of mental disability. In J. Wilson \& C. Lewiecki-Wilson (Eds.), Embodied rhetorics: Disability and language in culture (pp. 45-60). Carbondale: Southern Illinois University Press.

Prendergast, C. (2010). The unexpected schizophrenic: A post-postmodern introduction. In L. J. Davis (Ed.), The disability studies reader (3rd ed., pp. 288-300). New York, NY: Routledge.

Price, J., \& Shidrick, M. (2002). Bodies together: Touch, ethics and disability. In M. Corker \& T. Shakespeare (Eds.), Disability/postmodernity: Embodying disability theory. New York, NY: Continuum.

Price, M. (2012). Disability studies methodology: Explaining ourselves to ourselves. In K. M. Powell \& P. Takayoshi (Eds.), Practicing research in writing studies: Reflexive and ethically responsible research (pp. 159-186). New York, NY: Hampton Press.

Prince, M. (2010). Absent citizens: Disability politics and policy in Canada. Toronto, ON: University of Toronto Press.

Prince, M. (2012). Canadian disability activism and political ideas: In and between neoliberalism and social liberalism. Canadian Journal of Disability Studies, 1(1). Retrieved from http://cjds.uwaterloo.ca/index.php/cjds/article/view/16/16

Puar, J. K. (2013). The cost of getting better: Ability and debility. In L. J. Davis (Ed.). The disability studies reader (4th ed., pp. 15-28). New York, NY: Routledge.

Pruska-Oldenhof, I. (2013, June 23). Class discussion. Ryerson University.

Racher, F. E., \& Robinson, S. (2002). Are phenomenology and postpositivism strange bedfellows? Western Journal of Nursing Research, 25(5), 464-481.

Rapley, M. (2004). Intellectual disability as a diagnostic and social category. In The social construction of intellectual disability (pp. 30-77). New York, NY: Cambridge University Press. 
Razack, S. (1993). Story-telling for social change. Gender \& Education, 5(1), 55-70.

Rehorick, D. A., \& Nugent, L. (2008). Male experiences of pregnancy: Bridging phenomenological and empirical insights. In D. A. Rehorick \& V. Malhotra Bentz (Eds.), Transformative phenomenology: Changing ourselves, lifeworlds and professional practice (pp. 33-49). New York, NY: Lexington Books.

Richardson, L. (2000). Writing: A method of inquiry. In Denzin, N. \& Lincoln, Y. (Eds.), Handbook of qualitative research ( $2^{\text {nd }}$ ed., pp. 923-948). Thousand Oaks: Sage.

Rossiter, K., \& Clarkson, A. (2013). Opening Ontario's “saddest chapter": A social history of Huronia Regional Centre. Canadian Journal of Disability Studies, 2(3). Retrieved from http://cjds.uwaterloo.ca/index.php/cjds/article/view/99

Ryerson University, Policy of Senate. Policy on research involving human subjects. Policy No. 51. Approval, Oct. 4, 1999. Retrieved from http://www.ryerson.ca/content/dam/senate/policies/pol51.pdf

Salomon, D. (2013, June). Getting to solidarity: Towards the adjudicating of the conflict between the animal rights movements and the autistic pride movements. In Animals and disability. Panel presentation presented at the 26th Annual Conference for the Society of Disability Studies, Orlando, FL.

Saxton, M. (2010). Disability rights and selective abortion. In L. J. Davis (Ed.), The disability studies reader (3rd ed., pp. 120-132). New York, NY: Routledge.

Schwandt, T. A. (2007). Dictionary of Qualitative Inquiry (3 $3^{\text {rd }}$ ed.). Thousand Oaks, CA: Sage.

Scully, J. L. (2002). A postmodern disorder: Moral encounters with molecular models of disability. In M. Corker \& T. Shakespeare (Eds.), Disability/postmodernity: Embodying disability theory (pp. 48-61). London, England: Continuum.

Sedgwick, E. K. (2002). Paranoid reading and reparative reading, or, you're so paranoid, you probably think this essay is about you. In Sedgwick, E., Barale, M., Aina, M., Goldberg, J. \& M. Moon (Eds.), Touching feeling: Affect, pedagogy, and performativity (Series Q). (pp. 124-151). Durham: Duke University Press.

Shakespeare, T. (2006a). Critiquing the social model. Disability rights and wrongs (pp. 29-53). London, England: Routledge.

Shakespeare, T. (2006b). The role of non-disabled people in the world of disability. Disability rights and wrongs (pp. 185-198). London, England: Routledge.

Shier, M., Graham, J., \& Jones, M. (2009). Barriers to employment as experienced by disabled people: A qualitative analysis in Calgary and Regina, Canada. Disability \& Society, 24(1), 53-75. 
Shildrick, M. (2009). Dangerous discourses of disability, subjectivity and sexuality. New York, NY: Palgrave Macmillan.

Siebers, T. (2010). Disability and the theory of complex embodiment-For identity politics in a new register. In L. J. Davis (Ed.), The disability studies reader (3rd ed., pp. 316-333). New York, NY: Routledge.

Siebers, T. (2007, October). Identity politics, then and now. Conference paper presented at the 20th Anniversary Celebration, Institute for the Humanities, University of Michigan, Ann Arbor, MI. Retrieved from https://www.lsa.umich.edu/UofM/Content/humin/document/Siebers_Identity_Politics.pdf

Silva, C. F., \& Howe, D. P. (2012). The (in)validity of supercrip representation of paralympian athletes. Journal of Sport and Social Issues, 26(2), 174-194.

Simon, R. (2002). Riding the bus with my sister: A true life journey. Boston, MA: Houghton Mifflin Co.

Smith, A. D. (2006). Letters to a young artist. New York, NY: Anchor Press.

Smith, L. T. (1999). Imperialism, writing and theory. In Decolonizing methodologies (pp. 1937). London, England: Zed Books.

Snyder, S. \& Mitchell, D. (2001). Chapter 2: Narrative prosthesis: Disability and the dependencies of discourse. In Narrative prosthesis: Disability and the dependencies of discourse (pp. 46-64). Ann Arbor: University of Michigan Press.

Snyder, S., \& Mitchell, D. (2006). Cultural locations of disability. Chicago, IL: University of Chicago Press.

Soldatic, K. \& Meekosha, H. (2012). Disability and neoliberal state formations. In Thomas, C., Watson, N., \& Roulstone, A. (Eds.), Routledge handbook of disability studies (pp. 195210). Florence, KY: Routlege.

Solnit, R. (2013). The faraway nearby. New York, NY: Viking.

Solnit, R. (2014). Men explain things to me. Chicago, IL: Haymarket Books.

Solomon, A. (2015, March 11). The middle of things: Advice for young writers. The New Yorker. Retrieved from http://www.newyorker.com/books/page-turner/the-middle-ofthings-advice-for-young-writers

Somerville, M. (2006). The ethical imagination: Journeys of the human spirit. Toronto, Canada: Anansi Press. 
Somekh, B. \& Lewin, C. (Eds.), Theory and methods in social science research $\left(2^{\text {nd }}\right.$ ed.). Los Angeles, CA: Sage.

Sontag, S. (1978). Illness as metaphor. New York, NY: Farrar, Straus and Giroux.

Sontag, S. (2001a). A poet's prose. In Where the stress falls (pp. 3-10). New York, NY: Farrar, Straus and Giroux.

Sontag, S. (2001b). Where the stress falls. In Where the stress falls (pp. 10-30). New York, NY: Farrar, Straus and Giroux.

Sorenson, J. (Ed). (2014). Critical animal studies: Thinking the unthinkable. Toronto, Canada: Canadian Scholars' Press.

Spivak, G. (1988). Can the subaltern speak? In C. Nelson \& L. Grossberg (Eds.), Marxism and the interpretation of culture (pp. 271-313). Urbana: University of Illinois Press.Statistics Canada. (2008, February 7). Participation and activity limitation survey 2006: Analytical report. Retrieved from http://www.statcan.gc.ca/pub/89-628-x/89-628-x2007002-eng.htm

Spivak, G. (2011). Preface: Reading De la grammatologie. In S. Gaston \& I. Maclachlan (Eds.), Reading Derrida's Of Grammatology. (pp. xxix-xxxix). London: Continuum.

Stanton, T. \& I. C. H. Clare. (2012). Editorial: human rights and intellectual disabilities: an emergent theoretical paradigm? Journal of intellectual disability research, 56 (2), 10111013.

Starkman, M. (2013). The movement. In Lefrancois, B., Reaume, G., \& Menzies, R. (Eds.), Mad matters: A critical reader in Canadian mad studies (pp. 27-37). Toronto, ON: Canadian Scholars' Press.

Statistics Canada. (2014, September 14). Questionnaire(s) and reporting guide(s). Canadian survey on disability. Retrieved from http://www23.statcan.gc.ca/imdb/p3Instr.pl?Function=getInstrumentList\&Item_Id=1342 $76 \& \mathrm{UL}=1 \mathrm{~V} \&$

Stein, E. (2002). Phenomenology and the interpersonal. In Moran, D. \& Mooney, T. (Eds.), The phenomenology reader (pp. 227-242). New York, NY: Routledge.

Stein, E. (1989). Chapter II: The essence of acts of empathy. In On the problem of empathy. $\left(3^{\text {rd }}\right.$ ed., pp. 3-18). Trans. W. Stein. Washington, DC: ICS Publications.

Stewart, K. (2007). Ordinary affects. Durhan, NC: Duke University Press.

Stewart, K. (2008). Weak theory in an unfinished world. Journal of folklore research, 45(1), 7182. 
Stiker, H.-J. (1999). A history of disability (W. Sayers, Trans.). Ann Arbor: University of Michigan Press.

Stockholder, F. (1994). Naming and renaming persons with intellectual disabilities. In M. Rioux \& M. Bach (Eds.), Disability is not measles: New research paradigms in disability (pp. 154-179). North York, Canada: Roeher Institute.

Storey, J. (2006). Cultural theory and popular culture: An introduction (4th ed.). Athens: University of Georgia Press, 2006.

Straus, J. (2010). Autism as culture. In L. J. Davis (Ed.), The disability studies reader (3rd ed., pp. 535-559). New York, NY: Routledge.

Sullivan, M. (2005). Subjected bodies: Paraplegia, rehabilitation, and the politics of movement. In S. Tremain (Ed.), Foucault and the government of disability (pp. 27-44). Ann Arbor: University of Michigan Press.

Swenson, S. (2008). Neoliberalism and the human services: Threat and innovation. Journal of Intellectual Disability Research, 52(7), 626-633.

Talpade Mohanty, C. (2006). Under Western eyes: Feminist scholarship and colonial discourses. In M. G. Durham and D. M. Kellner (Eds.), Media and cultural Studies: Keyworks (Rev. ed., pp. 396-421). Malden, MA: Blackwell Publishing. (Original work published 1991)

Taylor, S. (2004). The right not to work: Power and disability. Monthly Review, 55 (10). http://monthlyreview.org/2004/03/01/the-right-not-to-work-power-and-disability/

Temple-Jones, J. \& Schenstead, A. (2015). [Spiritual care and music therapy in palliative care]. Unpublished manuscript.

Tester, K. (2004). The social thought of Zygmunt Bauman. London, England: Palgrave Macmillan.

Thompson, S. A. (2002). My researcher friend? my friend the researcher? my friend, my researcher? Mis/informed consent and people with developmental disabilities. In W. Van den Hoonaard (Ed.), Walking the tightrope: Ethical issues for qualitative researchers (pp. 95-106). Toronto, Canada: University of Toronto Press.

Thoryk, R., Roberts, P., \& Battistone, A.M. (2001). Both emic and etic: A view of the world through the lens of the ugly duckling. In L. Rogers \& B. Swadener (Eds.), Semiotics \& dis/ability: Interrogating categories of difference (pp. 187-208). Albany: State University of New York Press.

Titchkosky, T. (2001). Disability: A rose by any other name? 'People-first' Language in Canadian Society. Canadian Review of Sociology, 38 (2), 125-140. 
Titchkosky, T. (2002) Cultural maps: Which way to disability? In M. Corker \& T. Shakespeare (Eds.), Disability/postmodernity: Embodying disability theory (pp. 101-111). London, England: Continuum.

Titchkosky, T. (2008). Reading \& writing disability differently: The textured life of embodiment. Toronto, Canada: University of Toronto Press.

Titchkosky, T. (2011). The question of access: Disability, space, meaning. Toronto, ON: University of Toronto Press.

Titchkosky, T. (2013, July). Fork this! \& other encounters with disability life. Able-ism and the question of being human. Symposium conducted at the Ontario Institute for Studies in Education (OISE) at the University of Toronto, Toronto, Ontario.

Tichkosky, T. \& Michalko, R. (Eds.) (2009). Rethinking normalcy: A disability studies reader. Toronto, Canada: Canadian Scholars' Press.

Tregaskis, C., \& Goodley, D. (2005). Disability research by disabled and non-disabled people: Towards a relational methodology of research production. International Journal of Social Research Methodology, 8(5), 363-374.

Tompkins, A. (2014). Asterisk. Transgender studies quarterly, 1 (1-2), 26-27.

Tremain, S. (2005). Foucault, governmentality, and critical disability theory: An introduction. In Tremain, S. (Ed.), Foucault and the government of disability (pp. 1-26). Ann Arbor: University of Michigan Press.

Tremain, S. (2015). Foucault, governmentality, and critical disability theory: An introduction. In Tremain, S. (Ed.), Foucault and the government of disability (pp. 1-26). Ann Arbor: University of Michigan Press.

Union of the Physically Impaired Against Segregation, The. (2011, November 14). Social model of disability. Retrieved from http://www.gmcdp.com/socialmodel.html

Vagle, M. (2014). Crafting phenomenological research. Walnut Creek, CA: Left Coast Press.

Vandekinderen, C., Roets, G., \& Van Hove, G. (2013). The researcher and the beast: Uncovering processes of othering and becoming animal in research ventures in the field of critical disability studies. Qualitative Inquiry, 20(10), 1-21.

Van Den Hoonard, W. (2002). Introduction: Ethical norming and qualitative research. Walking the tightrope: Ethical issues for qualitative researchers (pp. 1-16). Toronto, Canada: University of Toronto Press. 
van Manen, M. (1990). Researching lived experience: Human science for an action sensitive pedagogy. London, Canada: The Althouse Press.van Manen, M. (1999). The pathic nature of inquiry and nursing. In I. Madjar \& J. A. Walton (Eds.), Nursing and the experience of illness: phenomenology in practice (pp. 17-35). New York, NY: Routledge.

van Manen, M. (2002). Writing in the dark: Phenomenological studies in interpretive inquiry. London, Canada: The Althouse Press.

van Manen, M. (2014). Phenomenology of practice: Meaning-giving methods in phenomenological research and writing. Walnut Creek. CA: Left Coast Press.

Vasalou, S. (2012). Wonder: toward a grammar. In Vasalou, S. (Ed.), Practices of wonder: Cross-disciplinary perspectives (pp. 16-63). Cambridge, UK: James Clark \& Co.

Vernon, J. (1979). Poetry and the body. Chicago: University of Illinois Press.

Wacquant, L. (2010). Crafting the neoliberal state: Workfare, prisonfare, and social insecurity. Sociological Forum, 25(1), 197-220.

Walton, J. (1999). On living with schizophrenia. In I. Madjar \& J. A. Walton (Eds.), Nursing and the experience of illness: Phenomenology in practice (pp. 98-122). New York, NY: Routledge.

Wendell, S. (1996). The rejected body: Feminist philosophical reflections on disability. New York, NY: Routledge.

Wendell, S. (2013). Unhealthy disabled: Treating chronic illnesses as disabilities. In L. J. Davis (Ed.), The disability studies reader (4th ed., pp. 161-176). New York, NY: Routledge.

What is Newgenics? (2015). Eugenics/Newgenics, University of Lethbridge. Retrieved from http://eugenicsnewgenics.com/2014/05/14/what-is-newgenics/

Willitts, P. (2012, August 1). Bad attitudes do not cause disability any more than good attitudes guarantee health. The Independent [blog post]. Retrieved from http://blogs.independent.co.uk/2012/08/01/bad-attitudes-do-not-cause-disability-anymore-than-good-attitudes-guarantee-health

Wipond, R. (2013). Pitching mad: New media and the psychiatric survivor perspective. In B. Lefrançois, R. Menzies, \& G. Reaume (Eds.), Mad matters: A critical reader in Canadian mad studies. Toronto, Canada: Canadian Scholars' Press.

Wisniewski, A. (2012). Paging Dr. Economicus: The economics of "obesity" in the Canadian Medical Association Journal. Canadian Journal of Disability Studies, 1(3), 22-44. Retrieved from http://cjds.uwaterloo.ca/index.php/cjds/article/view/55 
Wood, C. (Ed.). (2014). Criptiques. San Bernardino, CA: May Day Publishing.

Wordsworth, W. (1888). The idiot boy. In Complete poetical works. Retrieved from http://www.bartleby.com/145/ww137.html

Yates, S. (2005). Truth, power, and ethics in care services for people with learning difficulties. In Tremain, S. (Ed.), Foucault and the government of disability (pp. 65-77). Ann Arbor: University of Michigan Press.

Zhok, A. (2012). The ontological status of essences in Husserl's thought. In New yearbook for phenomenology and phenomenological philosophy (Vol. XI, pp. 99-130). Cambridge, England: Acumen (Cambridge University Press). 